$=2=7=$

3

3 

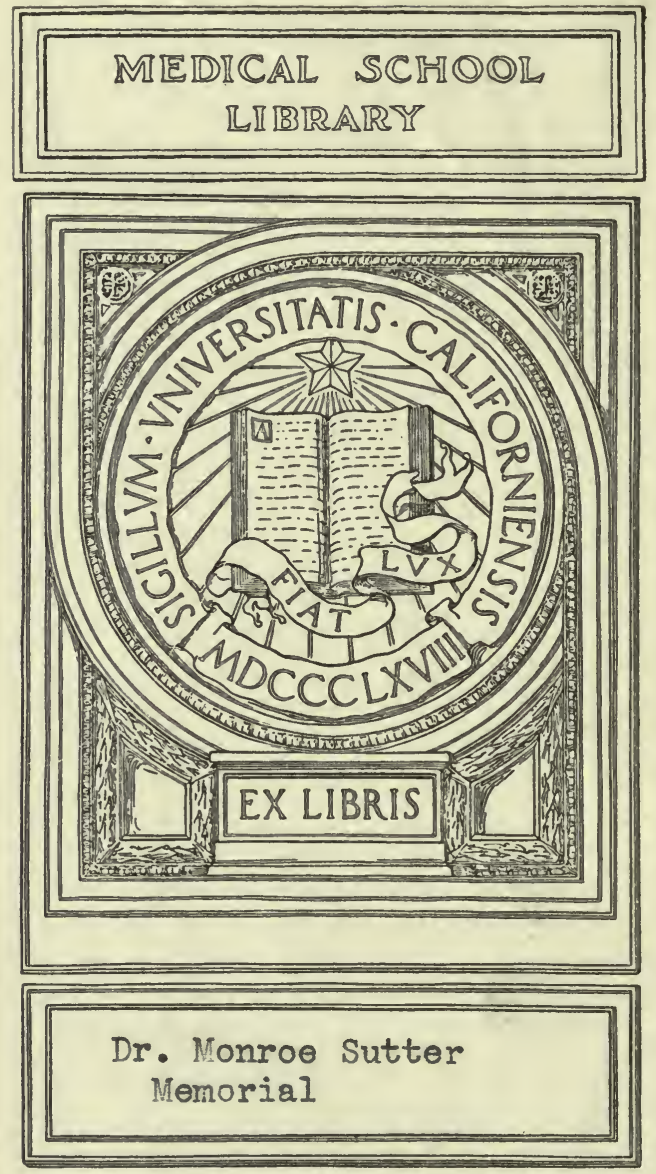
I

e 
Digitized by the Internet Archive in 2007 with funding from Microsoft Corporation 



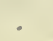

$+$$$
\text { - }
$$$$
\text { . }
$$ 


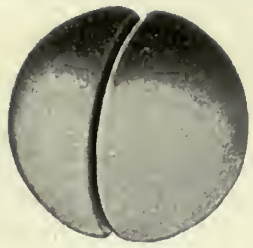

A

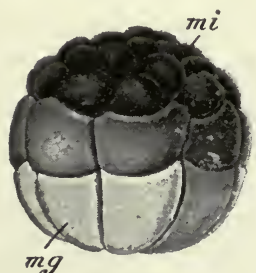

D
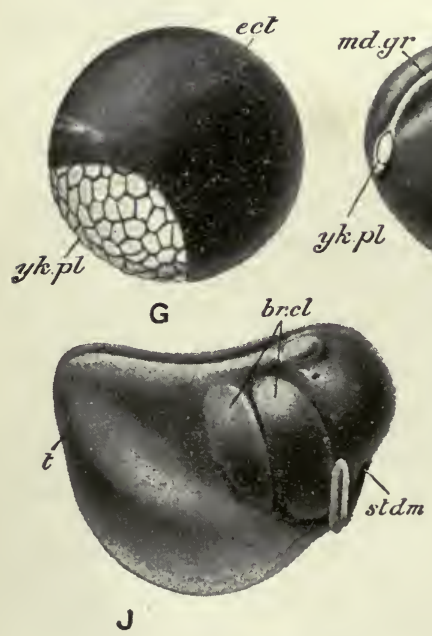

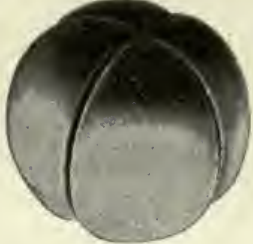

B

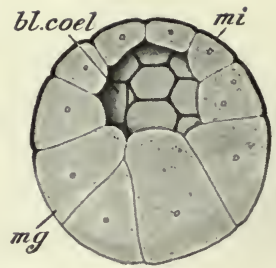

E

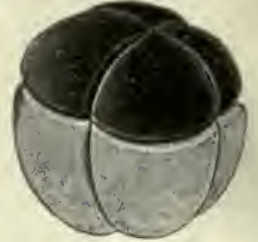

C

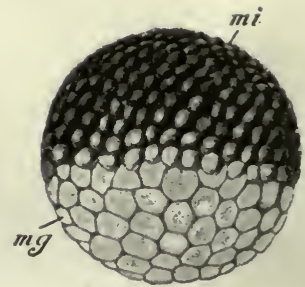

$\mathbf{F}$
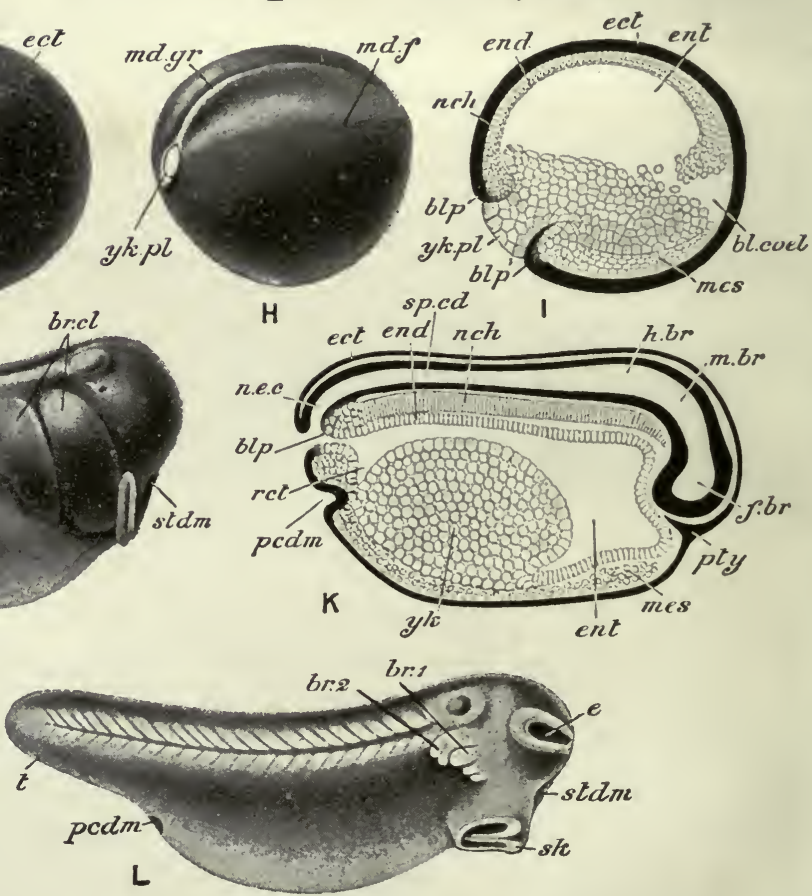

Development of the Frog. (From Parker and Haswell after Ziegler's models and Marshall.)

$A-F$, segmentation. $G$, overgrowth of ectoderm. $H, I$, establishment of germinal layers. $F, K$, assumption of the tadpole-form and establishment of nervous system, notochord, and enteric canal. $L$, newly-hatched tadpole. bl. coel., blastocoel. blp.. blp.,1 blastopore. br.i br...2 gills. $b r . c l$., depressions marking future gill-clefts. $e$, eye, ect.. ectoderm, end., endoderm. ent. enteron. $f . b r_{.}$fore-brain $h$. br. hind-brain, $m$. $b r_{. .}$mid-brain. $m d$. $f_{.}$, medullary folds md. gr., medullary groove. mes., mesoderm. mg., megameres. mi., micromeres. nch., no tochord. n.e.c., neurenteric canal. pcdm., proctoclæum. pty., pituitary invagination. rect. commencement of rectum. sk., sucker. sp. $c d$., spinal cord. st. dm., stomodæum. t., tail. $y k$., yolk cells. $y k$. pl., yolk plug. 


\section{An Introduction}

to

\section{Vertebrate Embryology}

Based on the Study of the Frog, Chick, and Mammal

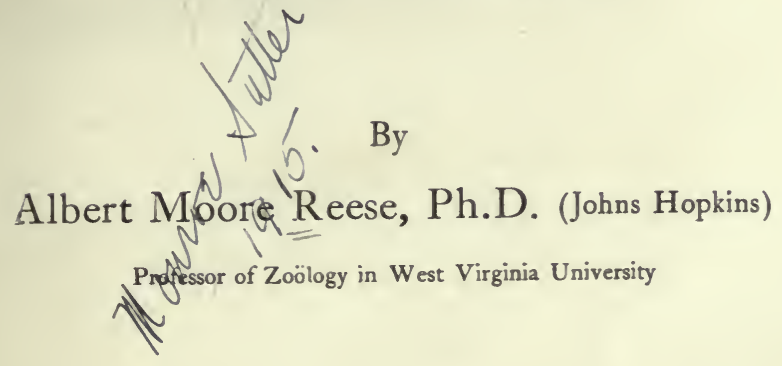

Second Edition, Revised and Enlarged

With 118 Illustrations

G. P. Putnam's Sons

New York and London

Tbe Rnickerbocker presg I 909 
Copyright, igO4

BY

ALBERT MOORE REESE

Copyright, rgog

BY

ALBERT MOORE REESE

(For additional material)

Tbe Iknickerbocker Dress, Hew Dork

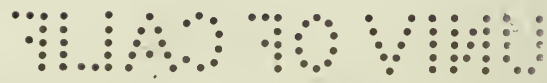

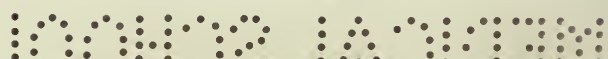




\section{PREFACE TO THE SECOND EDITION}

I T has been the author's intention, should a second edition of this book be demanded, to revise the chapters dealing with the development of the frog and chick, and to add a brief chapter upon the development of the mammal. The second part of this purpose has been carried out in the new chapter-Chapter IX-of the present edition, but this edition having been unexpectedly called for, the author has been unable, owing to pressure of other work, to do more than make the addition referred to, and correct a few typographical errors in the original chapters.

In what is said of the development of the mammal the chief aim has been to call attention to the main points of difference between the development of the bird and that of the mammal, and to explain the more difficult features in mammalian development. 
vi

\section{Preface}

The additional figures are nearly all taken from well-known works to which, in each case, acknowledgment is made.

The writer is again indebted to Professor Minot and to his publishers, Messrs. P. Blakiston's Son \& Co., and to the Macmillan Company for use of numerous electros.

West VIRGINIA UNIVERSITY, August X, 1909 


\section{PREFACE}

THIS small volume is the result of a need that the author has felt, for some years, for a concise text-book of embryology that described the development of both the chick and the frog. The only other single book, with which the author is acquainted, that describes the development of both these commonly studied forms is the large volume of Marshall, which is too cumbersome and expensive for a general, class text-book.

The present volume is intended as an outline, from which the student may learn the main facts about the embryology of the two animals in question; and the instructor is supposed in his lectures to enlarge upon this outline to any extent that he may see fit. Since the needs of the medical student have been largely considered in compiling the text, very little space has been given to theoretical discussions ; these may be given by the instructor, at whatever length may seem desirable. 
For purely pedagogical reasons, the development of the chick has been described by periods ; that is, all the changes that take place during a certain period are described in one section, instead of describing at one time, the complete development of any one organ.

The author does not lay claim to any great originality in the compilation of this volume. He has sought simply to collect, into convenient form, the more important facts of the subject under discussion, together with a series of figures that will suitably illustrate these facts.

Marshall and Morgan have been quoted at length, in several instances.

Nearly all the figures have been taken from well-known text-books of embryology, the author being stated in every case.

I am especially indebted to Dr. Charles S. Minot and his publishers, P. Blakiston's Son $\&$ Co., for the loan of the electros of the numerous figures that have been taken from Professor Minot's recent Laboratory Text of Embryology. Albert M. Reese.

Syracuse UNIVERSITY, March. 15, 1904. 


\section{CONTENTS}

CHAPTER I
THE DEVELOPMENT OF THE FROG
PAgE

CHAPTER II

THE DEVELOPMENT OF THE CHICK • • 90

CHAPTER III

THE DEVELOPMENT OF THE FIRST DAY . - I2O

CHAPTER IV

THE DEVELOPMENT OF THE SECOND DAY • - I39

CHAPTER V

THE DEVELOPMENT OF THE THIRD DAY • . I63

CHAPTER VI

THE DEVELOPMENT OF THE FOURTH DAY . . 222 ix 


\section{Contents}

\section{CHAPTER VII}

The DEVElopment OF THE Fifth DAY . . 263

\section{CHAPTER VIII}

THE DEVELOPMENT FROM THE SIXTH DAY TO THE TIME OF HATCHING

CHAPTER IX

THE DEVelopment of the mammal • • - 284

INDEX • • • • • • • • 


\section{ILLUSTRATIONS}

\section{The Development of the Frog}

FIGURE

I. Early Stages in the Development of the Frog

Embryo. (After Parker and Haswell).

Frontispiece

2. Egg of Starfish. (After Gegenbaur) • • 6

3. Ovarian Egg of Frog • • • • • • 7

4. Various Stages in the Development of the Frog. (After Brehm from Marshall) • 8

5. Vertical Sections of Segmenting Eggs • • I9

6. Sections of Three Stages of Segmentation of the Frog's Egg . . . . . 20

7. Longitudinal Vertical Section of a Frog Embryo, Showing Commencing Invagination. (After Marshall) • • • • •

8. Longitudinal Vertical Section of a Frog Embryo at a Later Stage in the Formation of the Mesenteron. (After Marshall) .

9. Longitudinal Vertical Section through a Frog Embryo, Showing the Completion of the Mesenteron. (After Marshall) . .

10. Transverse Section through the Middle of a Frog Embryo, at about the Stage Represented in Fig. 9. (After Marshall) . . 
FIGURE

II. Stages in the Early Development of the Frog, Seen Obliquely from the Posterior End. (After Ziegler from Marshall)

I2. A-Sagittal Section of Embryo Shown in Fig. I I, D. B-Sagittal Section of the Embryo Shown in Fig. $\mathbf{I}_{\mathbf{s}} \mathrm{E}$ (After Marshall)

13. Transverse Section of a Frog Embryo during the Formation of the Neural Canal. (After Marshall) .

14. Sagittal Section of a Tadpole at the Time of Hatching. (After Marshall) . .

I5. Transverse Section across the Middle of the Embryo Shown in Fig. Ir, D. (After Marshall)

r6. The Brain of the Frog. (After Marshall)

17. Longitudinal Vertical Section through the Anterior End of a Tadpole Shortly after Hatching. (After Marshall) . . .

18. Longitudinal Vertical Section through the Anterior Part of a Tadpole about the Time of Appearance of the Hind Legs. (After Marshall) .

19. Half Sections in the Transverse Plane of a Tadpole ro $\mathrm{mm}$. Long (left half) and of a Tadpole I $2 \mathrm{~mm}$. Long (right half). (After Marshall) .

20. Transverse Section through the Head of a Tadpole $61 / 2 \mathrm{~mm}$. in Length, about the Time of Hatching. (After Marshall) 


\section{Illustrations}

xiii

FIGURE

2I. Transverse Section through the Region of the Hind-Brain of a Young Tadpole

PAGE

22. Horizontal Section of a Tadpole at the Time of Hatching. (After Marshall) . .

23. Diagrammatic Figures of a $7-\mathrm{mm}$. Tadpole, Shortly after Hatching, Showing the Arrangement of the Blood Vessels: A-from Below; B-from the Side. (After Marshall)

24. A r 2-mm. Tadpole, Dissected from the Ventral Side. (After Marshall) . . . . 65

25. Diagrams to Illustrate the Mode of Development of the Heart . . . .

26. A Diagrammatic Figure of the Head and Neck of a r $2-\mathrm{mm}$. Tadpole, from the Right Side, to Show the Heart and Branchial Vessels. Gills and Gill Capillaries not Represented. (After Marshall)

27. Diagrammatic Figure of the Arterial System of the Male Frog, from Right Side. (After Marshall)

28. A 40-mm. Tadpole Dissected from the Ventral Surface. (After Marshall).

29. A Tailed Frog, near the Close of Metamorphosis, Dissected from the Ventral Surface. (After Marshall)

30. Diagrams to Illustrate the Development of the Head-Kidney. (Somewhat altered from Morgan) . • • . . . 
xiv Illustrations

3I. Transverse Section through the Body of a Tadpole at the Time of Hatching. (After Marshall) • $\quad$ • $\quad$. $\quad$ • $\quad$ • 84

32. The Skull of a $\mathbf{I} 2-\mathrm{mm}$. Tadpole: $\mathrm{A}$ - seen from the Right Side; B-seen from Dorsal Side; $\mathrm{C}$-seen from the Ventral Surface. (After Marshall) $•$.
The Development of the Chick

33. Semi-Diagrammatic View of the Egg of the Fowl, at the Time of Laying. (After Parker and Haswell, slightly altered from Marshall)

34. A-Yolk with the Blastoderm in the Centre, the Latter Showing the First Two Cleavage Planes. B-The Blastoderm on a I-arger Scale and at a Later Stage of Segmentation. (After Duval)

35. Surface View of the Blastoderm at a Later Stage of Segmentation than that Shown in Fig. 34, B. (After Duval) • • $\quad 9^{8}$

36. Longitudinal Section of the Blastoderm after the Completion of Segmentation. (After Duval)

IO4

37. Series of Diagrams to Illustrate the Formation of the Chick Embryo, Especially the Relations of the Embryo, Yolk-Sac, Amnion, and Allantois. (After Foster and Balfour), 


\section{Illustrations}

FIGURE

38. A-B-C-D-Diagrams Illustrating the Development of the Fœtal Membranes of a Bird. (After Parker and Haswell) . II7, II 8

39. Part of a Section through the Blastoderm after the Formation of the Definite Entoderm or Hypoblast. (After Duval)

40. Surface View of the Embryo at about the Sixteenth Hour of Incubation. (After Duval)

4I. Median Portion of a Transverse Section of an Embryo at the Time of Formation of the Primitive Streak. (After Duval) . .

42. Transverse Section of an Embryo of about Twenty-one Hours, through the Anterior Part of the Medullary Folds. (After Duval)

43. Three Transverse Sections across the Caudal End of the Medullary Groove of a Chick Embryo with Seven Segments. (After Minot) . . . . . .

44. Surface View of Embryo at the Twenty-third Hour of Incubation. (After Duval) .

44A. Anterior End of the Preceding Figure, More Highly Magnified to Show the Details. (After Duval)

45. Sagittal Section of an Embryo of Twenty-six Hours. (After Duval) . . .

46. Diagrammatic Representations of Chick Embryos: A - after Twenty Hours' Incubation; B-after Twenty-four Hours' Incubation. (After Parker and Haswell from Marshall) 
FIGURE

47. Surface View (dorsal) of an Embryo of Thirtythree Hours. (After Duval)

140

48. Transverse Section of a Chick Embryo with Seven Segments, to Show the Beginning of the Formation of the Heart. (After Minot)

142

49. Ventral View of the Anterior Region of the Embryo Shown in Fig. 47. (After Duval) I 46

50. Sagittal Section of the Embryo Shown in Fig. 47. (After Duval) . . . . . I50

5०A. Diagrammatic Representation of Fig. 50. (After Foster and Balfour) . . . I52

51. Sagittal Section of an Embryo Chick of Eightytwo Hours. (After Duval)

52. Transverse Section of a Chick Embryo with about Twenty-eight Segments. (After Minot) ${ }_{15} 6$

53. Transverse Section through the Heart Region of an Embryo of Thirty-three Hours. (After Duval)

54. Transverse Section through the Dorsal Region of an Embryo of Forty-six Hours. (After Duval)

55. Transverse Section through a Chick Embryo to Show a Slightly Later Stage in the Development of the Heart than is Shown in Fig. 48. (After Minot) . . . . 16 1

56. Diagram of the Circulation of a Chick Embryo at the End of the Third Day of Incubation, as Seen from Below. (After Minot) . . 166

57. Surface View of an Embryo of Fifty-two Hours. (After Duval) 


\section{Illustrations}

xvii

FIGURE

58. Transverse Section through the Anterior

PAGE

Region of a Chick Embryo with about

Twenty-eight Segments. (After Minot) .

59. Transverse Section through the Anterior

Region of a Chick Embryo with about Twenty-eight Segments. (After Minot).

I 80

6o. Transverse Section through the Fore-Brain of

a Chick of Fifty to Sixty Hours' Incubation 182

6r. The Eye of a Bird: A-Sagittal Section; BSurface View of Entire Organ. (After Parker and Haswell from Vogt and Yung) • $\quad 184$

62. Transverse Section through the Anterior Region of a Chick Embryo of about Twentyeight Segments. (After Minot) . • . 186

63. Transverse Section through the Anterior Part of an Embryo of Sixty-eight Hours. (After

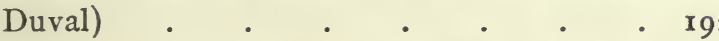

64. The Head of an Embryo Chick at the End of the Fifth Day of Incubation, Seen from Below. (After Marshall) . . . . 196

65. Diagram of the Arterial Circulation on the Third Day. (After Foster and Balfour) . 200

66. Diagram of the Venous Circulation of the Third Day. (After Foster and Balfour) . 20I

67. Diagram of a Portion of the Digestive Tract of a Chick Embryo during the Fourth Day. (Foster and Balfour from Götte) . . 205

68. Transverse Section of an Embryo of the Fourth Day. (After Duval) . . . 208 
70. Transverse Section through the Dorsal Region of an Embryo of Sixty-eight Hours. (After Duval)

71. Transverse Section Anterior to the Preceding. (After Duval) . . . . .

72. Two Stages in the Development of the Chick Embryo: A-at about the Fifth Day; Bat about the Ninth Day. (After Parker and Haswell from Duval) . . . .

73. Transverse Section through the Dorsal Region of a Chick Embryo of Ninety-six Hours. (After Duval)

74. Transverse Section through the Wolffian Body. (After Duval)

75. Heart of a Chick on the Fourth Day, Ventral View. (After Foster and Balfour) .

76. Diagrammatic Figure Showing the Arrangement of the Blood Vessels in a Chick Embryo at the End of the Fifth Day. (After Marshall) .

77. Diagram of the Venous Circulation at the Commencement of the Fifth Day. (After Foster and Balfour)

78. Diagram of the Venous Circulation during the Later Days of Incubation. (After Foster and Balfour) . $\quad . \quad$. $\quad .256$ 


\section{Illustrations}

xix

FIGURB

PAGE

79. Diagram of the Venous Circulation after the Commencement of Respiration by Means of the Lungs. (After Foster and Balfour) .

8o. Egg of Chick with Embryo and Fœtal Appendages. (After Parker and Haswell from Duval) . . . . . . . 266

8r. Two Views of the Heart of a Chick on the Fifth Day of Incubation: A-Ventral; BDorsal View. (After Foster and Balfour) . 268

82. Heart of a Chick on the Sixth Day, Ventral View. (After Foster and Balfour) .

83. Transverse Section through the Dorsal Region of a Chick Embryo with about Twenty-eight Segments. (After Minot).

84. Section through an Advanced Embryo of a Rabbit, to Show how the Pericardial Cavity Becomes Surrounded by the Pleural Cavities. (After Foster and Balfour)

85. Full-grown Human Ovum. (From Minot, after W. Nagel) . • • • • . 285

86. Human Spermatozoa. (From Minot, after Retzius) . . . . . . $\quad 287$

87. Ovum of Bat, with Four Blastomeres. (From Minot, after Van Beneden and Julin) . 289

88. Totally Segmented Ovum of a Rabbit. (From Marshall, after Van Beneden) . . . 29I

89. Early Stage in the Formation of the Blastodermic Vesicle of a Rabbit. (From Marshall, after Van Beneden) . . . . 29I 
90. Section through the Embryonic Shield of a Dog. (From Kollmann, after Bonnet) • 293

91. Surface View of the Embryonic Shield of a Dog. Magnified 120 Diameters. (From Kollmann, after Bonnet) • . . 294

92. Embryonic Area of a Dog, Showing the Primitive Streak. Magnified 120 Diameters. (From Kollnann, after Bonnet) . . 295

93. Diagrams Illustrating the Relations of the Allantois, etc., in Unguiculate Mammals. (From Minot) . . . . .

94. Diagram of an Early Stage of a Primate Embryo. (From Minot) • . . 298

95. Sagittal Section of a Rabbit Embryo and Blastodermic Vesicle, at the End of the Ninth Day. (From Marshall, after Van Beneden and Julin) . . . . . .

96. Sagittal Section of a Rabbit Embryo at the End of the Twelfth Day. (From Marshall, after Van Beneden and Julin) . . . . 300

97. Human Ovum. Age Seven Weeks. (From Kollmann) . . . . . . . 302

98. Semi-diagrammatic Outline of an Antero-posterior Section of a Human Uterus. (From Minot, after Allen Thompson) . . . 303

99. Human Uterus. About 40 Days' Pregnancy. (From Minot, after Coste) • . . 305

100. Transverse Sections of Two Human Umbilical Cords. (From Minot) . . . . 308 


\section{Illustrations $\quad \mathrm{xxi}$}

FIGUR: PAGE

101. Human Placenta at Full Term. Double Injection. One-half Natural Size. (From Minot) . . . . . . . 310

102. Human Embryo of $2.6 \mathrm{~mm}$. (From Minot, after His) • • • • • • . 3 II

103. Human Embryo at the End of the Seventh

Week. (From Kollmann) . . . . 313

104. Human Fetus at the End of the Fourth Month. (From Kollmann) . . . 315

105. Human Fetus of Six Months. (From Kollmann • • • • • • • . 3I7

106-I17. A Series of Figures Illustrating the Development of the External Genitalia in the Human Fetus. (From Kollmann) . 319-20

118. Figure to Illustrate the "Vertex-breech" Method of Measuring Human Embryos. (Altered from Kollmann) . . . 324 



\section{AN INTRODUCTION TO \\ VERTEBRATE EMBRYOLOGY}

\section{CHAPTER I}

THE DEVELOPMENT OF THE FROG

\section{INTRODUCTION}

$7 \mathrm{HE}$ eggs of the common frog (Rana virescens and allied species) may usually be found without difficulty in small ponds and pools of water, where they are laid, in the early spring, soon after the melting of the ice. They may easily be kept alive, in the laboratory, in shallow dishes of water, and their entire development thus observed. Their rate of development varies greatly with the temperature, so that if it be desirable, for any reason, to hurry the development, all that is necessary is to place the aquarium in a warm place ; or if it be desired to keep a lot of eggs 
in a certain state of development, this may be accomplished by keeping the aquarium in a cool place or by putting lumps of ice in the water.

During the act of spawning, which may last several days, the male clasps the female firmly with his fore legs and fertilizes the eggs as they leave the cloaca. With the act of spawning the parental instinct ceases, and the eggs are left to themselves, to develop or perish as the case may be.

As in the laboratory, so in nature, the rate of development depends upon the temperature of the water, but in a few days or a week the eggs have lost their spherical form and have become ovoid in shape; and in about ten days the head, body, and tail are marked off from each other by slight constrictions. The embryo now elongates rapidly and by the end of the second week is provided with three pairs of tiny external gills, and is able to work its way out of the jelly-like mass with which it is surrounded, and to swim freely in the water. At this time it has no true mouth, and so is dependent, for growth, upon the granules of yolk which were contained in the egg. For several days, until the appearance of the mouth, the tadpole is provided with a horseshoe-shaped sucker on the 


\section{The Development of the Frog}

lower side of the head, by means of which it attaches itself to any solid body that may be in the water.

As the mouth is being formed, the digestive tract becomes greatly elongated, so that the abdominal region of the body becomes rounded and swollen by the coiled mass of the intestine lying within. Being now provided with horny jaws, the young tadpole feeds actively upon the plants of its habitat, and is, therefore, no longer dependent upon the yolk for growth.

The gill-clefts make their appearance, at about this time, as four pairs of slit-like openings which connect the pharynx with the exterior. The edges of these slits become folded to form the internal gills, and as the internal gills increase in size, the external gills gradually diminish and are covered by two folds of skin which grow back over them from in front. These two opercular folds fuse together along the mid-ventral line, and their posterior edges fuse with the body-wall behind the gills, so that the latter are completely enclosed except for a sort of spout on the left side, through which water, taken into the gillchamber through the mouth, to bathe the gills, passes again to the exterior. 
The young tadpole has now practically the structure and habits of a fish, but very soon the rudiments of the hind legs appear as small protuberances at the base of the tail, one on each side of the cloaca ; and by the eighth week the joints and toes are formed, and the legs have about the same structure as in the adult.

The fore legs are formed at about the same time as are the hind legs, but they are hidden, for some time, by the operculum. The left fore leg, in the course of two or three weeks, projects through the above-mentioned opercular spout, while the leg of the opposite side has to force its way directly through the opercular fold.

The lungs, in the meantime, have become functional and the tadpole frequently comes to the surface to breathe, although, for a time, respiration takes place by means of both lungs and gills.

Before this remarkable metamorphosis is complete and the frog is ready to begin life as an air-breathing animal, the tail must be completely absorbed, the mouth, eyes, and other structures must be greatly changed, and the gills, gill-clefts, and other fish-like structures must diminish or entirely disappear. 


\section{The Development of the Frog}

\section{THE EGG}

Since every animal begins its individual existence as an ovum or egg, it may be well, before taking up the study of the frog's egg, to examine some egg that will more easily show the different structures of a typical ovum, the frog's egg being so large and so full of yolk that it is difficult for the beginner to distinguish its different parts. For this purpose the eggs of the starfish, or of the sea-urchin, are very convenient, and if some of these eggs be properly stained and mounted, the main features of their structure may be made out without difficulty.

The ovum, whether it be of microscopic size or $30 \mathrm{~mm}$. in diameter, as is the yolk of the hen's egg, is always a single cell. Although the egg of the common starfish is only as large as a small grain of sand, yet if it be examined under a moderate magnification of the microscope, it will be found to be made up of several distinct parts. Like most ova it is spherical in shape, and is enclosed in a thin cell-wall or vitelline membrane (Fig. 2). In the granular, protoplasmic contents of the egg two regions may be distinguished: a 
lighter portion which makes up the greater part of the egg and which is known as the cytoplasm, and a darker, spherical portion which lies in the cytoplasm and is known as the nucleus (germinal vesicle). Inside of the nucleus may be seen one or more small areas, the nucleoli (germinal spots)

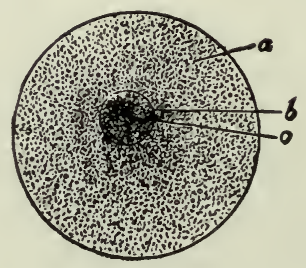

Fig. 2.-EgG of Starfish. (After Gegenbaur.)

a. Granular protoplasm.

b. Nucleus (germinal vesicle).

c. Nucleolus (germinal spot).

By the use of more refined methods and higher magnification many other details of structure might be brought out, but for these the reader is referred to more extensive textbooks.

The frog's egg is several thousand times the bulk of the egg of the starfish. being about $1.7 \mathrm{~mm}$. in diameter. This increase in size is 
The Development of the Frog

chiefly due to the large amount of food-yolk contained in the frog's egg (Fig. 3.)

As the eggs ripen and are set free from the ovary, they fall into the body cavity and pass forward into the abdominal openings of the oviducts. Passing slowly along these ducts. the eggs at last collect in large numbers in the

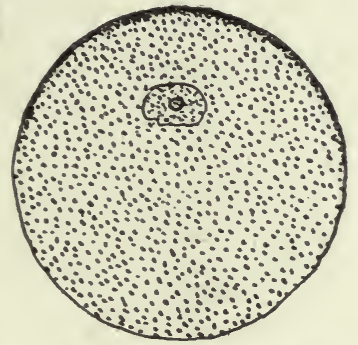

Fig. 3.-OVARIAN EGg OF FROG.

thin-walled, dilated posterior parts of the oviducts, where they remain until they are forced out into the water at the time of spawning.

Owing to the opacity of the frog's egg, the nucleus is only visible in sections, although it is very large, sometimes as much as one-third to one half the diameter of the egg (Fig. 3).

Before it is set free from the ovary, the egg has secreted around it, in some way that is not well understood, a thin vitelline membrane; 
and as it passes through the anterior, thickwalled part of the oviduct a gelatinous envelope is deposited around it. This envelope, on coming in contact with the water, swells enormously, and forms a mass of colorless jelly, characteristic of frog's spawn (Fig. 4). The
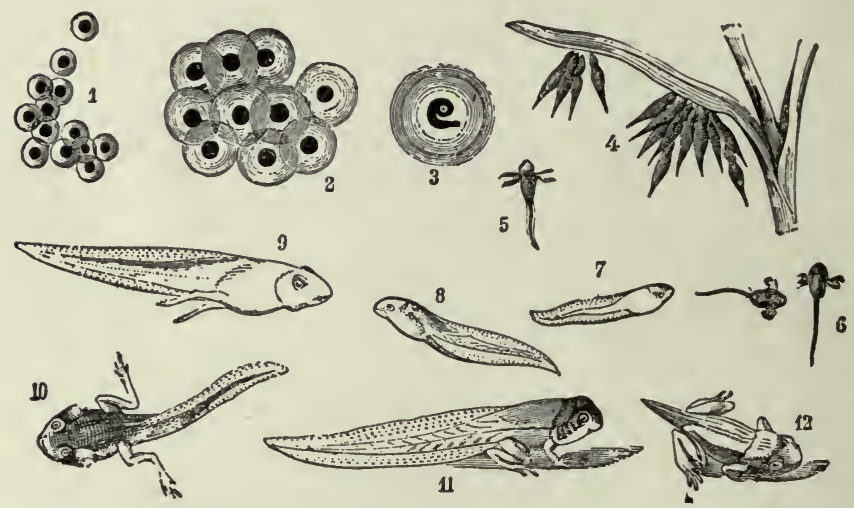

Fig. 4.-VARious Stages in the Development of THE Frog. (After Brehm from Marshall.)

1. Eggs just laid. 2. Eggs shortly after laying. 3. Tadpole shortly before hatching. 4. Tadpoles just hatched. 5 and 6 . Tadpoles with external gills. 7 and 8. Tadpoles with fully-formed opercular folds. 9 and 10 . Tadpoles with well-developed hind legs, shortly before the metamorphosis. 11. Tadpole during the metamorphosis. 12. Young frog with tail only partially absorbed.

thin, gelatinous envelope is said to begin to swell about one minute after it comes in contact with the water, and to reach its greatest expansion in three hours. Its purpose is to protect the soft eggs from being injured by 


\section{The Development of the Frog}

contact with surrounding objects, and also to hasten development by storing up heat, this latter power being due to the fact that it permits the heat of the sun to pass inward more rapidly than it permits the reflected heat to pass out again, with the result that the mass of spawn, in the sunlight, is warmer than the surrounding water. The jelly may also protect the eggs from being eaten by other animals.

The egg itself consists of a black and a white pole of approximately equal sizes, the dark color of the black hemisphere being due to the presence of a superficial layer of pigment in that region. The origin of this pigment is not clearly understood, but its purpose seems to be that of absorbing the heat of the sun, and in furtherance of this object the pigmented half of the egg is of less specific gravity than the other half, with the result that the dark pole is always the upper one and the one in which the segmentation takes place the more rapidly. This automatic orientation is made possible by the fact that the egg shrinks away from its vitelline membrane, between which and itself is secreted a small quantity of fluid in which the egg may easily rotate. 
A mass of frog's spawn may be compared to a number of hen's eggs which have been carefully broken into a dish, so that the yolks are all unbroken. The yolks of the hen's eggs correspond to the true eggs of the frog's spawn, and the white of the hen's egg to the jelly mass of the spawn. The white of the hen's egg, however, serves as food for the developing chick, while the jelly of the spawn probably serves no such purpose.

\section{Maturation of the $\mathrm{Egg}$}

As a rule, before an egg may begin its development, it must be fertilized, and before it can be fertilized it must undergo a process of ripening or maturation. The details of this maturation vary in different eggs, but the essential processes are about the same in all.

As has been stated above, the egg of the frog, when just set free from the ovary, contains a very large nucleus. It is the nucleus that is chiefly concerned in the maturation changes, and the first change that is noticed is a shrinkage of this large nucleus and a loss of the nuclear membrane. After passing through other changes, a description of which cannot be given here, the nucleus divides into two 


\section{The Development of the Frog}

equal parts, and one of these halves is extruaed from the egg and lies under the vitelline membrane at the upper or black pole. This extruded half of the nucleus is known as the first polar body, and its formation takes place while the egg is still in the oviduct of the frog. Shortly after the egg is laid and the sperm has entered it, the half of the nucleus that remained after the formation of the first polar body again divides into equal parts, and the second polar body is extruded. The part of the nucleus that remains after the formation of the polar bodies is known as the female pronucleus, and contains, as may easily be understood, just onefourth of the material of the original egg nucleus. The two small round polar bodies, lying side by side under the vitelline membrane at the dark pole of the egg, take no further part in the development of the egg, and eventually disappear.

What the purpose of the maturation of the egg-cell may be it is not possible at the present time to say; and so many theories on the subject have been advanced that it is very difficult to give any simple statement of the case.

The formation of the polar bodies or globules is the result of a form of cell division 
known as "reduction division." When the first globule is formed, it is by the division of the egg-cell into two cells, a large one and a very small one, the small one being the polar globule. In like manner the second globule is formed by the very unequal division of the larger of the first two cells, the larger cell of the latter division being the true female element which is capable of being fertilized.

The essential element of the nucleus, thát part which is especially concerned in heredity, or the transmission of parental characteristics, seems to be the chromosome. The number of chromosomes in the nucleus of any given species is normally constant.

It has been found that the number of chromosomes in the egg after maturation is just half what it was before that process, and the amount of chromatin is reduced to one quarter of the original quantity.

O. Hertwig thinks that the reduction divisions taking place in maturation are for the purpose of increasing the relative amount of cytoplasm, rather than for reducing the quantity of nuclear material. The cell that is left after the extrusion of the polar bodies, although containing only one fourth of the original 
chromatin, has retained practically all of the cytoplasm; so that the result of the formation of the polar bodies is practically to increase the cytoplasm fourfold. The objections to this theory cannot be given here.

One of the oldest and most celebrated theories in regard to the formation of the polar bodies is that of Minot. According to this theory the fertilized egg-cell is said to be hermaphrodite, that is, it is both male and female, since it is formed by the fusion of the male and female elements. When the fertilized egg divides for the first time the nuclear material is equally divided between the two blastomeres that are formed, so that each of these blastomeres must be hermaphrodite. If this be true of the first two blastomeres, it must be equally true of all the cells that are formed by the repeated division of the original egg-cell: hence the unfertilized egg-cell developed from the original egg must also be hermaphrodite; and before it can receive additional male chromatin, in the act of fertilization, it must get rid of the male chromatin that it already possesses, by extruding the polar bodies.

If this theory were true, it is evident that a child could not inherit the characters of its 
mother's father, nor the characters of any of its father's ancestors.

Delage and Herouard have elaborated a theory that is, briefly, as follows: The simplest organisms are capable of reproducing themselves indefinitely by a process of repeated division. More highly organized beings are not possessed of this indefinite power of division, and must occasionally undergo a process of fusion or conjugation. This process consists of two parts, the elimination of chromatic material (maturation), and the conjugation proper, or fertilization. The maturation is usually considered as an accessory phenomenon, whose object is simply to make the fertilization possible, but, according to this hypothesis, "The essential phenomenon is the chromatic reduction, and the fecundation is an addition which is advantageous but not indispensable."

In the simplest organisms metabolism is a closed cycle; but in more complicated beings this is not the case, and there is gradually accumulated a substance which is injurious and which affects all the functions of life, especially those concerned in cell division. Unless this substance is gotten rid of, the cell will die. 


\section{The Development of the Frog}

In the case of the tissue cells of the higher organisms there is no method of removing this substance, so that these cells must eventually perish; but in the case of the simplest unicellular organisms, and in the reproductive cells of the higher forms, this substance is removed in a single operation, and the cell thus enabled to begin a new series of divisions.

Labbé found among certain insects a reduction of chromatin, not followed by fecundation, that was followed by cell division and development; and other cases of parthenogenesis are known.

The expulsion of chromatic material is represented in higher organisms by the extrusion of the first polar body, and "if one could prevent the extrusion of the second polar body, all beings would develop parthenogenetically."

The formation of the second polar body reduces the amount of chromatin and the number of chromosomes, and makes impossible further development, until fresh chromatic material has been added by the process of fecundation.

It will be seen from the above examples 
that the processes of maturation and fertilization offer a wide field for speculation, but one into which it is not within the province of this book to enter.

\section{Fertilization of the $\mathrm{Egg}$}

As the eggs are extruded from the cloaca of the female, which process may take place in a few minutes or may be prolonged over several days, the spermatozoa are spread over them by the male and at once begin to bore their way through the jelly towards the eggs.

The exact nature of the changes that take place after the sperm enters the egg has not been entirely determined, but the essential points will be given. A few minutes after coming in contact with the vitelline membrane, the head of the spermatozoon works its way into the egg and moves towards the female pronucleus, with which it fuses to form the so-called segmentation nucleus. The head of the spermatozoon, after it has entered the egg, is known as the male pronucleus, and the essential act of fertilization is the fusion of the male and female pronuclei. The tail of the spermatozoon remains outside of the egg and apparently takes no part in the process 
of fertilization; the fate of the middle-piece, in the frog, is not well understood, but it is possible that it may effect segmentation in some way. As a rule, only one spermatozoon enters the egg, but it is likely that if two or more spermatozoa reach the vitelline membrane at the same time, they may all enter the egg, although only one male pronucleus will fuse with the female pronucleus. In some other animals the entrance of two or more spermatozoa into the egg (polyspermy) produces serious results, causing irregularities in segmentation; but in the frog the extra pronuclei probably disappear without producing any unusual effect.

\section{Segmentation of the Egg}

About two or three hours (depending on the temperature) after fertilization, the first indication of segmentation is seen as a furrow on the dark pole of the egg. This furrow gradually extends around towards the white pole until it completely encircles the egg (Fig. I, $A)$. By the time this has taken place, the contents of the egg have been separated into two parts by a plane corresponding to the superficial furrow, so that the egg is now 
completely separated into two blastomeres of approximately equal size, which, at first, tend to become spherical in shape, but which are soon flattened against each other to form hemispheres. Before the formation of this first cleavage plane, the segmentation nucleus has divided into two equal parts, one of which is found in each of the two blastomeres. In dividing, the nucleus passes through a complicated series of changes known as karyokinesis, for a description of which the reader is referred to more extensive text-books. The first cleavage plane corresponds to the mediolongitudinal (sagittal) plane of the future frog : this, however, is not true of all animals.

After a short resting period, the second cleavage plane is formed, preceded, as in the former and as in all subsequent cases, by the division of the nucleus of each blastomere. The second plane is also a vertical one beginning in the dark pole, and is at right angles to the first plane. The egg now consists of four more or less equal blastomeres (Fig. I, $B$ ).

The third plane is normally a horizontal one, at right angles to the first two, but not in the equatorial plane of the egg, so that the egg is divided into eight cells (Fig. I, C), four 


\section{The Development of the Frog}

small dark cells at the upper pole, and four larger white cells at the lower pole; that is to say, the third plane is horizontal but nearer the upper than the lower pole (Fig. 5, B).

The next division is by two vertical planes, at right angles to each other and half-way between the first two planes. Thus we have

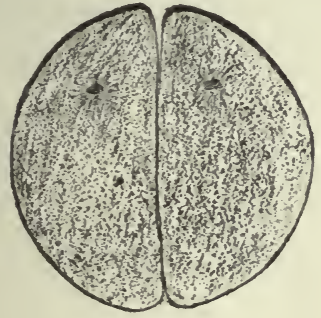

A

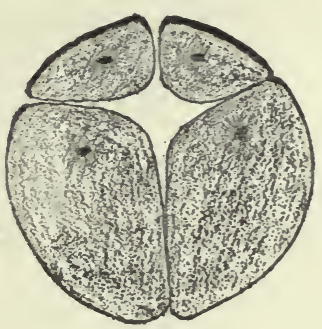

B

Fig. 5.-Vertical Sections of SEgmenting eggs. $A, 2$-cell stage. $B, 8$-cell stage.

the egg made up of sixteen blastomeres.

The thirty-two-cell stage is formed by two horizontal planes, one above and one below the first horizontal plane (Fig. I, D).

After the thirty-two-cell stage the segmentation proceeds so rapidly and so irregularly that it cannot be followed with certainty,--indeed it is seldom that the processes above described 
can be followed as far as the thirty-two-cell stage, irregularities often being seen as early as the four-cell stage.

As early as the eight-cell stage, sections of

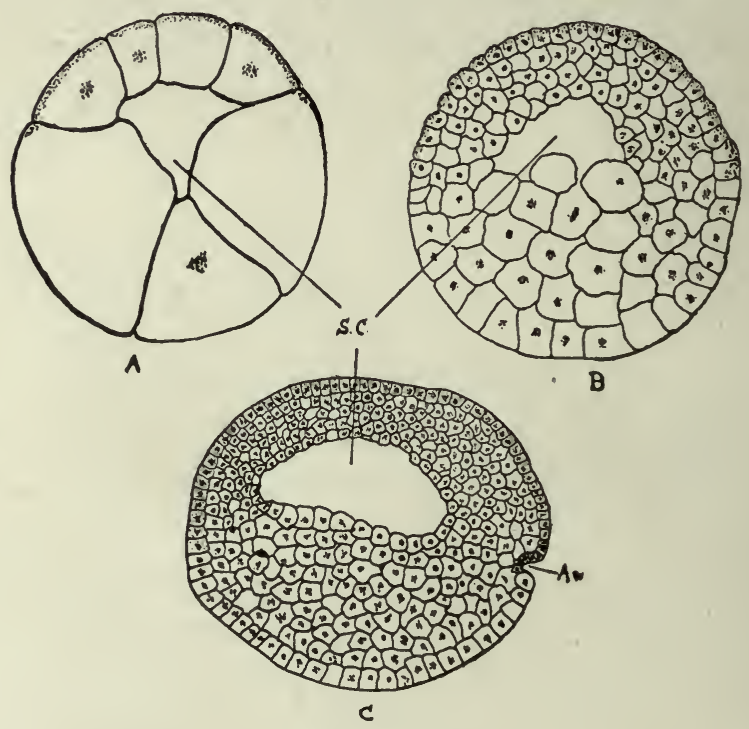

FIG. 6.

$A$ and $B$, early and late stages in the segmentation of the egg. $C$, beginning of the archenteron, $A r$. (gastrulation). $S C$, segmentationcavity (camera lucida; $\boldsymbol{C}$ slightly altered).

the egg (Fig. $5, B$ ) show a small central cavity, the segmentation cavity, which becomes larger as segmentation proceeds, and is filled with an albuminous fluid. This cavity, as will be seen, 


\section{The Development of the Frog}

eventually disappears and forms no part of the adult structure.

After the thirty-two-cell stage, a series of concentric segmentation planes are formed, dividing the blastomeres into several layers of cells. By the continuation of this process of cell-division the egg is eventually divided into several hundred cells (Figs. I, 6), those of the dark pole being much smaller, more sharply defined, and more numerous than those of the light pole. As is seen in the figures, the segmentation cavity lies nearer the dark pole, so that its roof is composed of a few layers of small, dark cells, while its floor is made up of many layers of ill-defined, yolk-filled cells. There is, however, no sharp dividing line between the pigmented and unpigmented cells, any more than there was between the dark and light poles of the unsegmented egg.

\section{Formation of the Germ-Layers}

The egg, at the close of segmentation, has been converted into a hollow sphere, with the cavity nearer the upper, or dark pole (Fig. 6). The cells of the dark hemisphere are arranged in two more or less distinct layers, while the large, unpigmented cells have no such regular 
arrangement. At this time a crescentic groove appears on one side of the egg at the border between the white and dark cells. This groove, whose convex side is upward, is the dorsal lip of the blastopore, and is the begin-

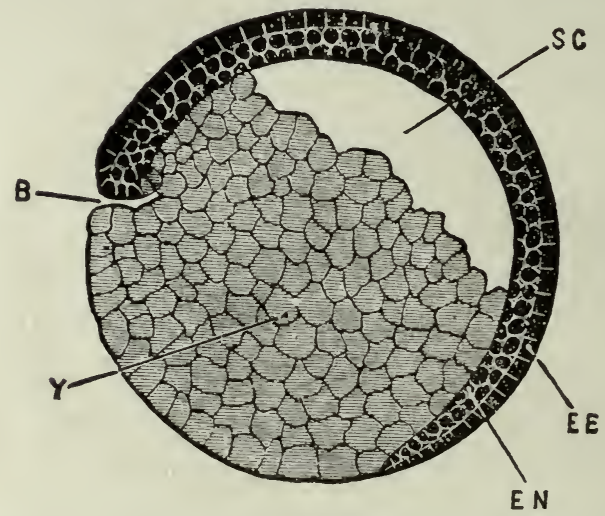

Fig. 7.-LONGITUdinal Vertical SECTION OF A FROG EMBRYO, SHOWING COMMENCING INVAGINATION. $\ 28$. (After Marshall).

$B$, blastopore. $E E$, outer or epidermic layer of ectoblast. $E N$, inner or nervous layer of ectoblast. $S C$, segmentation cavity. $Y$, yolk-cells.

ning of the process of invagination (Figs. 6, 7, and 8).

The horns of the crescent extend towards each other until they meet to form a circle (Fig. I, G), the blastopore, bounded on the outside by pigmented cells, and filled inside 


\section{The Development of the Frog 23}

with white cells. The mass of white cells which fills the blastopore is known as the yolk-plug (Fig. 8, YP).

By a rapid division of the black cells around

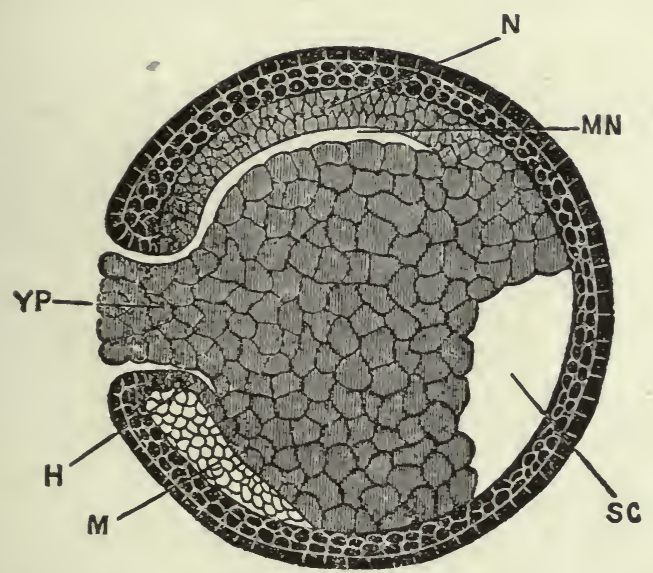

Fig. 8.-LONGITUdinal VERTICAL SECTION THROUGH A FROG EMBRYO AT A LATER STAGE IN THE FORMATION OF THE MESENTERoN. (After Marshall,)

$H$, invaginate entoblast. $M$, mesoblast. $M N$, mesenteron, $N$, notochord. $S C$, segmentation cavity. $Y P$, yolk-plug, filling up the blastopore.

the rim of the blastopore, especially at the dorsal lip, the exact nature of which process is in some dispute, the diameter of the blastopore is gradually reduced and the yolk-plug is withdrawn into the egg (Figs. 8 and 9).

This overgrowth of the black cells continues 
until the yolk-plug entirely disappears from the surface, and the blastopore is reduced to a narrow slit. The layer of black cells, which now completely surround the egg or embryo, is the upper germ-layer or ectoblast (Fig. 9).

Carefully prepared sections through the embryo at the time of the appearance of the dorsal lip of the blastopore may show, in the region where the white and black cells meet, a more or less clearly defined zone of cells extending equatorially around the embryo. This band is several cells deep, the inner cells passing insensibly into the yolkcells, the peripheral cells being indistinguishable from the ectoblast.

"This ring of cells, as subsequent development shows, is the beginning of the embryo, and the ring itself is composed of the material which subsequently forms the central nervous system, the mesoderm, the notochord, and a part of the entoderm." 1

By a process of concrescence, which is closely related to the closure of the blastopore, described above, this band of cells shifts towards one side of the embryo, and its right and left halves fuse to form a broad meridional band 


\section{The Development of the Frog}

extending into the dorsal lip of the blastopore. This process may be roughly illustrated, perhaps, by placing a rubber band around the equator of a ball, and then gradually slipping two opposite sides of the band towards one pole of the ball, until they meet and form a single broad band lying in a meridional instead of in an equatorial position.

This process of concrescence is difficult of determination, and it will probably not be practicable for students to work it out in the laboratory.

As has been said, the growth of the ectoblast over the yolk-cells takes place much more rapidly from the dorsal lip of the circular groove, which we have called the blastopore, so that, while this groove never becomes very deep on the lower side, on the upper side it becomes a long, narrow slit extending nearly to the opposite side of the embryo (Fig. 9, $M N)$. This slit, whatever may be the exact method of its formation, is the primitive digestive tract of the frog, and is known as the mesenteron or archenteron. It is much wider from side to side than it is in a dorso-ventral direction; and while its roof is made up of a more or less clearly defined layer of closely 
packed cells, its floor is a mass of undifferentiated yolk-cells. The cells forming the roof of the mesenteron are the beginning of the lower germ-layer, or entoblast (Fig. 9).

The mesenteron, opening to the exterior by

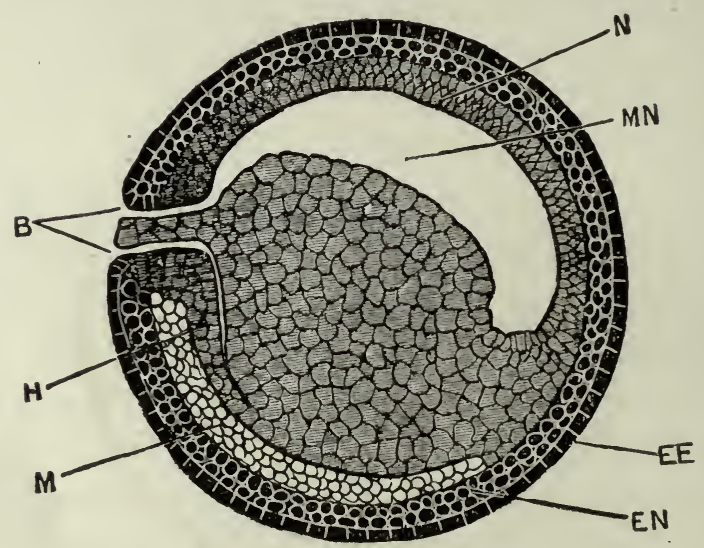

Fig. 9.-LongitudinAL VERTICAL SECTION THROUGH A FROG EMBRYO, SHOWING THE COMPLETION OF THE MESENTERon. (After Marshall.)

$B$, blastopore. $E E$, epidermic layer of ectoblast. $E N$, nervous layer of ectoblast. $H$, invaginate entoblast. $M$, mesoblast. $M N$, mesenteron, $N$, notochord.

the narrow blastopore (at the posterior end of the embryo), rapidly enlarges by forward growth and by the depression of the yolk-cells forming its floor, until it becomes a large cavity whose growth has caused the obliteration of the segmentation cavity (Figs. 8, 9, and 


\section{The Development of the Frog}

Io). The mouth and true anus will not be formed until later.

The notochord, or primitive backbone, is formed at this time as a rod-like thickening of

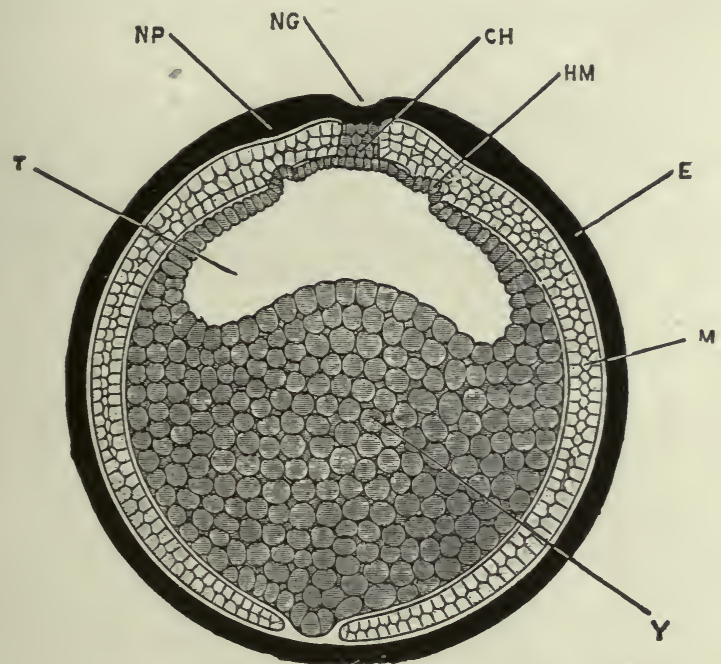

FIG. IO.-A TRANSVERSE SECTION THROUGH THE MIDDLE OF THE LENGTH OF A FROG EMBRYO, AT ABOUT THE STAGE REPRESENTED IN FIG. 9. (After Marshall.)

$C H$, notochord. $E$, ectoblast. $H M$, pouch-like diverticulum of the entoblast into the mesoblast. $M$, mesoblast. $N G$, neural groove. $N P$, neural plate. $T$, mesenteron. $Y$, yolk.

the entoblast, extending along the roof of the mesenteron in the middle line for the greater part of its length. It does not, for a time, separate from the rest of the cntoblast and is very indistinct; but it later forms a distinct rod of 
cells, which is a characteristic feature of all transverse sections of embryos (Figs. IO, I 2, 13 , and 15 ).

According to some workers the notochord is formed by a condensation and differentiation of mesoblast cells along the mid-dorsal region of the embryo. Since the mesoblast and entoblast are, in their origin, so closely associated, the exact method of formation of the notochord, whether from the one layer or the other, is not a matter of very great importance; but the majority of workers probably support the former view, - that is, that it is formed by a differentiation of a part of the entoblastic layer.

Like the formation of the archenteron, the origin of the middle germ-layer, or mesoblast, has been so variously described by different authors that it is quite a difficult matter to decide which is the most probable view. Although so difficult of determination in the case of the frog, the origin of the mesoblast in some other animals is easily made out.

Marshall states that it "arises in the frog as two lateral sheets of cells, split off from the outer surface of the hypoblast and yolk-cells."

Morgan says ". . . the cells that are to form the mesodermal layer are present at the time when the 


\section{The Development of the Frog}

dorsal lip of the blastopore has first appeared, and even just prior to that time. The innermost of those cells forming the ring around the egg are the cells that become the mesoderm. These cells are carried up to the median dorsal line of the embryo by the closure of the blastopore. They will then be found forming a layer or sheet of cells that separates itself on the outer side from the thick layer of small ectodermal cells (that has been simultaneously lifted up) and that is separated on the inner surface, but not very sharply, if at all, from the dorsal and dorso-lateral walls of the archenteron."

This layer of mesoblast, lying between the ectoblast above and the entoblast below, is described by Morgan as being continuous across the dorsal side of the embryo, but it is more often said to consist of two lateral portions, separated along the mid-dorsal line by the notochord, which is formed at about the same time.

The two plates of mesoblast rapidly extend towards the mid-ventral line, where they fuse and thus form a continuous layer under the ectoblast (Figs. Io and I 3 ).

Soon after its formation as a distinct layer, the mesoblast separates, beginning on each side of the notochord, into two layers, one lying next to the ectoblast and known as the somatopleure, and one lying next the entoblast, or yolk, and known as the splanchno- 
pleure. The space left between its two layers by this cleavage of the mesoblast will become the body-cavity, or coelom (Figs. I 3, $C$, and I 5).

As the yolk-plug is withdrawn within the egg, the lateral lips of the blastopore come together to form a slight ridge or streak of tissue, the primitive streak, in the centre of which is a narrow chink or groove, the primitive groove
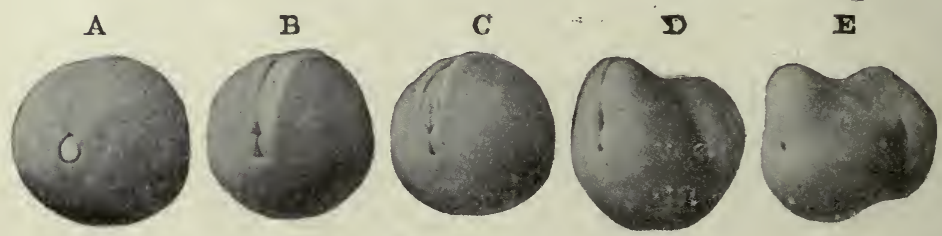

Fig. II.-STAges IN THE EARLy DEvelopment of THE FROG, SEEN OBLIQUELY FROM THE POSTERIOR END. (After Ziegler, from Marshall.)

$A$, yolk-plug stage. $B$, primitive streak and early neural folds. $C$, later neural folds. $D$, closure of neural canal and beginning of tail. $E$, completion of neural tube, closure of blastopore, presence of proctodæum, increase in tail.

(Fig. II $B, C$, and $D$ ). The primitive streak is very inconspicuous in the frog, but, as will be seen later, in the chick it is a very clearly defined structure.

\section{Fate of the Germ-Layers}

From the three germ-layers, whose origins have been briefly discussed, are derived all of the organs of the body. 


\section{The Development of the Frog $3 \mathbf{r}$}

From the ectoblast are derived the epidermis and the various structures derived from the epidermis, such as hairs, nails, etc.; the central and peripheral nervous systems; parts of the eye, ear, and nose; the lining of the mouth and anus; and the pineal gland and pituitary body.

From the entoblast are derived the lining epithelium of the digestive tract, with all its diverticula, such as lungs, liver, etc.; and the notochord; though there is some difference of opinion as to the origin of the latter structure.

From the mesoblast are derived all of the other organs of the body, such as bones, muscles, blood, blood-vessels, and uro-genital organs.

The development of the more important organs of the body will now be described, and it will be best to complete the discussion of cach organ in turn, rather than to attempt to describe their synchronous development.

Development of the Nervous System

Since the nervous system is one of the first to make its appearance in the frog, as well as in other animals, it is a convenient one with which to begin the discussion. 
The ectoblast, formed, as has been described, by the gradual spreading of the pigmented cells over the entire egg, soon shows two more or less distinct layers, an outer or epidermal, and an inner or nervous layer (Fig. 9).

At about the time of the closure of the blastopore, when the embryo is still almost spherical in shape (Fig. I I, B), the nervous layer thickens to form the neural plate, which extends along the dorsal side of the embryo, and causes it to be slightly flattened. The neural plate at its posterior end, which is just above the blastopore, is narrow, but it gradually widens as it extends forward for about one third of the circumference of the embryo. The edges of the neural plate soon begin to thicken and to be elevated slightly on all sides, forming the neural folds; and the neural groove is formed as a shallow furrow, extending forward from the blastopore along the middle of the neural plate (Fig. I, $H$, and Fig. I I, $B$ and $C$ ).

The neural folds (Fig. I $3, N F$ ) become more and more elevated until they meet and fuse along the mid-dorsal line, converting the neural groove into a closed tube, the neural canal (Fig. 15, NS). The fusion of the neura! 

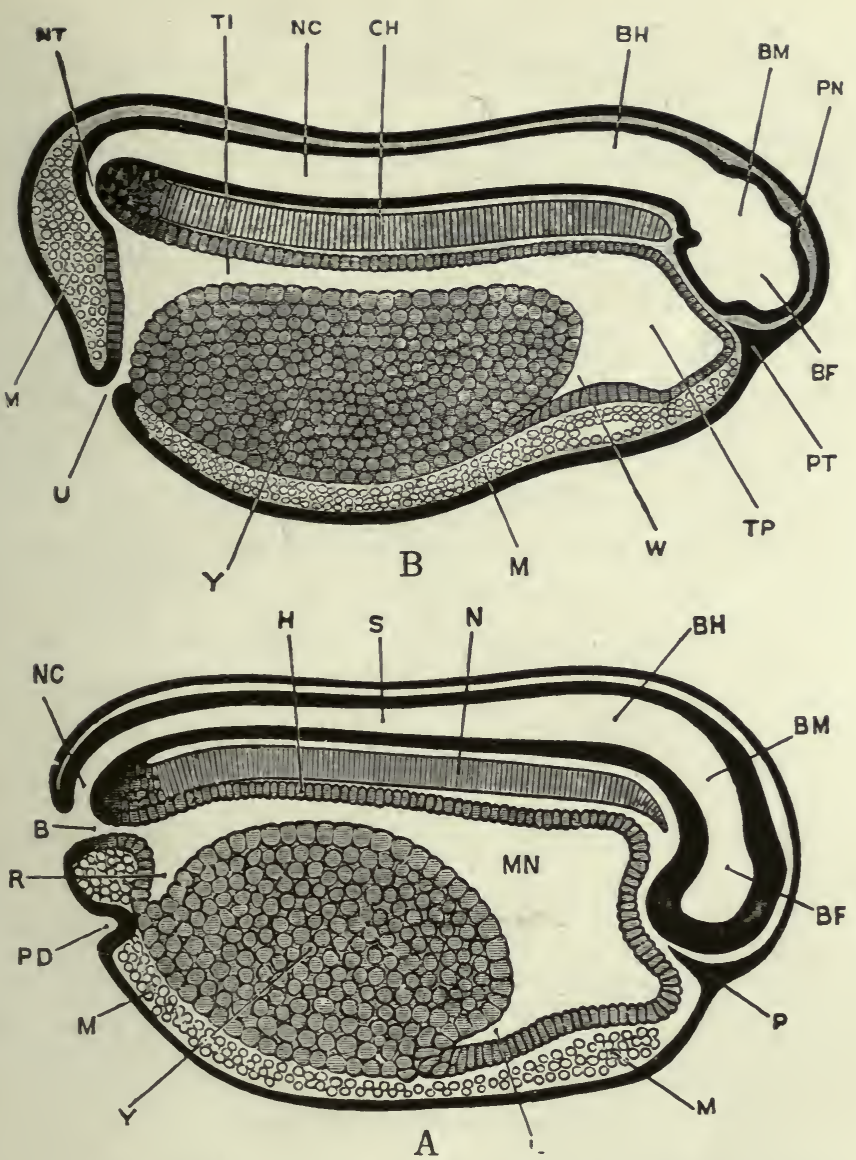

Fig. 12. A.-SAgittal Section of Embryo Shown in Fig, II, D, SHORTLY BEFORE THE CLOSURE OF THE BLASTOPORE. (After Marshall.)

$B$, blastopore. $B F$, fore-brain. $B H$, hind-brain. $B M$. mid-brain. $H$, entoblast. $L$, liver. $M$, mesoblast. $M N$, mesenteron. $N$, notochord. $N C$, neurenteric canal. $P$, beginning of pituitary body as in growth of ectoblast. $P D$, proctodæum. $R$, rectal diverticulum of mesenteron. $S$, central canal of spinal cord. $Y$, yolk-cells.

B.-SAgitTal SECtion of Fibryo shown in Fig, it, E, SHORTIy AFTER THE ClOSURF. OF THE BLASTOPORE. (After Marshall.)

$B F$, fore-brain. $B H$, hind-brain. $B M$, mid-brain. $C H$, notochord. $M$, mesoblast. $N C$, neural tube. $N T$, neurenteric canal. $P N$, pineal body. $P T$ pituitary body. $T I$, intestinal region of mesenteron. $T P$, pharyngeal region of mesenteron. $U$, proctodæal or cloacal opening. $W$, liver. $Y$, yolk-cells. 


\section{$34 \quad$ Vertebrate Embryology}

folds begins in what will be the neck region of the future tadpole, and extends forward and backward from that point, the extreme anterior end being the last to close in completely. As the neural folds, or medullary folds as they are often called, fuse together to form the neural or medullary canal, the epidermal layer of ectoblast fuses over the top, and forms, once more, a smooth, continuous layer (Figs. I 2 and $\mathrm{I}_{5}$ ).

It will be seen by an examination of the figures that the chief thickness of the wall of the neural tube is derived from the nervous layer of ectoblast, but that the layer of cells which lines the inside of the tube is from the epidermal layer (Fig. I3).

The extreme posterior ends of the neural folds extend on each side of the blastopore, so that, as they come together, they cover the blastopore, which persists for a time as a narrow passage, the neurenteric canal, connecting the mesenteron with the neural canal (Fig. I 2, $N C$ and $N T$ )。

The neural tube, formed as above described, becomes converted into the central nervous system, the anterior end forming the brain, the rest of the tube forming the spinal cord. 


\section{The Development of the Frog}

Of the changes that convert the simple tube into the adult cord little need be said. The walls thicken rapidly, and the originally large, circular canal is reduced to a narrow, vertical slit (Fig. I $5, N S$ ). As development proceeds,

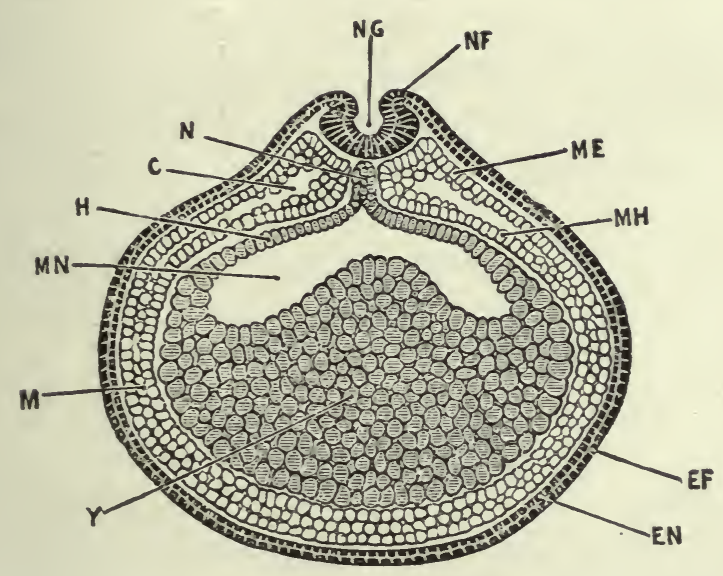

Fig. I3.-Transterse SEction THROUgh A FROG EMBRYO DURING THE FORMATION OF THE NEURAL CANAL. (After Marshall.)

$C$, colom. $E F$, epidermic layer of ectoblast. $E N$, nervous layer of ectoblast. $H$, entoblast. $M$, mesoblast. $M E$, somatopleuric layer of mesoblast. $M H$, splanchnopleuric layer of mesoblast. $M N$, mesenteron. $N$, notochord. $N F$, neural fold. $N G$, neural groove. $Y$, yolk-cells.

the relative size of the canal becomes smaller and smaller until, in the adult, it is seen as a tiny tube in the centre of the cord, lined with a thin layer of epithelial cells, derived 
from the epidermal layer of the original ectoblast.

The changes that convert the anterior end of the neural tube into the complicated structures of the adult brain are much more extensive, and must be described in more detail, although the limits of this work will not permit a full description.

The first indication of a separation of the brain from the rest of the neural tube is seen at about the time of the appearance of what is known as cranial flexure. As the name would indicate, cranial flexure is the bending of the brain, at about its middle region, so that the anterior end is pushed down, and comes to lie almost at right angles with the posterior part (Fig. I 2).

This cranial flexure takes place around the anterior end of the notochord, and persists throughout life, its apparent rectification being due to inequalities in the growth of the different parts of the brain. At this time the central nervous system has somewhat the shape of a retort, the bulb of the retort corresponding to the brain, and the neck of the retort corresponding to the spinal cord.

Two transverse folds appear very early in 
the brain region, dividing it into three more or less distinctly marked portions, the fore-brain, mid-brain, and hind-brain (Fig. 1 2.) The development of these regions of the brain will be taken up, briefly, in turn.

The hind-brain forms the medulla and cerebellum of the adult, its cavity remaining as the fourth ventricle. The floor and sides of the hind-brain become thickened, while the roof becomes very thin, except at the part next to the mid-brain, where the cerebellum is developed (Fig. 16).

The floor of the mid-brain thickens to form the crura cerebri, while from the roof grow out two hollow, ovoid bodies, the optic lobes. The cavity of the mid-brain persists as the Sylvian aqueduct or iter.

The walls of the fore-brain (thalamencephalon of the adult) thicken to form the optic thalami and its cavity, the third ventricle, is thus reduced to a narrow, vertical slit. From the floor of the fore-brain the infundibulum is formed as a hollow pouch, pushed out in a ventro-posterior direction (Figs. I 4, IN, I 7 , and 18,I). Since the pituitary body is so closely associated with the infundibulum, its origin will be spoken of at this time. 
At a very early period, a thickening of the nervous layer of the ectoblast is formed just below the anterior end of the neural canal. This collection of cells grows inward as a tongue of ectoblast tissue between the anterior end of the brain and the digestive tract (Figs. I4, $P T$, I 7 , and I $8, P$ ). The inner end of this tongue of cells becomes broader and hollow, and eventually separates from its stalk to form the pituitary body, which lies just under the infundibulum (Fig. I8, I). From the roof of the fore-brain, at the point where the neural tube finally closed, a small, hollow diverticulum is pushed out and becomes enlarged at the end (Figs. I 4 and I 7, PN). This is the pineal body, and when the skull is formed it cuts off the enlarged knob from its hollow stalk, the knob, which has become solid, remaining outside of the skull, and the stalk retaining its connection with the fore-brain.

The cerebral hemispheres, which form the larger part of the fore-brain, do not form until a comparatively late period. They begin as a large, median diverticulum from the front of the fore-brain (Figs. I 7, $C V$, and 18), which diverticulum is at first unpaired, but later becomes divided into the two hemispheres. 


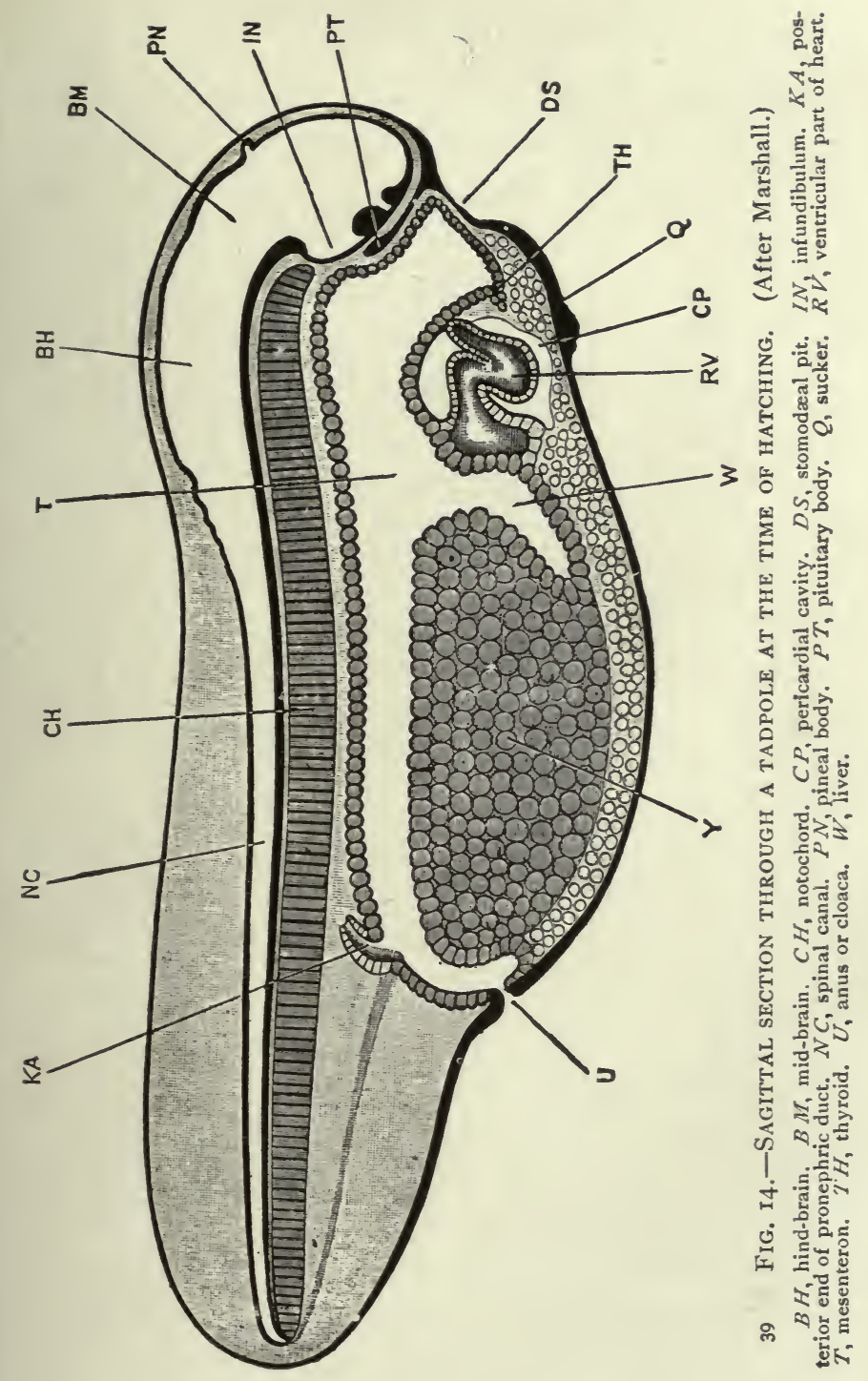


The olfactory lobe is formed by the fusion of an outgrowth from the anterior end of each cerebral hemisphere. The cerebral hemispheres are at first unpaired and later become double, while the olfactory lobe is at first double and afterwards becomes single.

There are many details in the development of the peripheral nervous system that are not yet clearly understood. The dorsal roots of the spinal nerves arise very early as outgrowths from the sides of the neural plates before the latter fuse together to form the neural canal. They grow down between the neural canal and the myotomes (Fig. I 5, ND) and become slightly enlarged, a short distance from their points of origin, to form the spinal ganglia. The ventral roots of the spinal nerves arise later as independent outgrowths from the ventral side of the neural canal, and fuse with the dorsal roots distal to the spinal ganglia.

\section{Development of the Sense Organs}

Since the organs of special sense are chiefly derived from the ectoblast, and since they are all closely connected with the brain, it is well to speak of their development at this point. 


\section{The Development of the Frog 4I THE Eye}

The development of the eye can be more easily made out in the chick than in the frog,

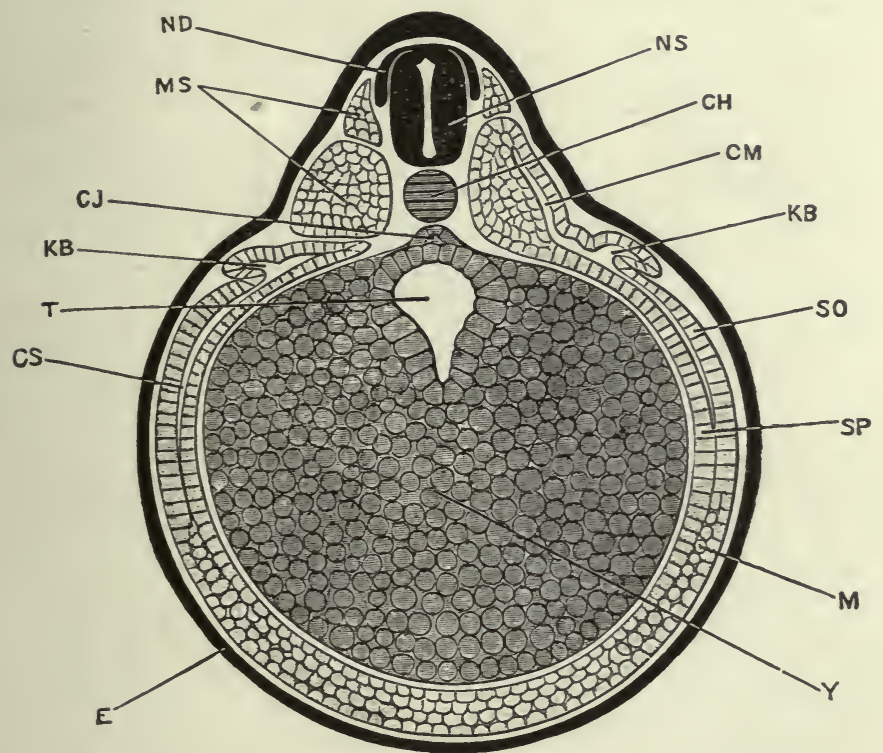

Fig. I5.-Transverse Section across the middle of the EMBRyo SHOwN IN Fig. II, D. (After Marshall.)

$C H$, notochord. $C J$, subnotochordal rod. $C M$, myocoel. $C S$, body cavity. $E$, ectoblast. $K B$, archinephric duct. $M$, mesoblast. $M S$, mesoblastc somite. $N D$, dorsal root of spinal nerve. $N S$, spinal cord. $S O$, somatopleure. $S P$, splanchnopleure. $T$, intestinal region of mesenteron. $Y$, yolk-cells.

so that many of the details will be left until the latter part of the book, since the process is essentially the same in both animals.

The first rudiment of the eye is seen in 
very young tadpoles as an evagination from each side of the fore-brain. This evagination, which is known as the optic vesicle, reaches a considerable size and becomes constricted off from the brain, so that it forms a large, hollow bulb connected with the brain by a very narrow stalk.

The walls of the optic vesicle are at first comparatively thin, but as the vesicle enlarges and approaches the superficial ectoblast, the wall of the vesicle that is next to the ectoblast begins to thicken and at the same time to be pushed in on itself (Fig. I9, OC); this invagination of the optic vesicle continues until the two walls are in contact, and the cavity of the original optic vesicle is obliterated. The cupshaped structure which is thus formed, and which is still connected with the fore-brain by the narrow stalk, is known as the optic cup. The thick inner wall of the optic cup forms the essential part of the retina, while the thin outer wall forms the pigmented layer that surrounds the retina. The rim of the optic cup is not complete, like the rim of an invaginated hollow rubber ball, but is interrupted, at one place, as a narrow slit known as the choroid fissure. Through the choroid fissure the sur- 
rounding mesoblast enters the optic cup and forms the vitreous humor. The outer layers of the eye are formed from the mesoblast. As the optic vesicles approach the superficial ectoblast, the inner layer of the latter becomes thickened, and eventually separates from the outer layer and lies at the opening of the optic cup as a hollow spherical, or ovoid body, the lens vesicle (Figs. I9, OL, and 20 OL). By the growth of its walls, chiefly the inner, the cavity of the lens vesicle is obliterated and the adult lens is formed.

\section{THE EAR}

The ear begins as a thickening, followed by an invagination of the inner or nervous layer of the ectoblast. This invagination begins very early and, in the frog, never opens to the exterior. It is, almost from the first, connected with the brain by the auditory nerve. The invagination gradually closes to form a comparatively thin-walled cavity, lying in the region of the hind-brain, known as the auditory vesicle. This vesicle, whose walls are composed of a single layer of cells (Fig. 21,E), forms the lining of the inner ear. A more complete description of the development of the ear will be given in connection with the chick. 


\section{The Nose}

The nose, like the eye and ear, begins at a very early period, and is first seen as two thickenings of the inner layer of the ectoblast,
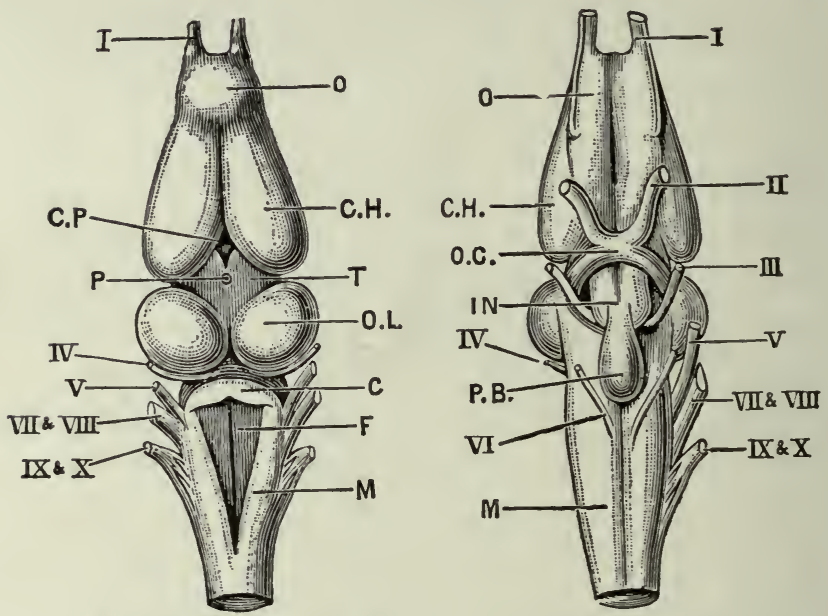

Fig. 16.-The BRAIN OF THE FROG. (After Marshall.) Figure on left is a dorsal view; figure on right is a ventral view.

$C$, cerebellum. $C H$, cerebral hemisphere. $C P$, choroid plexus of third ventricle. $F$, fourth ventricle. $I N$, tuber cinereum. $M$, medulla oblongata. $O$, olfactory lobe. $O C$, optic chiasma. $O L$, optic lobe. $P$, stalk of pineal body. $P B$, pituitary body. $T$, thalamencephalon.

$I$, olfactory nerve. $I I$, optic nerve. $I I I$, third or motor oculi nerve. $I V$, fourth nerve. $V$, fifth or trigeminal nerve. $V I$, sixth nerve. $V I I$ and $V I I I$, combined root of facial and auditory nerves. $I X$ and $X$, combined root of glossopharyngeal and pneumogastric nerves.

one on each side of the anterior end of the head. An invagination of both layers of theectoblast now takes place (Fig. 22, OF), forming the nasal pits whose openings to the exterior 
will form the anterior nares. The lining of the nasal pits will become connected with the brain by the olfactory nerves, and will form the olfactory epithelium of the nose. From the inner side of the nasal pits a diverticulum grows down to open into the mouth cavity as the posterior nares.

\section{Development of the Alimentary Tract}

The origin of the primitive digestive tract or archenteron has already been given : it now remains to describe the further changes that take place in the digestive tract itself, and to describe the development of the various structures that are derived from it.

The digestive tract may, for convenience, be divided into three regions: (1) the mesenteron (whose formation has been described), which is lined with entoblast and from which are developed the liver, pancreas, lungs, gill clefts, etc.; (2) the stomodaum, which forms the mouth; (3) the proctodaum or cloacal region. The first region is lined throughout with entoblast, while the latter two are both lined with ectoblast. The reason for this difference will be seen when the development of the mouth and anus is described. 
The anterior end of the digestive tract early becomes expanded into what may be called the pharynx, and there is a similar though smaller expansion at the posterior end (Figs. I $2 T P$ and 22). The entoblast at first forms a more distinct layer on the dorsal side of the mesenteron than it does on the ventral side, but it very soon extends entirely around the cavity as distinct layer.

In the frog the primitive mouth or blastopore closes entirely, so that the digestive tract may be for a short time a completely closed cavity, but in some other animals the blastopore persists as the permanent anus.

Shortly before hatching, a depression of the ectoblast may be seen on the ventral side of the head (Fig. I 4, DS) ; this is the beginning of the stomodæum. The depression becomes deeper and deeper until it is separated from the front of the pharynx by only a thin septum (Fig. I 7, $S D$ ). Soon after hatching this sep. tum becomes perforated and the mouth opening is formed. The lips now grow forward, the jaws become formed, and the tadpole begins to take food from the surrounding water (Fig. I 8 ).

The proctodæum or anal opening is formed 


\section{The Development of the Frog}

before the stomodæum. Before the neural canal has been completely closed a small de-

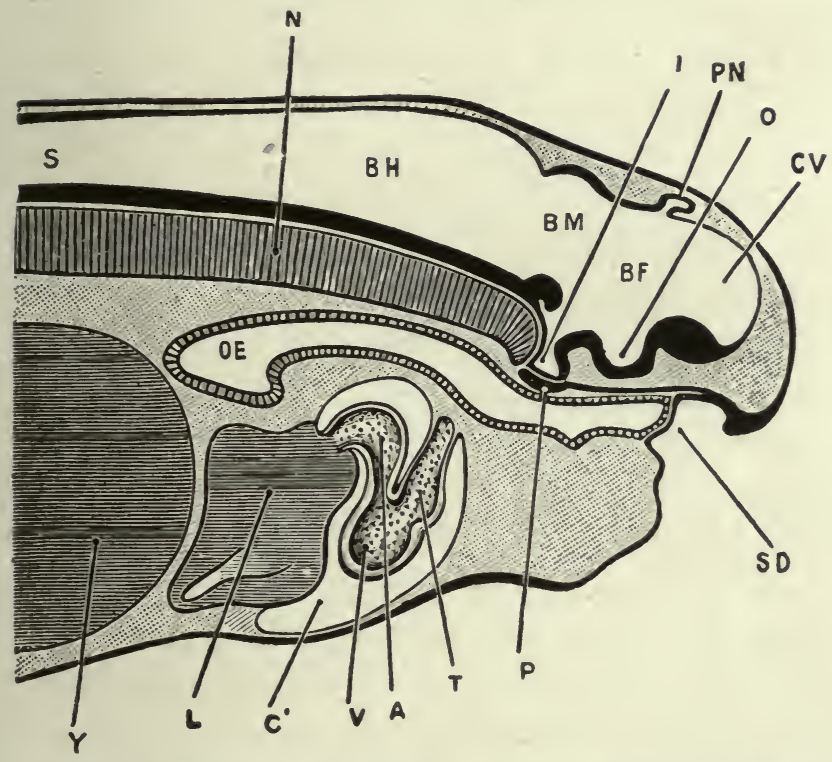

FIG. I7.-LONGITUDINAL VERTICAL SECTION THROUGH THE ANTERIOR END OF A TADPOLE SHORTLY AFTER THE TIME OF HATCHING. LENGTH OF THE TADPOLE, 8 MM. (After Marshall.)

$A$, auricle of heart. $B F$, fore-brain. $B H$, hind-brain. $B M$, mid-brain. $C^{\prime}$, pericardial cavity. $C V$, vesicle of cerebral hemispheres. $I$, infundibulum. $L$, liver. $N$, notochord. $O$, depression of floor of fore-brain from which the optic vesicles arise. $O E$, œsophagus. $P$, pituitary body. $P N$, pineal body. $S$, central canal of spinal chord. $S D$, stomodæum. $T$, truncus arteriosus. $V$, ventricle. 1 , yolk-cells.

pression is seen below the blastopore (Fig. I 2, $P D)$; this is the beginning of the anal invagination. At the same time a diverticulum 
grows backward from the posterior end of the digestive tract towards this invagination (Fig. I2), with which it finally fuses and thus puts the hind gut in communication with the exterior (Figs. I $2 U$, and I $4, U$ ). The formation of the proctodæum may be completed before the closure of the blastopore, so that the hinder end of the digestive tract may have two openings to the exterior.

It will be understood, from the above description, why it is that the oral and anal cavities are lined with ectoblast instead of with entoblast, as is the rest of the digestive canal.

The liver may be early recognized as a diverticulum pushed out from the front end of the digestive tract in a ventro-posterior direction (Figs. I 2 and 14, W). The walls of this diverticulum thicken and become folded, and the mesoblast penetrates between these folds. The diverticulum, which is evidently lined with entoblast, persists as the bile duct, and from it an outgrowth arises to form the gall bladder.

The pancreas arises as a pair of hollow outgrowths from the mesenteron back of the liver. 


\section{The Development of the Frog 49}

The lungs arise from the narrow part of the digestive tract which lies just back of the wide anterior end or pharynx. A longitudinal fold

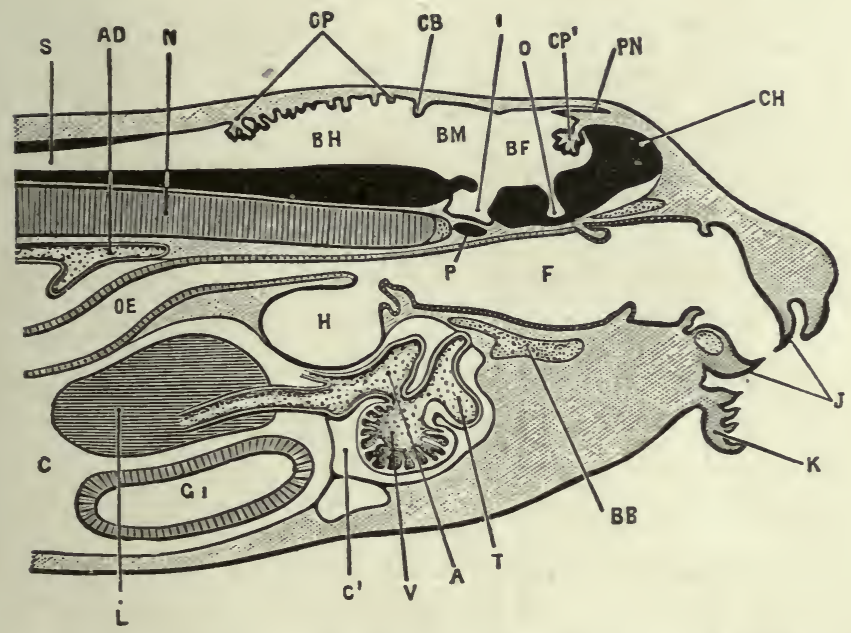

Fig. I8.-LONGITUdINAL VERTICAL SECTION THROUGH THE HEAD AND ANTERIOR PAR'T OF THE BODY OF A TADPOLE ABOUT THE TIME OF APPEARANCE OF THE HIND LEGS. LENGTH OF TADPOLE, I2 MM. $\times$ I4. (After Marshall.)

$A$, auricle of heart. $A D$, dorsal aorta. $B B$, basi-branchial cartilage. $B F$. fore-brain. $B H$, hind-brain. $B M$, mid-brain. $C$, colom or body-cavity. $C^{\prime}$, pericardial cavity. $C H$, cerebral hemisphere. $C B$, rudimentary cerebellum. $C P$, choroid plexus of fourth ventricle. $C P^{\prime}$, choroid plexus of third ventricle. $F$. pharynx. $G$, stomach. $H$, lung. $I$, infundibulum. $J$, horny jaws. $K$, lio. $L$, liver. $N$, notochord. $O$, depression of floor of fore-brain from which the optic nerves arise. $O E$, œsophagus. $P$, pituitary body. $P N$, pineal body. $S$, central canal of spinal chord. $T$, truncus arteriosus. $V$, ventricle.

appears in each side of the mesenteron, at this place, and by the meeting of these folds the digestive tract is divided into a dorsal portion 


\section{Vertebrate Embryology}

or cesophagus, and a ventral portion or larynx. From the laryngeal chamber the lungs arise as hollow lateral outgrowths, some time after hatching, when the tadpole is about $8 \mathrm{~mm}$. long. At about the time of the formation of the lungs the tubular œsophagus becomes solid and remains closed until after the formation of the oral opening. What the significance of this curious fact may be is not known.

The thyroid body begins, at about the time of hatching, as a small, median depression in the floor of the pharynx. The depression becomes deeper, especially at its posterior end, and finally loses its connection with the pharynx and lies as a solid rod of cells just in front of the pericardium. When the tadpole is about I $2 \mathrm{~mm}$. in length the thyroid becomes separated into right and left halves by the growth of a median longitudinal septum, and after considerable growth each of these halves is converted into the adult structure by the rearrangement of its cells to form the round or oval vesicles that are characteristic of the thyroid gland.

The bladder arises at about the time of metamorphosis as an outgrowth from the ventral wall of the hind gut. 
The Development of the Frog 5 I

\section{Development of the Gill Cleffts and FoldD}

The gill clefts are five pairs of narrow, vertical slits which connect the cavity of the pharynx with the exterior. The portions of the wall between the clefts, and also in front of the first and behind the last clefts are the gill folds or arches. The most anterior cleft is known as the hyomandibular cleft, the others, from before back, are the first, second, third, and fourth gill clefts. The arch in front of the hyomandibular cleft is called the mandibular arch, the arch between the hyomandibular and the first gill clefts is the hyoid arch, and the other arches, like the clefts, are called the first, second, third, and fourth.

The gill clefts, or, as they are often called, the visceral or branchial clefts or pouches, begin to develop before the tadpole hatches, and are best studied in horizontal sections. The first three pairs of pouches begin almost simultaneously as evaginations of the entoblastic wall of the pharynx, which push outward towards the ectoblast. The third and fourth pouches are formed in succession behind the first three. All of the pouches grow outward until they come in contact with the ectoblast, 
with whose inner layer they fuse (Fig. 22). The two lamellæ of entoblast that make up the pouches are at first in contact with each other, so that there is no actual cleft between them (Fig. 22, $H M, H C .4$ ); but at about the time of the opening of the mouth the lamellæ

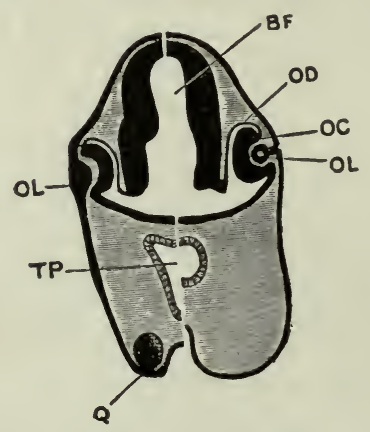

Fig. I9.-HALF SECTIONS IN THE TRANSVERSE PLANE OF A TADPOLE, IO MM. LONG (LEFT HALF) AND OF A TADPOLE I 2 MM. LONG (RIGHT HALF). X $35 . \quad$ (After Marshall.)

$B F$, fore-brain. $O D$, outer wall of optic cup (pigment layer of adult retina); $O C$, inner wall of optic cup (remainder of adult retina). $O L$, lens, attached to epiblast in younger tadpole, but forming a hollow vesicle at the later stage. $T P$, pharynx. $Q$, sucker. [G. H. F.]

separate from each other to form the actual clefts, all of which open to the exterior except the hyomandibular pair, which recede from the ectoblast and persist, for a time, as a pair of diverticulæ from the front part of the pharynx. 
The Development of the Frog 53

The Eustachian tube and the tympanic cavity develop near the hyomandibular cleft, but it is doubtful if any such close relation exists between those structures and the hyomandibular cleft as exists in some other animals.

The other visceral clefts persist for a considerable time, but towards the end of the tadpole stage they close up and disappear.

The fate of the gill arches is of more importance, but as it is more easily studied in the chick, a very brief statement will suffice at this time. The mandibular arch, as its name would indicate, becomes converted into the essential part of the lower jaw. The hyoid arch, as its name indicates, forms the greater part of the hyoid apparatus, while the other four arches almost entirely disappear. During the larval period there is present in each visceral arch a rod of cartilage, which is closely joined to its fellow of the opposite side ventrally but is separated from it dorsally. Thus there is in each pair of arches a $U$-shaped bar of cartilage which serves to stiffen the walls of the pharynx.

The gills, of which there are two sets, the external and the internal, are developed in connection with the gill arches. 
Even before the tadpole is hatched there may be seen, on each side of the neck region, a series of vertical folds, or thickenings; these are the visceral folds, and it is upon them that

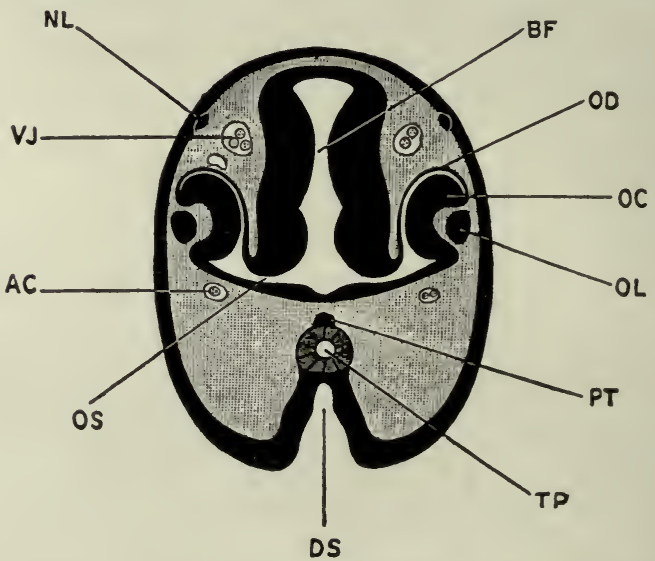

Fig. 20. - Transverse Section through the HEAD OF A TADPOLE $61 / 2$ MM. IN LENGTH ABOUT THE TIME OF HATCHING, THE SECTION PASSING THROUGH THE FORE-BRAIN AND DEVELOPING EYES. (After Marshall.)

$A C$. carotid artery. $B F$, fore-brain. $D S$, stomodæal pit. $N L$, cutaneous or lateral line branch of trigeminal nerve. $O C$, inner wall of optic cup. $O D$, outer wall of optic cup. $O \dot{L}$, lens. $O S$, optic stalk. $P T$, pituitary body. $T P$, pharynx. $V \mathcal{F}$. jugular vein.

the gills are developed (Figs. I, J, L, and 22).

The external gills appear first, reach their maximum development, and then are replaced by the internal gills. The external gills arise, shortly before hatching, upon the first and 
second gill arches, and a little later a third pair is formed upon the third arch. The external gills reach their greatest development at about the time of the opening of the mouth, and at that time each of the first two consists of from five to seven main lobes, with numerous secondary lobes along their posterior borders (Fig. 23, $A$ ). The gills on the third arch are much smaller than those of the arches in front, and are nearly covered by them. The course of the circulation in the external gills may be easily seen under the microscope, each main lobe and each minor lobe being supplied with an efferent and an afferent blood-vessel (Fig. 23, EF and $A F$ ).

The opercular folds arise, before the mouth opens, as two folds of skin from the hyoid arches; they unite with each other in the ventral line, and grow backward as a sort of hood over the external gills (Fig. 24). The posterior border of this hood fuses with the body wall behind the gills, on the right and ventral sides, but remains open on the left side as a sort of spout (Fig. 24, OA), through which the gills of that side frequently protrude, and through which the water, taken into the gill chamber through the mouth, passes again to 
the exterior. The opercular folds are not completed until after the formation of the mouth.

The internal gills arise quite early as a double row of papillæ on the first, second, and third visceral arches, below the external gills, and as a single row on the fourth arch. They are very vascular, and when the external gills begin to shrivel, they take up the function of respiration. The inner borders of the gill arches develop a sort of straining apparatus, to prevent solid substances from passing from the pharynx into the gill chamber.

At the end of the tadpole life, as the lungs begin to function, the gill chamber is filled and gradually obliterated by the growth of lymphoid and epithelial tissue, the gill clefts are closed by the fusion of their edges, and the gills are almost entirely absorbed, small portions persisting in the adult as the so-called tonsils.

The Development of the Heart and Blood Vessels

As has been stated above, the heart and blood vessels, as well as the blood itself, are formed from mesoblast, the chief point of interest being the changes that take place at 


\section{The Development of the Frog 57}

metamorphosis, when the circulation changes from practically that of a fish to that of the adult frog. Since changes similar to these

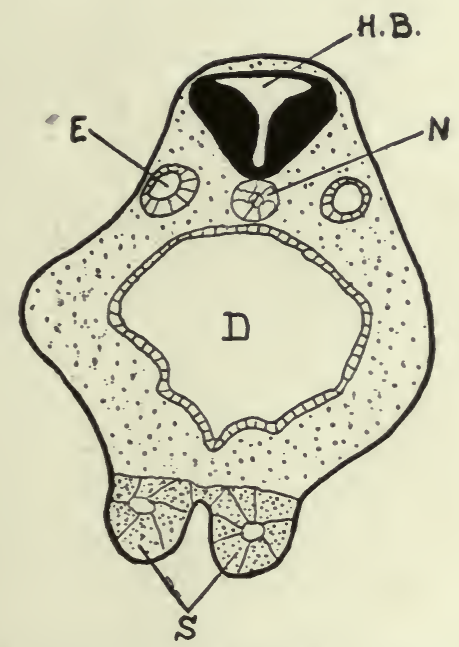

Fig. 21.--Transverse SECTION THROUGH THE REGION OF THE HIND-BRAIN OF A YOUNG TADPOLE.

$D$, digestive tract.
notochord. $S$, sucker. (Camera lucida.)

take place in even the highest animals, they are of more than passing interest.

The development of the heart and pericardium, though difficult to follow out in detail in the laboratory, will be readily understood from the following description, studied in connection with Fig. 25 : 
"The heart appears at the time when the medullary folds have rolled in, and have met along the mid-dorsal line; it lies below the pharynx, and anterior to the liver (Fig. I2). The mesoderm in this region shows a tendency to split into two sheets, and, where the heart is about to develop, a cavity, a part of the cœlom, appears between the sheets. A cross-section of the larva (Fig. 25, $A$ ) shows on each side of the mid-ventral line in the region of the heart the somatic and splanchnic layers widely separated from each other. The cœlomic cavities of the right and left sides are not continuous across the middle line, but anterior and posterior to this section the cœlomic cavity is found to be continuous before and behind with the general cœlomic space on each side. A few scattored cells lie in the middle line between the splanchnic layer and the wall of the pharynx (Fig. 25,E). These cells have been described as originating from the ventral wall of the archenteron, and, if so, have had a different origin from the other cells of the heart.

"At a somewhat later stage of development the walls of the cœlomic cavities of the right and left sides separate further (Fig. 25, B). The splanchnic layer thickens, and begins to surround the proliferation of scattered 'endodermal cells.' 'These endodermal cells arrange themselves in a thin-walled tube stretching throughout the heart region (Fig. 25). Subsequent development shows that this tube becomes the endothelial lining of the heart. Around this endothelial tube the thickened splanchnic layers now begin to push in from the sides between the tube and the lower wall of the pharynx. The tube becomes finally entirely surrounded by mesoderm (Fig. 25). The mesoderm from the sides that has 


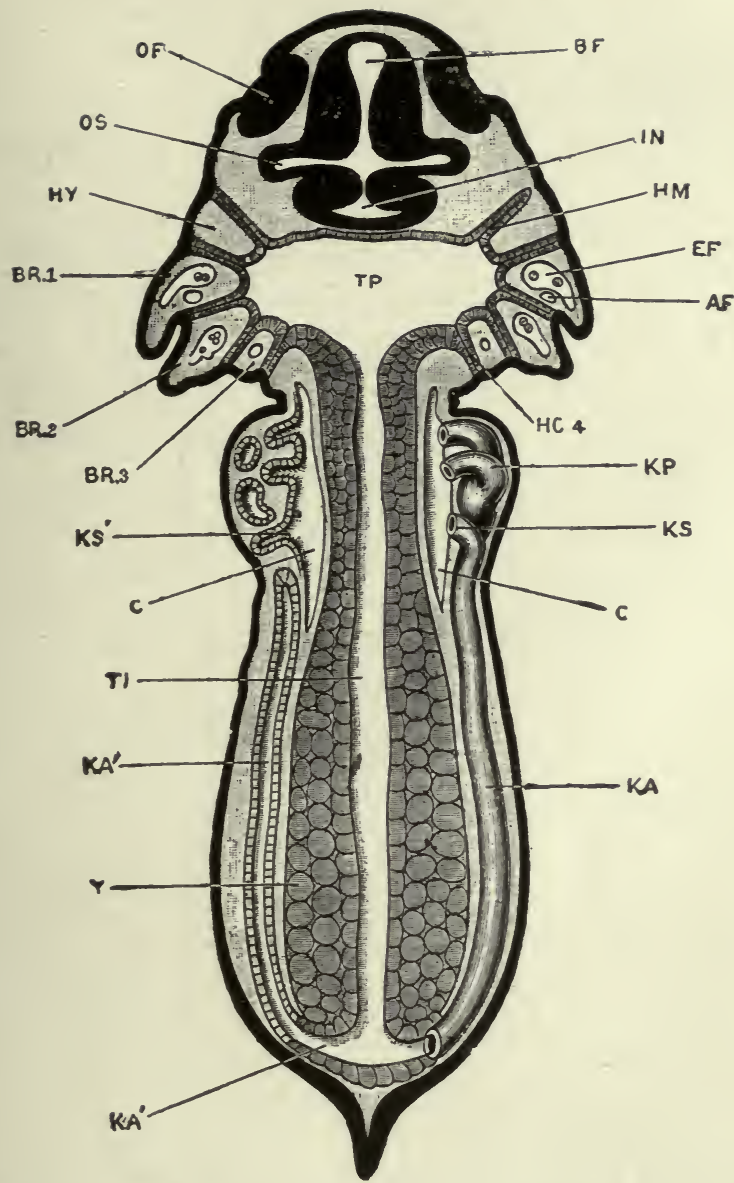

Fig. 22, - Horizontal SECTION OF A TADPOLE AT THE TIME OF HATCHing. (After Marshall.)

$A F$, afferent branchial vessel of the first branchial arch. $B F$, fore-brain. $B R .1, B R .2, B R .3$, first, second, and third branchial arches. $C$, body-cavity or coelom. $E F$, efferent branchial vessel of first branchial arch. $H M$, hyomandibular gill-pouch. $H Y$, hyoid arch. IN, infundibulum. $K A$, archinephric duct of right side. $K A^{\prime}$, archinephric duct of left side, seen in section. $K P$, headkidney or pronephros. $K S$, third nephrostome of right head-kidney. $K{ }^{\prime} S^{\prime}$, same of left side, seen in section. $O F$, olfactory pit. $O S$, optic stalk. $T P$, pharyngeal region of mesenteron. $T I$, intestinal region of mesenteron. $Y$, yolk-cells. 
met beneath the pharynx forms the dorsal mesentery of the heart. The mesoderm around the tube continues to thicken, and forms later the musculature of the heart.

"At first the heart has also a ventral mesentery formed by the union of the walls of the cœlomic cavities below it (Fig. 25), but later the mesentery is in part absorbed and the cœlomic cavities become continuous below from side to side, forming the pericardial chamber. The outer layer of somatic mesoderm gives rise to the pericardium itself.

"The tubular heart is attached at its posterior end to the liver and anteriorly to the wall of the pharynx. It becomes free ventrally and also dorsally along the middle of its course, and owing to an increase in length is bent on itself into an $\Omega$-shaped tube (Fig. 14)."

A series of transverse constrictions now gives indication of the division of the heart into the various chambers, though there are, for a time, no actual partitions between the different regions. A septum is finally formed which divides the single auricle into right and left halves, and by the time of metamorphosis the heart has practically the adult structure.

Without distinguishing between the external and internal gills, the larval circulation is, briefly, as follows: "The venous blood, returned from the body at large, enters the posterior end of the heart, or sinus venosus; from

$$
\text { 'Morøan. }
$$




\section{The Development of the Frog 6r}

this it passes into the second or auricular chamber, thence to the ventricle, and from that to the truncus arteriosus (Fig. I 7)." As there is, at first, no division into right and left sides, the blood passes in succession through these various chambers.

"The truncus arteriosus divides distally into right and left branches, from each of which four afferent branchial vessels (Fig. 26, A F, I-4) arise. The four vessels of each side run outwards along the hinder borders of the four branchial arches, giving off along their whole length numerous branches to the gill-tufts on these arches From the gills the blood, now aërated, passes into the efferent branchial vessels (Figs. 23 and 26, EF, 1-4). These lie alongside of the afferent branchial vessels, and just in front of them, but do not communicate with them except through the capillary loops of the gills. The four efferent branchial vessels of each side unite in the dorsal wall of the pharynx to form the dorsal aorta. the two aortæ are continued forwards to the head as the carotid arteries, while posteriorly they unite to form the single dorsal aorta, from which branches arise supplying all parts of the body (Figs. 24, $A$, and 26, $A$ ).

The lungs arise at a very early stage, but are for a long time extremely small and of little functional importance. Each lung receives blood from a branch of the fourth efferent branchial vessel (Fig. 26, $A P$ ), and returns it directly to the auricle by the pulmonary vein. As the tadpole increases in size, and the lungs become of greater importance, a septum appears, dividing the auricle into 
systemic or venous, and pulmonary or arterial cavities. Simultaneously with this, valves are formed in the truncus arteriosus, by which the streams of venous and arterial blood are kept apart to a certain extent. At the time of the metamorphosis the gill circulation is cut off, by the establishment of direct communications between the afferent and efferent branchial vessels (Fig. 26), and the pulmonary circulation becomes of much greater importance than before."

The branchial blood vessels, or aortic arches, are six in number, and lie in the visceral arches, the afferent vessel lying parallel and posterior to the efferent vessel (Fig. 26). Of the branchial vessels, only those lying in the first, second, third, and fourth arches are functional, the vessels of the mandibular and hyoid arches being in a rudimentary condition.

Although the afferent and efferent vessels lie so close together, there is at first, as has been said, no communication between them except through the gill capillaries (Fig. 23) which are given off from their sides, first to the external and then to the internal gills. As the direct communication between the afferent and efferent vessels, which lies near the ventral end of the arch (Fig. 26), becomes larger it is evidently easier for the blood to flow 


\section{The Development of the Frog}

through that passage than to pass through the fine capillaries of the gills, so that the supply of blood to the gills is gradually cut off, and the amount of blood that goes to the lungs is correspondingly increased; but for a time the tadpole breathes both by gills and by lungs.

If the tadpole be prevented from coming to the surface to breathe, as by fastening wire netting just below the surface of the water, it is said that the change to the lung-breathing condition may be indefinitely postponed.

The changes in the circulation that take place at metamorphosis are chiefly concerned with changes in the branchial blood vessels, or, as they are called after the disappearance of the capillaries and the establishment of the direct communication, the aortic arches. Some of the details of these changes have not been made out as satisfactorily as is to be desired, but the main points are pretty definitely established.

Since the branchial blood vessels in the mandibular and hyoid arches are, from the first, rudimentary, they may be disregarded in this discussion. After the establishment of the direct communication between the afferent and efferent branchial vessels, the blood passes 

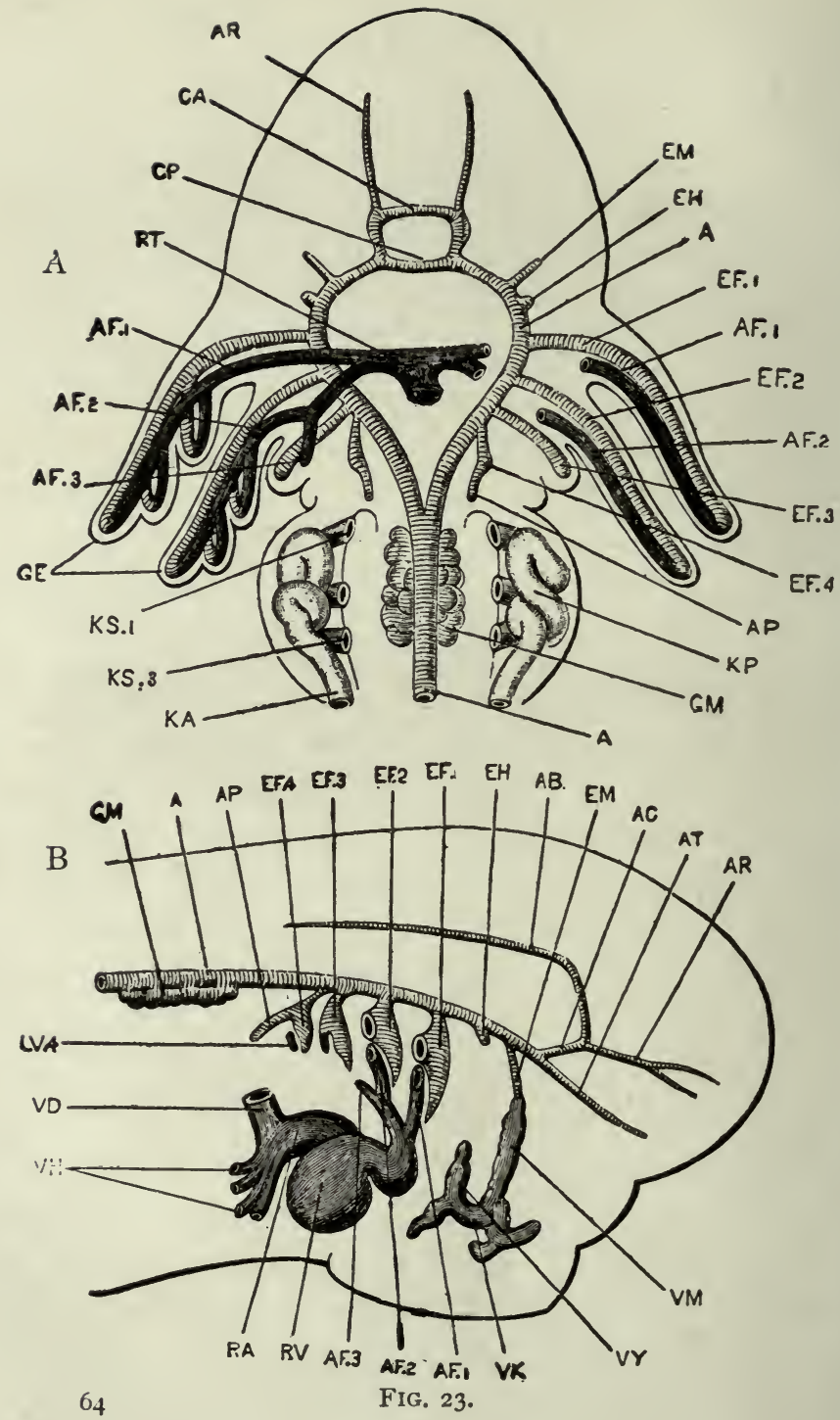
Fig. 23. A.-Diagrammatic figure of the head and ANTERIOR PART OF THE BODY OF A 7-MM. TADPOLE, SHORTLY AFTER HATCHING; SHOWING THE BRANCHIAL BLOOD VESSELS FROM THE VENTRAL SURFACE. THE HEART HAS BEEN REMOVED.

B.-SAME EMBryo, FROM THE RIGHT SIDE. THE heART IS REPRESENTED IN SITU, BUT THE EXTERNAL GILLS OF THE FIRST AND SECOND BRANCHIAL ARCHES HAVE BEEN CUT OFF SHORT AT THEIR BASES. (After Marshall.)

$A$, dorsal aosta. $A B$, basilar artery. $A C$, carotid artery. $A F .1, A$ F.2, $A F .3$, afferent branchial vessels of the first, second, and third branchial arches. $A P$, pulmonary artery. $A R$, anterior cerebral artery. $A T$, anterior palatine artery. $C A$, anterior commissural vessel. $C P$, posterior commissural vessel. $E F .1, E F .2, E F .3, E F .4$, efferent branchial vessels of the first, second, third, and fourth branchial arches. $E H$, efferent vessel of hyoid arch. $E M$, efferent vessel of mandibular arch. $G E$, external gills. $G M$, glomerulus. $K A$, segmental duct. $K P$, head-kidney or pronephros. $K S .1, K S .3$, first and third nephrostomes of head-kidney. $L V .4$, efferent lacunar vessel of fourth branchial arch. $R A$, auricle. $R V$, ventricle. $R T$, truncus arteriosus. $V D$, Cuvierian vein. $V H$, hepatic veins. $V K$, vein of sucker. $V M$, mandibular vein. $V Y$, hyoidean vein. 


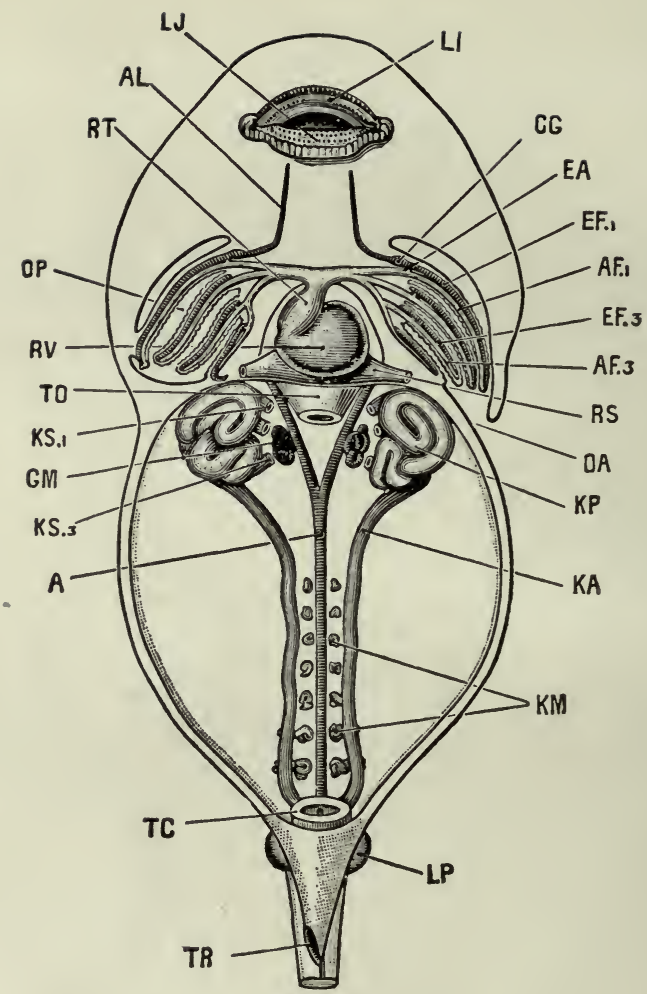

Fig. 24.-A I2-MM. TADPOLE DISSECTED FROM THE VENTRAL SURFACE TO SHOW THE HEART, THE INTERNAL GILLS, THE BRANCHIAL VESSELS, AND THE HEAD-KIDNEYS AND THEIR DUCTS. THE TAIL, WHICH IS ABOUT DOUBLE THE LENGTH OF THE HEAD AND BODY, HAS BEEN REMOVED. $\times$ 22. (After Marshall.)

$A$, dorsal aorta. $A F .1, A F .3$, afferent branchial vessels of first and th $\mathbf{r} 1$ branchial arches. $A L$, lingual artery. $C G$, carotid gland. $E A$, junction be. tween afferent and efferent branchial vessels of first branchial arch. $E F .1, E F .3$, efferent branchial vessels of first and third branchial ar:hes. $G M$, glomerulus. $K A$, archinephric or segmental durt. $K M$, Wolffian tubules. $K P$, pronephros or head-kidney. $K$ S. $1, K S .3$, first and third nephrostomes of head-kidney. $L I$, upper lip. $L J$, lower lip. $L P$, hind limb. $O A$, aperture of opercular cavity. $O P$, opercular cavity. $R S$, sinus venosus. $R T$, truncus arteriosus. $R V$, ventricle. $T C$, cloaca. $T O$, esophagus, cut short. ' $T R$, rectal spout. 


\section{The Development of the Frog 67}

from the bulbus arteriosus directly around the pharynx, through the four aortic arches, into the dorsal aorta. Previous to this time a branch has grown out from the fourth aortic arch to the lung, the pulmonary artery (Fig. 26, $A P$ ), andeas the gills diminish more and more in size, this vessel becomes larger and larger until it carries all of the blood that formerly went to the gills for purification. From the lungs the blood is brought back directly to the heart by the pulmonary veins.

The first aortic arch, on the completion of metamorphosis, becomes the carotid arch of the frog, which carries blood to the head (Fig. 27, I). That portion of the dorsal aorta between the openings of the first and second aortic arches may remain open, but more commonly becomes entirely obliterated.

The second aortic arch of the tadpole becomes the systemic arch of the adult frog (Fig. 27, 2).

The third aortic arch gradually diminishes in size, and eventually entirely disappears.

The fourth aortic arch of the tadpole becomes the pulmo-cutaneous arch of the frog, carrying blood to the lungs and skin, as the name would indicate (Figs. 26 and 27,3). 
It retains its connection with the dorsal aorta for a considerable time, but eventually becomes separated from it, so that all of the blood that now passes from the bulbus arteriosus directly to the aorta must pass through the third or systemic arch (Fig. 27, 2).

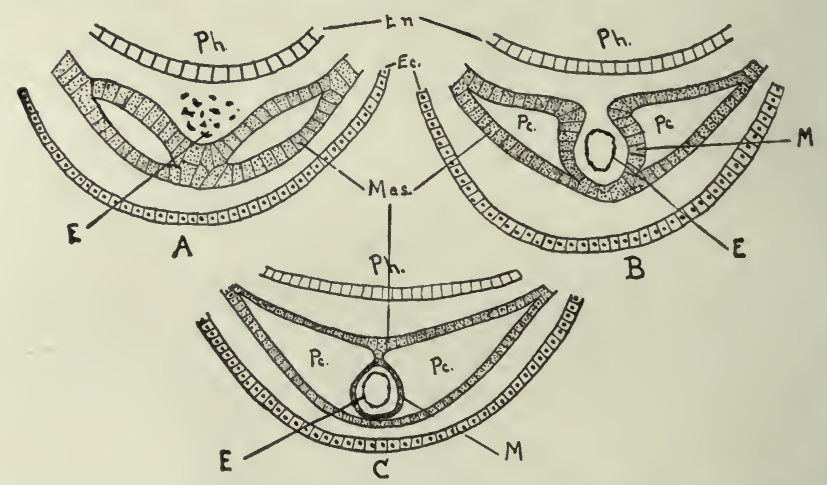

Fig. 25.-Diagrams to illustrate the mode of DevelopMENT OF THE HEART. $E n$, entoderm. $E c$, ectoderm. $E$, endothelial lining of the heart.
$M$, muscular wall of heart. Mes, mesoderm. $P c$, pericardium. $P h$, pharynx. (Somewhat altered from Morgan.)

The carotid gland, a characteristic structure in the anatomy of the frog, is formed as an elaboration of the direct communication between the afferent and efferent vessels of the first branchial arch.

The development of the other blood vessels will be described in connection with the chick, 
where they approach more nearly the condition in man and other mammals.

The spleen, since it is so intimately associated with the blood, may be mentioned at this time. "The spleen arises as a spherical bud on the mesenteric artery : it consists of cells similar to those of the lymphatic tissue, and, like these, is said to be derived originally from the entoblast cells of the mesenteron." 1

Development of the Celom and the Muscular System

The formation of the mesoblast as a layer of cells between the ectoblast and entoblast, and the splitting of this mesoblast into two layers, the somatopleure and splanchnopleure, with the body-cavity or cœlom between them, has already been mentioned (Fig. I5).

The sheet of mesoblast on each side of the body rapidly grows ventralward until it meets and fuses with its fellow of the opposite side, so that there is very early a complete layer of mesoblast over the ventral side of the embryo (Figs. I3, $M$, and 15). Along the mid-dorsal line, however, the two sheets of mesoblast remain distinct, being separated by 
the notochord (Fig. I $3, N$ ). In the anterior end of the embryo the mesoblast is much thinner, and does not there split into the two layers.

On each side of the notochord the mesoblast becomes thickened to form the segmental plate, which does not, at first, show any separation into two layers; later, however, the body-cavity does extend into the segmental plate, for a time, but eventually disappears from that region.

At about the time when the medullary folds are coming together to form the neural canal, the segmental plate on each side of the notochord begins to be broken up into blocks by a series of vertical connective tissue septa at right angles to the notochord. These blocks or segments are the mesoblastic somites or myotomes. The mesoblastic somites are, at first, not separated from the lateral sheets of mesoblast, but very soon after their formation they become separated from the lateral mesoblast, and, by the thickening of their walls, especially the inner, their cavities are obliterated. At a somewhat later stage the mesoblastic somites are largely converted into muscles, whose $>$-shaped arrangement may be 


\section{The Development of the Frog 7 I}

easily seen in the transparent tail of the young tadpole (Fig. I, L). The lateral plates of the

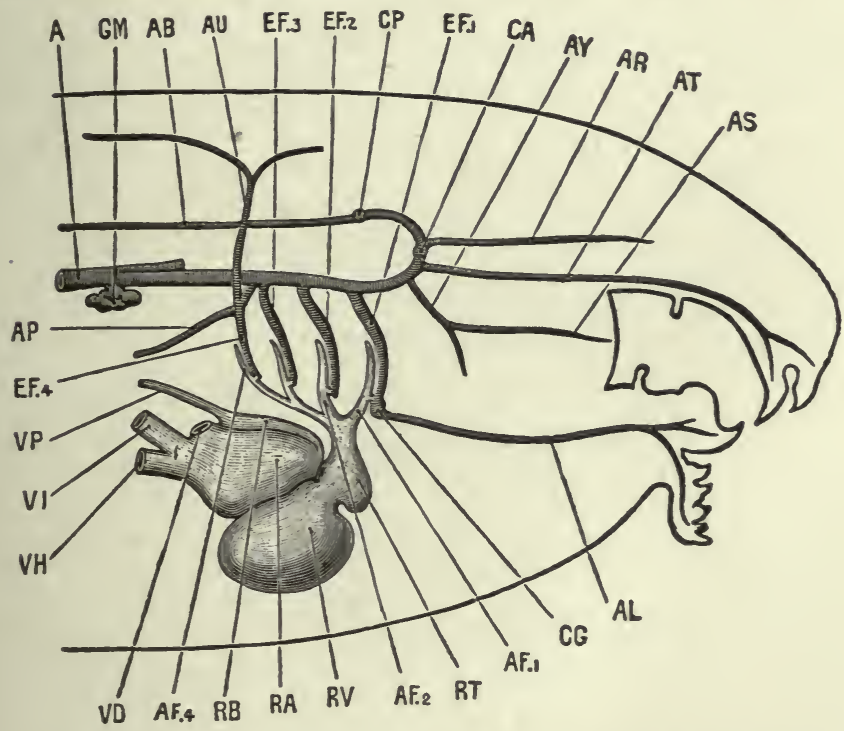

Fig. 26.-A DiAgRAMMATIC FIGURE OF THE HEAD AND NECK OF A I2-MM. TADPOLE, FROM THE RIGHT SIDE, TO SHOW THE HEART AND BRANCHIAL VESSELS. THE GILLS AND THE GILL CAPILLARIES ARE NOT REPRESENTED. $\times 35$. (After Marshall.)

$A$, dorsal aorta. $A B$, basilar artery. $A F_{0} 1, A F \cdot 2, A F .4$, afferent branchial vessels of first, second, and fourth branchial arches. $A L$, lingual artery. $A P$, pulmonary artery. $A R$, anterior cerebral artery. $A S$, posterior palatine artery. $A T$, anterior palatine artery. $A U$, cutaneous artery. $A Y$, pharyngeal artery. $C A$, anterior commissural vessel. $C G$, carotid gland. $C \dot{P}$, posterior commissural vessel. $E F .1, E F .2, E F .3, E F .4$, efferent branchial vessels of first, second, third, and fourth branchial arches. $G M$, glomerulus. $R A$, right auricle. $R B$, left auricle. $R T$, truncus arteriosus. $R V$, ventricle. $V D$, Cuvierian vein. $V H$, hepatic vein. $V I$, posterior vena cava. $V P$, pulmonary vein.

mesoblast, the somatopleure and the splanchnopleure, remain comparatively thin and are 
largely converted into muscle, the somatopleure and ectoblast forming the body wall, while the splanchnopleure and entoblast form the wall of the digestive tract.

By the separation of the somatopleure and splanchnopleure the cœlom is greatly enlarged, and, at the same time, a small portion is separated from the anterior end as the pericardial cavity.

\section{The Development of the Skeleton}

"The vertebral column.-The earliest skeletal structure, and for a time the only one, is the notochord, the development of which from the hypoblast of the middorsal wall of the mesenteron has already been described. It forms a cellular rod extending from the blastopore to the pituitary body ; and as the tail is formed, it extends back into it. The notochord consists of vacuolated cells, filled with fluid, and is invested by a delicate structureless sheath (Figs. 12 and I $_{3}, N$ ).

"About the time of appearance of the hind legs, a delicate skeletal tube, at first soft, but soon becoming cartilaginous, is formed round the notochord from the mesoblast. This tube grows upwards at the sides of the spinal cord, as a pair of longitudinal ridges, with which a series of cartilaginous arches, which appeared at the sides of the spinal cord at a slightly earlier stage, very soon become continuous.

"By the appearance of transverse lines of demarcation, the cartilaginous sheath of the notochord becomes cut 


\section{The Development of the Frog}

up into a series of nine vertebra, followed by a posterior unsegmented portion, which later becomes the urostyle. This transverse division does not affect the notochord, which remains as a continuous structure until the complete absorption of the tail at the end of the metamorphosis. Shortly after the metamorphosis thin rings

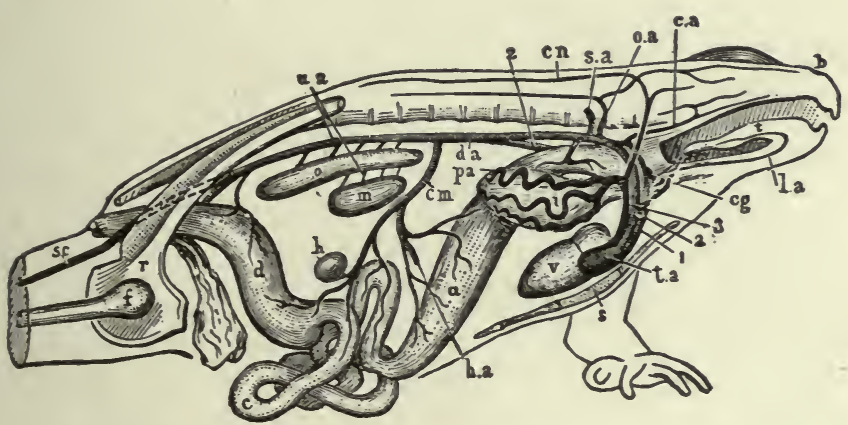

Fig. 27.-DiagramMatic FIGURE OF THE ARTERIAL SYSTEM OF THE MALE FROG, FROM THE RIGHT SIDE. (After Marshall.)

$a$, stomach. $b$, nostril. $c$, small intestine. $c a$, carotid artery. $c g$, carotid gland. $c m$, coliaco-mesenteric artery. $c n$, cutaneous artery. $d$, large intestine. $d a$, dorsal aorta. $f$, femur. $h$, spleen, $h a$, hepatic artery. $i_{0}$ right lung. $l a$, lingual artery. $m$, testis. $o$, kidney. $o a$, occipito-vertebral artery, $p a$, pulmonary artery. $r$, pelvic girdle. $s$, sternum. $s a$, subclavian artery. sc, sciatic artery. $t$, tongue. $t a$, truncus arteriosus. $u a$, urinogenital arteries. $v$, ventricle. 1, carotid arch. 2, systemic arch. 3, pulmocutaneous arch.

of bone, slightly constricted in their centres, so as to be hourglass-shaped in section, are developed in the membrane investing the cartilaginous sheath of the notochord: these correspond with the nine vertebræ already present, and form the first rudiments of the vertebral centra. In the intervertebral regions, between the successive bony rings, annular thickenings of the 
cartilaginous sheath occur, which grow inwards so as to constrict and ultimately obliterate the notochord. Each of these vertebral rings becomes, after the metamorphosis, divided into an anterior and a posterior portion, which fuse with the bony centra of the adjacent vertebræ, and ossify to form their articular ends.

"From the circumference, and from the articular ends of each vertebra, ossification gradually spreads inwards ; but a small portion of notochord persists in the middle of each centrum for a long time, or even throughout life.

"The vertebræ are not placed opposite the myotomes, but alternate with these; so that each vertebra is acted on by two myotomes on each side, one pulling it forwards, and the other backwards.

"The transverse processes are at first independent of the corresponding vertebræ, but very early fuse with them. They extend into the septa between the myotomes, and probably correspond to the ribs of other vertebrates.

"The urostyle is the part of the axial skeleton behind the vertebræ; it is not divided into vertebræ at any stage in development. The anterior end of the notochord, imbedded in the base of the skull, is gradually encroached on by the cartilage and bone around it, and ultimately completely absorbed.

"The skull.-The skull of the tadpole consists almost entirely of cartilage; none of the bones of the skull, with the exception of the parasphenoid, appearing until nearly the time of metamorphosis. In the adult frog this cartilaginous skull is replaced to a considerable extent by cartilage bone; while other bones, primitively 


\section{The Development of the Frog}

distinct, and probably of dermal origin - the membrane bones-graft themselves to it.

"The three morphologically distinct elements of which the skull consists may with advantage be described separately.

" $a$. The cranium, or brain case.-This in its fully formed condition is an unsegmented cartilaginous tube, enclosing the brain: it is developed as follows :

"In the front part of the head a pair of longitudinal cartilaginous bars, the trabeculce cranii, appear in tadpoles of about $10 \mathrm{~mm}$. length: these grow back alongside of the notochord as a pair of horizontal parachordal rods (Fig. 32).

"The hinder ends of the trabeculæ are some little distance apart, and between them is a space in which the pituitary body lies. In front of this pituitary fossa, the trabeculæ unite to form a plate of cartilage, which underlies the anterior end of the brain, and is produced into blunt processes at its outer angles.

"The parachordals grow rapidly: they extend inwards so as to meet each other both above and below the notochord, which they now completely surround. The two parachordals soon fuse together to form the basilar plate, which, with the trabeculæ, forms a firm cartilaginous floor to the brain case. At their hinder ends the parachordals grow upwards to form the side walls of the cranium. Further forwards the pituitary foramen becomes closed by a thin plate of cartilage, and the lateral margins of the parachordals and trabeculæ grow upwards so as to form the side walls of the skull, the roof remaining imperfect in this region.

"The first bone to be developed is the parasphenoid. 


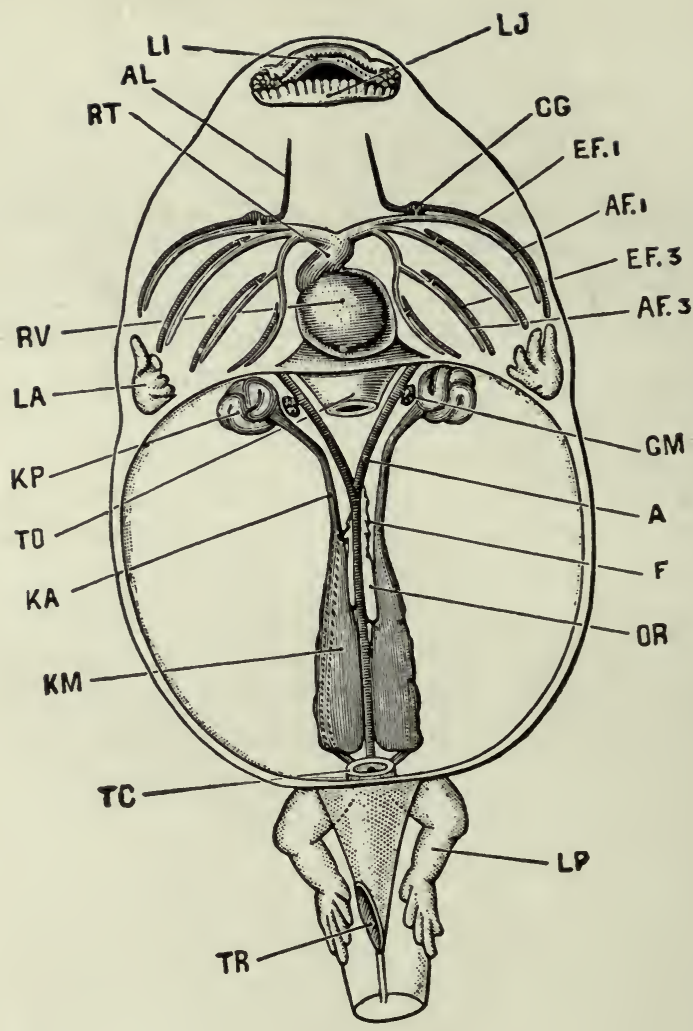

FIG. 28.-A 40-MM. TADPOLE DISSECTED FROM THE VENTRAL SURFACE TO SHOW THE HEART, THE BRANCHIAL VESSELS, AND THE HEAD-KIDNEYS AND WOLFFIAN BODIES. THE TAIL HAS BEEN CUT OFF. $\times 5$. (After Marshall.)

$A$, dorsal aorta. A F.1, A F.3, afferent branchial vessels of first and third branchial arches. $A L$, lingual artery. $C G$, carotid gland. $E F .1, E F .3$, efferent branchial vessels of first and third branchial arches. $F$, fat body. $G M$, glomerulus. $K A$, archinephric or segmental duct. $K M$, wolffian body. $K P$, pronephros or head-kidney, now degenerating. $L A$, fore-limb, still within oper. cular cavity. $L I$, upper lip. $L J$, lower lip. $L P$, hind-limb. $O R$, genital ridge. $R T$, truncus arteriosus. $R V$, ventricle. $T C$, cloaca. $T O$, œsophagus, cut short. $T R$, cloacal spout. 


\section{The Development of the Frog 77}

The exoccipitals, the frontals and parietals, which are the first to separate, and other bones soon follow; and by the time the metamorphosis is complete and the tail absorbed, all the bones of the adult cranium are present, except the sphenethmoid, which does not appear till some months later.

" $b$. The sense capsules.-The cartilaginous auditory capsules appear in tadpoles of about $12 \mathrm{~mm}$. length as thin shells of cartilage investing the auditory vesicles. They are at first quite independent of the cranium, but before the completion of the opercular folds they fuse with the upgrowing parachordals to form part of the side walls of the skull. The pro-otic appears at about the time of completion of the metamorphosis.

"The optic capsules are thin shells of cartilage, forming part of the sclerotic coats of the eyes. They arise about the same time as the auditory capsules, and, unlike the other sense capsules, they remain distinct from the cranium throughout life, in order to secure mobility of the eyeballs.

"The olfactory capsules are from their first appearance very closely connected with the anterior ends of the trabeculæ, which grow up between them to form the median vertical internasal septum. They develop later than the auditory and optic capsules." 1

c. The visceral skeleton.-The cartilaginous bars lying in the visceral arches make up what is known as the visceral skeleton, and as the structure and fate of these bars were described in a previous section, a more detailed discussion will be left until the similar structures in the chick are taken up.

${ }^{1}$ Marshall. 


\section{The Development of the Uro-Genital ORGANS}

\section{The Urinary Organs}

There are several points, in connection with the development of the urinary organs in the frog, that have been differently described by various investigators. We shall here follow the description given by Marshall, whom we shall quote at some length.

\section{General Account}

"The excretory organs of the tadpole, during the early stages of its existence, are the head kidneys or pronephra. These are a pair of globular organs imbedded in the dorsal wall of the body at its anterior end, immediately behind the constricted neck region (Figs. 24 and $28, K P$ ). Each head kidney is a convoluted tube with glandular walls, opening into the body-cavity by three ciliated mouths or nephrostomes (Fig. 24, $K S$ ), and continued back along the dorsal wall as the archinephric or segmental duct, $K A$, to the hinder end of the body, where it joins with the corresponding duct of the opposite side, and opens into the cloaca. The head kidneys and their ducts are well developed in the tadpole at the time of hatching: they subsequently increase considerably in size, and are the sole excretory organs of the tadpole during its early stages. In tadpoles of about $12 \mathrm{~mm}$. length the adult kidneys or Wolffian bodies (Fig. 24, $K M$ ), 


\section{The Development of the Frog 79}

begin to form in the hinder part of the body as a series of paired tubules, which grow towards and open into the segmental duct. These Wolffian tubules rapidly increase in number, as well as in size and complexity, and become bound together by connective tissue to form the compact Wolffian bodies or kidneys of the fully formed tadpole (Fig. 28, $K M$ ). At the same time the head kidneys diminish in size, and undergo degenerative changes, and by the time of the metamorphosis (Fig 29, KP) have almost completely disappeared. The Wolffian bodies persist as the kidneys of the frog; and by a series of further changes the ureters and generative ducts of the adult become established.

\section{The Head Kidney and its Duct}

"In tadpoles of about $3 \frac{1}{2} \mathrm{~mm}$. length, i. e., some time before hatching, a pair of longitudinal grooves appears along the inner surface of the somatopleure, extending from the neck to the hinder part of the body, and lying a little distance to the right and left of the notochord (Fig. 15, $K B$ ). The lips of each groove soon meet and fuse so as to convert the groove into a tube or duct. The closure of the tube takes place from behind forwards, and at the anterior end is effected imperfectly, three holes or nephrostomes, one behind another, being left, through which the tube opens into the body-cavity. As the embryo grows, the anterior end of the duct becomes convoluted and twisted on itself to form a ball, the three nephrostomes becoming at the same time lengthened out into short tubes (Fig. $3^{\circ}$ ). This convoluted mass is the head kidney or 


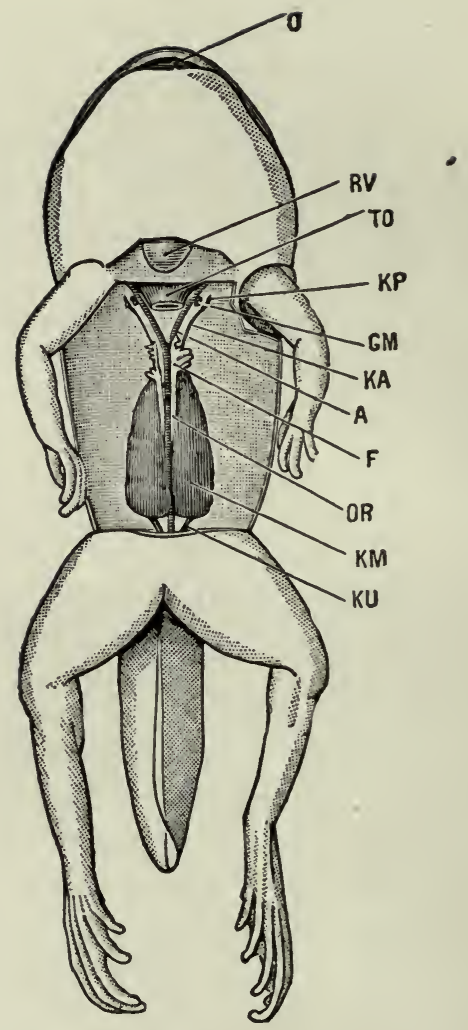

Fig. 29.-A TAILED FROG, NEAR THE ClOSE OF THE MEtAMORPHOSIS, DISSECTED FROM THE VENTRAL SURHACE TO SHOW THE KIDNEYS AND REPRODUCTIVE ORGANS. $\times 4$. (After Marshall.)

$A$, dorsal aorta. $F$, fat body. $G M$, glomerulus. $K A$, archinephric or segmental duct. $K M$, Wolffian body. $K P$, head-kidney, disappearing. $K U$, ureter. $O$, mouth. $O R$, genital ridge. $R V$, tip of ventricle. $T O$, œesophagus, cut short. 


\section{The Development of the Frog 81}

pronephros. The hinder part of the duct is the archinephric or segmental duct: it remains straight, or nearly so, and shortly before the tadpole hatches acquires an opening into the cloaca.

"At the time of hatching, the excretory organs thus consist on each side of (I) a head kidney, which is a convoluted tube, lined by a glandular epithelium, and opening into the anterior end of the body-cavity by three ciliated openings, the nephrostomes; and (2) the archinephric or segmental duct, which is the posterior part of the tube, and runs back along the dorsal bodywall nearly straight to the cloaca, into which it opens.

"The head kidney is closely surrounded by, indeed almost imbedded in, the posterior cardinal vein (Fig. $3 \mathrm{I}, V C$ ), and it is from the blood of this vein that the epithelial cells of the head kidney tubules separate the excretory matters, which are then passed down the duct to the exterior.

"The head kidney continues to increase in size, the tubules becoming still more convoluted, and lateral diverticula arising from their sides, until the tadpole is about I $2 \mathrm{~mm}$. in length, and the hind limbs are just commencing to appear. It remains stationary for a time and then, in tadpoles of about $20 \mathrm{~mm}$. length, begins to degenerate; the tubules become obstructed; some of them become collapsed, others for a time irregularly dilated; the whole organ steadily diminishes in size, and in tadpoles of $40 \mathrm{~mm}$. (Fig. $28, K P$ ) is not more than half its former size. It now shrinks rapidly, and at the time of the metamorphosis (Fig. 29, KP) has almost disappeared, all three nephrostomes having closed up, and the organ being reduced to a few small pigmented and 
irregularly twisted tubules, which have separated from the duct, and which soon disappear completely.

"Opposite the head kidney an irregular sacculated outgrowth, the glomerulus, arises from the aorta on each side (Figs. 28 and 31, GM); this appears first at about the time of hatching, and its development keeps pace with that of the head kidney. It lies immediately opposite the nephrostomes, and very close to these, though not touching them. It begins to diminish in size at about the same time as the head kidney. At the time

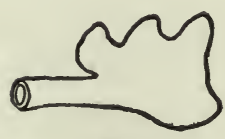

A
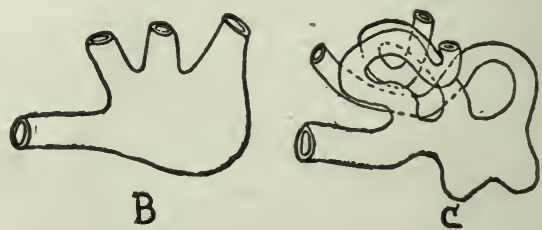

Fig. 30.-Diagrams to illustrate the Development of the HEAD-KIDNEY. (Somewhat altered from Morgan.)

of the metamorphosis (Fig. 29, GM) it is very small, and after the first year it can no longer be recognized. Its close relation to the head kidney, and the fact that its growth and subsequent degeneration keep pace with those of the head kidney, point to a close physiological connection between the two organs, though it is not easy to imagine what precise function the glomerulus subserves.

\section{The Wolffian Body}

"The Wolffian body, or kidney, first appears in tadpoles of from Io to $12 \mathrm{~mm}$. in length. It arises on each side as a series of small solid masses of mesoblast cells 


\section{The Development of the Frog 83}

lying along the inner side of the segmental duct, between this and the aorta (Fig. 24, $K M$ ). They develop from behind forwards, the hindermost pair being a short distance in front of the cloaca, and the most anterior ones about three segments behind the head kidney.

"These solid masses soon become elongated into twisted rods, which then become tubular, and growing towards the segmental duct meet and open into it. At their opposite ends these Wolffian tubules, as they are termed, dilate into bulb-like expansions, which become doubled up by ingrowths of little blood vessels, derived from the dorsal aorta, and so form Malpighian bodies. From the necks of the Malpighian bodies, short solid rods of cells grow towards the peritoneal epithelium and fuse with it. These rods soon become hollow, and open into the body-cavity by ciliated funnel-shaped mouths or nephrostomes: their opposite ends break away from the Wolffian tubules and open directly into the renal veins on the ventral surface of the kidney. The Wolffian tubules rapidly increase in number; they also branch freely, and so give rise to a complicated system of glandular tubules, which, when bound together by blood vessels and connective tissue, form the Wolffian body or kidney of the frog. The nephrostomes persist; and in the adult frog as many as 200 or more are present on the ventral surface of the kidney, as minute funnel-like ciliated openings, leading by short tubes into the renal veins.

\section{The Wolffian and Müllerian Ducts}

"So far we have only described one duct on each side, the segmental duct, which acts as the excretory duct first of the head kidney, and then of the Wolffian 
body as well. We have now to consider in what way the ureters and generative ducts of the adult frog are formed. About the time of the metamorphosis the head kidney,

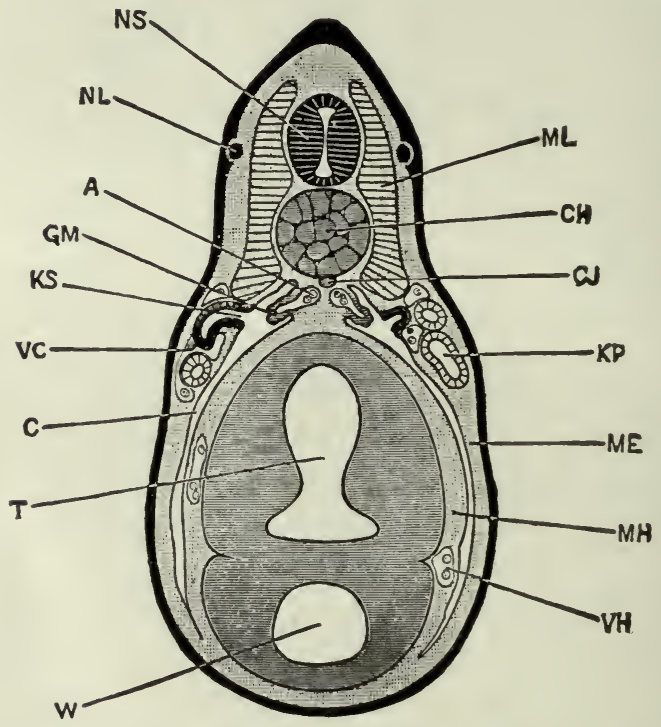

Fig. 3i.-Transverse section through THE body OF a TADPOLE AT THE TIME OF HATCHING; THE SECTION PASSING THROUGH THE SECOND PAIR OF THE NEPHROSTOMES, AND THE THIRD PAIR OF MYотомеs. $\times$ 50. (After Marshall.)

$A$, aorta. $C$, cœolom or body-cavity. $C H$, notochord. $C J$, subnotochordal rod. $G . M$, glomerulus. $K P$, segmental or archinephric duct. $K S$, second nephrostome of left side. $M E$, somatopleuric layer of mesoblast. $M H$, splanchnopleuric layer of mesoblast. $M L$, myotome. $N L$, lateral line branch of pneumogastric nerve. $N S$, spinal cord. $T$, intestinal region of mesenteron. $V C$, posterior cardinal vein. $V H$, hepatic vein. $W$, liver diverticulum.

which has become rudimentary, separates completely from the duct, which now ends blindly a short distance in front of the Wolffian body. 


\section{The Development of the Frog 85}

"A little later, after completion of metamorphosis and the entire disappearance of the tail, this anterior end of the segmental duct, in front of the Wolffian body, becomes divided somewhat obliquely into two ; an anterior part, which is now isolated from the Wolffian body, and will be called the Müllerian duct; and a posterior part, the Wolffian duct, which is simply the posterior part of the original segmental duct, and receives the Wolffian tubules of the kidney.

"The Müllerian duct becomes connected in front with the peritoneal epithelium, and acquires an opening into the anterior end of the body-cavity. At its hinder end it grows back along the outer side of the Wolffian duct to the cloaca, into which it opens. So far the changes are the same in both sexes. In the male frog the Müllerian duct persists in this condition throughout life, and may be recognized as a slender, longitudinal streak lying in the thickness of the peritoneum a short distance to the outer side of the kidney, and extending some distance in front of it. In the female frog the Müllerian duct becomes the oviduct, the anterior opening being carried forward first as a groove, and then by closure of the lips as a tube, to the position characteristic of the peritoneal opening of the adult oviduct; while the posterior part becomes greatly convoluted and acquires thick glandular walls ; the hindermost part of the oviduct remains thinner walled, but of much greater capacity.

"The Wolffian duct becomes in both sexes the ureter. In the female frog it undergoes no further change of importance. In the male frog the hinder end of the IVolffian duct becomes dilated into a much-branched glandular enlargement, the vesicula seminalis. 

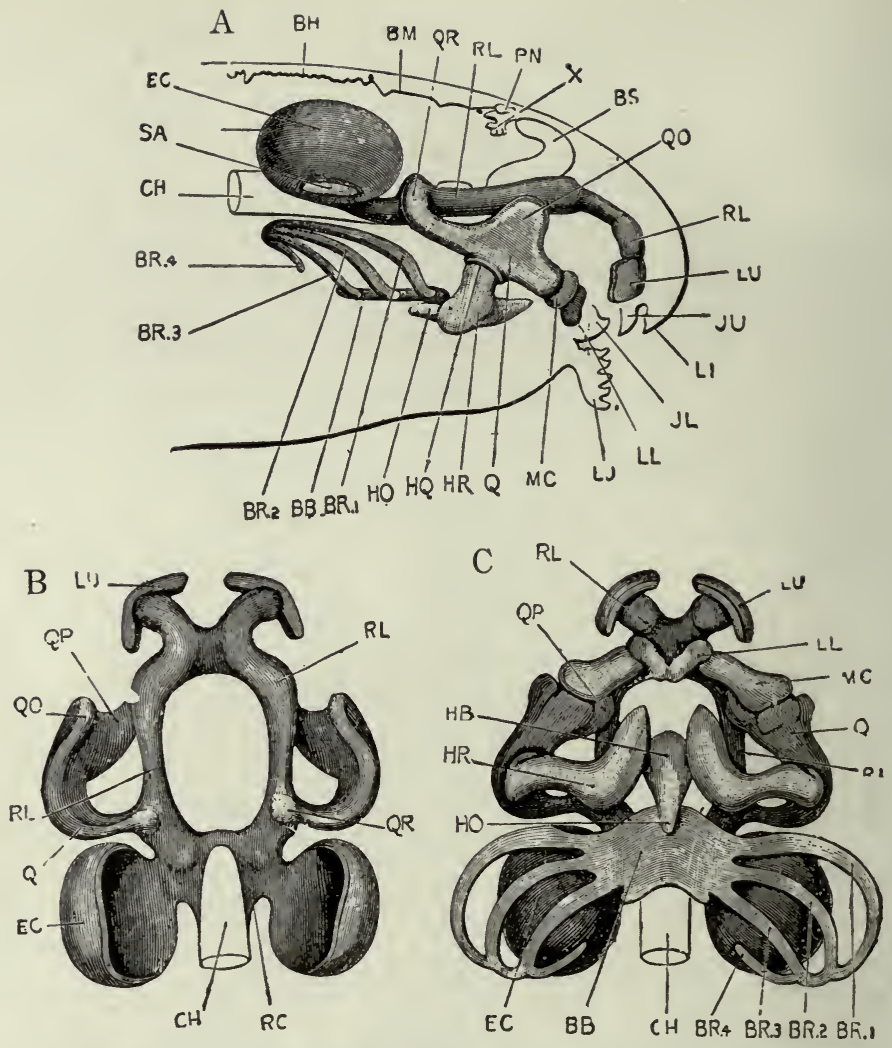

Fig. 32. A.-The SKULL OF A I2-MM. TADPOLE, SEEN FROM THE RIGHT SIDE. THE NOTOCHORD, THE BRAIN, AND THE ENTIRE HEAD ARE REPRESENTED IN OUTLINE, IN ORDER TO SHOW THE RELATIONS OF THE SKULL TO THEM.

B.- THE SAME SKULl From THE DORSAL SURFACE. THE LOWER JAW AND THE HYOIDEAN AND BRANCHIAL BARS ARE OMITTED.

C.-SAME SKull From the ventral Surface. (A, B, and C are all from Marshall.)

$B B$, basi-branchial. $B H$, roof of hind-brain. $B M$, roof of mid-brain. $B R .1, B R .2, B R .3, B R .4$, first, second, third, and fourth branchial bars. $B S$, cerebral hemisphere. $C H$, notochord. $E C$, auditory capsule. $H B$, basihyal. $H O$, urohyal. $H Q$, articulation of ceratohyal with quadrate. $H R$, ceratohyal. $\mathcal{F} L$, lower jaw. $\mathcal{F} U$, upper jaw. $L I$, upper lip. $L \mathcal{F}$, lower lip. $L L$, lower labial cartilage. $L U$, upper labial cartilage. $M C$, Merkel's cartilage, $P N$, pineal body. $Q$, quadrate. $Q O$, orbital process of quadrate. $Q P$. palato-pterygnid process. $Q R$, connection of quadrate with trabecula. $R C$, paracordal cartilage. $R L$, trabecula cranii. $S A$, membranous patch in which stapes is developed later. $X$, choroid plexus of third ventricle. 


\section{The Development of the Frog}

\section{The Vasa Efferentia}

"In both sexes at an early stage, as the Malpighian bodies are forming in the Wolffian body, those nearest to the genital ridges give off tubular branches from their capsules into the ridges.

"In the female frog these tubules are said to expand very greatly, and to give rise to the chambers or cavities in the adult ovary; but the point is not established with certainty.

"In the male frog these tubules become the vasa efferentia; they become connected with the spermatic tubules, and, as at the other ends they open into the Wolffian tubules, they form passages along which the spermatozoa can get from the testis to the Wolffian duct or ureter, and so out."

\section{The Genital Organs}

The reproductive organs begin to develop in young tadpoles shortly after the opening of the mouth, as longitudinal ridges or thickenings of the peritoneal epithelium, lying near the mesentery and close to the inner borders of the kidneys. These thickenings are known as the genital ridges, and are found in all tadpoles, there being as yet no sexual distinctions.

From the posterior two thirds of the genital ridges the ovaries, or testes, as the case may 
be, develop, while from the anterior third the fat bodies are developed.

The genital ridge is primarily formed by the change in the shape of the cells of the peritoneal epithelium at that place. While most of the epithelial cells of the peritoneum are flat, those that are to form the genital ridge become more cuboidal or columnar, at the same time dividing and becoming several cells deep; a vascular core of connective tissue now grows into the genital ridge from the basement membrane of the peritoneum.

Some of these epithelial cells grow more rapidly than the rest and become spherical in shape, while the smaller cells collect around the large ones to form capsules or follicles. The large round cells are known as primitive germ cells or gonoblasts, and from them are developed, at the time of metamorphosis, when the sexes become differentiated, either true ova or eggs, in the case of the female, or spermatozoa, in the case of the male.

The limits of this work will not permit a description of the histological changes that take place in the conversion of the primitive ova into the true sexual elements, and, indeed, 


\section{The Development of the Frog 89}

there are some points in this process that are not fully determined with certainty.

The development of the oviduct, etc., has been sufficiently described in connection with the urinary organs. 


\section{CHAPTER II}

THE DEVELOPMENT OF THE CHICK

\section{The EGG}

7 HE egg of the chick (Fig. 33) is of large size, oval in shape and usually somewhat larger at one end than at the other. It is protected by a more or less hard shell of organic material impregnated with calcareous salts. Lying close to the inside of the shell is the shell membrane, which is of two layers; these two layers, sometimes called the inner and outer shell membranes, are closely attached to each other except at the large end of the egg where they are separated somewhat to form the air space (Fig. 33,a). The shell and the membranes are sufficiently porous to allow gases to pass through them slowly.

Filling the space inside of the shell membranes is the white or albumen of the egg, in the centre of which, in turn, lies the yolk. At opposite poles of the yolk, and apparently 


\section{The Development of the Chick 9I}

attached to it, are the chalaze, which seem to be merely more condensed portions of the albumen that are twisted, and have been said to serve to hold the yolk in the centre of the egg, though it is difficult to see how they can serve any such purpose, as they are not attached at their outer ends.

The yolk is the essential part of the egg and corresponds, as has been previously pointed out, to the true ovum or egg of the frog, or other animals. It is bright yellow in color, spherical in shape, and about an inch in diameter. It is surrounded and held in shape by the thin, elastic vitelline membrane, and exhibits on one side, normally the upper one, no matter how the egg has been opened, a small, whitish circle, the blastoderm or cicatricula (Fig. 33, bl). The yolk substance is made up of a great number of yolk granules, of which two main kinds may be distinguished, the yellow and the white. If the yolk of a hard-boiled egg be carefully cut, with a sharp knife, vertically through the blastoderm, it will be noticed that the white and the yellow yolk are arranged in concentric layers, the yellow being the more abundant; and that there is a flaskshaped mass of white granules in the centre of 
the yolk so situated that the top of the neck of the flask lies under the blastoderm.

Although of so large a size, the yolk of the hen's egg is a single cell, its great size being chiefly due to the large number of yolk gran-

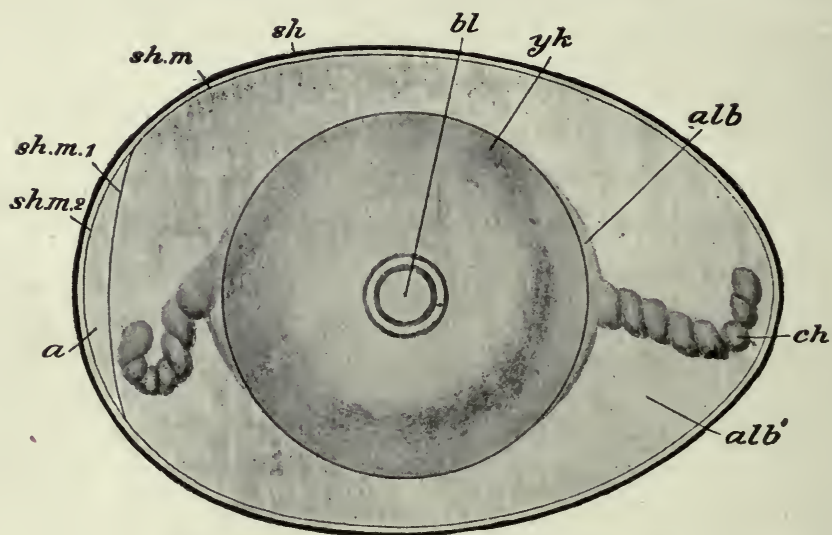

Fig. 33.-Semi-Diagrammatic view of the EgG of the DoMestic Fowl, at THE time of LAYING. (After Parker and Haswell, slightly altered from Marshall.)

$a$, air-space. $a l b$, dense layer of albunen. $a l b^{\prime}$, more fluid albumen. $b l$, blastoderm. $c h$, chalaza. sh, shell. sh.m, shell-membrane. sh.m.1, sh.m.2, its two layers separated to enclose air-cavity.

ules which it contains. These yolk granules serve as food for the developing embryo ; and it is to the abundance or scarcity of this food yolk that the great variation in the sizes of ova is largely due. In mammals, for example, there is practically no food yolk, and the eggs 


\section{The Development of the Chick 93}

are of almost microscopic size; hence the mammalian embryo is dependent upon its mother for food during its development, and an arrangement known as the placenta is present to permit an interchange of food and gases between the blood of the parent and that of the embryo. The frog's egg, though so much smaller than that of the chick, contains a large amount of food material, as we have already seen, and the embryo frog develops quite independently of its mother; but while the chick, at the time of hatching, has practically the adult structure, the young frog, at the time of hatching, is a very different animal from the adult frog, and must obtain food for its further growth from its surroundings.

The preceding is a description of the egg at the time of its laying. Such an egg has already passed through the earlier stages of its development, and is in a resting condition, simply awaiting suitable conditions of temperature, moisture, etc., to proceed with its complete development. The statement that the yolk is a single cell is really true only from the time it leaves the ovary until it is fertilized, or until a short time after fertilization, when segmentation begins. 


\section{Vertebrate Embryology}

\section{Maturation of the EGG}

Since- the processes of maturation in the chick take place long before the egg is laid, it is very difficult to work them out, and they are imperfectly known: but it is probable that the changes that take place are more or less similar to those that have been briefly described in speaking of the maturation of the frog's egg.

The nucleus or germinal vesicle of the growing ovum is large, and lies near the centre of the egg; but as the egg matures, the nucleus moves towards the surface and eventually lies just beneath the vitelline membrane, in a lenticular area, the germinal disc, which is nearly free from food yolk.

When fully ripe, the egg bursts from the ovary into the body-cavity, and enters the funnel-like end of the oviduct. As it passes through the upper or thin-walled part of the oviduct, it has secreted around it, by the walls of the oviduct, the white or albuminous envelope, in spiral bands; the spiral arrangement being especially evident in the more dense albumen of the chalazæ. This spiral arrangement is caused by the rotation of the ovum by the spirally arranged folds in the upper part of the oviduct. It probably takes about three 
The Development of the Chick 95

hours for the egg to pass through the upper part of the oviduct. The egg next passes into the lower part of the oviduct, or uterus, where it remains for a considerable time, twelve to eighteen hours, and where it receives the shell membranes and the shell. The length of time which the egg remains in the uterus varies considerably, and there is a corresponding variation in the state of development when the egg is finally laid.

\section{Fertilization of the EGg}

The same difficulties that were encountered in the study of the maturation of the hen's egg are met in the study of the processes of fertilization, since those processes take place, as a matter of course, before the egg enters the uterus where the shell is formed. About all that is known with certainty is that the spermatozoon enters the egg in the upper part of the oviduct, or even before it leaves the ovary, so that development has ustally been taking place for a good many hours before the egg is laid.

The spermatozoa are said to retain their power of impregnation for about two weeks. 
96

\section{Vertebrate Embryology}

\section{Segmentation of the EgG}

Segmentation begins at about the time the egg enters the uterus, and is usually completed when the egg is laid; so that the hen's egg is in a more advanced state of development, at the time of laying, than is the frog's egg.

It will be remembered, in the case of the frog, that, in the process of segmentation, the

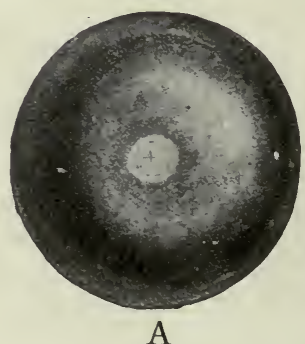

A

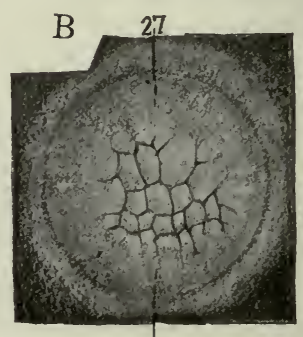

27

Fig. 34. A. - Yolk WITH THE BLASTODERM IN THE CENTRE, THE LATTER SHOWING THE FIRST TWO CLEAVAGE PLANES. B.-THE BLASTODERM, ON A LARGER SCALE AND AT A LATER STAGE OF SEgMENTATION. THE OUTLINES OF A DOZEN OR MORE CELLS MAY BE SEEN. (After Duval.)

entire egg was divided by the segmentation planes that passed through it; but that the blastomeres or segments into which the egg was divided were not all of the same size. Such a case, where the whole egg is divided by the segmentation planes, is known as complete or holoblastic segmentation; and where, as 
in this case, also, the blastomeres are of unequal size, the segmentation is said to be unequal. A more common form of cleavage, seen, for example, in the starfish, is where the entire egg divides into equal blastomeres; this is known as complete and equal segmentation. The holoblastic form of cleavage is common in the case of small eggs where the food yolk is in small quantity.

In other eggs, such as those of Birds, Reptiles, and many Arthropods, we have what is known as meroblastic or partial cleavage; in this form of segmentation the cleavage planes do not extend entirely through the egg, so that only a part of the egg is divided into the segments or blastomeres. In the Arthropods there is a superficial layer of protoplasm entirely round the egg that is free from yolk, and it is in this layer that segmentation takes place; such a form of partial segmentation is known as superficial.

In the chick we have an example of what is known as discoidal segmentation. Instead of having, as in the Arthropods, a layer of yolkfree protoplasm entirely round the egg, there is, in the chick, a small disc-shaped area, the above-mentioned germinal disc, lying on one 
side of the egg; and segmentation is confined to this small area. We have, then, these four main methods of segmentation : the complete, which may be equal or unequal, and the partial, which may be superficial or discoidal.

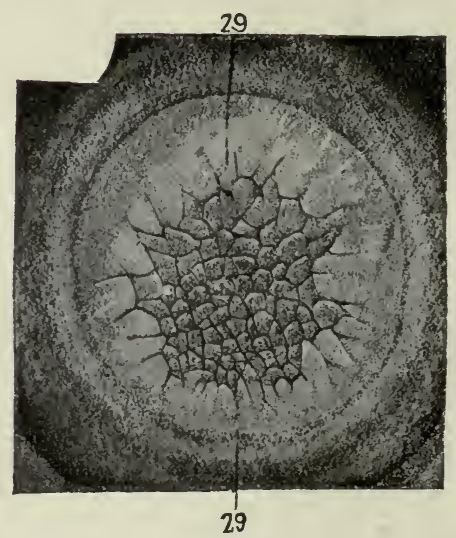

Fig. 35.-SURFACE VIEW OF THE BLASTODERM AT A LATER STAGE OF SEGMENTATION THAN THAT SHOWN IN FIG. 34 B. Also SOMEWhat MORE ENLARGED. (After Duval.)

It may be well, at this point, to give a brief description of the relation between the amount and distribution of the food yolk, and the phenomena of segmentation and gastrulation.

Total cleavage occurs in eggs which, as a rule, are small, and which contain a small or moderate amount of yolk. If this small 


\section{The Development of the Chick}

amount of yolk be evenly distributed throughout the egg, the cleavage will be equal, as in the eggs of Amphioxus and Mammals. If the yolk be rather more abundant, and be concentrated nearer one pole (vegetative) of the egg, the cleavage ivill be unequal (usually only after the third division), as in the eggs of Cyclostomes and Amphibia.

Partial cleavage takes place in eggs which are often very large, and which contain a large amount of yolk. This food yolk is so unequally distributed that the egg contents may be divided into a formative yolk, in which alone the process of cleavage takes place, and a nutritive yolk, which does not divide and which serves as food for the nourishment of the growing embryo. If the food yolk be accumulated at one pole of the egg segmentation will be confined to a disc-shaped area of formative yolk situated at the opposite or animal pole; this is the discoidal form of cleavage found in Fishes, Reptiles, and Birds.

When the food yolk is collected at the centre of the egg, with the formative yolk investing it, the cleavage will be superficial. The nucleus is, in this case, usually in the centre of the egg, and the daughter nuclei which are formed by 
its division migrate to the superficial layer of protoplasm which then divides into as many segments as there are daughter nuclei. In this way a germ-membrane is formed around the outside of the egg. This form of cleavage is illustrated by many Arthropods.

At the close of segmentation the egg, as was described in connection with the frog, is converted into a hollow sphere known as the blastula.

By a process of invagination the blastula is converted into a gastrula, a two-walled sac, opening to the exterior by the blastopore. As the blastula is the result of the process of segmentation, its form will be dependent upon the amount and distribution of the food yolk; and in like manner the character of the gastrulation will also depend upon the yolk.

In some eggs gastrulation is so plain and evident that it may easily be made out, but in other eggs it is so masked by the large amount of food yolk that it is very difficult to determine.

Four kinds of gastrulæ are sometimes described :

I. Where the egg is small and free from yolk, as in Amphioxus, the archenteron is wide, 
The Development of the Chick Ior

and each germ-layer is made up of a single layer of cylindrical cells. This is a simple and typical form of gastrula.

2. In some forms, the Amphibia, for example, the large mass of yolk is accumulated on the floor of the archenteron and reduces that cavity to a narrow fissure.

3. In Fishes, Reptiles, and Birds the egg is large and contains a large amount of food yolk. Since this yolk does not segment, it can take no part in the process of invagination which is confined, in consequence, to the germinal disc. The yolk is very slowly enclosed by a cellular wall, the ectoderm growing around it most rapidly, and the mesoderm being the last to enclose it.

4. In Mammals the egg is small, and the inner germ-layer is derived from the thickened region of the blastula, probably by a process of invagination, since an aperture comparable to the blastopore of Birds is seen at a later stage. For a time the inner germ layer ends freely below, so that the archenteron is closed below by the ectoderm only, a condition comparable to that found in Birds, if we imagine the yolk material to have been absorbed before the completion of the middle germ-layer. 
In vertebrates the gastrula is distinctly bilaterally symmetrical, so that the future head and tail ends, as well as the dorsal and ventral sides, of the embryo may be recognized.

In the chick, with which we are now especially concerned, we have seen that the segmentation was confined to the small germinal disc, and that it was completed by the time the egg was laid.

The first indication of segmentation that is seen is a slight vertical furrow extending across the centre of the germinal disc, but not reaching quite to the sides (Fig. 34, A). Soon another vertical furrow is formed at right angles to the first, so that the germinal disc is now divided into four equal parts (Fig. $34, A)$. Four radial furrows are next formed, lying about half-way between the first two, and then several cross-furrows divide the eight radial segments into smaller central and larger peripheral ends (Fig. 34, B). The central group of smaller cells does not lie exactly in the centre of the germinal disc, but a little nearer to one side than to the other (Fig. 34).

Furrows, running in all directions, now appear in rapid succession, and the germinal disc is soon divided into a large number of 
The Development of the Chick I03

cells by these vertical and horizontal cleavage planes. The cells nearer the centre of the germinal disc continue to be smaller than those nearer the periphery until nearly the close of segmentation (Fig 35), when the peripheral célls continue to divide for a little longer time and thus are finally reduced to the same size as the central cells. Each of these small cells contains a nucleus which is probably derived from the repeated division of the original segmentation nucleus of the egg.

\section{The Blastoderm}

By the time the egg is laid, the germinal disc has been changed, by this process of segmentation, to a sharply defined circular cap of cells which, by its less specific gravity, always lies at the upper pole of the egg, as has already been mentioned (Fig. 33 bl). This circular cap or blastoderm is usually about $3.5 \mathrm{~mm}$. in diameter when the egg is laid, though its condition at that time varies somewhat, depending upon the length of time the egg remains in the uterus before being laid.

If examined carefully from the surface, the 
blastoderm will exhibit two areas: around the periphery of the disc will be seen a band that is whiter and more opaque than the central part; this is known as the area opaca; the central, more transparent part is known as the area pellucida. In the centre of the area pellucida may be seen a white area (sometimes called the nucleus of Pander) which is

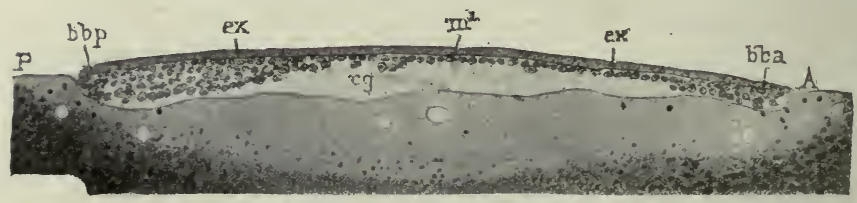

Fig. 36-LONGITUdinal SECTION OF THE BLASTODERM AFTER THE COMPLETION OF SEgMENTATION. (After Duval.)

$e x$, ectoderm. in.1, primitive entoderm. $b b p$, cells that form the thickened rim of the blastoderm. $c g$, sub-germinal cavity.

the top of the flask-shaped mass of white yolk which lies in the centre of the egg.

If vertical sections of the blastoderm be made, and examined under the microscope (Fig. 36), it will be found to be composed of two layers of cells; the upper layer or ectoderm (ex) composed of short columnar or cubical cells of uniform size and closely packed together, is more or less distinct and sharply defined; the lower layer of cells (in. I) is much less sharply defined and is composed 
The Development of the Chick 105

of cells of various sizes and shapes. Between these two layers is sometimes seen, at an early period, before the egg is laid, a very small cleft-like space, the segmentation cavity, corresponding to the large and distinct cavity of that name which was seen in the frog's egg. At a somewhat later period may be seen a more distinct cavity, the subgerminal cavity, (cg) lying between the lower layer cells and the yolk.

In the centre of the blastoderm, the cells of the lower layer are few and scattered, while around the periphery they are more numerous and form a comparatively thick layer (Fig. 36). It is this difference in the thickness of the different regions of the blastoderm that produces the distinction into an area opaca and an area pellucida, when the blastoderm is viewed from above.

Owing to the extreme delicacy of the blastoderm, it is difficult to obtain sections that will show the above points.

During incubation the blastoderm continually increases in size until it completely encloses the yolk. In this growth the area opaca increases much more rapidly than the area pellucida, and retains its circular outline, 


\section{06}

\section{Vertebrate Embryology}

while the area pellucida soon becomes oval and then pyriform in outline (Fig. 46, ar. pl).
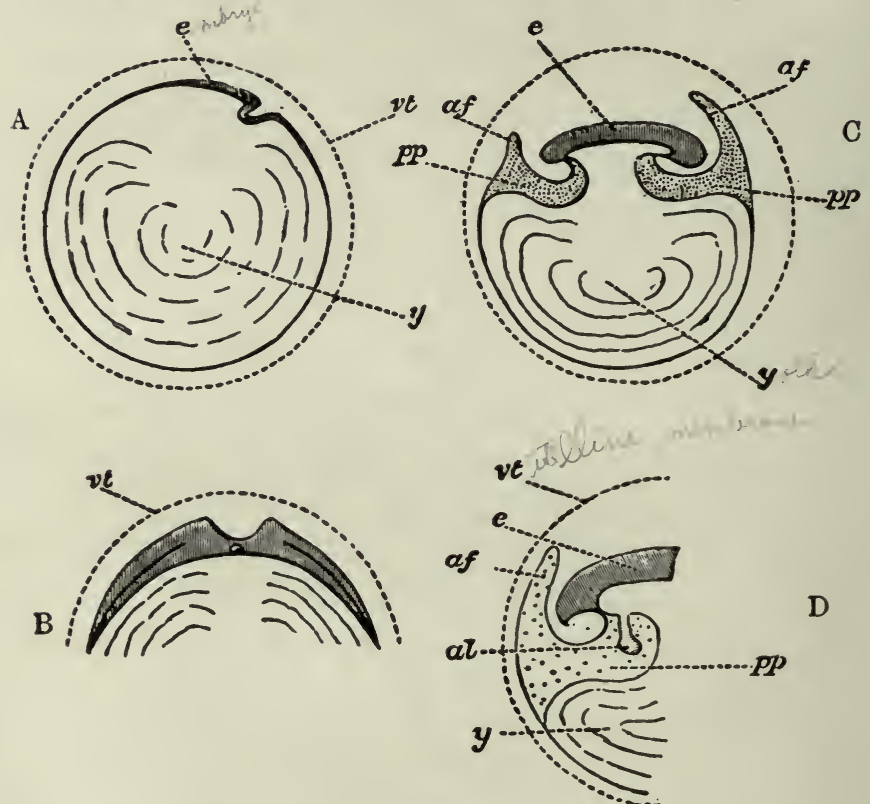

Fig. 37. (After Foster and Balfour.)

"Fig. 37, $A$ to $N$, forms a series of purely diagrammatic representations, introduced to facilitate the comprehension of the manner in which the body of the embryo is formed, and of the various relations of the yolk-sac, amnion, and allantois.

"In all $v t$ is the vitelline membrane, placed, for convenience sake, at some distance from its contents, and represented as persisting in the later stages; in the actual egg it is in direct contact with the blastoderm (or yolk), 


\section{The Development of the Chick 107}

and early ceases to have a separate existence. In all $e$ indicates the embryo, $p p$ the general pleuroperitoneal space, af the folds of the amnion proper; ae or ac the cavity holding the liquor amnii; al the allantois; $a^{\prime}$ the alimentary canal; $y$ or $y s$ the yolk or yolk-sac.

" $A$, which may be considered as a vertical section taken longitudinally along the axis of the embryo, represents the relations of the parts of the egg at the time of the first appearance of the head-fold, seen on the right-hand side of the blastoderm $e$. The blastoderm is spreading both behind (to the left hand in the figure), and in front (to the right hand) of the head-fold, its limits being indicated by the shading and thickening for a certain distance of the margin of the yolk $y$. As yet there is no fold on the left side of $e$ corresponding to the head-fold on the right.

" $B$ is a vertical transverse section of the same period drawn for convenience sake on a larger scale (it should have been made flatter and less curved). It shews that the blastoderm (vertically shaded) is extending laterally as well as fore and aft, in fact, in all directions; but there are no lateral folds, and therefore no lateral limits to the body of the embryo as distinguished from the blastoderm.

"Incidentally it shews the formation of the medullary groove by the rising up of the laminæ dorsales. Beneath the section of the groove is seen the rudiment of the notochord. On either side a line indicates the cleavage of the mesoblast just commencing.

" In $C$, which represents a vertical longitudinal section of later date, both head-fold (on the right) and tail-fold (on the left) have advanced considerably. The alimentary canal is therefore closed in, both in front and be- 
hind, but is in the middle still widely open to the yolk $y$ below. Though the axial parts of the embryo have become thickened by growth, the body-walls are still thin; in them, however, is seen the cleavage of the mesoblast, and the divergence of the somatopleure and splanchnopleure. The splanchnopleure both at the head and at the tail is folded in to a greater extent than the somatopleure, and forms the still wide splanchnic stalk. At the end of the stalk, which is as yet short, it bends outwards again and spreads over the surface of the yolk. The somatopleure, folded in less than the splanchnopleure to form the wider somatic stalk, sooner bends round and runs outwards again. At a little distance from both the head and the tail it is raised up into a fold, af, af, that in front of the head being the highest. These are the amniotic folds. Descending from either fold, it speedily joins the splanchnopleure again, and the two, once more united into an uncleft membrane, extend some way downwards over the yolk, the limit or outer margin of the opaque area not being shewn. All the space between the somatopleure and the splanchnopleure, $p p$, is shaded with dots. Close to the body this space may be called the pleuroperitoneal cavity; but outside the body it runs up into either amniotic fold, and also extends some little way over the yolk.

" $D$ represents the tail end at about the same stage on a more enlarged scale, in order to illustrate the position of the allantois al (which was for the sake of simplicity omitted in $C$ ), shewn as a bud from the splanchnopleure, stretching downwards into the pleuroperitoneal cavity $p p$. The dotted area representing as before the whole space between the splanchnopleure and the somatopleure, it is 


\section{The Development of the Chick Iog}

evident that a way is open for the allantois to extend from its present position into the space between the two limbs of the amniotic fold $a f$.
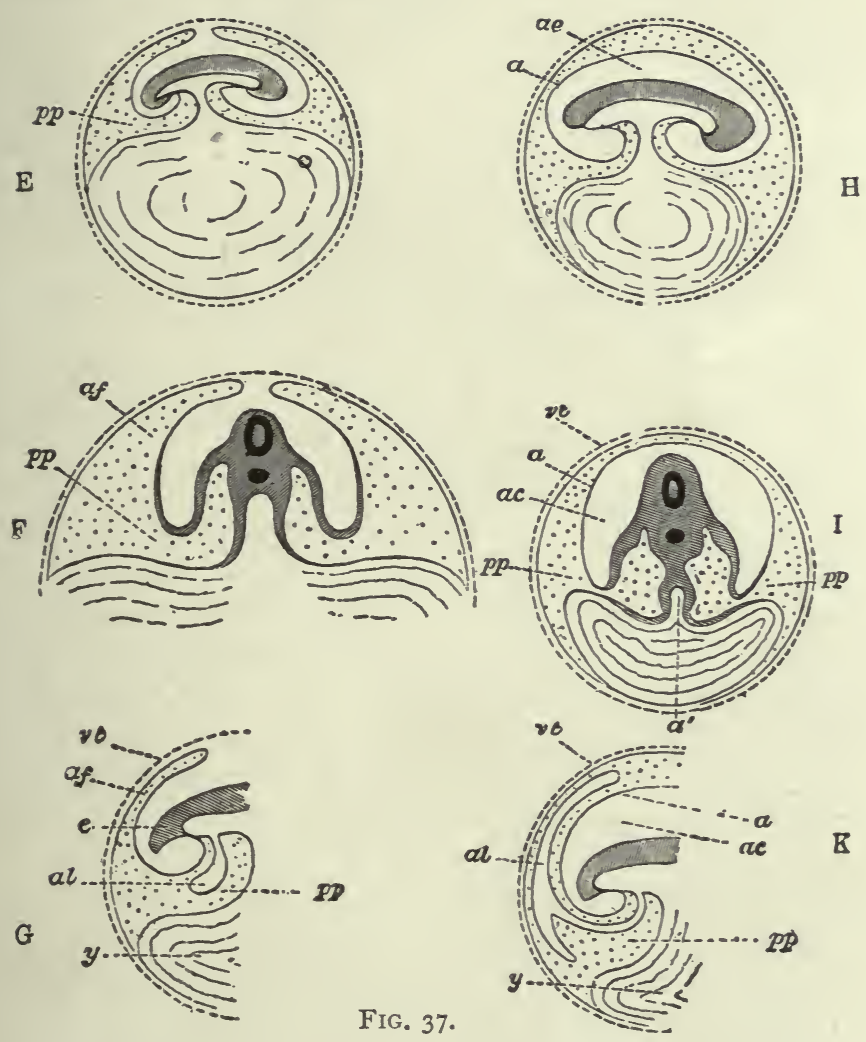

" $E$, also a longitudinal section, represents a stage still farther advanced. Both splanchnic and somatic stalks are much narrowed, especially the former, the cavity of 
the alimentary canal being now connected with the cavity of the yolk-sack by a mere canal. The folds of the amnion are spreading over the top of the embryo and nearly meet. Each fold consists of two walls or limbs, the space between which (dotted) is as before merely a part of the space between the somatopleure and splanchnopleure. Between these arched amniotic folds and the body of the embryo is a space not as yet entirely closed in.

" $F$ represents on a different scale a transverse section of $E$ taken through the middle of the splanchnic stalk. The dark ring in the body of the embryo shews the position of the neural canal, below which is a black spot, marking the notochord. On either side of the notochord the divergence of somatopleure and splanchnopleure is obvious. The splanchnopleure, more or less thickened, is somewhat bent in towards the middle line, but the two sides do not unite, the alimentary canal being as yet open below at this spot; after converging somewhat they diverge again and run outwards over the yolk. The somatopleure, folded in to some extent to form the bodywalls, soon bends outwards again, and is almost immediately raised up into the lateral folds of the amnion $a f$. The continuity of the pleuroperitoneal cavity within the body with the interior of the amniotic fold outside the body is evident; both cavities are dotted.

" $G$, which corresponds to $D$ at a later stage, is introduced to shew the manner in which the allantois, now a distinctly hollow body, whose cavity is continuous with that of the alimentary canal, becomes directed towards the amniotic fold.

" In $H$ a longitudinal, and $I$ a transverse section of later date, great changes have taken place. The several 


\section{The Development of the Chick I I}

folds of the amnion have met and coalesced above the body of the embryo. The inner limbs of the several folds have united into a single membrane $(a)$, which encloses a space ( $a e$ or $a c$ ) round the embryo. This membrane $(a)$ is the amnion proper, and the cavity within it, $i$. e., between it and the embryo, is the cavity of the amnion containing the liquor amnii. The allantois is omitted for the sake of simplicity.

"It will be seen that the amnion $a$ now forms in every direction the termination of the somatopelure; the peripheral portions of the somatopleure, the united outer or descending limbs of th: folds $c_{f}^{, f}$ in $C, D, F, G$ having been cut adrift, anc! now forming an independent continuous membrane, the serous membrane, immediately underneath the vitelline membrane.

"In $I$ the splanchnopleure is seen converging to complete the closure of the alimentary canal $a^{\prime}$ even at the stalk (elsewhere the canal has of course long been closed in), and then spreading outwards as before over the yolk. The point at which it unites with the somatopleure, marking the extreme limit of the cleavage of the mesoblast, is now much nearer the lower pole of the diminished yolk.

"As a result of these several changes, a great increase in the dotted space has taken place. It is now possible to pass from the actual peritoneal cavity within the body, on the one hand round a great portion of the circumference of the yolk, and on the other hand above the amnion $a$, in the space between it and the serous envelope.

"Into this space the allantois is seen spreading in $K$ at al. 
" In $L$ the splanchnopleure has completely invested the yolk-sac, but at the lower pole of the yolk is still continuous with that peripheral remnant of the somatopleure now called the serous membrane. In other words, the cleavage of the mesoblast has been carried all round the yolk $(y s)$ except just at the lower pole.
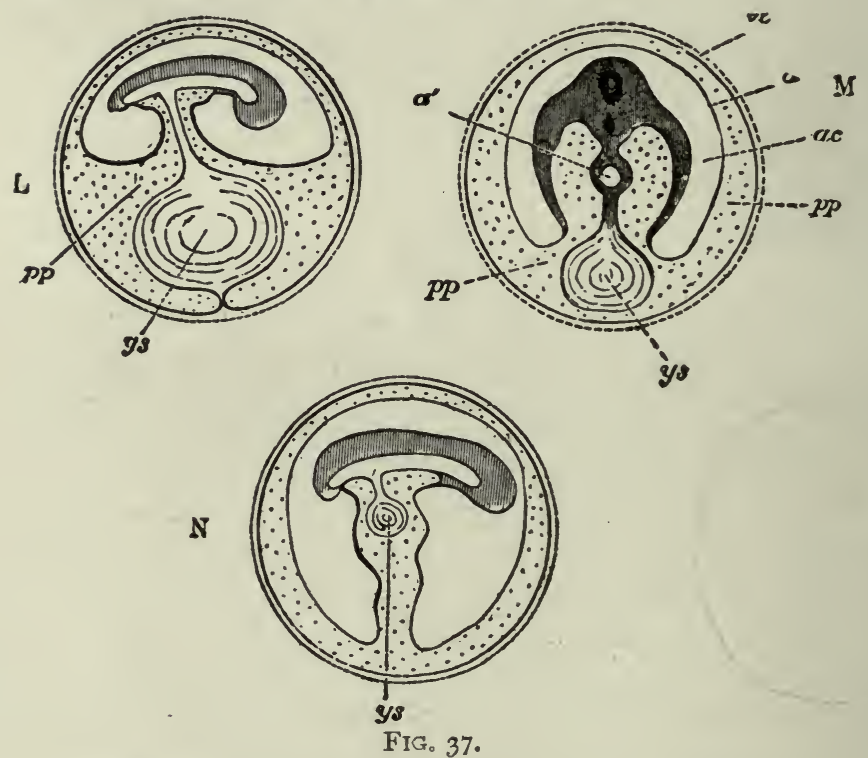

"In $M$ the cleavage has been carried through the pole itself; the peripheral portion of the splanchnopleure forms a complete investment of the yolk, quite unconnected with the peripheral portion of the somatopleure, which now exists as a continuous membrane lining the interior of the shell. The yolk-sac $(y s)$ is therefore quite loose in the pleuroperitoneal cavity, being con- 


\section{The Development of the Chick I 3}

nected only with the alimentary canal $\left(a^{\prime}\right)$ by a solid pedicle.

"Lastly, in $N$ the yolk-sac ( $y$ s) is shewn being withdrawn into the cavity of the body of the embryo. 'The allantois is as before, for the sake of simplicity, omitted; its pedicle would of course lie by the side of $y s$ in the somatic stalk marked by the usual dotted shading.

"It may be repeated that the above are diagrams, the various spaces being shewn distended, whereas in many of them in the actual egg the walls have collapsed, and are in near juxtaposition."

We have now described, in some detail, the condition of the egg at the time of laying, and the changes that it has undergone previous to that time.

To facilitate the study of the subject in the laboratory, the development of the chick from this point will be described by periods. For example, the changes that take place during the first day will first be described, then all the changes of the second day, then of the third day, and so on to the end of incubation, at the twenty-first day. Since the changes that take place after the first week are chiefly those of growth, most of the space will be given to the changes of the first four or five days.

Before beginning the more detailed description of the changes that take place during 
the first day, it may be well to give a very brief summary of the whole process of development.

\section{Summary of Development}

A very careiful stz?dy of the series of diagrams in Figs. 37 and $3 \mathcal{E}$ will greatly aid in the comprehension of the more detailed description that is to follow, keeping in mind that the dotted areas marked "op," in Fig. 37, are, in reality, spaces and not izssue, as might naturally be inferred from the diagrams.

After having followed the development of the various organs and systems of organs in the frog, the only features in the development of the chick that will be apt to give trouble are the folding off of the embryo from the yolk and the development of the amnion and allantois, structures not found in the frog.

An understanding of the way in which the embryo becomes folded off from the rest of the egg may, perhaps, be obtained in the following way: cut out four circles of cloth, say $75 \mathrm{~cm}$. in diameter, of three different colors. Put the two circles that are of the same color together and then put these two circles between the other two. 
The Development of the Chick II5

Let these superimposed circles represent a greatly enlarged blastoderm that has been removed from the yolk to which it was originally attached. The upper layer of cloth will represent the ectoblast, the bottom layer will represent the entoblast, and the two similarly colored layers in the middle will represent the two layers of the mesoblast after their separation. The method of the formation of these three germ layers, during the first day of incubation, will be described under the head of the first day's development.

As the yolk takes no actual part in the formation of the embryo, other than as a supply of food for the growth of the constantly enlarging chick, it may be omitted in our model.

Now spread the cloth blastoderm upon a table and place under its centre a small object, such as a bottle. If now the fingers of one hand be pushed under one end of the bottle, carrying, of course, the three germ layers with them, we shall have represented the formation of the head fold that is represented and described in Figs. 37 and 38 . By pushing under the cloth at the other end of the bottle, in the same way, we may represent the formation of the tail fold; and in a like manner the lateral 
folds may be formed. If these folds, the head, tail, and lateral, be pushed under far enough they will meet under the centre of the bottle, and we shall have the bottle, with its surrounding layers of cloth, connected with the rest of the model by only a sort of stalk, which is hollow and is composed of the three layers of cloth (cf. Fig. 37, H and L). The bottle is used simply to give a solid object around which the folding may more easily be done, but we are to consider the space occupied by the bottle as an empty space.

We have now represented what is sometimes called the embryo-sac, or simply the embryo, in contradistinction to the yolk-sac, or simply the yolk. The embryo remains connected with the yolk throughout the period of incubation by the yolk-or somatic-stalk, and as the embryo increases in size, the yolk-sac is, by absorption, constantly diminished (Fig. 37). The space occupied by the bottle, in our model, represents the digestive tract of the chick, and is lined, as will be seen by examination of the model, by the lower germ layer or entoblast. The body-cavity would be difficult to represent in the cloth model, but it can be imagined to exist as the narrow space between the two 
The Development of the Chick i 7

layers of similarly colored cloth which we have called the mesoblast.

The formation of the amnion (Fig. 38, am.f) may be represented in our model by lifting up with the fingers a small fold of the upper

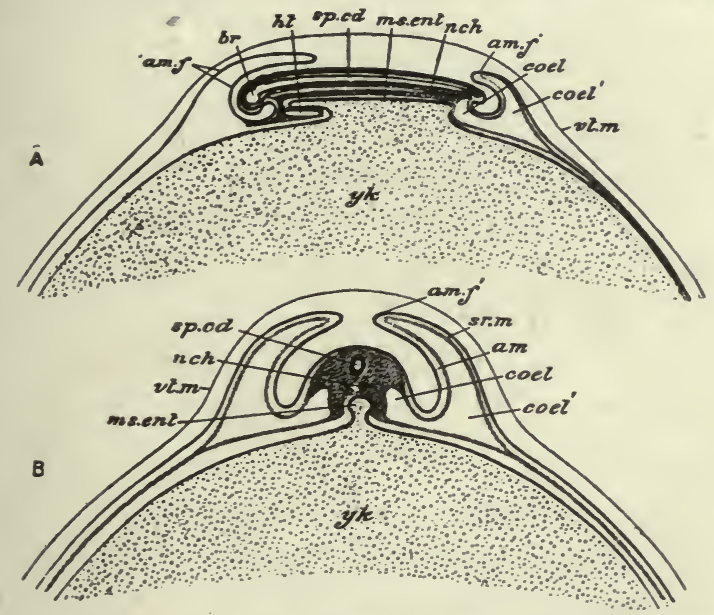

Fig. 38. A B-Diagrams illustrating the Development of the fCETAL MEMbranes of A BIRD. (After Parker and Haswell.)

$A$, early stage in the formation of the amnion, sagittal section. $B$, slightly later stage, transverse section.

and second layers of cloth, and pulling these two layers back over the head end of the embryo ; this fold will correspond to the head-fold of the amnion (Fig. 38, am.f). Similar folds might be lifted up at the posterior end and at the sides of the embryo model, to represent 
the tail and lateral folds of the amnion. The way in which these folds fuse together will be

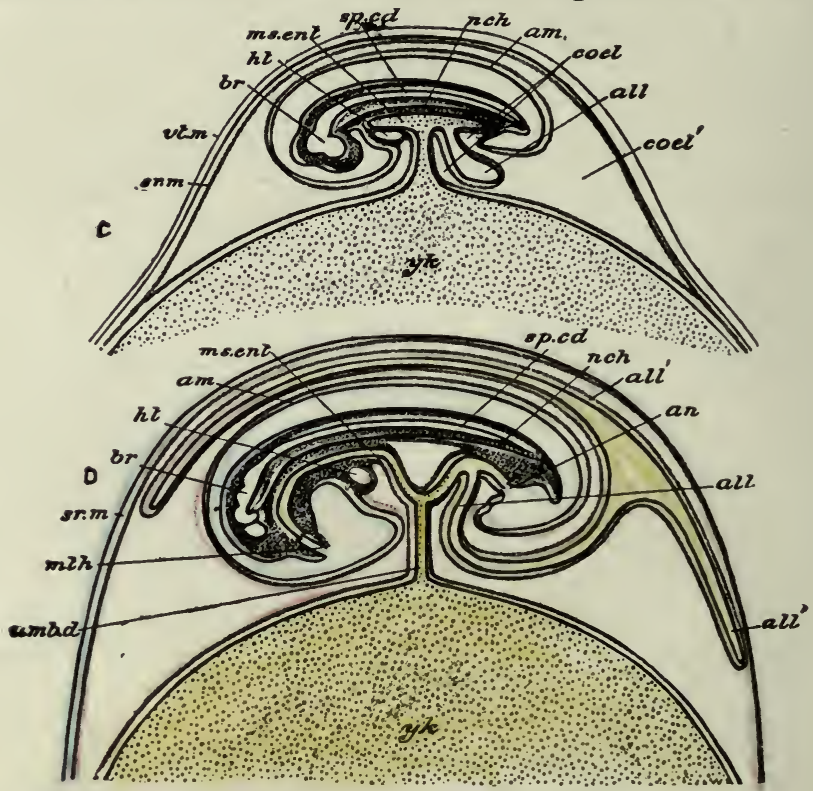

Fig. 38. C D-Diagrams illustrating the development of THE FCETAl membranes of A BIRD. (After Parker and Haswell.)

$C$, stage with completed amnion and commencing allantois. $D$, stage in which the allantois has begun to envelop the embryo and yolk-sac. The ectoderm and entoderm are represented by black lines; the mesoderm is gray.

all, allantois. a $l l^{\prime}$, the same growing round the embryo and yolk-sac. $a m$, amnion. a $m$. $f, a m$, $f^{\prime}$, amniotic fold. $a n$, anus. br, brain. coel, colome. coel', extra-embryonic colome, $h t$, heart. ins.ent, mesenteron. $m t h$, mouth. $n c h$, notochord. $s p . c d$, spinal chord. $s r . m$, serous membrane. $u m b . d$, umbilical duct. $v t . m$, vitelline membrane. $y k$, yolk-sac.

explained later, and will readily be understood by study of Figs. 37 and 38 .

The formation of the allantois cannot readily 


\section{The Development of the Chick I I9}

be represented in the cloth model, but is easily understood from Fig. 38. It arises, as will be explained later, as a thin-walled pouch from the posterior end of the digestive tract, and as it increases in size it extends up around the upper side of the embryo, between the inner and outer layers of the amnion (Fig. 38, all).

Neither the amnion nor the allantois form any permanent part of the actual embryo, and both are cast off at the time of hatching. 


\section{CHAPTER III}

\section{THE DEVELOPMENT OF THE FIRST DAY}

I speaking of the age or state of development of an embryo, it is customary to date from the time of the beginning of the process of incubation, whether that process be carried out under a hen or in an incubator: but it must not be supposed that all eggs will reach exactly the same state of development at the same time. Various things will influence this state; for example, the season of the year, the length of time the egg was retained in the uterus before being laid, etc.; so that when we speak of an egg being at the thirty-six-hour stage, we shall mean that the egg in question has reached a state of development that is commonly reached by eggs after that period of normal incubation. It is simply a convenient and commonly used method of speaking of embryos that have reached a certain state of development. 


\section{Development of the First Day I 2 I}

It will be remembered that the blastoderm, at the time of laying, is a small, disc-shaped structure, like an inverted watch-glass, lying on top of the egg just beneath the vitelline membrane.

- In sections it shows two more or less distinct layers, the ectoblast, consisting of a single

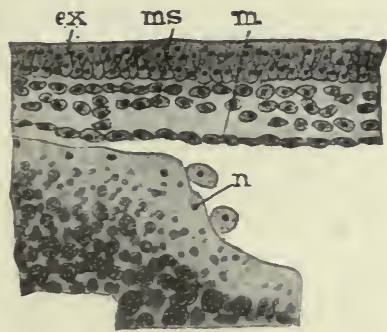

Fig. 39.-PART OF A SECTION THROUGH THE BLASTODERM AFTER THE FORMATION OF THE DEFINITE ENTODERM OR HYPOBLAST. (After Duval.)

$e x$, ectoderm. in, entoderm. $m s$, mesoderm.

layer of closely packed, columnar cells : and the lower layer cells, which are more irregular in outline and are not arranged in so definite a layer as are the cells of the ectoblast (Fig. 36).

One of the first changes that take place, during the first part of the first day, is the formation of a definite entoblast by the flattening 
and joining together, in a distinct membrane, of these lower layer cells (Fig. 39). In this process of the formation of the entoblast, some of the lower layer cells are left between the ectoblast and the newly formed

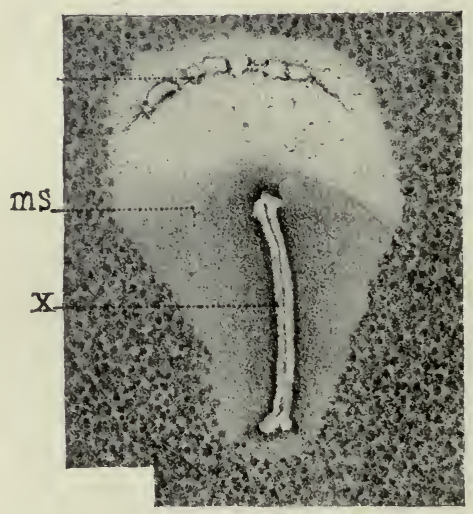

Fig. 40.-SURFACE VIEW OF THE EMbryo AT ABOUT THE SIXTEENTH HOUR OF INCUBATION. (After Duval.)

$m s$, mesoblast forming the darker area in the posterior region of the area pellucida. $X$, primitive streak.

entoblast; these scattered cells probably form, as will be noted later, a part of the mesoblast or middle germ layer. They are mostly confined to the posterior end of the area pellucida, where they form a slight opacity, which is sometimes called the embryonic shield. 
Development of the First Day I 23

The differentiation of the entoblast begins in the centre of the area pellucida, and gradually extends towards the area opaca, where it is formed at a somewhat later period, and where it is composed of cells of a different shape from those of the pellucid area.

While the entoblast is being formed, the blastoderm has increased considerably in size, and the area pellucida, which in the unincubated egg is often very indistinct, becomes sharply marked off from the opaque area.

About the middle, or during the second half, of the first day, a very characteristic structure, the primitive streak, makes its appearance. With the naked eye, or under a low power of the microscope, it is seen (Fig. 40, $X$ ) as a distinct linear opacity in the posterior half of the now pear-shaped area pellucida.

It might here be mentioned that the broad end of the area pellucida corresponds to the head end of the future chick; and that if the egg be held with its large end towards the right, in nearly every case the head of the embryo will point away from the observer.

If vertical sections be cut through the primitive streak, at right angles to its long axis (Fig. 4I, $p p$ ), it will be found that the streak 
is caused by an elongated group of cells that have been proliferated off from the ectoblast, and now lie between the ectoblast and entoblast. These cells gradually spread out on each side of the primitive streak, and form a part of the mesoblastic layer.

The primitive streak, for a time, keeps pace

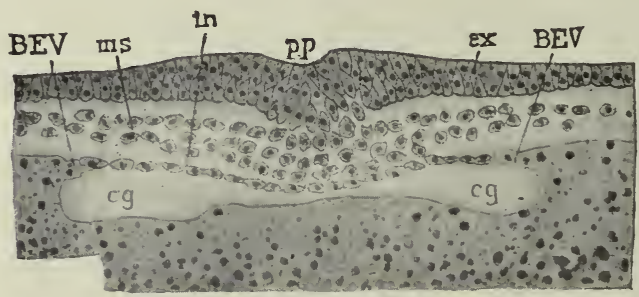

Fig. 4I.-MEdian PORTION OF A TRANSVERSE SECTION OF AN EMBRYO AT THE TIME OF THE FORMATION OF THE PRIMITIVE STREAK. (After Duval.)

$c g$, subgerminal cavity, $e x$, ectoderm. $i n$, entoderm. $m s$, mesoderm. $p p$, primitive groove.

in growth with the area pellucida, and as that area grows more rapidly at its posterior end, the primitive streak increases in length almost entirely from its hinder end.

A median furrow, varying somewhat in width and depth, in different embryos, makes its appearance in the upper surface of the primitive streak (Figs. 40 and $4 \mathrm{I} p p$ ), and is known as the primitive groove. 


\section{Development of the First Day I 25}

The meaning of the primitive streak and groove has been much discussed. It is now generally considered to correspond, in part at least, to the elongated lips of the blastopore in the frog, that have come together, on the clostre of the blastopore, as has been described in a previous part of this book. The primitive groove would correspond to the line of fusion of the two lips of the blastopore.

The mesoblast in the chick seems to be derived from three distinct sources, though it is not easy to make out these points.

One of these sources has been mentioned in the primitive streak. A second source is the scattered group of cells that was left between the ectoblast and entoblast on the formation of the latter as a distinct layer of cells. In the middle and lateral parts of the area pellucida, at about the time of the formation of the primitive streak, cells are budded off from the upper side of the entoblast and become mesoblast.

The mesoblast cells, derived from these three sources, very soon unite to form a continuous layer, so that it is impossible to tell from which source any particular cell was 


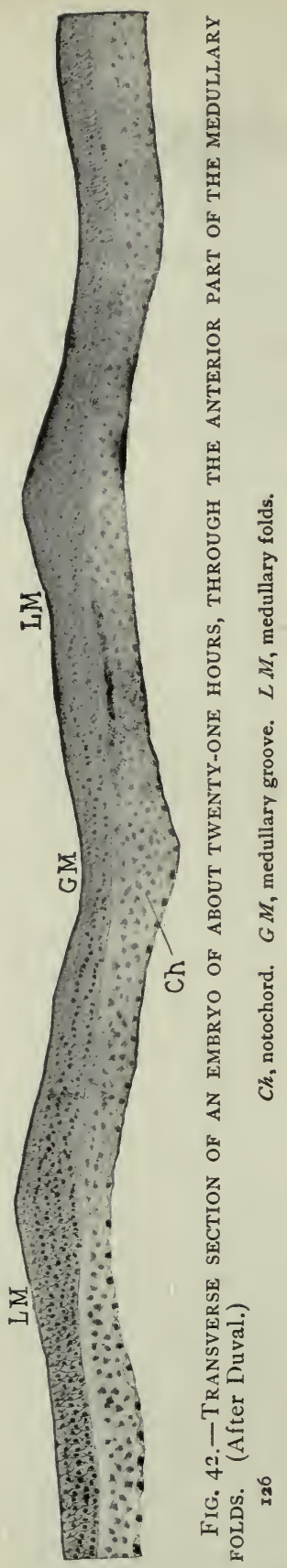


Development of the First Day 127

derived ; this sheet of mesoblast extends until it passes the boundaries of the area pellucida, and forms a middle layer in the irner zone of the area opaca. This zone of the area opaca which contains the mesoblast, and which immediately surrounds the area pellucida, is known as the vascular area, because it is in it that the blood vessels that absorb the yolk, for the growth of the embryo, are formed (Fig. 80, ar. vasc).

The cells of the mesoblast are usually not closely packed together, and may generally be recognized by their angular or stellate form (Figs. 42 and 48 ).

At about the time of the formation of the primitive streak and the differentiation of the mesoblast, the entoblast, in front of the primitive streak, becomes thickened to form a longitudinal axis or rod of cells, the notochord (Fig. 42, ch). The notochord remains for some time attached to the entoblast from which it is derived, but it later separates from this, and forms a distinct and separate rod, similar to that which we have already seen in the frog.

While the entoblast has been forming (about the fifteenth to the twentieth hour) the 

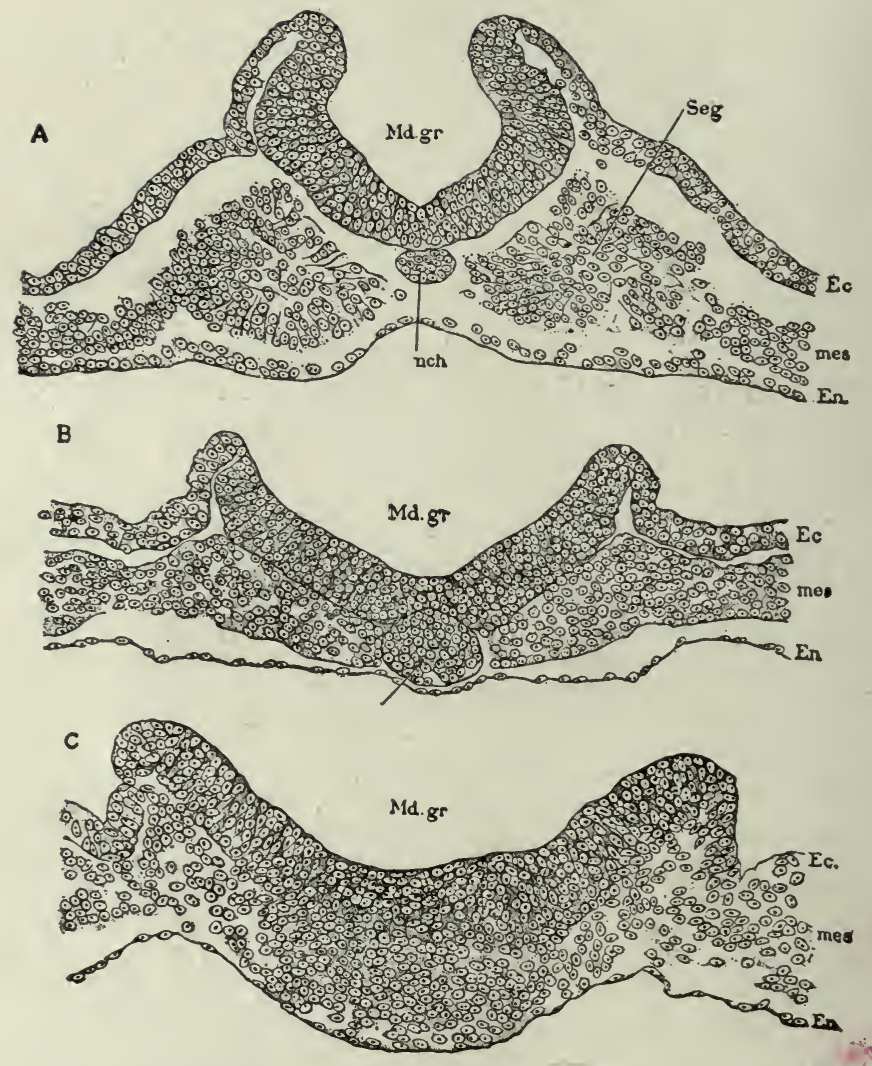

Fig. 43.-Three transverse Sections ACross THE CAUdAL END OF THE MEDULLARY GROOVE OF A CHICK EMBRYO WITH SEVEN SEGMENTS. (After Minot)

$A$, section through one of the segments. $B$, section posterior to the segments. $C$, section just in front of the primitive streak. $M d . g r$, medullary groove; $n c h$, notochord; Ec, ectoderm; mes, mesoderm; En, entoderm; Seg. mesoblastic somite. 


\section{Development of the First Day 129}

ectoblast has become thickened, in a line above the developing notochord, to form the medullary plate. The sides of the medullary plate

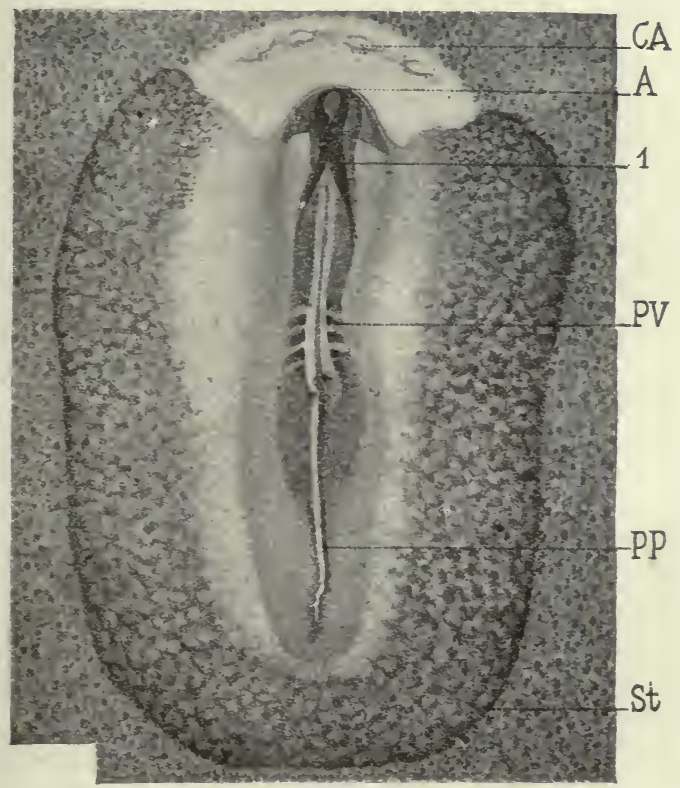

Fig. 44.-SuRface view of embryo at the twenty-third HOUR OF INCUBATION. (After Duval.)

$A$, anterior limit of head. $\not p$, primitive streak. $p v$, mesoblastic somites. $S t$, sinus terminalis, bounding the vascular area. I, region where the medullary folds have almost met to form the medullary canal.

soon become elevated as the medullary folds, with the medullary groove between them (Figs. 43 and 44). The medullary folds, before the 
end of the first day, become very pronounced, and in the region of the future brain (the medullary folds, as was described in connection with the frog, are the beginning of the nervous system) they arch over untii they meet in the middle line to enclose the medullary canal, though they do not actually fuse together until a somewhat later period. The appearance of the medullary folds at the end of the first day of incubation, as seen from the surface, is shown in Fig. $44(A)$. It will be noticed in this figure that, while the folds are nearly in contact for a considerable part of their length, they are still widely separated at the extreme anterior end, where a triangular space is left: and at the posterior end the two folds diverge widely, and gradually diminish in height as they pass back on each side of the primitive streak. At the extreme anterior end the two folds are continuous with each other, across the base of the triangle mentioned above.

During the second half of the first day the head-fold makes its appearance, and, by the end of the day, it has progressed so far (Fig. $44, \mathrm{~A})$, that the head region of the embryo is distinctly marked off. The formation of 


\section{Development of the First Day I 3 I}

the head-fold has been illustrated with the cloth model, and is shown in Figs. 37 and 38 : it is best seen in sagittal sections, one of which is represented in Fig 45 .

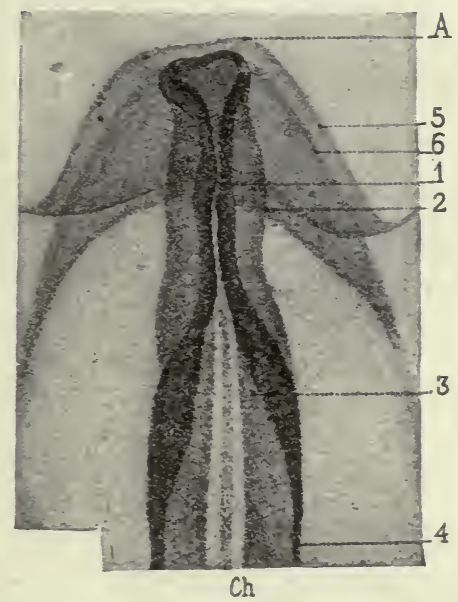

Fig. 44 (A).-ANTERIOR PART OF THE PRECEDING FIGURE, MORE HIGHLY MAGNIFIED TO SHOW DETAILS. (After Duval.)

$A$, anterior end of head. $C h$, notochord. r, region where the medullary folds will first fuse to form the medullary canal. 2 , lateral limits of medullary folds. 3 and 4, posterior regions of medullary folds. 5, lateral limits of head region. 6, limit of entoderm.

By the formation of the head-fold the anterior end of the digestive tract, or fore-gut, is also formed (Fig. 45, Ph). The tail-fold and the lateral folds do not begin to form until later.

In some cases, before the end of the first 
day, a slight crescentic fold is seen in the area pellucida just in front of the head-fold (Fig. 44, A); this is the beginning of the amnion, but a description of its development, in addition to what has already been given, will be given at a later place.

One of the most important changes of the latter part of the first day has to do with the mesoblast. After it has become fully established, the mesoblast on each side of the notochord forms (as seen in cross section) a sort of wedge-shaped sheet of tissue, with the base of the wedge next to the notochord. At about the twenty-first hour, each of these sheets of mesoblast splits into two layers (similar to the cleavage of the mesoblast seen in the frog), the upper layer being known as the somatopleure, the lower layer the splanchnopleure. The space between the two layers forming, as in the frog, the body-cavity or coelom. The somatic layer becomes closely associated with the ectoblast and forms the body-wall; while the splanchnic layer, together with the entoblast, forms the wall of the digestive tract (Fig. 52).

At about the twenty-second hour, almost immediately after its cleavage, the mesoblast on 


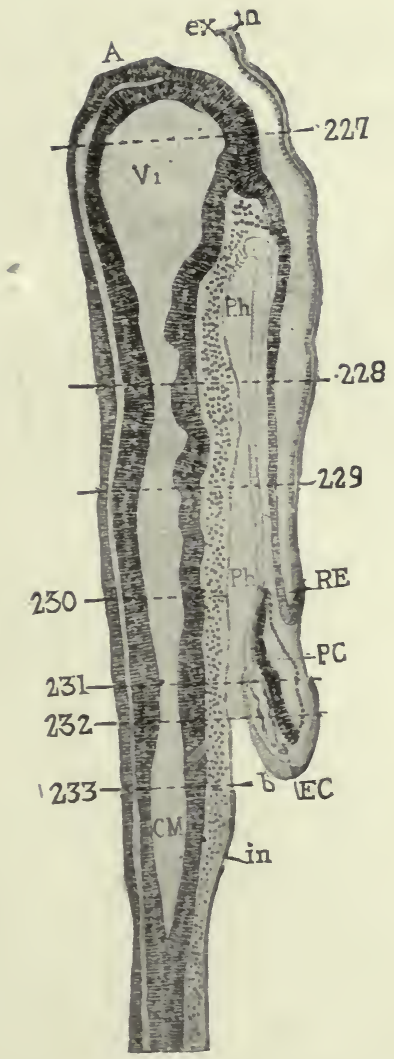

Fig. 45.-SAgitTal (MEdian - LONGitudinal) Section of AN EMBRYO OF 26 HOURS. (After Duval.)

$A$, anterior end of head. $C M$, medullary canal. $E C$, endothelium of heart. $R E$, limit of head-fold. $e x$, ectoderm. in, entoderm. $P C$, pericardium. $P h$, pharynx or fore-gut. $V_{\mathbf{r}}$, fore-brain. $b$, mesoderm. 
each side of the body becomes split by a series of vertical clefts, at right angles to the long axis of the body, and extending for a short distance outwards from the notochord. Immediately after the formation of these short, transverse clefts, there is formed a vertical, longitudinal cleft on each side of the notochord, which divides each sheet of mesoblast into a vertebral plate, lying next to the notochord, and a lateral plate, lying further from the median line.

The lateral plate consists of two continuous sheets of mesoblast, the somatopleure and splanchnopleure; while the vertebral plate is divided by the transverse clefts into a series of more or less cubical blocks, the mesoblastic somites or proto-vertebra (Figs. 44, $p v$, and 52 , Seg.). The first pair of somites is formed in the neck region, and by the end of the first day, there are usually five or six pairs present. The second and possibly the third pairs of somites are formed in front of the first pair; and the others, which appear in rapid succession, are formed in regular order behind these first two or three pairs.

The number of pairs of somites at any given time affords a convenient method of estima- 
Development of the First Day I35

ting the age of chick embryos, during the first two days. As has been said, the first somite is formed at about the twenty-first or twentysecond hour; and at the end of the first day five or six pairs are present. By the thirtysixth hour, there are about fifteen pairs of somites: and by the end of the second day, there are twenty-seven or twenty-eight pairs. After the end of the second day the number of somites can no longer be used to estimate the age of embryos, though the somites continue to increase in number until the fourth day. The somites are formed in the neck, trunk and tail regions, but do not extend into the head.

In the first three or four somites, the cleavage of the mesoblast extends close up to the notochord before the lateral plate is separated from the vertebral, so that there is a cavity in these somites that is continuous with the body-cavity. This cavity is not seen in the other somites, and eventually disappears from these.

The neurenteric canal, which was described, in connection with the frog (page 34), as a narrow passage connecting the neural canal with the extreme posterior end of the digestive 


\section{I36 Vertebrate Embryology}

tract, is seen in the early stages of the chick embryo as two or three small depressions in the floor of the posterior end of the neural canal. These depressions usually appear, one after the other, during the first three days, and, though they seldom are seen to open

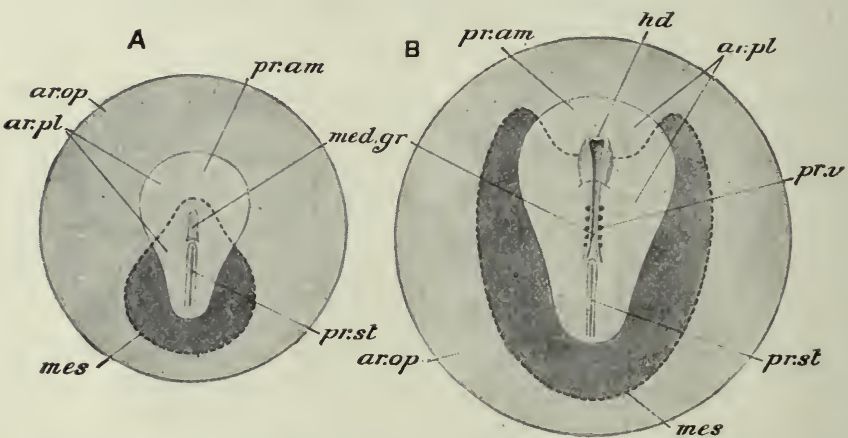

Fig. 46.-Diagrammatic REPRESENTATIONS OF CHICK EMBRYOS; $A$, AFTER TWENTY HOURS' INCUBATION; $B$, AlTER TWENTY-FOUR hours' incubation. (After Parker and Haswell, from Marshall.)

ar. $o p$, area opaca; $a r . p l$, area pellucida; $h d$, head; med. $g r$, medullary groove; mes, mesoderm indicated by dotted outline and deeper shade; pr.am, proamnion; $p r . s t$, primitive streak; $p r . v$, proto-vertebræ.

into the digestive tract, they seem to be homologous with the neurenteric canal of the frog and of other animals.

We shall now briefly summarize the more important changes that take place during the first day :

I. The entoblast is formed by the rearrange- 
Development of the First Day ${ }^{1} 37$

ment of the lower layer cells into a thin but definite layer.

2 The primitive streak, with the primitive groove along its axis, is formed as a linear proliferation of cells from the lower side of the ectoblast. These cells spread out on each side to form a part of the mesoblast.

3. The pellucid area becomes pear-shaped; and the vascular area becomes distinguishable as an inner zone of the area opaca.

4. The medullary plate is formed in front of the primitive streak, and its edges become elevated, as the medullary folds, and meet (without yet fusing), in the region of the brain, to form the medullary canal.

5. The notochord is formed as a medial, rod-shaped thickening of the entoblast, in front of the primitive streak.

6. The development of the head-fold marks the beginning of the head.

7. The mesoblast becomes split into two layers, the somatopleure and the splanchnopleure, with the body-cavity between them.

8. The vertebral plates are separated from the lateral plates, and in the former about five pairs of mesoblastic somites are formed.

It may be well, before taking up the de- 


\section{I38 Vertebrate Embryology}

velopment of the second day, to emphasize the importance of clearly understanding the changes of the first day, and the changes that were described in the brief summary. If the figures to which reference is made are carefully studied, there should be but little difficulty in understanding the processes that are described. 


\section{CHAPTER IV}

THE DEVELOPMENT OF THE SECOND DAY

I $\mathrm{T}$ will be convenient, and will facilitate the study of sections, in the laboratory, to divide the second day into two parts; describing first the changes that take place from the twenty-fourth to the thirty-sixth hour, and then those that take place during the second half of the day.

\section{From the 24TH TO THE 36 Th Hour}

During this period the embryo not only becomes much more clearly outlined, but its texture becomes more firm, so that, while it was very difficult to remove an eighteen-hour embryo from the egg without tearing, it is quite an easy matter to remove an embryo of thirty to thirty-six hours.

The medullary folds are rapidly coming together, and, by the thirty-sixth hour, the entire anterior region is closed in to form the 


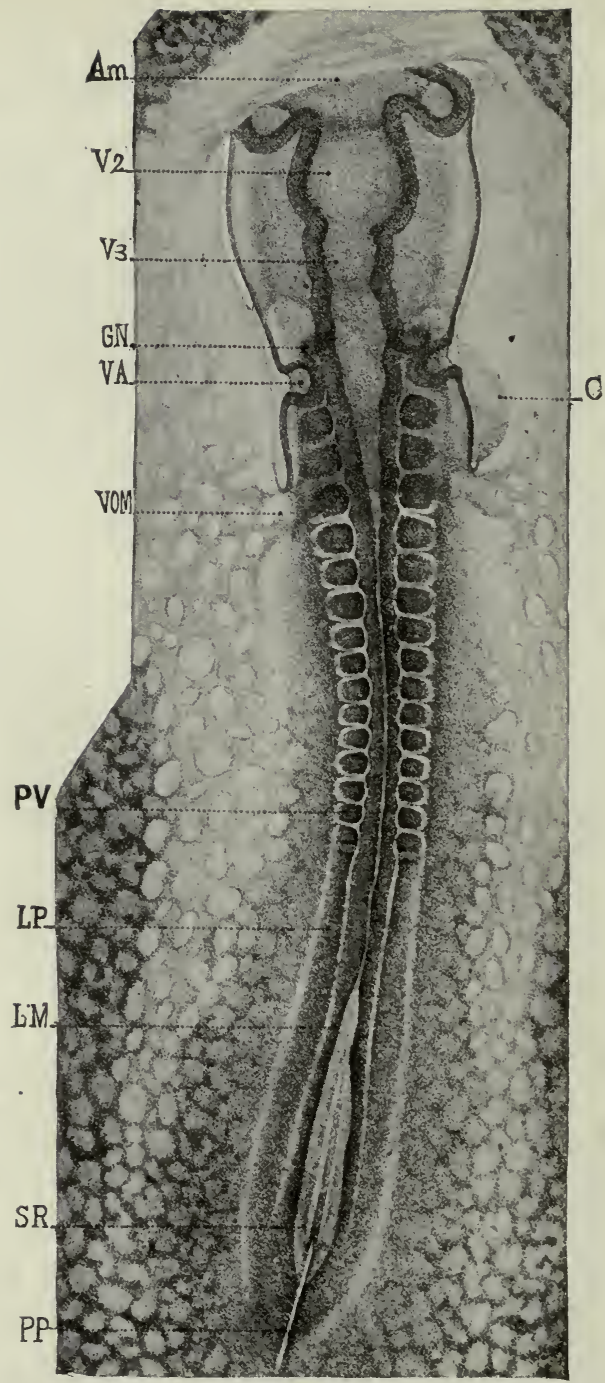

Fig. 47.-SURFACE VIEW (DORSAL) OF AN EMBRYO OF 33 HOURS. (After Duval.)

$A m$, head-fold of annion. $C$, heart. $G N$, nerve ganglion. $L M$, medullary fold. $L P$, mesoblast that will segment into mesoblastic somites. $P P$, primitive streak $P V$, mesoblastic somites. $S R$, sinus rhomboidalis. $V * 2$ and $V 3$, mid- and hind-brains. $V A$, auditory pits. $V O M$, vitelline vein. 


\section{Development of the Second Day I4I}

medullary canal, except for a small chink at the extreme end.

The anterior end of the medullary canal now begins to enlarge slightly and to be constricted off from the rest of the tube (Fig. 47) this enlargement is the beginning of the fore-brain, and from each side of it there is soon seen a small lateral diverticulum, the optic vesicle, whose further development will be described later.

Behind the fore-brain two other slight constrictions of the neural canal are formed (Fig. 47) marking the positions of the mid-brain, $V_{2}$, and the hind-brain, $V_{3}$. At the posterior end of the embryo the medullary folds are still some distance apart, forming what is known as the sinus rhomboidalis (Fig. 47, $S R$ ), along the floor of which may sometimes be seen the primitive streak, pp.

The beginning of the ears may be seen as

$\checkmark$ a pair of small depressions, the auditory pits, just back of the hind-brain (Fig. 47, VA).

The mesoblastic somites have increased in number, and by the thirty-sixth hour, as has already been mentioned, there are usually fifteen pairs of them (Fig. 47, $P V$ ).

The head is now more clearly defined, owing 
partly to the slight increase in the depth of the head-fold and partly to the slight lifting of the head above the surrounding blastoderm. The increase in depth of the head$\checkmark$ fold causes a corresponding increase in the

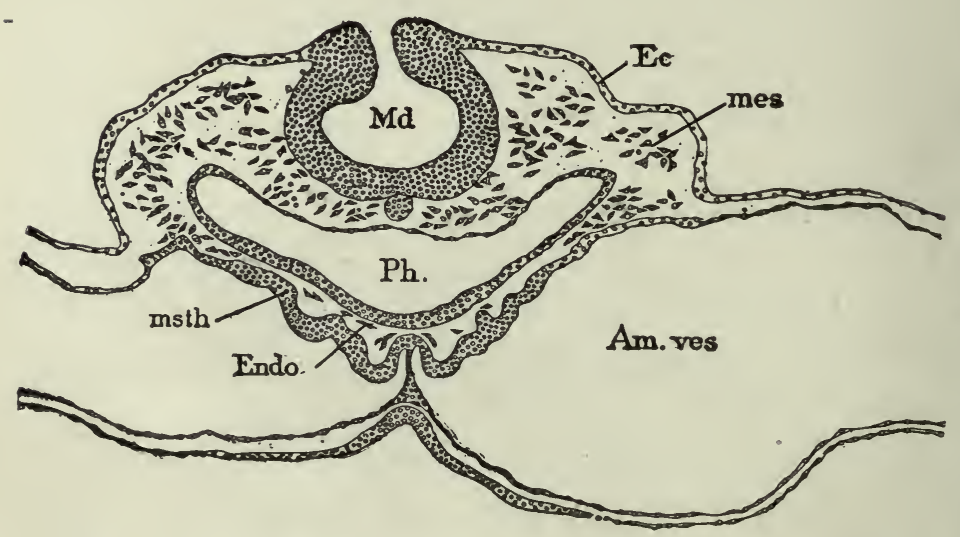

Fig. 48.-TRANSVERSE SECTION OF A CHICK EMBRYo WITH SEVEN SEGMENTS; TO SHOW THE BEGINNING OF THE FORMATION OF THE HEART. (After Minot.)

$M d$, medullary groove; $E c$, ectoderm; mes, mesenchyma; Am. ves, amniocardiac vesicle; $P h$, pharynx; $m$ sth, mesothelium; Endo, cells to form the rudiment of the endothelial heart.

length of the fore-gut (Fig. 50), which, in cross section (Fig. $48, P h$ ), is a shallow cavity, in a dorso-ventral direction; but is broad and crescentic, from side to side, with the convex side of the crescent downwards. 
Development of the Second Day 143

\section{The Heart}

During the first half of this day the heart makes its appearance as a sort of hollowing out of the mesoblast in the anterior end of the embryo, under the fore-gut (Fig. 48 , Endo). The walls of the heart consist of an outer muscular coat, formed of the splanchnic mesoblast, and an endothelial lining whose origin is said, by some, to be from the entoblast.

The heart consists, at first, of two longitudinal vessels, in contact anteriorly but diverging posteriorly, which together form a $\mathrm{V}$-shaped structure, with the point of the $\mathrm{V}$ towards the head of the embryo.

As development proceeds, the arms of the $\mathrm{V}$ fuse together, from before back, thus converting the $\mathrm{V}$ into a $\mathrm{Y}$, with the stem of the $\mathrm{Y}$ towards the head. The cavities of the two tubes that thus build up the heart are at first quite distinct, even after the two tubes have come in contact with each other: but they soon unite to form one cavity, the endothelial lining remaining as two distinct cavities for a short time after the muscular walls have fused. The muscular walls of the tubes are incomplete on the dorsal side, for a time, 


\section{4 \\ Vertebrate Embryology}

but after the fusion of the tubes the walls are completed.

The stem of the $\mathrm{Y}$, developed as above described, forms the heart (Fig. 49, C), while the diverging arms of the $\mathrm{Y}$ are continuous

$\checkmark$ with the large vitelline veins which bring the blood back to the heart from the vascular area (Fig. 49, VOM).

At the thirtieth hour, then, the heart is a short, straight tube which is attached to the ventral wall of the fore-gut or pharynx.

The point of divergence of the vitelline veins is at the hindermost angle of the headfold, and as the head-fold is pushed farther and farther back, the heart, or straight part of the $\mathrm{Y}$, is correspondingly lengthened. But the tubular heart seems to grow more rapidly than does the place to which it attached, with the result that it is bent into a loop, with the convexity of the loop to the right side of the embryo (Fig. 49, C). This looping of the $\checkmark$ heart is made possible by the fact that, while it was at first attached to the wall of the foregut throughout its whole length, it soon becomes detached from that wall for the greater part of its length, retaining its attachment only at the ends. The end of the heart into 


\section{Development of the Second Day 145}

which the vitelline veins empty may be called the venous, and the opposite, the arterial end.

Shortly after its appearance the heart begins to beat slowly, the pulsations starting at the venous and passing to the arterial end. This pulsation of the heart begins before there is any differentiation of its mesoblast into muscular tissue.

\section{Vascular System}

The anterior end of the heart, which may be called the bulbus arteriosus, branches immediately into two narrow vessels, or aortic arches, one of which passes upwards on each side of the digestive tract to its dorsal side, where it turns sharply towards the posterior again as the dorsal aorta. The two dorsal aortæ lie close on each side of the notochord and under the mesoblastic somites (Fig: 54, Ao). At this stage of development they remain entirely separate from each other and pass back, in the position mentioned, towards the tail. Before reaching the tail, however, each gives off a large branch, the branch, in fact, being larger than the aorta, from which it arises, known as the vitelline artery: these vitelline arteries 
146 Vertebrate Embryology

carry the blood back to the vascular area, whence it was brought, it will be remembered, by the vitelline veins.

The details in the development of the blood and the blood vessels have been differently described by different workers.

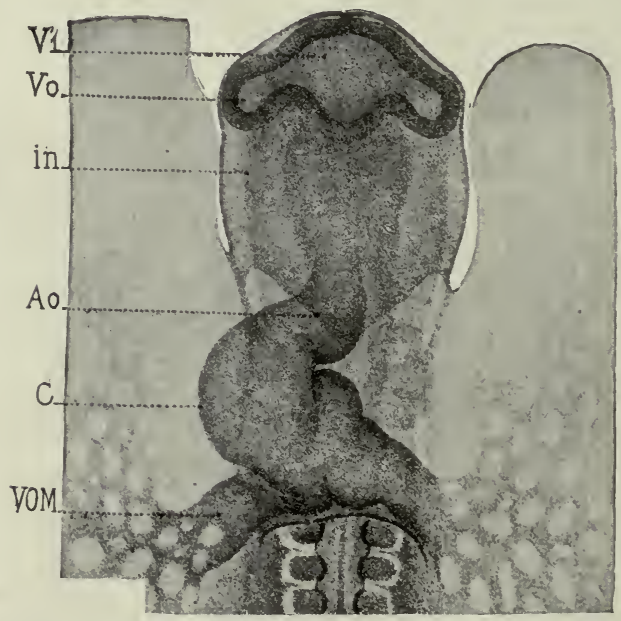

Fig. 49.-VENTRAL VIEW OF THE ANTERIOR REgion OF THE EMBRYO SHOWN IN Fig. 47. (After Duval.)

$A o$, bulbus arteriosus. $C$, heart, curved towards the right side of the embryo. in, lateral limit of the cavity of the pharynx. $V^{1}$, fore-brain. $V o$, optic vesicle. $V O M$, vitelline vein.

According to one view, the entire vascular system is derived from mesoblast; according to another view, the endothelial lining of the 
Development of the Second Day 147

veins and arteries and the entire wall of the capillaries are derived from the entoblast.

The first indication of the formation of the blood vessels is seen, on the first day, as a reticulated appearance in that part of the mesoblast surrounding the chick that has been called the vascular area. This network becomes more distinct during the second day, and begins to show irregular, reddish blotches, which are known as blood islands, because from their cells the blood corpuscles are formed. These changes take place in the splanchnic layer of mesoblast, which is separated, at this time, from the somatic layer by the extension of the body-cavity into the extra-embryonic area of the mesoblast.

The network is due to the development of what is known as the angioblast, which is a set of cells collected between the mesoblast proper and the endoderm. The cords of the angioblast are at first solid, but they soon acquire lumena, which, by becoming united, form a continuous though indefinite vessel. The first of these channels to take on a definite form and position is one that forms a sort of circular boundary to the entire vascular area and is known as the sinus terminalis (Fig. ${ }^{6}$ ). This 
indefinite network of blood vessels lies all in one plane, and the meshes are more or less filled with mesoblast cells.

The blood islands, which appear first in the area opaca but soon are found also in the area pellucida, are spots where there are collections of cells attached to the walls of the blood vessels. The development of hæmoglobin in these cells gives the reddish color that makes the blood islands so conspicuous in surface views of fresh specimens. The development of the blood islands is more marked around the caudal end of the embryo.

Soon after the blood vessels have become hollow, the blood islands, which in cross section appear as local thickenings usually of the dorsal walls of the vessels, bud off cells into the cavity of the blood vessels; these cells form the first blood corpuscles. It is from these primitive corpuscles, according to a commonly accepted hypothesis, that all of the colored corpuscles of the body are descended. They are at first characterized by the possession of a rounded nucleus, with a distinct nucleolus and a very small amount of protoplasm. After being set free in the lumen of the blood vessel the protoplasm of each cell increases, 
Development of the Second Day I 49

and the cells soon begin to multiply rapidly by mitotic division.

The origin of the first white corpuscles is still uncertain. In the chick they do not appear until about the eighth day; and it seems probable that they have no real relationship to the red corpuscles. It is probable that they are of several kinds and have several distinct origins.

By the development of buds from the vessels already formed the vascular area continues to increase in extent. Some of these buds, during the second day, begin to grow towards and into the embryo, through whose tissue they work their way along certain prescribed paths. While this growth is going on, certain of the vessels increase in size and become arteries or veins, while other vessels remain small as capillaries. Certain of these larger vessels unite with the posterior end of the heart, which has already been formed and has begun to beat ; and other vessels unite with the anterior end to form the larger vessels of the arterial system. Since the heart has begun to beat, and the corpuscles have already been formed, the circulation is established as soon as the blood vessels become connected with the heart. 


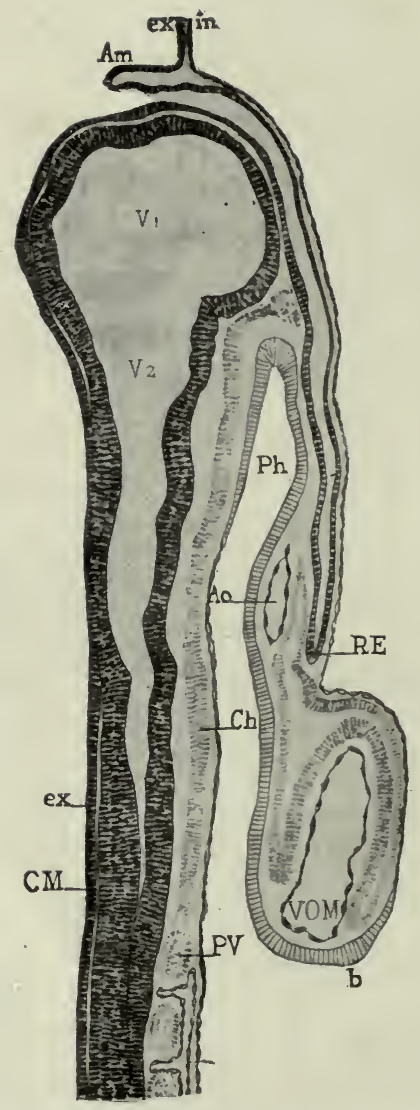

FIg. 50.-SAgitTAL SECTION OF THE EMBRYO REPRESENTED IN FIG. 47. (After Duval.)

$A m$, head-fold of the amnion. $A o$, aorta. $C h$, notochord. $C M$, medullary canal. ex, ectoderm. in, entoderm. Ph, pharynx or fore-gut. $P V$, mesoblastic somites. $R E$, posterior limit of ectoderm of head-fold. $V^{1}$ and $V^{2}$, fore- and mid-brains. $V O M$, venous portion of heart. 


\section{Development of the Second Day I5I}

The other embryonic vessels, at least their endothelial lining, are formed by buds given off from these first-formed vessels, just as happened in the case of the vessels of the vascular area.

The outer coats (media and adventitia) of the veins and arteries are formed by differentiation of the surrounding mesoblast.

\section{The Wolffian Duct}

The first indication of the uro-genital system in the chick, as in the frog, is the Wolffian duct.

It arises at this time, when the embryo has about ten mesoblastic somites, as a small ridge from the uncleft mesoblast that lies at the outer side of the last three somites. A cross section through this region of the embryo (Figs. 52 and 54) shows the Wolffian duct projecting, on each side, into the triangular space between the ectoblast above, the somite on the inside, and the somatic mesoblast on the outside. At this time it is merely a solid rod of cells, extending for two or three somites, and without a central lumen.

Summary - The most important changes of the first half of the second day are : 


\section{Vertebrate Embryology}

I. The fusion of the medullary folds throughout the greater part of their length to form the neural canal.

2. The dilation of the anterior. end of the neural canal to form the fore-brain, which, in

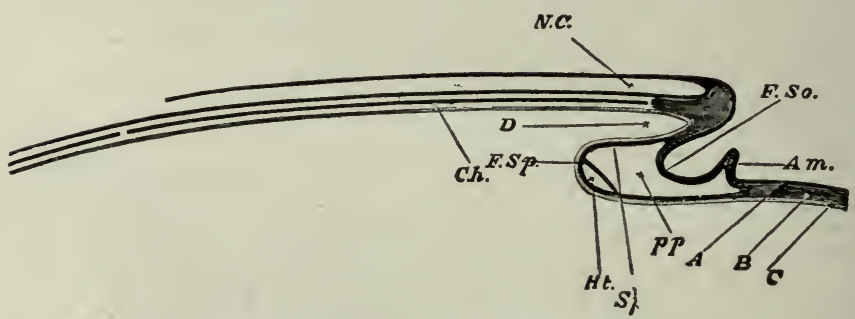

Fig. 50 (A). - Diagrammatic Representation of Fig. 50. (After Foster and Balfour.)

N.C., neural canal. Ch., notochord. $D$, commencing fore-gut or front part of the alimentary canal. $F$. So, somatopleure, raised up in its peripheral portion into the amniotic fold, $A m$. $S p$., splanchnopleure; at $S p$. it forms the under wall of the fore-gut : at $F$. $S p$. it is turning round to run forward; just at its turning-point, the heart, $H t$, is being developed. $\not p$, pleuroperitoneal or body cavity. $A$, ecto derm. $B$, mesoderm. $C$, entoderm.

turn, begins to push out on each side a hollow diverticulum, the optic vesicle; and the indication of the position of the mid- and hind-brain as slight enlargements of the neural canal behind the fore-brain.

3. The increase of the head-fold, and the elevation of the head above the level of the blastoderm.

4. The increase in the number of the mesoblastic somites. 


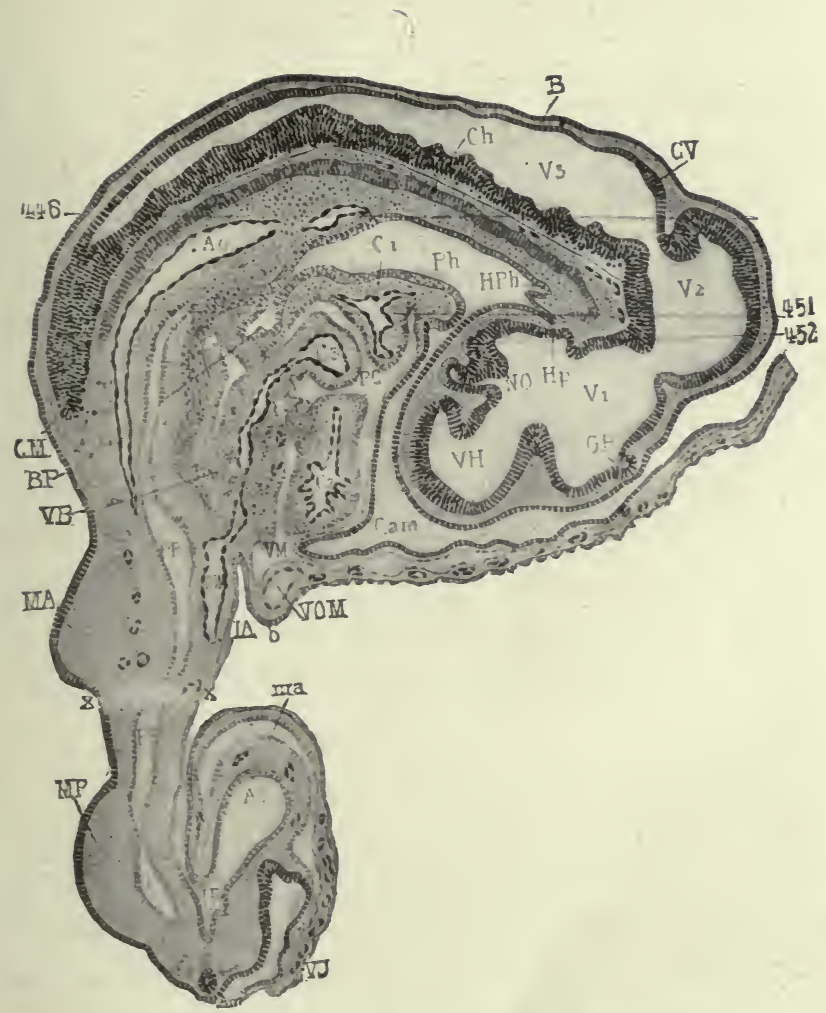

Fig. 51.-SAGITTAL SECTION OF AN EMBRYO CHICK OF 82 HOURS. (After Duval.)

$A l$, allantois. $A m$, amnion. $A O$, aorta. $B$, spinal canal, $B P$, lung. $C^{1}$, bulbus arteriosus. $C^{2}$, ventricle. $C^{3}$, auricle. $C a m$, bottom of head-fold. $C h$, notochord. $C M$, wall of neural tube, $C V$, cerebellum. $G P$, pineal gland. $H P$, hypophysis. $I A$, posterior end of fore-gut. $I P$, hind-gut. $M A$, rudiment of wing. $M a$ mesoblast of allantois. $P C$, pericardium. $P h$, pharynx. $P P$, body wing. $V^{i}, V^{2}$, and $V^{3}$ fore, mid-, and hind-brain. $V B$, liver. $V H$, cerebral hemisphere. $V J$, umbilical wall. $V O M$, vitelline vein. $x x$, place of interruption of section, part of the dorsal region being omitted. 


\section{I54 Vertebrate Embryology}

5. The formation of the tubular heart and of some of the blood vessels.

6. The appearance of the Wolffian duct, or, rather of a longitudinal rod of cells that will later become hollow to form the duct.

From the 36Th to the 48Th Hours.

During the second half of the second day the separation of the embryo from the yolk-sac becomes much more plainly marked. This is brought about by the formation of a tail-fold, similar to the head-fold, and of lateral folds (Fig. 38), so that by the end of this period, the whole outline is distinct, from head to tail.

The brain.-During this period the neural canal becomes entirely closed, even the sinus rhomboidalis being fused. The constrictions that mark off the anterior end of the neural canal into what we have called the fore-, mid-, and hind-brain become more evident, and before the close of the day the fore-brain begins to grow forwards as an unpaired vesicle which is the first indication of the cerebral hemispheres. The walls of the brain lie close under the ectoblast, but between the two is seen, in sections, a small amount of mesoblast which will form the skull. 


\section{Development of the Second Day 155}

The optic vesicles become considerably elongated and are constricted at their bases into stalks. Instead of projecting straight out from the sides of the fore-brain, they are now pressed downwards and backwards.

The crafial nerves make their appearance at the end of this period, but their development will be described later on.

Owing, probably, to the more rapid growth of the dorsal wall of the medullary canal, in the region of the mid-brain, the brain becomes bent downwards, around the anterior end of the notochord, at the end of this period, just as it did in the frog (page 36 ): this downward bending of the brain is known as cranial flexure (Fig. 51).

The notochord, whose origin during the first day has been described, is by this time a conspicuous cylindrical rod, lying under the medullary canal for the greater part of its length (Fig. 54).

The heart, by the end of this period, has become still more markedly bent and twisted, so that it is now somewhat S-shaped, with the venous end rather above and behind the arterial end. The venous and arterial ends have apparently come close together, with the inter- 
mediate portion hanging as a loop between them. The venous portion now forms a swelling on each side, the rudiments of the auricles, while the arterial end becomes enlarged to form the beginning of the bulbus arteriosus.

Som. W.D.Seg.Sp.c. N Ec. Mes.

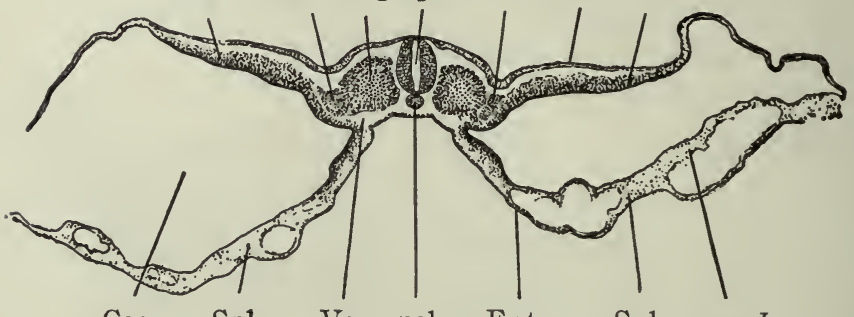

Coe. Spl. Ve. nch. Ent. Spl. mes. ${ }^{\text {I }}$

Fig. 52.-Transverse Section of a Chick embryo with about TWENTY-EIGHT SEgMeNTS. (After Minot.)

Coe, cœlom. Ec, ectoderm. Ent, entoderm. Mes, somatic mesoderm. mes, ${ }^{1}$ splanchnic mesoderm. $N$, nephrostome, nch, notochord. Seg, segment. Som, somatopleure. Sp.c, spinal chord. Spl, splanchnopleure. $V e$, blood-vessel. $W D$, Wolffian duct.

The point of the loop will develop into the ventricles (Fig. 57).

The vascular system.-A single pair of aortic arches has already been mentioned as extending from the bulbus arteriosus to the dorsal side of the digestive tract, where each one is continued to the posterior end of the embryo as a dorsal aorta. Before the end of this day $\checkmark$ the two dorsal aortæ unite, behind the head, 
Development of the Second Day 157

to form a single vessel lying just under the notochord (Fig. 7I, A O); but, after continuing for a short distance towards the tail, this single aorta again divides into two vessels, from each of which is given off the large vitelline artery "that has already been mentioned (Fig. 65). After giving off the vitelline arteries the dorsal aortæ continue, with greatly diminished calibre, to the tail.

A second pair of aortic arches is now formed behind the first, and even a third pair may be formed before the close of the second day, so that the front of the bulbus arteriosus is connected with the dorsal aortæ by two or three pairs of vessels (Figs. 65 and 76 ).

The sinus terminalis and the other vessels of the vascular area are now well developed, so that a real circulation of the blood is possible, which was not the case for a time, even after the heart had begun to beat.

The course of the circulation at the end of the second day is, then, somewhat as follows: the blood, after being brought back by the vitelline veins, is forced, by the contraction of the heart, through the aortic arches into the dorsal aorta: passing back through the aorta, a small portion goes into the tail of the embryo, 
I 58 Vertebrate Embryology

but the greater part passes out to the vascular area. The blood that goes to the vascular area through the vitelline arteries gets back into the vitelline veins in two ways: it may pass directly to the veins from the arteries through the connecting capillaries; or it may

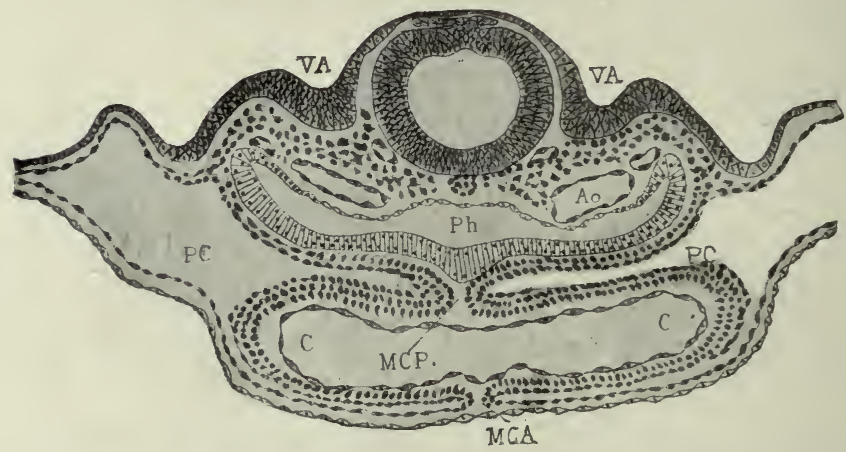

Fig. 53.-TRANSVERSE SECTION THROUGH THE HEART REgION OF AN EMBRYO OF 33 HOURS. (After Duval.)

$A o$, aorta. $C$, cavity of heart. $M C A$ and $M C P$, mesoblastic part of the heart. $P C$, pericardial region of body cavity. $P h$, pharynx. $V A$, auditory pits.

pass into the sinus terminalis, at a middle point on each side, and then pass through this large vessel both forwards and backwards: the larger part passes forwards until a point near the head is reached, when it is returned to the vitelline veins through two large parallel vessels. At this time the blood that flows towards the tail, in the sinus terminalis, is simply dis- 
Development of the Second Day 159

tributed to the vascular area in that region, as there is, as yet, no vessel connecting the posterior part of the sinus terminalis with the vitelline veins. These veins run parallel to and a little in front of the vitelline arteries. The course of the circulation at this time may be understood from Fig. 56, which is of a somewhat later period.

The Wolffian duct, during this period, continues to elongate both anteriorly and pos-

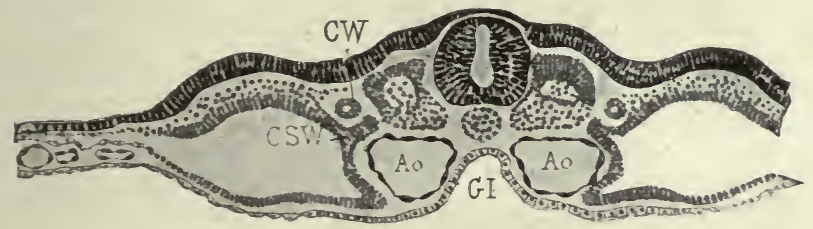

Fig 54.-TRansverse Section through the dorsal REgion OF AN EMBRYO OF 46 HOURS. (After Duval.)

$A o$, aorta. $C S W$, nephrostome of Wolffian body. CW, Wolffian duct. $G I$, alimentary canal.

teriorly, and its posterior end becomes free from the mesoblast and lies in the space between the ectoblast and mesoblast. A small lumen now appears near its middle point and gradually extends both forwards and backwards. At a later period (on the fourth day) the duct opens into the cloaca.

The Wolffian body makes its first appearance 
160

Vertebrate Embryology

on this day, but its development will be described at a later time.

The amnion usually makes its appearance during the second day, though, as has been noticed, it may sometimes be seen as a very small rudiment at the end of the first day.

As was stated in the summary of development, the head-fold of the amnion is the first to appear. The mesoblast in spreading does not extend into the region immediately in front of the head: this small area, which consists of but two layers, the ectoblast and the entoblast, is known as the pro-amnion (Fig. 46, pr. am), and it is in this place that the head-fold of the amnion is formed; therefore this head-fold is, for a time, made up only of ectoblast, but at a little later period the mesoblast extends into it, so that it, like the tail- and lateral-folds, is made up of both ectoblast and mesoblast. The actual method of development of the head-fold of the amnion was sufficiently described in speaking of the cloth model (page I I4), and attention may be again called to Fig. 38 .

By the end of this day, the head and neck of the embryo are covered by the amnion; the tail- and lateral-folds of the amnion are well started, but are not so far advanced in develop- 


\section{Development of the Second Day $16 \mathrm{r}$}

ment as the head-fold. As will be seen by examination of Figs. 37 and 38 , the space between the two layers of the amnion (dotted in
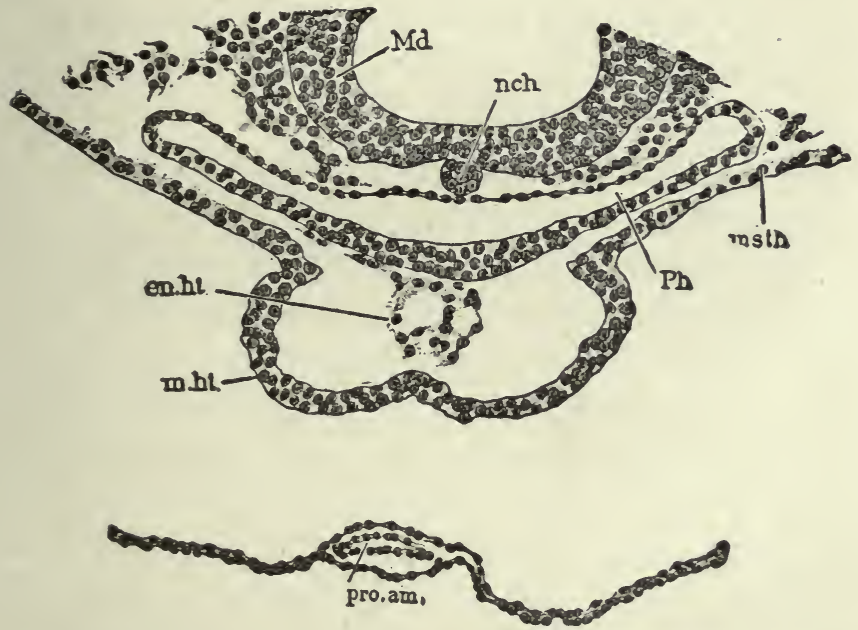

Fig. 55. - TRANSVERSE SECTION THROUgh A CHICK EMBRYO, TO SHOW A SLIGHTLY LATER STAGE IN THE DEVFLOPMENT OF THE HEART THAN IS SHOWN IN FIg. 48. (After Minot.)

$M d$, wall of medullary tube. $n c h$. notochord. $m s t h$, mesothelium. Ph. pharynx. pro. am, tip of pro-amnion. en.ht, endothelial heart. m.ht, muscular heart.

Fig. 37) is continuous with the body or pleuroperitoneal cavity.

The allantois may make its appearance before the close of this day, but it will be better to defer its description until the following day's development is discussed. 


\section{Summary}

The most important events of the second half of the second day are :

I. The change in shape and position of the optic vesicles.

2. The origin of the unpaired rudiment of the cerebral hemispheres from the front of the fore-brain.

3. The cranial flexure becomes visible.

4. The auditory pits become deeper and more pronounced.

5. The curvature of the heart increases and the rudiments of the auricles and bulbus arteriosus appear.

6. The head-fold advances rapidly and the tail- and lateral-folds make their appearance.

7. The circulation of the vascular area is definitely established.

8. The amnion covers the head and neck of the embryo, and its tail- and lateral-folds are well marked.

9. The first indication of the allantois is seen. 


\section{CHAPTER V}

THE DEVÉLOPMENT OF THE THIRD DAY

INCE there is no especial advantage in dividing the third day into two periods, as was done with the second day, it will be treated as a single period.

Of all the twenty-one days of the chick's embryonic development, the third is, perhaps, the most eventful in the number of structures that make their appearance.

There is a marked increase in the size of the embryo and of the blastoderm during this day, the blastoderm now covering about half of the surface of the yolk. There may also be noticed a corresponding decrease in the amount of the white of the egg, due either to its direct absorption by the blood vessels of the vascular area, or to the absorption of the yolk which is, in turn, replaced by the white.

The diminution of the white brings the vascular area close to the inner surface of the shell membrane, so that it is now possible for 
an aeration of the blood to take place, and the vascular area serves both as an organ of absorption and of respiration. In fact the vascular area, at this time, reaches its greatest activity, for while it may become greater in extent, it later loses the function of a respiratory organ (after the formation of the allantois), and serves, for the rest of the period of incubation, merely as an organ of absorption.

There are certain changes that take place in the vascular area during the third day. Owing to the growth of the embryo, the vitelline veins, which, during the second day, were some distance in front of the vitelline arteries, are brought nearer and nearer to these arteries until they lie so close to them that the two vessels can hardly be distinguished. During this day the sinus terminalis reaches its greatest functional activity. The bilood that empties into it from the vitelline arteries flows, as before, both forwards and backwards, that is, towards the head and towards the tail. The blood that flows towards the head usually gets back into the vitelline veins through two large vessels that lie parallel to the long axis of the embryo (Fig. 56) ; occasionally, however, there is only one of these vessels, the one which 


\section{Development of the Third Day 165}

empties into the left vitelline vein ; and in any case the left vessel is the larger, if two are present. The blood that flows backwards in each half of the sinus terminalis empties into a single posterior vessel, and through that is brought back to the left vitelline vein (Fig. 56). This posterior vessel, bringing blood from the hinder half of the sinus terminalis, was not present, it will be remembered, during the second day.

The folding off of the embryo from the yolk makes great progress, during this day, so that it is now more clearly outlined by the deepening of the head-, tail-, and side-folds, and is a tubular body or sac (embryo-sac) connected with the yolk-sac by a sort of wide stalk. By examining Fig. 38 , it will be seen that this stalk is a double tube; the inner tube or stalk is known as the splanchnic stalk, and is continuous with the now clearly defined digestive canal: the outer tube or stalk is the somatic $\checkmark$ stalk, and its cavity is continuous with the body-cavity, while its walls are a continuation of the somatopleure (study carefully Figs. 37 and 38 ).

A remarkable change in position takes place during this day. Up to the close of the second 
day, the embryo has been lying "face downwards " upon the yolk. During the third day, $\checkmark$ the embryo turns over until it lies on its left

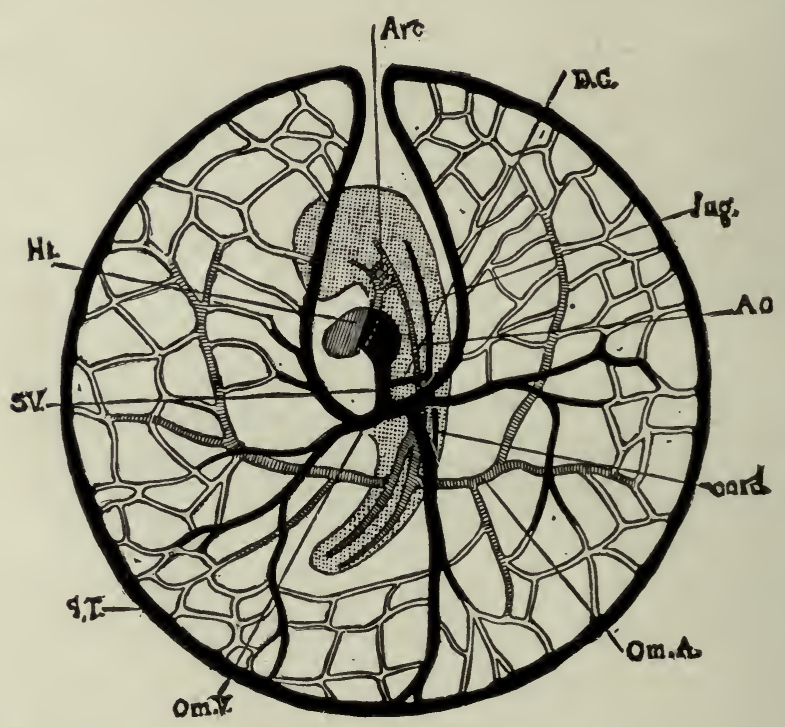

Fig. 56.-Diagram of the Circulation of a CHICK EMBryo. AT THE END OF THE THIRD DAY OF INCUBATION, AS SEEN FROM THF, UNDER SIDE. (After Minot.) The embryo, with the exception of the heart, is dotted; the veins are black.

Ao, aorta. Arc, aortic arches. card, cardinal vein. DC, duct of Cuvier. Ht, heart. $F u g$, jugular vein. Om.A, vitelline artery, $O m . V$, vitelline vein. $S T$. sinus terminalis. $S V$, sinus venosus.

side (Figs. 57 and 80). The head, which is the first part to be affected by this change, begins to turn early in this day, and by the 


\section{Development of the Third Day 167}

middle of the day the body is twisted so that, on looking down upon the embryo, the anterior end is seen in profile while the posterior end is still seen from the dorsal side (Fig. 57). By the end of the third, or early in the fourth day the embryó has completed the change in position. At the same time that the embryo is turning over to its left side, a marked curvature of the body begins and becomes so great, at a later stage, that the head and tail almost touch each other.

As the embryo turns to its left side, the vitelline vein of that side becomes much larger than the other vein, and the right vitelline vein dwindles in size and at last disappears.

The cranial flexure increases very markedly, during this period, so that the fore-brain now lies ventral to the hind-brain, and the midbrain is often the most anterior part of the head, along a straight axis through the centre of the embryo (Fig. 57).

The amnion.-As the amnion becomes practically complete during this day, its entire history will be given so that it need not be more than referred to again.

At the end of the second day, it will be remembered, the head-fold of the amnion covered 
the head and neck of the embryo, while the tail- and lateral-folds had started to develop, but were not nearly so far advanced as the head-fold. By the end of the third day, the different folds of the amnion have met, and covered all of the embryo except a small spot at the posterior end. During the fourth day the amnion becomes complete and entirely covers the embryo (Figs. 37 and 57). As the head-, tail-, and side-folds of the amnion meet, their outer layers all fuse together to form a continuous sheet, the outer or false amnion (the serous membrane); while the inner layers fuse to form the inner or true ammion (Fig. 38). Between the inner and outer layers of the amnion is a space, continuous, as has been said, with the body-cavity, into which the allantois, presently to be described, grows.

The space between the true amnion and the embryo is the amniotic cavity; and in it is soon developed a watery fluid, which is, at first, very small in quantity, but which later increases enormously.

Up to the fifth day, the amniotic cavity is very small, so that the true amnion invests the embryo quite closely; but during the later days of incubation, the amniotic fluid becomes 


\section{Development of the Third Day 169}

so abundant that the embryo can move freely in the amniotic cavity; and a rocking motion is given the embryo by the contraction of muscle fibres that are developed in the amniotic membrane. What the purpose of this rocking motion may be is not easy to say, but the chief object of the amsion and its contained fluid is probably for the protection of the soft and delicate embryo.

The amnion is not really a part of the embryo proper, and is left in the shell at the time of hatching. It is a very characteristic structure in the development of the three higher groups of Vertebrates,-Reptiles, Birds, and Mammals.

The allantois.-Although the allantois originates during the second day and continues to increase in size throughout a greater part of the period of incubation, it will be convenient to describe its complete history at this point, so that it need be merely mentioned at subsequent periods. We cannot do better than quote at length from the account of the development of the allantois given by Marshall.

"The allantois is really an appendage of the alimentary canal, arising as an outgrowth of its ventral wall, in front of the cloaca; it is therefore lined by hypoblast, like all other outgrowths of the mesenteron, while the 
rest of the thickness of its walls is formed by the splanchnopleuric mesoblast.

"The allantois of the chick is homologous with the bladder of the frog. It differs mainly from this in the fact that, while arising in the same manner, it is not confined within the body of the embryo, but, growing rapidly, passes out beyond this as a thin-walled vascular sac (Figs. 38,72 , and 80 ), which spreads out in close contact with the inner surface of the egg-shell, and acts as the respiratory organ of the embryo during the greater part of its development.

"In the chick the allantois commences to form about the middle of the second day. At this time the tail fold is not yet established, so that the allantois (Fig. ${ }^{\mathrm{I}}$, Al.) appears at first as a pocket-like fold of the splanchnopleure, lying a short way behind the embryo, and with its cavity opening ventralwards.

"On the formation of the tail fold, early on the third day, the part ot the splanchnopleure from which the allantois arises becomes doubled forwards under the embryo to form the ventral wall of the gut, and the allantois now appears as a saccular depression of the ventral wall of the hind-gut (Fig. $38, \mathrm{C}$ ).

"During the third day the allantois increases considerably in size, projecting downwards and forwards, as a hollow, thick-walled bud from the ventral surface of the hind-gut, into the body cavity, or space between the somatic and splanchnic layers of the mesoblast. During the fourth day, by its further growth, the allantois passes out beyond the embryo, and turns up along its right side, into the space between the two layers of the amnion, which, from the mode of formation of the 


\section{Development of the Third Day 171}

amnion, is directly continuous with the body cavity of the embryo (Figs. $37, \mathrm{G}-\mathrm{K}$, and $38, \mathrm{C}$ ).

"On the fifth and following days the allantois grows rapidly; from the first it is very vascular, and the blood vessels now increase greatly in size; the arteries, which lie in its superficial layer, are derived directly from the aorta (Fig. 76); while the veins, V A, which lie in its inner or deeper layer, join the vitelline veins from the yolk-sac, and, passing through the liver, reach the heart. By the seventh or eighth day (Fig. $38, \mathrm{D}$ ) the allantois has spread all around the upper half of the egg, covering over the embryo, and extending half around the yolk-sac as well. It is still saccular, and its cavity contains fluid. Its outer wall lies in very close contact with the outer layer of the amnion, or false amnion, and soon fuses with this completely, so that from this time the allantois lies in close contact with the shell membrane.

"In its further growth the allantois does not follow the yolk-sac; but, keeping close to the egg-shell and carrying the somatopleure before it, it extends so as gradually to enclose the mass of white, which still remains on the under surface and near the small end of the egg. The allantois, about the sixteenth day, completely encloses this plug of white or albumen, and from this time the absorption of the plug proceeds rapidly, the albumen being apparently carried by the allantoic vessels to the embryo, and aiding in its nutrition.

"Towards the close of incubation deposits of urates occur in the cavity of the allantois, indicating that it serves as a receptacle for the excretory matters formed within the embryo itself, as well as a respiratory organ in the more restricted sense of the term. 
"Shortly before the time of hatching the allantoic vessels become constricted, by the closure of the body walls at the umbilicus.

"The allantois itself shrivels up, and is cast off as the chick works its way out of the shell."

In the highest group of Vertebrates, the Mammals, the allantois becomes developed into a structure known as the placenta, by which the embryo is attached to the parental uterus, and through which it receives nourishment from its mother.

The allantois, then, like the amnion, is an extra-embryonic structure, and is cast aside at the time of hatching.

The brain.--Since the limits of this book will permit the discussion of only the most important points in the development of the brain, and since the development of the important features in the chick is essentially the same as in the frog, the reader is referred to the first $\checkmark$ part of this book (pages $3 \mathrm{I}-40$ ) for a description of the development of the brain. There are some points of difference which might be mentioned; for example: the cerebellum in $\checkmark$ the frog remains very small and inconspicuous throughout life, while in the chick it eventually becomes very large, though for the first part of 


\section{Development of the Third Day ${ }^{173}$}

the period of incubation it is as small, relatively, as in the frog; again: the olfactory lobes in the frog are at first separate, but later fuse together, while in the-chick they remain distinct throughout life. There are differences, of course, in the relative sizes of the various parts of the two brains, but, as has been said, the main features in development are essentially the same in the two forms, and a more detailed description, if desired, may be found in larger works.

The peripheral nervous system.-In the development of the cranial and spinal nerves there is such close resemblance between the frog (page 40) and the chick that but little need be said at this place. They arise (the cranial nerves, perhaps, a little earlier than the spinal) during the latter part of the first or the early part of the second day (Fig. 53), before the medullary folds have fused together along the mid-dorsal line. As in the frog, there are many points in the development of the peripheral nervous system that are still under discussion.

The sympathetic nevvous system. - The origin of the sympathetic nervous system in the chick has been the subject of much debate. It is 
probably derived from the spinal nervous system, and is hence merely a specialized part of that system. According to this view it originates as a series of outgrowths from the spinal ganglia, which outgrowths extend inward until they nearly reach the dorsal aorta: at their inner ends they become enlarged to form the sympathetic ganglia, and these ganglia send out processes which fuse to form the longitudinal commissures.

\section{The Development of the Sense Organs}

The development of the sense organs, the eye, ear, and nose, though, in most respects, similar to the development of the same organs in the frog, will be described in more detail than was done in connection with the frog.

The eye.-Although it begins in the early part of the second day and is not completed until late in the period of incubation, it will be most convenient to describe the entire development of the eye at this point, rather than wait until the development of the following days is discussed. In any case, the greater part of the changes here described take place before the end of the third day. 


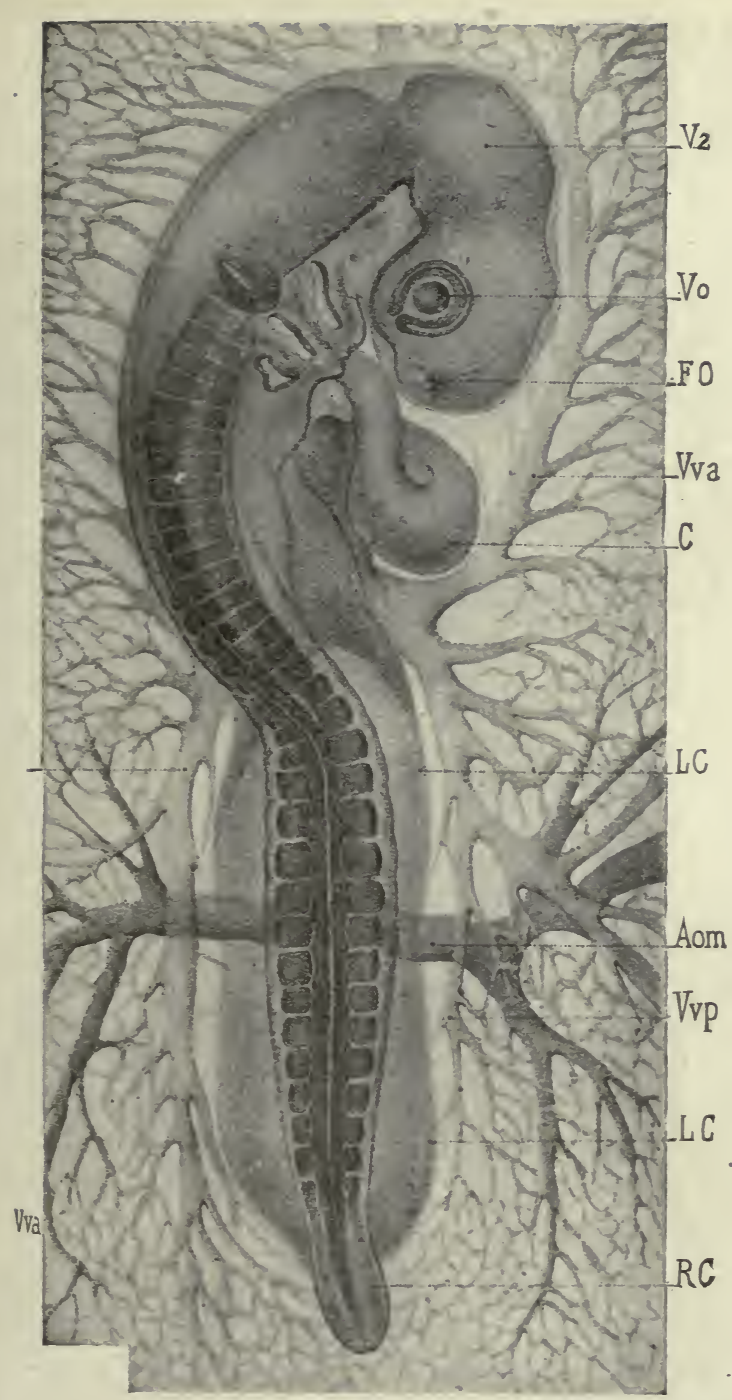

Fig. 57.-SuRface view OF AN EMbryo OF 52 HOURS. (After Duval.)

$A o m$, vitelline artery. $C$, heart. $F O$, olfactory pit. $L C$, lateral limits of body. $k^{\prime} C$, tail. $V^{2}$, mid-brain. $V v a$ and $V v p$, anterior and posterior branches of the vitelline vein. $V_{0}$, eye. 
As has already been described, the first indication of the formation of the eye is seen on the second day, when the optic vesicles are pushed out from the sides of the fore-brain. By the end of the second day these vesicles are very prominent, and are constricted at their bases to a narrow stalk, known as the optic stalk (Fig. 6o, O S). The optic stalk is hollow and connects the optic vesicle with the lower part of the fore-brain. At the end of the second day, a slight thickening is seen in the superficial ectoblast at the nearest point to the outer wall of the optic vesicle (Fig. 59, L). This is the first indication of the lens. This thickening becomes pitted in to form, by the fusion of the lips of the pit, a closed sac (Figs. 59, L, and 6o; L), the lens vesicle. The lens vesicle, during the third day, separates from the superficial ectoblast, and the latter becomes again a continuous layer (Fig. 6o, L). The outer wall of the lens vesicle, after its separation from the ectoblast, remains thin; while the inner wall becomes thicker and thicker, by the growth and elongation of its constituent cells, until, on the fourth day, it comes in contact with the thin front wall and entirely obliterates the cavity of the vesicle. 


\section{Development of the Third Day 177}

While the cells of the inner wall are elongating until they form what might almost be called

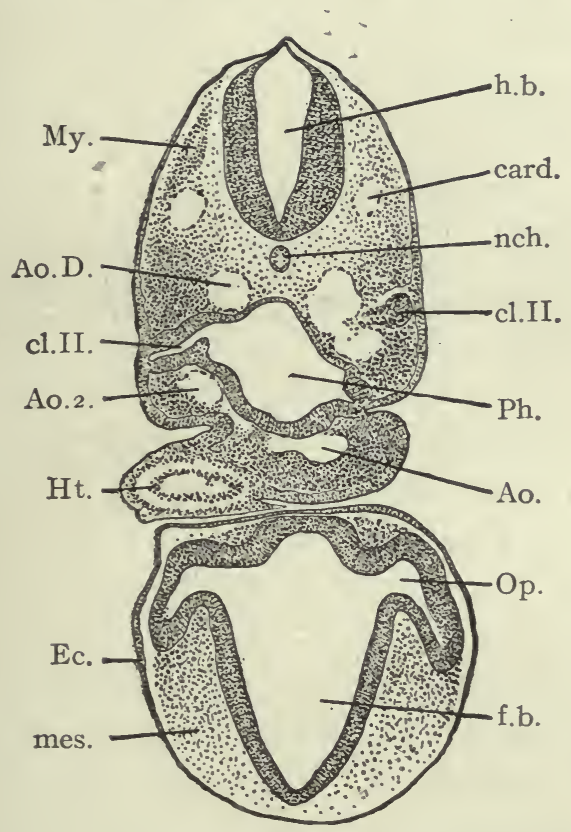

Fig. 58.-TRANSVERSE SECtion THROUGH THE ANTERIOR REGION OF A CHICK EMBRYO WITH ABOUT TWENTYEIGHT SEGMENTS. (After Minot.)

Ao., trunk of the aorta. Ao.D., descending aorta. $A o 0^{2}$, second aortic arch. card., anterior cardinal vein. cl.II., second entodermal gill-pouch. Ec., ectoderm. $f . b$., fore-brain. $h . b_{\text {. }}$, hind-brain. $H t$, heart. mes., mesoderm. My., muscle plate. nch, notochord. $O p$, , optic vesicle. Ph., pharynx.

fibres, the cells of the outer wall, except at the periphery of the lens, where they become con- 
tinuous with the cells of the inner wall, are becoming flatter and flatter, until they form a mere membrane: this membrane forms the epithelial lining of the lens capsule. The lens capsule is probably a cuticular membrane secreted by the epithelial cells of the lens vesicle, though it has been held, by some, to be of mesoblastic origin.

As the ectoblast thickens to form the lens vesicle, the optic vesicle becomes invaginated, from the side next to the lens vesicle, just as a hollow rubber ball might be pushed in on one side with the finger (Figs. 59 and 60). The invaginated optic vesicle is now known as the optic cup, o c, and consists, naturally, of two walls: of these walls, the inner soon becomes the thicker, and this inequality in the thickness of the two walls becomes greater as development proceeds. The two walls of the optic cup gradually approach each other until they meet and thus obliterate the cavity of the original optic vesicle (Fig. 60).

The lips of the optic cup lie close to the circumference of the lens, and by their growth the depth of the cup is constantly increased. This growth of the lips of the optic cup takes place at all points except one : at a point near 


\section{Development of the Third Day 179}

the optic stalk the lips do not increase in height, and a cleft or fissure, the choroid fissure (Fig. 64, O H), is left at that place. The exact method of formation of the choroid fissure is not easy to determine. The invagination of the optic vesicle to form the optic cup may be partly caused by the mechanical pushing inward of the lens, but it is probably also caused by the unequal growth of the walls of the vesicle. In a similar manner the unequal growth of the lips of the cup may cause the formation of the choroid fissure ; but there is some evidence to show that the fissure may be, in part, the result of the growth of the fibres of the optic nerve. The choroid fissure is a very transient structure; by the sixth day its edges have met, and shortiy afterwards they fuse, so that by the ninth day no trace of the fissure remains.

The inner wall of the cup, which is the thicker almost from the first, by the third day consists of elongated, nucleated cells arranged in a single row perpendicular to the surface of the cup. The thickness of this inner wall continues to increase, and by a process of histological differentiation that is difficult to follow, it is converted into the retina. The outer 
wall of the optic cup becomes thinner, as the inner wall increases in thickness, until it is re-

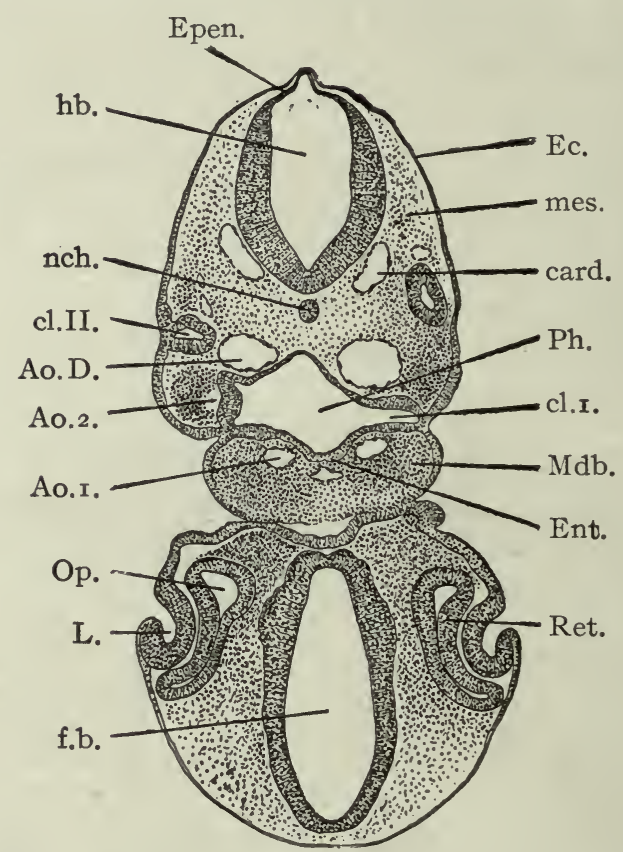

Fig. 59.-Transverse Section through the ANTERIOR REGION OF A CHICK EMBRYO WITH ABOUT TWENTYEIGHT SEGMENTS. (After Minot.)

Ao.D., descending aorta. Ao. ${ }^{1}$, first aortic arch. $A o .^{2}$, second aortic arch. card., anterior cardinal vein. cl $I$., first gill cleft. $c l . I I$., second gill cleft. $E_{c}$., ectoderm. Ent., entoderm. Epen., roof of hind-brain. $f . b$., fore-brain. $h . b$., hind-brain. L., invagination of lens. Mdb., mandibular arch. mes., mesoderm. nch., notochord. Op., optic vesicle. Ph., pharynx. Ret., retina.

duced to a single layer of flattened cells which soon become darkly pigmented, and form the 


\section{Development of the Third Day i8I}

layer of pigmented cells that lies close to the outer ends of the rods and cones. The whole of the sensory part of the retina is, therefore, derived from the inner layer or wall of the optic cup.

It is sometimes stated that the optic nerve is formed by the hollow stalk of the optic cup; but it is probable that it is formed by an outgrowth of cells from the retina, this outgrowth extending along the optic stalk to the brain, and forming the fibres of the optic nerve. The growth of these fibres may have, as has been mentioned, something to do with the formation of the choroid fissure.

The choroid and sclerotic coats are formed from a layer of condensed mesoblast that collects around the optic cup: and an ingrowth of mesoblast, through the choroid fissure, is converted into the vitreous humor.

The retina does not, of course, cover the entire inner surface of the optic cup. The edges of the optic cup, beyond the limits of the retina, form a part of the iris. In this region the two layers of the cup completely fuse, and their cells become deeply pigmented. Fusion now takes place between this layer of pigmented cells and the choroid layer that has 
formed outside of it, and, by the inward growth of what we may now call the iris, the opening of the optic cup is reduced to a small circular opening, the pupil.

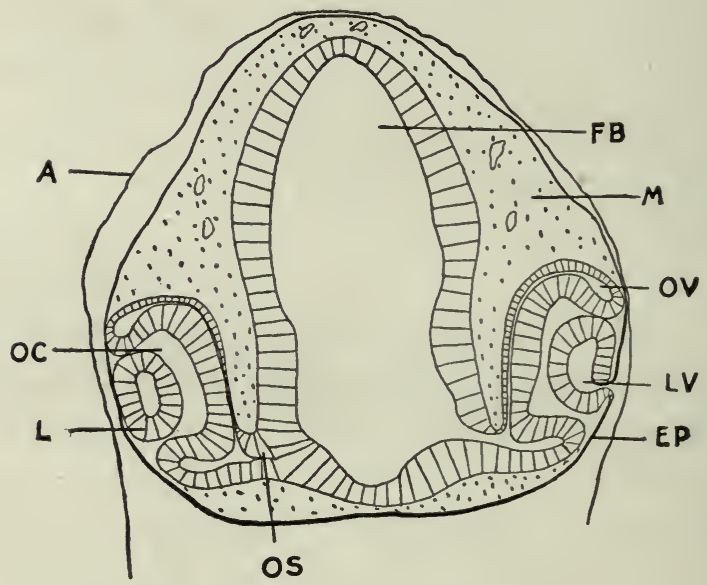

Fig. 6o. - Transverse SeCtion through THE ForeBRAIN OF A CHICK OF 50 TO 60 HOURS' INCUBATION. To illustrate the formation of the optic cup, lens vesicle, etc.

$A$, the amnion. $E P$, superficial ectoblast, $F B$, cavity of the fore-brain. $L$, Lens. $L \dot{V}$, lens vesicle. $M$, mesoblast. $O C$, cavity of the optic cup. OS, stalk connecting the optic cup with the forebrain. $O V$, remains of the cavity of the original optic vesicle.

The pecten originates as a vascular tuft of mesoblast which grows into the cavity of the optic cup through the choroid fissure, near the origin of the optic stalk. It is first seen at about the fifth day, and by the tenth day it 
Development of the Third Day 183

becomes folded to form the fan-like structure of the adult pecten. Before the time of hatching it becomes deeply pigmented. The pecten is a structure characteristic of the eyes of birds and of many reptiles : its exact function is not known with certainty (Fig. 6I).

The cornea, which is apparently simply a continuation of the sclerotic coat, is made up of mesoblast which grows in between the lens and the superficial epithelium. It is, at first, structureless, but certain of the mesoblast cells become converted into the corneal corpuscles. These corpuscles form a layer in the middle part of the thickness of the cornea, while the inner and outer surfaces remain structureless and form the anterior and posterior membranes. The layer of surface epithelium persists as the conjunctival epithelium.

The anterior chamber of the eye forms between the lens and the cornea, and in this chamber the aqueous humor collects.

"The eyelids are folds of integument around the eye; there are three of them, an upper and a lower eyelid, and the third eyelid or nictitating membrane which arises on the inner or nasal side of the eye. The lacrymal glands are solid ingrowths of the conjunctival epithelium, which appear on the eighth 


\section{I84 Vertebrate Embryology}

day. The lacrymal duct is also at first solid: it appears as a ridge of epidermis, along the line of the lacrymal groove, extending from the eye to the olfactory pit. This ridge sinks into the mesoblast, and soon splits off from the epiblast for a greater part of its length, but remains attached at its ends to the

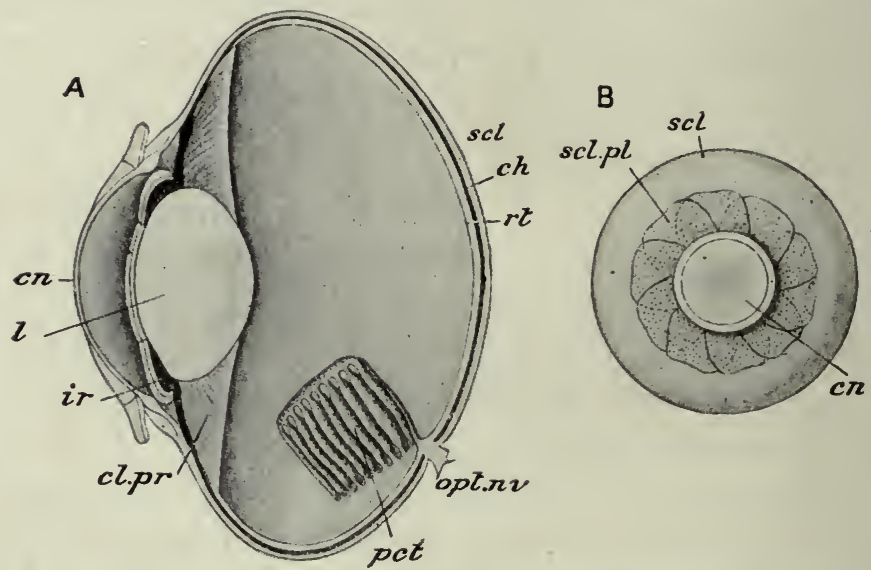

Fig. 6r.-The eye of a bird (Columba livia). $A$, in sagittal section ; $B$, external view of entire organ. (After Parker and Haswell, from Vogt and Yung.)

$c n$, cornea. ch, choroid. cl.pr, ciliary process. ir, iris. l, lens. opt.nv, optic nerve. pct, pecten. $r t$, retina. scl, sclerotic. scl.pl, sclerotic plates.

lower eyelid and to the wall of the olfactory pit respectively. About the twelfth day it acquires a central lumen, and becomes the tubular duct."

The ear. The ears begin about the middle of the second day, as has been mentioned, ${ }^{1}$ Marshall. 


\section{Development of the Third Day 185}

as a pair of small pits pushed in from the surface ectoblast, in the region of the hind-brain, (Fig. 47, $V A$ ). These auditory pits rapidly deepen and, by the end of the third day, they close together and become entirely separate from the surface ectoblast which fuses over them so that they are not visible from the surface (Fig. 62, Ot.d.). These closed cavities, lined with epithelium, are the auditory or otic vesicles and from them, by a process of twisting and unequal growth, the membranous labyrinths of the ears are formed. The ends of the auditory nerves very soon come in contact with the epithelial linings of the auditory vesicles, and by the early part of the third day they have fused with them. The places where this fusion occurs will be subsequently developed into the special patches of sensory epithelium found in the adult ear.

The development of the tympanic membrane, tympanic cavity, and Eustachian tube will be described in another place, when the fate of the gill arches and clefts is described.

It will be remembered that the auditory vesicle in the frog was formed from the inner or nervous layer of epithelium, and that the vesicle was never open to the 


\section{86 \\ Vertebrate Embryology}

exterior; while in the chick the entire thickness of the epithelium is involved in the

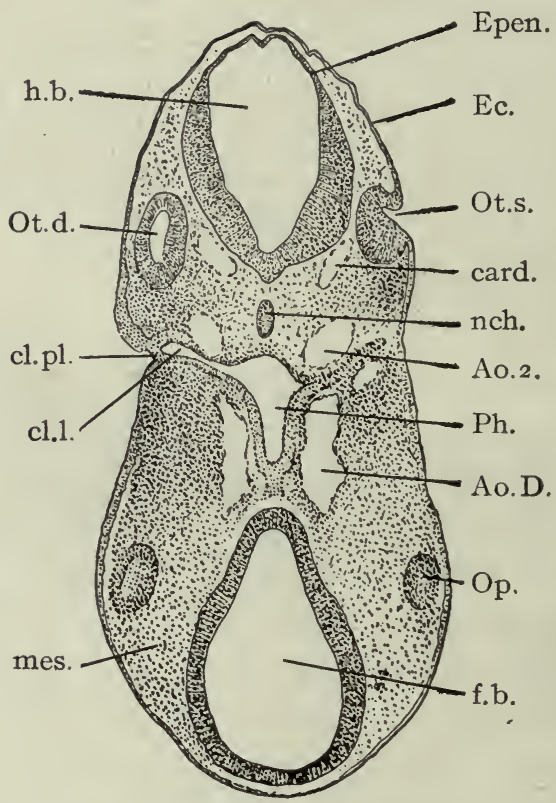

Fig. 62.-TRANSVERSE SECtion THROUGH THE ANTERIOR REGION OF A CHICK EMBRYO OF ABOUT TWENTYEIGHT SEGMENTS. (After Minot.)

$A o . D$., descending aorta. Ao.2, second aortic arch. card., anterior cardinal vein. cl.pl., closing plate. $c l . l$, first gill pouch. $E c_{\text {. }}$, ectoderm. Epen., roof of hind-brain. f.b., fore-brain. $h . b$, hindbrain. mes., mesoderm. nch., notochord. Op., optic vesicle. Ot.d., right otocyst (ear vesicle). Ot.s., left otocyst. Ph., pharynx.

formation of the auditory pits, and after the pits become closed to form the vesicles 


\section{Development of the Third Day 187}

the superficial epithelium once more becomes continuous.

The nose. The olfactory organs begin, in the early part of the third day, as two thickenings of epithelium on the under side of the fore part of the head. These thickened patches soon become pushed in to form pits, the olfactory pits, and the olfactory nerves very early fuse with the inner walls of the pits. The olfactory pits are formed in the same way as are the auditory pits and the pits that form the lens vesicles of the eyes, but while the lens and auditory pits become closed completely, the olfactory pits remain permanently open to the exterior as the external nares or nostrils (Fig. 64, OK).

The epithelial lining of the olfactory pit becomes folded and wrinkled to form the sensory epithelium of the nose. The posterior nares, or the opening of the nose into the back part of the mouth, is a distinct formation, and appears, about the beginning of the fourth day, as a groove leading from the nasal pit to the outer and anterior angle of the stomodæum. This groove, lying between the fronto-nasal process (the 
triangular part of the face, between the two nasal grooves) and the maxillary arch (forming the upper jaw), becomes deeper, and, during the fifth day, is converted into a closed tube, by the fusion of its edges, the above-mentioned fronto-nasal process and maxillary arch. The groove is thus converted into a tube leading from the nose into the front part of the mouth cavity. By the forward growth of the beak, and the formation of a horizontal septum, the palatine bone, the opening of this tube, the posterior nares, comes to lie in the back rather than in the front part of the oral cavity (Fig. 64.) In the development of the sense organs, the eye, ear, and nose, there are many points in common, but it should be especially noted that in all three of these organs the essentially sensory parts, in each case, are derived either directly or indirectly from the ectoblast.

The Visceral Clefts and Arches. Owing to the unequal rates of growth of the different parts of the chick, the relative positions of the various organs are constantly changing. During the second day, it will be remembered, the heart was formed in the mesoblast, under the anterior end of the digestive tract or mes- 
Development of the Third Day 189

enteron (Fig. 49, C). During the third day the heart has shifted its position so far to the rear that there is a distinct space between it and the now more sharply defined head (Fig. 57) : this space may be called the neck; in this region there has been no cleavage of the mesoblast, so that the three layers, the entoblast, mesoblast, and ectoblast form one continuous layer of tissue as we pass outwards from the fore-gut or pharynx to the exterior.

The entoblastic lining of the pharynx, during the latter part of the second or early part of the third day, becomes pushed out, on each side, as four narrow pouches, the visceral or gill pouches, similar to the five pouches that have been described (pages $5 \mathrm{I}$ and 52$)$ in connection with the frog.

The first three of these pouches, during the third and fourth days, open to the exterior, their entoblastic walls fusing with the surface ectoblast (Fig. 63, fb). Each gill, branchial or visceral cleft, as it is variously called, is an actual, narrow chink opening from the anterior end of the digestive tract to the exterior. Owing to the curvature of the neck, the clefts are not parallel to each other, but converge slightly towards a point 


\section{Vertebrate Embryology}

ventral to the middle part of the neck (Fig. 72). Although the visceral clefts may be seen, without difficulty, in favorable whole mounts of chicks of the proper age, they are quite small, and show better in horizontal sections (Fig. 63), or in chicks that have been dissected so as to lay open the cavity of the pharynx.

There has been considerable discussion in regard to the visceral clefts, some workers holding that none of the clefts actually open to the exterior; but it seems fairly certain that all of the clefts normally open to the exterior, except the last or most posterior one. There is also some discussion as to the time of opening and closing of the branchial clefts: while there is probably a good deal of individual variation in this respect, it seems likely that none of the clefts open to the exterior before the early part of the third day, and that they have all closed before the beginning of the sixth day. It must not be forgotten that when we speak of the development of, say, the fifth day, we mean the average state of development reached by chicks during that number of days of incubation. 
Development of the Third Day igi

As in the case of the frog, the most anterior, and first formed gill cleft is called the hyomandibular cleft, while the others, from before back, are the first, second and third gill clefts. In the frog, it will be remembered, there were five pairs of visceral clefts. The fate of the visceral clefts will be discussed a little later.

The parts of the side walls of the pharynx between the gill clefts, and also the anterior border of the hyomandibular cleft and the posterior edge of the third or last cleft, become somewhat swollen and rounded, and are known as the gill arches. (Figs. 63, $A B$, 72). As in the frog, again, the first arch is known as the mandibular, the second arch as the hyoid, and the other arches as the first, second, and third.

In development and structure, then, the visceral arches and clefts of the chick and frog are essentially the same, except for the presence, in the frog, of an extra pair of arches and clefts, and of the gills which border the visceral arches of the frog, but are not present at any stage in the development of the chick. The presence in the chick of these fish-like though, to it, functionless 
structures is to be explained only by assuming that the birds are descended from aquatic and gill-breathing animals. The frog, being less distantly removed from the fish, or fish-like ancestors, still retains the gills in a functional condition, during the early part of its development.

Although the changes involved in the

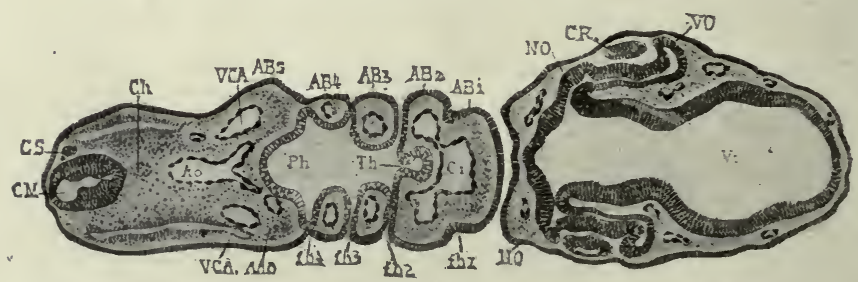

Fig. 63.-TRANSVERSE SECtION THROUGH THE ANTERIOR PART of AN EMBRyo of 68 HOURs. Owing to the curvature of the embryo the section passes through it twice. (After Duval.)

$A B B_{1-5}$, first to fifth branchial arches. $A A O$, aortic arch of the fifth branchial arch. $A o$, aorta. $C \mathrm{I}$, bulbus arteriosus. $C h$, notochord. $C . M$, medullary canal. $C R$, lens. $f b \mathrm{x}-4$, first to fourth visceral clefts. $G S$, spinal ganglion. $N O$, optic nerve. $P h$, pharynx. Th, thyroid gland. $V \mathrm{x}$, fore-brain. $V C A$, anterior cardinal vein. $V O$, optic cup.

ultimate fate of the visceral clefts and folds do not take place until a later period, it will be convenient briefly to describe those changes at this point, and then, perhaps, merely recall them to mind at the proper times.

As has been said, all four of the visceral clefts become closed, after a short time, so 


\section{Development of the Third Day 193}

that, as far as can be seen in surface views, they disappear. The first, second, and third clefts do, apparently, completely disappear and leave no trace in the adult; but the most anterior cleft, the hyomandibular, although, like the rest, closing at the outer end, does not close throughout its length, and retains its connection with the cavity of the pharynx. The exact changes that now take place are somewhat in dispute, but it seems reasonably certain that the inner, unclosed portion of the cleft forms an enlargement, at its outer end, which becomes the tympanic cavity, while the rest of the cleft persists as the Eustachian tube.

The external auditory meatus is built up as a short tube on the outside of the head, opposite the position of the tympanic cavity; it may be partially formed by a slight depression of the surface ectoblast. The layer of tissue, formed by the closure of the outer end of the hyomandibular cleft, which lies between the tympanic cavity and the external auditory meatus, becomes the tympanic membrane. It is evidently composed of three parts; an external layer of ectoblast, from the surface; an inner layer of entoblast, from 
the lining of the cleft; and a middle layer of mesoblast, from the uncleft mesoblast of the neck region. During a greater part of fotal life the tympanic membrane is very thick, and bears little resemblance to the structure in the adult.

The changes above described, like many others given in even so brief an account as this, can be made out only with great difficulty, so that the student who is just beginning the study of embryology will generally have to take such statements for granted.

The fate of the visceral folds should, perhaps, be discussed in connection with the development of the skeleton, but it will be convenient to take up the discussion at this point, along with that of the visceral clefts, with which they are so intimately associated.

The last two arches, the so-called second and third arches or folds, apparently entirely disappear and leave no trace in the adult.

Parts of the two arches in front of these, that is, the first visceral and the hyoid, become converted into the hyoid apparatus of the adult.

The first arch, the mandibular, is the most important, in regard to the adult structures 


\section{Development of the Third Day 195}

that are derived from it. The main branch of this arch, on each side, meets its fellow of the opposite side in the mid-ventral line, and fuses to form the basis of the mandible or lower jaw; hence its name, the mandibular arch (Fig. 64, MN). From the anterior edge of the dorsal end of each half of the mandibular arch a small branch grows forward and downward, during the fourth or fifth day (Fig. 64, MX), towards a triangular median process from the front of the head. This median process has already been mentioned, and is named, from the region of the head formed by it, the fronto-nasal process (Fig. 64, FP). The branches or processes from the mandibular arch are the maxillary processes, and from them the upper half of the jaw is formed. The two maxillary processes do not meet each other in the middle line, as do the two parts of the mandibular arch, but fuse with each side of the median frontonasal process, to form the upper half of the jaws.

The abnormality known as harelip, sometimes seen in human beings, is caused by the failure of one of the maxillary processes to fuse completely with the fronto-nasal 
I96 Vertebrate Embryology

process. The space between the mandibular arch behind, and the fronto-nasal and maxillary processes in front, will be the mouth of the chick.

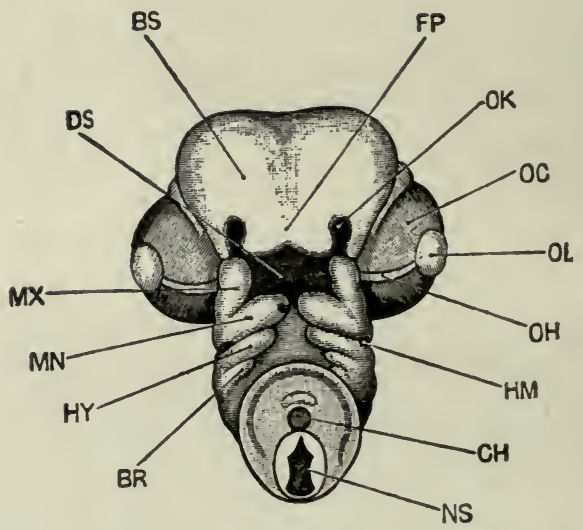

FIG. 64.-THE HEAD OF AN EMBRYO CHICK AT THE END OF THE FIFTH DAY OF INCUBATION ; SEEN FROM BELOW. (After Marshall.) Compare Fig. 72, $A$, for a side view of an embryo of about the same age.

$B R$, first branchial arch. $B S$, cerebral hemispheres. $C H$, notochord. $D S$, mouth. $F P$, fronto-nasal process. $H M$, hyomandibular cleft. $H Y$, hyoid arch, $M N$, mandibular arch. $M X$, maxillary arch. NS, spinal cord, seen in section where the neck has been cut across. $O C$, eye. $O H$, choroid fissure. $O K$, olfactory pit. $O L$, lens.

The relation of the parts, just described, to each other may, perhaps, be made more clear in the following way:-with the hands

- in front of the body, and pointing downwards, bring the tips of the fingers together, the fingers of each hand being slightly sepa- 


\section{Development of the Third Day 197}

rated. The thumbs should, at first, be closely pressed against the forefingers, and should be considered as fused with them. If the fingers and hands are slightly bent, there will be a space between the two hands that may be taken to represent the pharnyx of the chick, while the four fingers will represent the first four gill arches, and the spaces between the fingers will represent the first three gill clefts. The closure of the visceral clefts may be represented by bringing the fingers of each hand together. The forefingers, which should, in reality, be the only ones which actually meet in the mid-ventral line, will represent the mandibular arch, forming the lower half of the mouth. The formation of the maxillary arch, by processes budded out from the upper ends of the mandibular arch, may be represented by separating the thumbs from the forefingers, and pointing them towards each other, without letting them come in contact ; the triangular space between the thumbs, thus held, being filled, in the imagination, by the fronto-nasal process. The angles between the thumbs and the forefingers will represent the angles of the mouth. Of course, to make the comparison more striking, there 
should be one more finger, to represent the hindermost arch and cleft, but as the hinder arches and clefts form no part of the adult chick, this omission is of little consequence.

Further details in the building up of the face and head will be given later.

The vascular system. By the end of the second day, as has already been said, there are two or three pairs of aortic arches present, which carry the blood from the bulbus arteriosus around the pharynx to the dorsal aorta.

When, on the third day, the visceral folds and clefts become established, they bear a very definite relation to the aortic arches. The first aortic arch lies in the first or mandibular fold; the second arch lies in the second or hyoid fold; the third arch in the third fold, etc.; each arch lies in its corresponding fold (Fig. 63, $A B$ ), and is separated from the adjacent arches by the visceral clefts.

The heart, during this day, becomes still more twisted, and in cross-sections of the chick it is seen, usually, as two large cavities (Fig. 69, $C_{2}, C_{3}$ ) under the body of the dorsal region. It is relatively enormously large, and lies, as yet, entirely outside of the body-cavity (Fig. 57, C). The ventrally 


\section{Development of the Third Day 199}

projecting loop, the ventricular portion, is becoming more pointed, as the apex of the heart, and is separated by slight constrictions from the auricular region, on the one hand, and the bulbus, on the other. There is, at this time, no séparation of the heart into right and left sides.

The point at which the two vitelline veins unite to empty into the heart now becomes pushed farther towards the tail, so that, instead of these veins emptying simultaneously into the auricular portion of the heart, they first unite to form a large single vessel which then leads into the heart (Figs. 66 and $76, V E$ ). This single vein which brings all of the blood from the vascular area back to the heart, first through the two vitelline veins, and then, as the right vein dwindles and disappears, through $\checkmark$ the left vein only, is called the meatus venosus; the portion nearest to the heart being sometimes called the sinus venosus; and the part farther from the heart the ductus venosus.

The dorsal aorta now gives off numerous branches (Figs. 65 and 76 ) to various parts of the constantly enlarging embryo, and the blood that is carried away from the heart by these branches is brought back chiefly by two 


\section{Vertebrate Embryology}

large veins on each side of the body (Fig. 66, $J, C)$; these are the anterior and posterior cardinal veins; the anterior cardinals, as the name would suggest, bringing the blood back

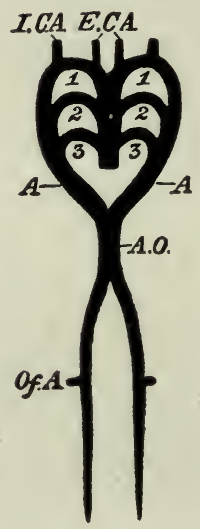

Fig. 65.-DiAgraM OF THE ARTERIAL CIRCULATION ON THE THIRD DAY. (After Foster and Balfour.)

$1,2,3$, the first three pairs of aortic arches. $A$, the vessel formed by the junction of the three pairs of arches. A.O., dorsal aorta, formed by the junction of the two branches, $A$; it quickly divides into two branches, which pass down one on each side of the notochord. Of.A., vitelline artery. E.CA., I.CA., external and internal carotid arteries

to the heart from head region, and the posterior cardinals bringing it back from the posterior end of the body. The anterior and posterior cardinal veins of each side unite to form a common vein that empties, at right angles, into the sinus venosus (Figs. 66, $d c$, 


\section{Development of the Third Day $20 \mathrm{I}$}

and $76, V D)$; this transverse vein is called the ductus Cuvieri, or Cuvierian vein.

In order to understand fully the evolution of the complex avian circulation from the simple and fish-like circulation of the embryonic chick, it is important that each stage in the development should be clearly understood. A brief description of the course of the circu-

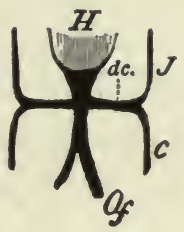

Fig. 66.-Diagram of the venous circulaTION OF THE THIRD DAY. (After Foster and Balfour.)

$H$, heart. $J$, jugular or anterior cardinal vein. $c$, inferior or posterior cardinal vein. $O f$, vitelline vein. $d c$, ductus Cuvieri.

lation of the blood at this period will, there. fore, be given.

The blood, on entering the heart, is forced, by the contraction of its walls, through this much-twisted but, as yet, undivided tube, to the bulbus arteriosus; from the bulbus it passes dorsalward, around each side of the pharynx, through the three pairs of aortic arches to the two dorsal aortæ which lie 


\section{Vertebrate Embryology}

above the pharynx, on each side of, or just below, the notochord. Through small arteries that are given off from the first aortic arch, or from the anterior ends of the dorsal aortæ (Fig. 65, I.CA, and E.CA), a small amount of blood finds its way into the head of the embryo, but the greater part of the blood passes posteriorly through the at first double and then single (Fig. 65) aorta; the single aorta soon becomes double again, as has been previously described, and through these two posterior aortæ the blood passes to the hinder end of the embryo. Only a small part of the blood is distributed to the hinder end of the embryo, at this period, however, the greater part passing to the vascular area through the two large vitelline arteries that are given off, one on each side, from the posterior paired aortæ (Fig. 65, Of.A). The blood from the vascular area returns, through the vitelline veins, to the meatus venosus, and thence to the auricular region of the heart. The blood from the anterior end of the embryo returns, by the anterior cardinal veins, to the Cuvierian veins, where it meets the blood from the posterior end of the embryo that has been brought forward to that point by the posterior car- 
Development of the Third Day 203

dinal veins. Through the Cuvierian veins or ducts the blood passes into the meatus venosus and thence into the heart.

The alimentary canal.-By the rapid folding off of the embryo from the yolk, during this day, the digestive tract becomes enclosed for the greater part of its length. As a matter of convenience, it is sometimes divided into three regions: the anterior end that is completely enclosed, having not only roof and sides, but also a floor, is known as the fore-gut; the middle region that is still open to the yolk, and consequently has roof and sides, but no floor, is the mid-gut; and the posterior region which, like the fore-gut, is completely enclosed, is the hind-gut.

As the closing in of the digestive tract continues, the fore- and hind-guts, of course, increase in length at the expense of the mid-gut until the seventh day, when the opening to the yolk is reduced to such a narrow opening that the mid-gut may be considered to have disappeared. At the end of the third day, the fore-gut about corresponds to what will be the œsophagus and stomach; the hind-gut will be the large intestine; and the mid-gut will form the small intestine. 


\section{Vertebrate Embryology}

Up to this time the alimentary canal lies very high up in the body-iavity, being separated from the notochord and the aortæ by only a broad, thin layer of mesoblast (Figs. 48, $\dot{P} h$ and 70). During this day, however, the digestive canal, for a greater part of its length, draws away from the upper side of the body-cavity, to which it remains attached by a constantly narrowing band of tissue, the mesentery (Figs. $7 \mathrm{I}$ and 73).

The mesentery is composed of mesoblast that is continuous with that which surrounds the entoblast of the digestive canal, and this mesoblast consists of an undifferentiated middle layer, in which the blood vessels are later developed, and a superficial layer of epithelium, continuous with the epithelial lining of the peritoneal cavity. In the anterior part of the fore-gut the withdrawal of the digestive tract from the notochord is very slight, as there is little or no development of the mesentery in the region of the œsophagus.

The anterior end of the œsophageal region is broadened out to form the pharynx, where the gill clefts are developed, as has been described. The hinder end of the œesophageal 


\section{Development of the Third Day 205}

region is smaller and more nearly round in cross-section, and is the œsophagus proper; its posterior limit is indicated by the position of the lungs, whose development will shortly be described. The fore-gut still ends blindly

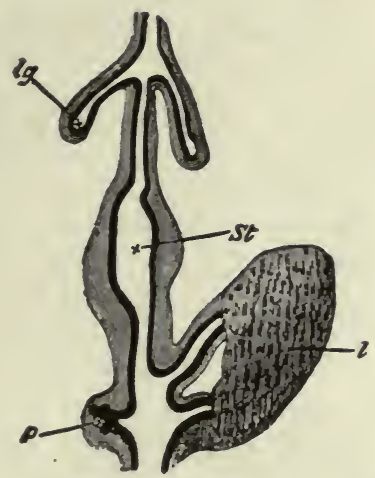

Fig. 67.-Diagram OF A PORTION OF THE DIGESTIVE TRACT OF A CHICK DUKING THE FOURTH DAY. (After Götte, from Foster and Balfour.)

The black inner line represents the hypoblast, the outer shading the mesoblast. lg, lung diverticulum. St, stomach. $l$, two hepatic diverticula with their terminations united by cords of hypoblast cells. $p$, diverticulum of pancreas.

in front, as the mouth has not yet been formed.

It might here be mentioned that, during the sixth day, the lumen of the œsophagus becomes completely closed for the greater part of its length, and remains closed for two or three days. Mention has already been made of 


\section{Vertebrate Embryology}

a similar closure of the œsophagus in the frog, and the same phenomenon is seen in other animals. In the chick the œsophagus gradually reopens, from behind forwards, at about the ninth day. What the significance of this curious fact may be is not known.

The part of the digestive tract behind the œsophagus becomes dilated, on the third day, to form the beginning of the stomach (Fig. 67, $S t)$; and the short space between the pyloric end of the stomach and the open mid-gut may

$\checkmark$ be recognized as the duodenum from the fact that there are seen, in this region, the beginnings of the liver and pancreas. The development of the latter two organs will be described a little later.

The posterior end of the digestive tract may be, for a part of the third day, connected with the neural tube by the narrow canal which was described in connection with the frog (p. 34), and was called the neurenteric canal. In front of the neurenteric canal is seen the beginning of the cloaca, as a small pittingin of the external ectoblast to meet the entoblast. This invagination of the ectoblast is known as the proctodaum, but it does not open into the digestive tract until several days 


\section{Development of the Third Day 207}

later (about the fifteenth day); so that the digestive tract now ends blindly at each end. The proctodæum in the chick is very shallow, and forms only the actual external opening of the cloaca.

$\mathrm{Up}$ to the sixth day, the digestive tract remains practically straight; - but after that time it begins to grow faster than the cavity in which it is contained, so that it begins to twist and form the loops characteristic of the adult intestines.

About the sixth day the gizzard is formed as a thick-walled outgrowth from the end of the stomach.

The lungs.-The first trace of the lungs is seen on the third day as two small, hollow outgrowths from the ventral side of the œsophagus near its anterior end (Fig. 67, lg). At the point of origin of these small pouches, the œsophagus becomes laterally constricted, so that in cross-section it is hourglass-shaped (Fig. 68). By the meeting of the lateral constrictions, the œsophagus is divided into two parts: the upper part, or cesophagus proper, and the lower part, into which the lung rudiments open, which will be the trachea. At the anterior limits of the lateral constrictions the 


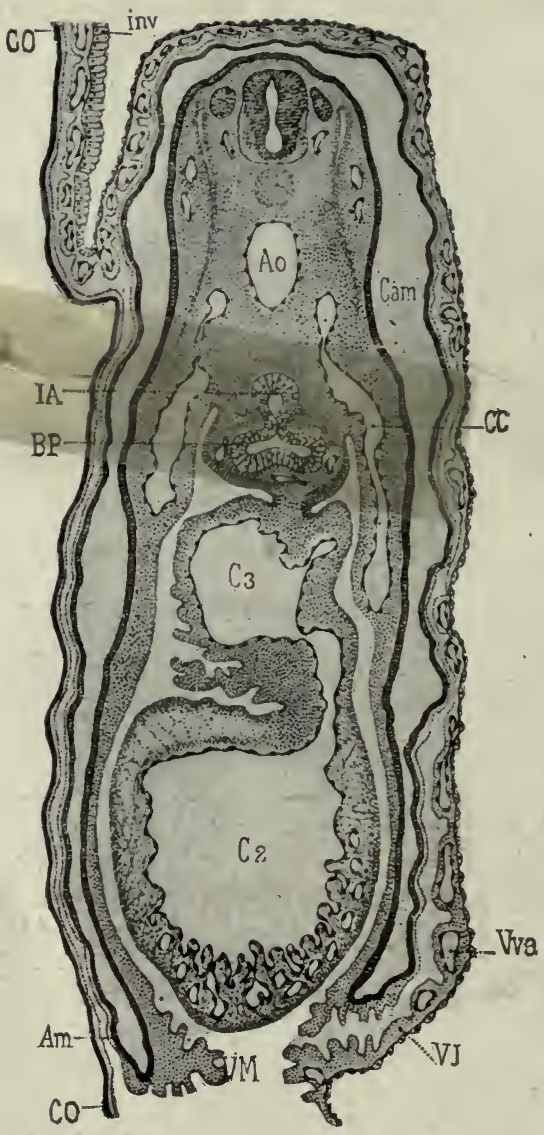

Fig. 68.-TRANSVERSE SECTION OF AN EMBRYO OF THE FOURTH DAY, PASSING THROUGH THE ANTERIOR PART OF THE LUNG RUDIMENTS. (After Duval.)

$A m$, amnion. $A o$, aorta. $B P$, bud of lung. $C_{2}$ and $C_{3}$, heart. $C C$, Cuvierian duct. $C a m$, amniotic cavity. $C U$, chorion. $I A$, fore-gut. $V v a$, anterior branch of vitelline vein. $V J$, wall of umbilical stalk. $V M$, mesoblast of pericardium. 


\section{Development of the Third Day 209}

trachea and œsophagus are continuous, and at $\checkmark$ this point will be the glottis.

As the two lung rudiments grow backwards, the mesoblast gradually collects around them as two lobes (Fig. 69, BP), and it is from the mesoblast of these lobes that the elastic, muscular, cartilaginous and other tissues of the lungs and bronchial tubes are formed. The epithelial lining of the lungs, down to the smallest air-cells, is formed by the continuous branching of the two original entoblastic outgrowths from the œsophagus; so that while the chief thickness of the walls of the lungs, as well as their blood vessels, is formed of mesoblast, the entire epithelial lining is of entoblastic origin.

"The air sacs, which are structures very characteristic of birds, appear about the eighth day as thin-walled saccular diverticula from the hinder edges of the lungs."

The liver.-The origin of the liver, as a median outgrowth from the floor of the digestive tract, was briefly described in the case of the frog: its development in the chick will be described more in detail.

"The liver arises, about the middle of the third day, 
as a tubular diverticulum from the posterior end of the fore-gut, in the angle between the two vitelline veins, and immediately behind their point of union. A second diverticulum arises from the same spot almost directly afterwards; it is similar to the first, but of rather smaller size. Both these diverticula have hypoblastic walls, with thin mesoblastic investments (Fig. 67, l).

"Towards the latter part of the third day, as the folding off of the embryo from the yolk-sac proceeds, the liver diverticula are found to arise definitely from the part of the mesenteron which will later become the duodenum. At the same time they come into very close relation with a very large median vein, the meatus venosus, which is formed by the union of the right and left vitelline veins behind the heart (Fig. 76, VE).

"The two liver diverticula lie one on each side of the meatus venosus, and in very close contact with this. The hypoblastic cells forming the walls of the diverticula now begin to proliferate freely, growing out as solid strands of cells, which form an irregular reticulum closely surrounding the meatus venosus; the meshes of the reticulum being occupied by capillary blood vessels, which develop in the mesoblast, and early acquire connection with the meatus venosus itself. These processes proceed rapidly during the fourth and fifth days, and by the end of the fifth day (Figs. 76 and 83 ) the liver is an organ of considerable size, consisting of a network of solid rods of hypoblast cells, which branch and anastomose freely in all directions; the meshes of the network being occupied by blood-vessels, which penetrate all parts of the liver, and are in free communication with the meatus venosus, round which the liver is formed. 


\section{Development of the Third Day 2II}

"The liver continues to grow rapidly, and by the tenth day is the largest organ in the abdominal cavity. The trabecular network of hypoblast cells becomes the liver parenchyma; the tubular diverticula from the duodenum branch out freely in the substance of the liver, and become the two bile ducts of the adult bird; while the gall bladder arises on the fifth day as a saccular outgrowth from the right or larger of the two primary diverticula.

"The early formation of the liver in the chick, and its large size during the greater part of the developmental history, indicate that it must be of considerable functional importance during embryonic life. Its relation to the blood system, and especially the fact that it intercepts the blood returning from the yolk-sac to the heart, suggest that its chief purpose is connected with the elaboration of food material which is obtained from the yolk-sac, and at the expense of which the nutrition of the embryo is effected."

The pancreas arises a little later than the liver, as a tubular diverticulum from the intestine just back of the liver (Fig. 67, p). A second diverticulum is formed at about the eighth day, and, still later, a third appears. These diverticula persist as the three pancreatic ducts of the adult, but the lobes with which they are connected fuse together.

The thyroid body.-At the close of the 1 Marshall. 
second day the thyroid body originates as a pit from the floor of the pharynx, opposite the first pair of visceral arches (Fig. 63, Th). This pit deepens and elongates, and gradually closes up, by the fusion of its sides, to form a solid rod of entoblast lying in a longitudinal position under the floor of the pharynx, just in front of the truncus arteriosus. By the sixth day, it separates from the pharynx, and lies freely in the mesoblast of that region. It now becomes bilobed, and the lobes send out solid rods of tissue, which become hollowed out to form the vesicles of the adult thyroid. The thyroid gradually shifts its position backwards, and becomes surrounded with a sheath of vascular connective tissue.

Changes in the mesoblast.-If a tranverse section through the middle region of a secondday chick be compared with a similar section of a chick at the end of the third day, a marked difference in the depth, in a dorsoventral direction, will be seen (Figs. 70 and $7 \mathrm{I})$. This increase in depth is due to three chief causes: to the greater slope of the sides, on account of the formation of the side folds; to the increase in the mesoblast between the notochord and the digestive tract; and to the 


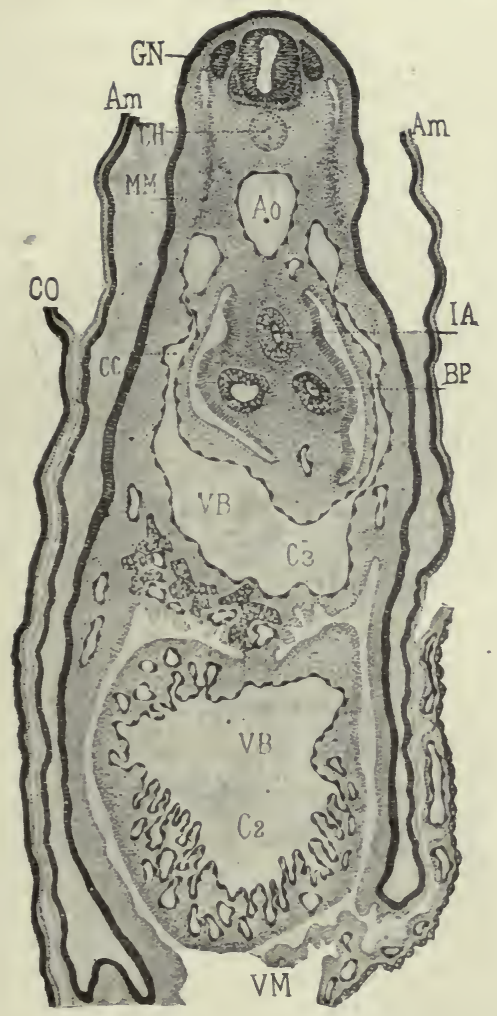

FIG. 69.-TRANSVERSE SECTION OF AN EMBRYO OF THE FOURTH DAY, JUST POSTERIOR TO THE PRECEDING. (After Duval.)

$C H$, notochord. $G N$, nerve ganglion. $M M$, muscle plate. $V B$, liver. Other lettering as in Fig. 68. 
changes that take place in the mesoblastic somites.

The formation of the mesoblastic somites has already been described, and it will be remembered that, at the end of the second day, they were more or less triangular masses of tissue, frequently with a small central cavity, probably a continuation of the bodycavity. Each somite now increases in depth, and its cavity, the myocoel, shifts its position until it lies in the upper part of the somite, instead of near the centre. Then the upper part of the somite, with the myocoel, separates from the lower part, and forms what is known as the muscle plate. The muscle plate consists of closely packed cells, while the lower part of the somite is made up of loosely arranged cells of the stellate form so characteristic of undifferentiated mesoblast (Fig. 48, mes). The muscle plates are, at first, nearly horizontal, with their inner ends slightly dorsal to their outer ends, but they become more and more steeply inclined until, at the end of the third day, they are almost vertical (Fig. 69, $M M$ ).

The cells of the ventral walls of the muscle plates become converted into bands of longitudinal muscle fibres, which bands remain di- 


\section{Development of the Third Day 215}

vided into blocks corresponding to the original somites: thus in the chick embryo we have a metameric arrangement of muscles similar to the arrangement of the muscles in the adult fish.

The outer end of the muscle plate rapidly

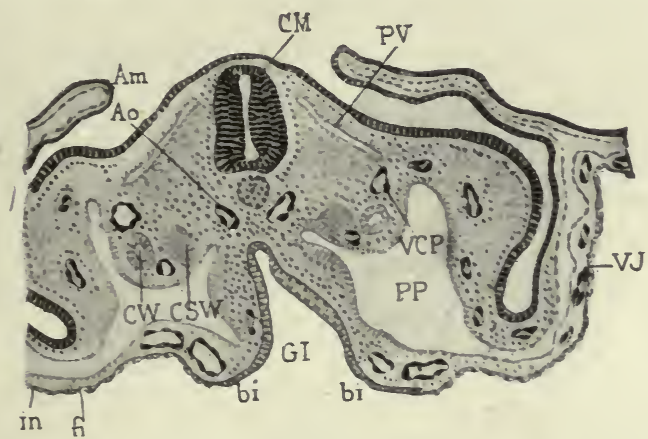

Fig. 70.-TRANSVERSE SECTION THROUGH THE DORSAL REGION OF AN EMBRYO OF 68 HOURS. (After Duval.)

$A m$, amnion. $A o$, aorta. $b i$ and in, hypoblast. $C M$, neural canal. $C W$. Wolffian duct. $C S W$, nephrostome, or segmental canal of Wolfian body. $G I$, alimentary canal. $P V$, muscle plate. $V C P$, posterior cardinal vein. $V J$, wall of umbilical stalk.

extends into the somatopleure, or body-wall, and becomes largely converted into muscle fibres from which the muscles of the back and trunk are formed. The median portion of the mesoblastic somite, left after the formation of the muscle plates, is converted, as will be described later, chiefly into the vertebræ. The 
origin of the muscles of the appendages is independent of the muscle plates.

The Wolffian body.-During the third day, the mass of mesoblast between the mesoblastic somites and the point of divergence of the somatopleure and the splanchnopleure, the intermediate cell-mass, becomes very prominent, and is covered with a sharply defined layer of epithelial cells (Fig. 54). The intermediate cell-mass is of importance because from it, or in it, are developed the urinary and reproductive organs. The development of the Wolffian duct has already been described. The origin of the Wolffian body, or embryonic kidney, of the chick will now be briefly outlined.

It will be recalled that, in the frog, the embryonic or temporary excretory organ was the head-kidney or pronephros; and that, as the Wolffian body or permanent kidney was developed, the pronephros gradually disappeared. In the chick, the embryonic kidney is the mesonephros or Wolffian body, and this ceases to function as an excretory organ shortly after hatching, and is replaced, in that capacity, by the metanephros or permanent kidney. The pronephros, in the chick, is an extremely 


\section{Development of the Third Day 2 I 7}

rudimentary structure, appearing after the formation of the Wolffian body, and disappearing again almost immediately.

There are, then, three pairs of excretory organs in the chick: the pronephros or head kidney, which never functions as a kidney, and which almost completely disappears very early in embryonic life; the mesonephros or Wolffian body, which develops sooner than the pronephros, attains a large size, and functions as the kidney during embryonic life ; and the metanephros or permanent kidney, which begins to develop quite early, but does not become functional until after hatching.

The Wolffian body extends for the greater part of the dorsal region of the embryo chick, as far back as about the thirtieth somite (Fig. 74). In its fully developed condition it consists of a mass of convoluted tubules, opening, at one end, into the Wolffian duct, and expanded, at the other end, into a $\mathrm{Mal}$ pighian body. The tubules of the anterior and posterior ends of the Wolffian body have different methods of development, and hence must be described separately. That part of the Wolffian body which lies anterior to about the sivscent? somite begins as a series 
of small pits or nephrostomes pushing into the mesoblast from the body-cavity, a little below and to the median side of the Wolffian duct (Fig. 54,CWS). Between the bottoms of these little nephrostomes and the Wolffian duct small twisted rods of cells appear which soon become hollow, and open into the Wolffian duct, at one end, and into the nephrostomes at the other. Thus, through these Wolffian tubules, the body cavity is brought into communication with the Wolffian duct. These tubules soon degenerate, and nearly all of them disappear completely.

The Wolffian tubules of that part of the Wolffian body that lies back of the sixteenth somite do not open into the body-cavity: that is, there are no nephrostomes. The tubules of this region begin as small vesicles in the mesoblast between the Wolffian duct and the body cavity. These vesicles become elongated to form the tubules, and, at their inner ends, acquire connection with the cavity of the Wolffian duct, while their outer ends become enlarged to form the Malpighian bodies. By the increase in the number of the tubules, and by the increase in the length of each tubule, causing it to become greatly 


\section{Development of the Third Day 2 I9}

twisted and convoluted, the Wolffian body becomes greatly enlarged, and causes the marked ridge that projects into the bodycavity on each side of the median line (Fig. 7I).

Owing to the above-described changes that

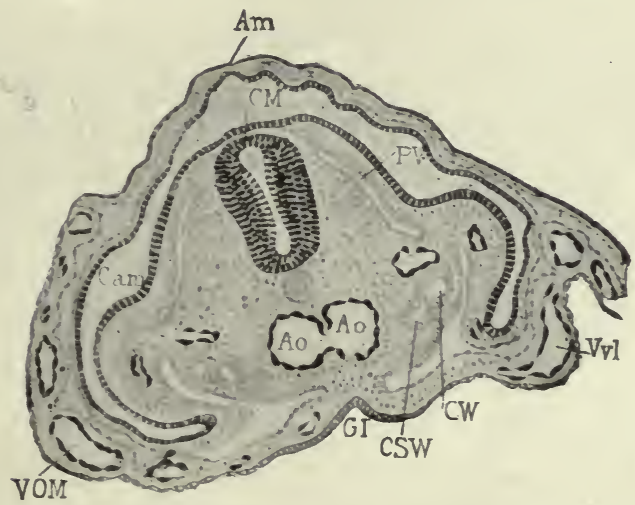

Fig. 71.-TRANSVERSE SECTION THROUGH THE DORSAL REGION OF AN EMBRYO OF 68 HOURS, A SHORT DISTANCE ANTERIOR TO THAT REPRESENTED IN Fig. 70. (After Duval.)

Cam, amniotic cavity. $V O M$ and $V v l$, vitelline veins. Other lettering as in Fig. 7 o.

have taken place in the mesoblast of the trunk, the position of the Wolffian duct is changed, during this day. Instead of lying close under the ectoblast as it did during the second day (Fig. 54, CW), it shifts its position downwards until it lies near the middle of the 
intermediate cell-mass, and may even project, somewhat, into the body-cavity (Fig. 7 I, CW).

The final fate of the Wolffian body, as well as the development of the pronephros and the metanephros, will be taken up later.

Summary of the third day :

I. Turning of the embryo to lie on its left side.

2. Increase of cranial flexure, and beginning of body flexure.

3. The formation of the four gill clefts and the five gill arches.

4. The completion of the circulation of the vascular area; the increased curvature of the heart, and the indication of its division into chambers; the appearance of new aortic arches, of the cardinal veins, and of the meatus venosus.

5. The formation of the optic cup.

6. The formation of the lens vesicle.

7. The formation of the nasal pits.

8. The closing in of the auditory vesicles.

9. The first indication of the cerebral hemispheres, and the separation of the hind-brain into cerebellum and medulla oblongata.

Io. The definite establishment of the cranial and spinal nerves. 


\section{Development of the Third Day $22 \mathrm{I}$}

I I. The formation of the fore-gut and hind-gut; and the separation of the former into œsophagus, stomach, and duodenum, and of the latter into large intestine and cloaca.

12. The formation of the lungs as diverticula from the œsophagus just anterior to where it enlarges to form the stomach.

I3. The formation of the liver and pancreas as diverticula from the duodenum, just posterior to the stomach.

I4. Formation of the muscle plates; and other mesoblastic changes.

15. Definite formation of the Wolffian bodies.

I6. Growth of the allantois.

I7. The completion of the amnion. 


\section{CHAPTER VI}

THE DEVELOPMENT OF THE FOURTH DAY

N opening an egg at the end of the fourth day of incubation (Fig. 72), one is struck with the increase in size of the embryo, which now, on account of the rapid absorption of the white of the egg, lies so close to the shell that the latter must be removed with some care, in order that the embryo may not be injured.

The germinal membrane now embraces about half of the yolk, and the vascular area is very prominent, though the sinus terminalis has already begun to diminish in distinctness.

The distinctness of the outlines of the embyro is somewhat obscured by the amnion, which now forms a complete covering over it. There is, as yet, very little fluid in the amniotic cavity, so that the inner amnion forms a very close investment of the embryo (Fig. 57).

The folding off of the embryo has continued, 
Development of the Fourth Day 223

until now the splanchnic stalk is reduced to a very narrow but distinct tube, connecting the yolk-sac with the nearly enclosed mid-gut. The somatic stalk has not progressed so far, so that there is a ring-shaped space between it and the splanchnic stalk: through this space projects the allantois, which is very much in evidence as a large, sac-like object, connected by a narrow stalk with the hind-gut, just in front of the well-developed tail (Fig. 72, $a l l$ ).

The cranial flexure increases to such an extent, during this day, that the front end of the head forms an acute angle with the neck and hind-brain; and by the increase of the body flexure as well, the outer curvature of the embryo forms almost a semicircle, and the forebrain and tail are only a short distance apart (Fig. 72).

The embryo continues to increase in depth (compare Figs. $7 \mathrm{I}$ and 73), and the muscle plates are now nearly vertical in position, and extend to about the point of separation of the somatopleure and the splanchnopleure. Just beyond this point of separation, the somatopleure is elevated to form a longitudinal ridge, on each side, known as the Wolffian ridge (Fig. 71). 
One of the most important and characteristic events of this day is the appearance of the appendages, the wings and legs. They are formed as local swellings or thickenings of the Wolffian ridge. Each limb consists of a core of compact mesoblast covered with a layer of ectoblast. The swellings that are to form the wings appear just back of the region of the heart, while the legs are formed just in front of the tail (Fig. 72, f.l and h.l). The limb buds are, at first, conical or triangular in outline, but they soon begin to differentiate, so that, by the end of this day, it may be possible to distinguish between the wings and legs by their shape as well as by their position; the wings being comparatively long and narrow, while the legs are short and broad.

The head.-The cerebral hemispheres (Fig. $5^{\mathrm{I},} V H$ ) are becoming very large compared with the thalamencephalon, $V_{I}$, from which they sprang; and the separation of the cerebellum from the medulla is becoming more marked. The mid-brain is now relatively larger than at any other time, and forms the large rounded protuberance at the angle of the cranial flexure (Fig. 72, m.br). The eyes are enormously large, compared with the size of the 


\section{Development of the Fourth Day 225}

embryo, and project strongly from the sides of the head. The mesoblast surrounding the brain is increasing in amount, and is beginning to show slight indications of the forma-

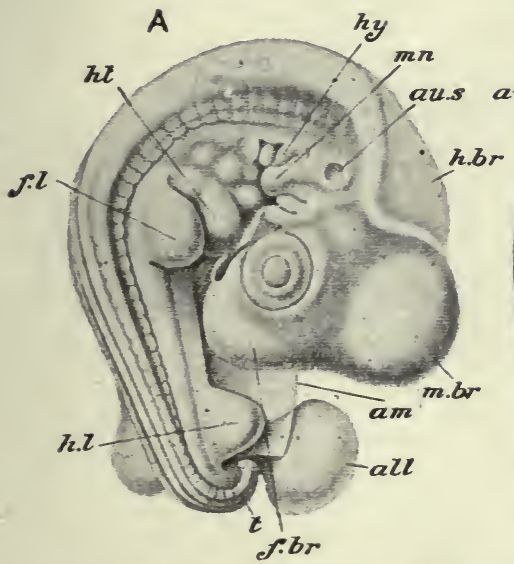

B

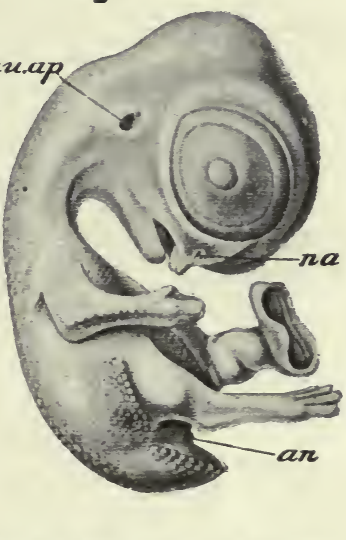

Fig. 72.-Two STAGES IN THE DEVELOPMENT OF THE CHICK EMBRYo. A, AT ABOUT THE FIFTH DAY OF INCUBATION; B, AT ABOUT THE NINTH DAY OF INCUBATION. IN A THE AMNION HAS BEEN ALMOST ENTIRELY REMOVEn, AND IN B ALL OF THE FCETAL APPENDAGES, EXCEPT A SMALL PART OF THE UMBILICAL STALK, HAVE BEEN REMOVED. (After Parker and Haswell, from Duval.)

all, allantois. $a m$, cut edge of amnion. $a n$, anus. $a u . a p$, auditory aperture. $a u . s$, auditory sac. $f . b r$, fore-brain. $f l$, fore-limb. h.br, hind-brain. $h . l$, hindlimb. $h t$, heart. $h y$, hyoid arch. $m . b$, mid-brain. $m n$, mandibular arch. $n a$, nostril. $t$, tail.

tion of the skull. All these changes begin to give the anterior end of the chick the appearance of a distinct head. The fronto-nasal process (page 195) begins to show prominently as an outgrowth from the fore part 
of the head, and the maxillary process of the mandibular arch is also becoming well developed (Fig. 64, $M X$ ). The nasal pit is deep, and is connected with the mouth invagination or stomodæum by the groove that will form the posterior nares, in the way described on page i 87 . The bottom of the stomodæum is now separated from the front end of the alimentary canal by only a thin partition, and, by the end of this day, this partition becomes perforated and puts the stomodæum into communication with the rest of the digestive tract. As the mouth is formed by the pushing in of the ectoblast in front of the anterior end of the pharynx, and by the upgrowth of the parts surrounding this invagination, it is evident that the buccal cavity must be lined with ectoblast instead of with entoblast, as is the rest (except the cloaca) of the digestive tract (compare with frog, page 46).

By gently pressing the head of the fresh embryo the cranial nerves and their ganglia may be seen, on each side of the auditory vesicles.

The vertebral column.-Although the formation of the vertebral column does not proceed very far during this day, it will be a convenient 
Development of the Fourth Day 227

place to describe the entire development of that important structure in more or less detail.

During the fourth day, the mesoblastic somites increase in number from about thirty to forty, and each somite has been divided, as has been explained, into an outer part, or muscle plate, and an inner part of less differentiated mesoblast from which the vertebral column will be developed. This mesoblast increases in amount, and by sending out processes both above and below the neural canal, and also below the notochord, these structures become completely surrounded by mesoblast, which, by the end of the fourth day, has acquired a considerable thickness, and is sometimes known as the membranous vertebral column. This membranous vertebral column still retains the tranverse lines of segmentation of the original mesoblastic somites. Early on the fifth day, however, these lines of demarcation disappear, and the mesoblast surrounding the neural canal and the notochord becomes a continuous tube. This does not apply to the muscle plates, which retain their original planes of segmentation.

During the fifth day, the mesoblast in immediate contact with the notochord becomes 
cartilaginous, and forms a continuous cartilagi. nous sheath around the notochord throughout its entire length. At the sides of the spinal cord there are formed paired bars of cartilage, which soon fuse with the cartilaginous sheath of the notochord, and form the rudiments of the neural arches.

Before the end of the fifth day, marked histological changes take place in the cartilaginous tube surrounding the notochord. Opposite the points of attachment of the neural arches the cartilage becomes more mature, while in the spaces between the arches it retains its embryonic character. In this way the cartilaginous tube, though still an unsegmented structure, is marked off into a series of vertebral and intervertebral rings; the vertebral rings being the parts to which the neural arches are attached, the intervertebral rings the parts between the neural arches.

About the end of the fifth day, each intervertebral ring becomes divided transversely into two equal parts, and each of these parts attaches itself to the adjacent vertebral ring. In this way, the once continuous cartilaginous sheath of the notochord becomes divided into a series of segments, each segment consisting 
Development of the Fourth Day 229

of a vertebral ring, with its attached neural arch, and the anterior and posterior halves, respectively, of the succeeding and preceding intervertebral rings. The segments so formed become the vertebre of the adult. The planes of this secondary or permanent segmentation, as it is sometimes called, do not correspond with the planes of segmentation of the mesoblastic somites, or the primary segmentation. The secondary segmentation takes place in such a way that the lines of separation between the newly formed vertebræ lie opposite the centres of the muscle plates. By this alternate arrangement of the muscle segments and the vertebral segments, each vertebra is acted upon, on each side, by two muscles, the preceding muscle being attached to the anterior half of the vertebra, the succeeding muscle to the posterior half. The advantage of this arrangement in producing motion or bending of the spinal column is too evident to need explanation.

Although the segmentation of the cartilaginous tube that surrounds the notochord has been called "secondary," it is really not secondary in the strictest sense of the word. This segmentation is concerned only with the 
vertebral column, not with the musculature, and before this segmentation takes place, the vertebral column is represented by the unseg. mented notochord.

Until about the sixth or the seventh day, the notochord is undiminished in size and of nearly uniform diameter throughout; but after that time it is constricted and encroached on, at regular intervals, by the growth inwards of the centra of the vertebræ, and it finally disappears, though a trace of it long remains, in the intervertebral regions, as the ligamenta suspensoria.

Ossification begins about the twelfth day, in the centrum of the second or the third cervical vertebra, and gradually extends backwards. The neural arches ossify a little later, and independently of the centra, each having two centres of ossification.

About the seventh day, the centrum of the first cervical vertebra, or atlas, separates from the rest of the bony ring, and becomes attached to the axis, of which it forms the odontoid process.

In the embryo of seven days there are present forty-five vertebræ, of which the hindermost five or six fuse, at a later period, to form the pygostyle. 


\section{Development of the Fourth Day 23I}

The notochord.-In connection with the development of the vertebral column, a few words should be said about the changes that take place in the notochord. The origin of the notochord, during the first day, as a longitudinal, rod-like thickening of the entoblast has been mentioned. It is at first a solid rod

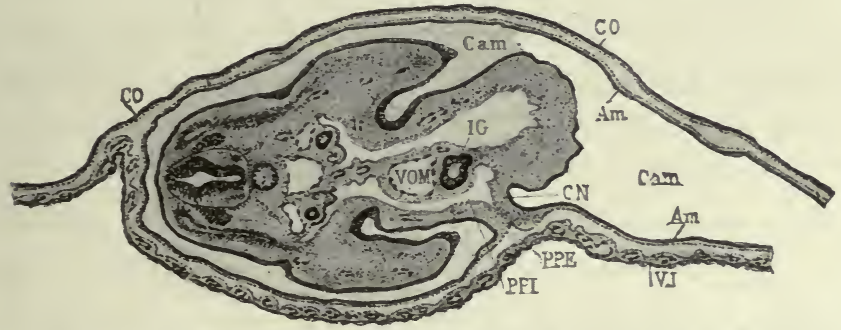

Fig. 73.-TRANSVERSE SEction THROUGH THE DORSAL REgION OF AN EMBRYO OF 96 HOURS. (After Duval.)

$A m$, amnion. Cam, amniotic cavity. CO, chorion. $I G$, alimentary canal. $P P E$, body cavity (external). $P P I$, body cavity (internal). $V J$, wall of umbilical stalk. VOM, vitelline vein.

of somewhat radially arranged cells, but during the third day some of the central cells become vacuolated, their protoplasm collecting as a thin peripheral layer, while a clear, apparently watery material, collects in the centre. In the peripheral layer of protoplasm the nucleus is seen.

Towards the end of the third day, a thin structureless sheath is formed around the 
notochord, probably as a product of the peripheral cells. During the fourth day, all the cells of the notochord become vacuolated, and the vacuoles continue to increase in size until, on the sixth day, they make up almost the entire cell, the protoplasm being reduced to an extremely thin wall around each cell; the nuclei are very indistinct if not quite invisible. Thus is the notochord converted into a spongy network, the fine meshes of the network being the remains of the walls of the originally solid cells (Figs. 55, nch, 73). The notochord reaches its greatest development on the sixth day; and after that time it is gradually encroached on by the growth of the vertebræ, as has already been described, until it finally disappears.

The notochord is the most characteristic structure of the great group of animals known as the chordata, being found in all representatives of this group, either during the embryonic period only, or throughout life. In the higher members of the group, as in the chick, it is a very prominent and characteristic embyronic structure, but disappears in the adult : in some of the lowest members of the group, as in the little fish-like Amphioxus, it persists 
Development of the Fourth Day 233

throughout life as the animal's "backbone" or primitive vertebral column.

The Wolffian bodies.-By the end of this day, the tubules of the anterior end of the Wolffian body have disappeared; but the tubules of the posterior end have increased in size, and become very much convoluted, so that the intermediate cell-mass, in which they lie, projects still more prominently into the body-cavity. In cross-sections of the chick, the convoluted Wolffian tubules are seen cut across at various angles : they may usually be distinguished from the Wolffian duct by the fact that their walls are made up of a somewhat thicker epithelium than that of the duct (Figs. 73 and 74). The glomeruli of the Malpighian bodies are usually seen, in crosssections, to be filled with blood corpuscles.

As has been said, the Wolffian body, or mesonephros, functions as the kidney during the greater part of the embryonic life of the chick, but disappears before hatching, or at least ceases to function, and is replaced by the permanent kidneys. In most of the fishes and amphibians the Wolffian body is the functional kidney throughout life.

The pronephros and the Müllerian duct.-" Towards 


\section{$234 \quad$ Vertebrate Embryology}

the end of the fourth day, three pit-like involutions of the peritoneal epithelium appear, one behind another, close to the outer side of the Wolffian duct, and three or four somites behind its anterior end (Fig. 74, M ). A ridge-like thickening of the peritoneal epithelium connects the three pits of each side with one another, and grows backwards behind the third pit as a solid rod of cells, lying along the outer side of the Wolffian duct, and very close to this. This rod soon becomes tubular, ending blindly behind, but opening in front into the body cavity through the three pits. These three pits form the head-kidney of the chicken embryo, and the tube into which they open is the commencement of the Müllerian duct. Towards the end of the fifth day the two hinder pits close up and disappear. The anterior pit persists, and forms the peritoneal opening of the Müllerian duct or oviduct. The Müllerian duct itself grows rapidly backwards; it lies in close contact with the outer wall of the Wolffian duct, and in its hinder part appears to be formed from cells derived from the wall of the Wolffian duct. About the end of the sixth day, the Müllerian duct has grown backwards as far as the cloaca. It remains blind at its hinder end in the male, but in the female opens, at a later stage, into the cloaca" 1

and becomes the oviduct. It is only on the left side of the female, however, that the Müllerian duct becomes the oviduct: on the right side it practically disappears, though a trace of it may persist in the adult. In the male 
Development of the Fourth Day 235

both Müllerian ducts degenerate and become almost completely obliterated.

The metanephros or permanent kidney.-The permanent kidneys begin to develop towards the end of the fourth day, in the mesoblast between the hinder end of the Wolffian body and the cloaca. The posterior end of the Wolffian body is in the thirtieth somite, while the cloacal opening of the Wolffian duct is opposite the thirty-fourth somite, so that there is a space of three or four somites between the two points; it is in this space that the first trace of the permanent kidney appears.

Like the mesonephros, the first part of the metanephros to be formed is its duct, the ureter. The ureter is formed as an anteriorly directed diverticulum from the dorsal side of the posterior end of the Wolffian duct. It grows forwards on the outer side of the mass of mesoblast that lies behind the Wolffian body, and, for a time, opens, as is evident from its method of formation, into the hinder end of the Wolffian duct: but on the sixth day it acquires a separate opening into the cloaca. From the ureter lateral outgrowths arise, and these, becoming connected with rods of tissue in the surrounding mesoblast, 
form the tubules and Malpighian bodies of the permanent kidney, very much in the same way that the tubules of the Wolffian body were formed.

The metanephros is very small, compared to the Wolffian body, during a large part of the period of incubation; but shortly before hatching, it increases rapidly in size, and grows forwards, dorsal to the Wolffian body. Before describing the origin of the reproductive organs proper, the ovaries and testes, it will be well to recapitulate briefly the changes undergone by the urinary organs in changing from the embryonic to the adult condition.

The Wolffian body, in the male, almost entirely disappears, but a small portion of it persists in the adult, chiefly as the epididymis. In the female a very small portion of the Wolffian body persists in the adult, as the parovarium, a body that lies in the mesentery between the ovary and the kidney. The Wolffian duct persists in the male as the vas deferens: in the female it disappears.

The head-kidney or pronephros is, in both sexes, a very rudimentary and transient structure, and leaves no trace in the adult.

The Müllerian duct never opens into the 
Development of the Fourth Day 237

cloaca in the male, and almost completely disappears in the adult. In the female, the right Müllerian duct becomes rudimentary, while the left duct becomes enlarged to form the oviduct, its peritoneal opening persisting as the funnel-1:ke opening of the adult oviduct.

The ureter in the adult of both sexes is formed as a narrow anteriorly directed diverticulum from the posterior end of the Wolffian duct.

The reproductive organs. - The collection of cells lying at the upper angle of the bodycavity and somewhat below and to the outside of the aorta (Fig. 73) has already been spoken of as the intermediate cell-mass; and it has been mentioned that by the fourth day this intermediate cell-mass projects, as a rounded ridge, into the upper part of the body-cavity, and may be now called the genital ridge, or Wolffian ridge. The term "genital ridge" is applied, by some workers, to the whole ridge that fills the upper angle of the body-cavity on each side: other authors use the term "Wolffian ridge" for the entire ridge, and restrict the term genital ridge to the inner part of the large ridge, next to the splanchnopleure, where the reproductive organs are 
actually formed. We shall use the term "Wolffian ridge" for the entire mass of mesoblast that projects into the upper part of the body-cavity, and that forms the externally visible ridge that has already been spoken of as the Wolffian ridge (page 223).

The whole Wolffian ridge is for a time covered evenly with a single layer of columnar epithelium, which may even extend, for a short distance, over the adjacent parts of the somatopleure and splanchnopleure (Fig. 70). The central part of the. Wolffian ridge is occupied by the Wolffian body and duct, and it is, in fact, the increase in size of the former that is the chief cause of the increase in prominence of the Wolffian ridge (Fig. 74). The epithelial cells covering this middle portion of the ridge rapidly lose their columnar character and become flattened. The cells of the outer part of the ridge, next to the somatopleure, retain for a longer time their columnar character, and it is here that the involution to form the Müllerian duct takes place.

At the inner angle of the Wolffian ridge, next to the splanchnopleure, the columnar cells, instead of diminishing in distinctness, become more distinct, and even become several layers 


\section{Development of the Fourth Day 239}

in depth. At the same time the mesoblast of that region becomes thickened to form a dense area under the epithelial cells (Fig 74, EE). This is the true genital ridge or sexual eminence, from which the ovary or testis will be formed.

Certain of the cells of the germinal epithe-

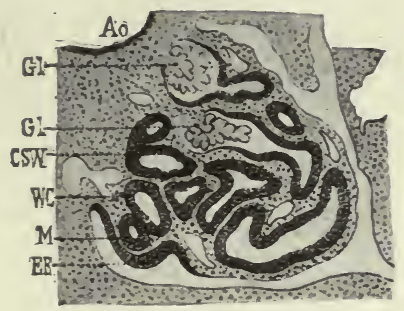

Fig. 74.-TRANSVERSE SEction through the WOLFFIAN BODY. (After Duval.)

$A o$, aorta. CSW, segmental tube, $E E$, germinal epithelium. $C l$, glomeruli. $M$, Müllerian duct. $W C$, Wolffian duct.

(The position of the Muillerian duct $(M)$ is apparently wrongly indicated in this figure. It should be on the outer side of the Wolffian duct.)

lium soon become distinguishable from the rest, on account of their greater size, more rounded outline, and large nuclei. These conspicuous cells, which have a common origin with the other epithelial cells of the genital ridge, are the primitive germ cells or gonoblasts (Fig. 74).

Up to this stage the development is the 
same in all embryos, whether male or female, and it is not at first possible to say whether the embryo will develop into a male or into a female.

In the female the epithelium increases enormously in thickness, and the cells of the thickened patch of mesoblast under it increase in numbers to form the stroma of the ovary. The primitive ova increase in size, and the smaller cells of the epithelium arrange themselves around each ovum as a sort of capsule, the follicular epithelium. Some of the ova sink down into the underlying mesoblast, which also sends processes up into the epithelium, and each ovum becomes surrounded by a vascular sheath of connective tissue; the ovum with its follicular epithelium and vascular sheath now constitutes a Graafian follicle.

It is only on the left side that the abovedescribed changes take place: the ovary on the right side of the chick remains in a rudimentary condition throughout life, or may disappear entirely.

The development of the testis is not so easily determined as that of the ovary. From the first, it is more closely associated with the Wolffian body. As the epithelium thickens, 
Development of the Fourth Day 24I

it forms into rod-shaped masses which are separated by septa of mesoblast derived from the patch of thickened mesoblast underneath. These rods of epithelial cells probably become converted into the seminiferous tubules, though the exact way in which this occurs is not clearly understood. The development of the spermatozoa (spermatogenesis) from the cells of the seminiferous tubules will be found described in larger books of embryology, or in text-books of histology.

The heart.- The heart undergoes some marked changes during this day (Fig. 75). The pointed loop which will form the apex of the ventricles still projects somewhat towards the right, but it is coming to point in a more ventral direction. Well-marked constrictions now separate the ventricles from the auricles, on one side, and from the bulbus, on the other (Fig. 75). Although there is no external indication of its formation; there is developed, during this day, an incomplete septum dividing the ventricle into two chambers. The septum being, as yet, incomplete the two chambers of the ventricle communicate freely with each other. The bulbus arteriosus and the auricles have increased in size, and the I6 


\section{Vertebrate Embryology}

latter now lie nearly as far forward as the ventricles. There is probably no division of the auricles into two chambers, though the external appearance would indicate such a division. This appearance is due to the great development of the auricular appendages. ${ }^{1}$

The vascular system.-Since, by the end of

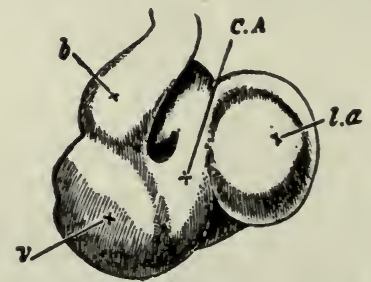

FIG. 75.- HEART OF A CHICK ON THE FOURTH DAY OF INCUBATION VIEWED FROM THE VENTRAL SURFACE. (After Foster and Balfour.)

l.a, left auricular appendage. C.A, canalis auricularis. $v$, ventricle. $b$, bulbus arteriosus.

this day, the vascular system reaches a state of considerable complexity, and since its further development is difficult to determine in the laboratory, it will be the best to give, at this place, the entire history of the vascular system, from the fourth day to the establishment of the adult circulation. The condition of the vascular system at the close of the

${ }^{1}$ Marshall states that the interauricular septum is formed on this day. 


\section{Development of the Fourth Day 243}

third day has already been described (pages 198-203).

The changes that take place in the arterial system will first be described, and then the changes that occur in the venous system. At the close of the third day, it will be remembered, three pairs of aortic arches had been formed, from before backwards, lying in the mandibular, hyoid and first viscal folds.

During the fourth day, two other pairs of aortic arches appear, in the second and third visceral folds. There are thus in the chick five pairs of aortic arches, corresponding to the anterior five of the six pairs found in the tadpole. But in the chick, there are no gill capillaries at any stage of development; and there is never any distinction between the afferent and efferent branchial vessels, the blood flowing through one continuous vessel from the truncus arteriosus to the dorsal aorta. The condition of the aortic arches in the chick embryo is more comparable to the condition in the frog after metamorphosis.

The main changes that convert the arteries of the embryo into the condition which they attain in the adult chick are the following: 
about the fourth or fifth day, the middle parts of the first and second, the mandibular and hyoid, aortic arches disappear. The lower ends of these two arches persist as the small mandibular or lingual arteries (Fig. 76, AL): while their upper or dorsal ends persist as the carotid arteries, each of which immediately divides into an internal and an external branch (Fig. 76, $A C$ ), the former going to the brain and the latter to the face.

By the sixth day, the ventricular septum is complete, and its front edge fuses with the hinder edge of the septum that divides the truncus arteriosus into right and left sides. The front edge of this latter septum arises between the fourth and fifth aortic arches in such a way that all of the blood that comes from the left side of the truncus arteriosus (and consequently from the left ventricle) passes into the third and fourth aortic arches; while the blood from the right ventricle passes into the fifth aortic arch.

About the seventh day, the right and left parts of the truncus arteriosus separate completely from each other, the right branch remaining in connection with the fifth aortic arch, as the pulmonary trunk; and the left 


\section{Development of the Fourth Day 245}

branch retaining its connection with the third and fourth arches, as the systemic trunk.

The dorsal communication between the third and forth aortic arches (Fig. 76) soon becomes obliterated; and the ventral ends of the third arches become converted into the subclavian arteries, which carry blood to the anterior appendages. The blood from the left side of the heart now passes through the third aortic arch to the anterior appendages, and through the fourth arch to the dorsal aorta. The fourth pair of aortic arches are from the fifth day much larger than either of the other pairs that are still present. For a time the two arches of the fourth pair are of the same size, but the arch of the left side soon begins to diminish, and eventually almost completely disappears; the right arch increases in size as the left diminishes, and forms the systemic arch of the adult chick. It is to be noticed that in man it is the left arch that persists as the systemic arch.

As early as the middle of the third day, the pulmonary arteries are formed in the walls of the lungs, and when the fifth pair of aortic arches makes its appearance the pulmonary arteries become attached to and open into the 
ventral ends of these arches (Fig. 76, $A P$ ). The dorsal end of the fifth arch between the point of union of the pulmonary artery and the dorsal aorta (Fig. $76, A^{5}$ ) is known as the ductus Botalli. During almost the entire period of incubation, the ductus Botalli remains open and offers the blood from the right side of the heart an easy passage into the dorsal aorta, so that little, if any, of it passes through the lung capillaries. At the time of hatching, the ductus Botalli begins to shrivel up, and finally becomes entirely closed, so that all of the blood from the right side of the heart must pass into the pulmonary circulation. The lower half of the fifth aortic arch then becomes the pulmonary artery.

To recapitulate briefly. The dorsal ends of the first and second aortic arches persist as the carotid arteries: the ventral ends of these two arches persist as the lingual arteries. The ventral ends of the third arches persist as the subclavian arteries. The fourth arch, on the right side, persists as the systemic arch; the fourth arch, on the left side, disappears. The ventral ends of the fifth arches persist as the pulmonary arteries.

As has been described, the two dorsal aortæ, 


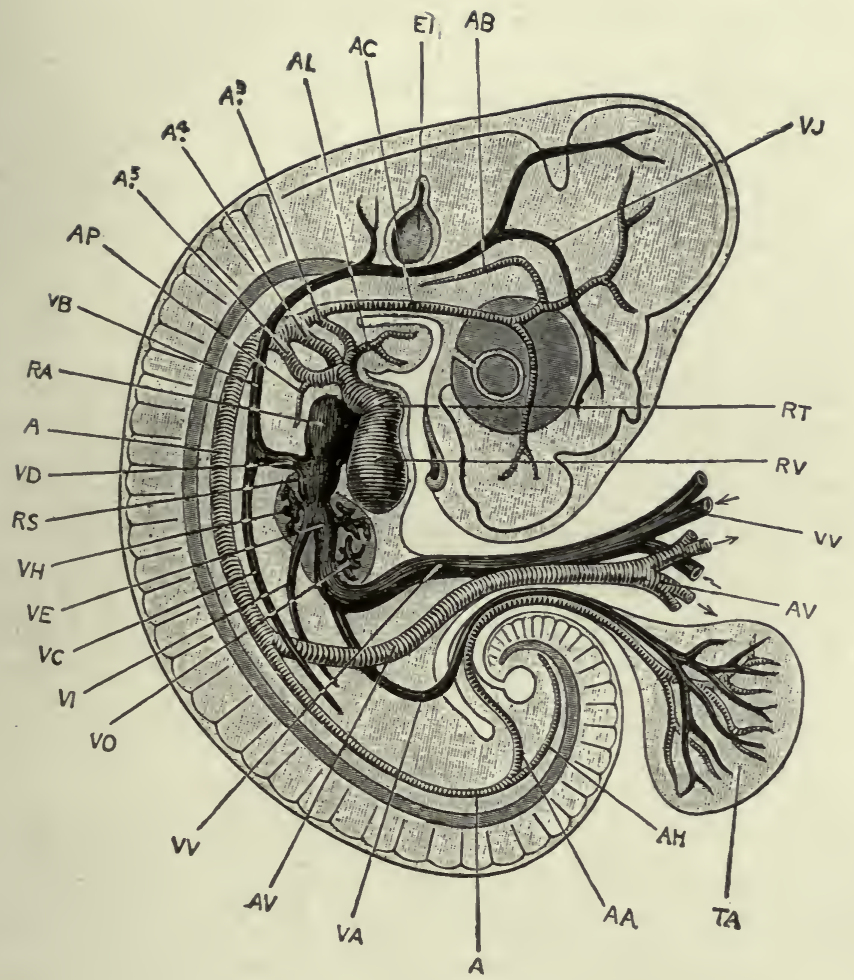

Fig. 76.-A DiAgrammatic FIgURE SHOWING THE ARRANGEMENT OF THE BLOOD VESSELS IN A CHICK EMBRYO AT THE END OF THE FIFTH DAY OF INCUBATION. THE AMINION HAS BEEN REMOVED, AND THE VITELLINE VESSELS CUT SHORT A LITTLE DISTANCE FROM THE EMBRYO. (After Marshall.)

$A$, dorsal aorta. $A^{3}, A^{4}, A^{5}$, third, fourth, and fifth aortic arches of the right side, lying in the first, second, and third branchial arches respectively. $A A$, allantoic artery. $A B$, basilar artery. $A C$, carotid artery. $A H$, caudal artery, the terminal portion of the dorsal aorta. $A L$, lingual artery. $A P$, pulmonary artery. $A V$, vitelline artery. $E I$, auditory vesicle. $R A$, right auricle. $R S$, sinus venosus. $R T$, truncus arteriosus. $R V$, right ventricle. $T A$, allantois. $V A$, allantoic vein. $V B$, anterior cardinal vein. $V C$, posterior cardinal vein. $V D$, Cuvierian vein. $V E$, meatus venosus. $V H$, efferent hepatic vessel. $V I$, posterior vena cava. $V J$, jugular vein. $V O$, afferent hepatic vessel. $V V$, vitelline vein. 
formed by the fusion of the dorsal ends of the aortic arches are at first separate from each other throughout their entire length; and each gives off from its posterior half a large vitelline artery which carries the blood to the vascular area (Fig. 65, Of.A). By the end of the second day the two aortre have met and fused for a short distance, in the middle region of the embryo; and by the fourth day this fusion has become much more extensive, and extends backwards beyond the point where the vitelline arteries are given off. By this time the roots of the two vitelline arteries have united, for a short distance, into a common trunk (Fig. 76, $A V$ ); and, of the two vitelline arteries into which this common trunk quickly divides, the left is much the larger.

Some distance posterior to the point of origin of the vitelline artery, and just back of the point of separation of the two dorsal aortæ, the allantoic or umbilical arteries arise (Fig. $76, A A)$. Through them the blood passes to the allantois, as the name would lead one to infer. The left allantoic artery is, from the first, generally the larger, and it eventually carries all of the blood to the allantois, as the right artery entirely disappears. 


\section{Development of the Fourth Day 249}

The vitelline and allantoic arteries are, of course, purely embryonic structures, and disappear at the time of hatching, when the yolk has all been absorbed or taken into the digestive tract, and the allantois is cast off and left in the shell.

From the hinder region of the dorsal aorta are given off arteries that carry the blood from the left side of the heart to the various structures of the abdominal cavity.

The changes that take place in the venous system are, if anything, rather more complicated than those that have just been described in connection with the arteries; but if each step in the development be understood, there should be no difficulty in understanding the entire process; and a clearer understanding of the adult circulation can be obtained by the study of its development than, perhaps, in any other way.

The development of the venous system has been described for the first three days of incubation. At the end of the third day, it will be remembered, the blood entered the auricular portion of the heart through the large vein that was called, in its entirety, the meatus venosus. The meatus venosus was largely 
formed by the union of the two large vitelline veins, bringing blood back from the vascular area, but also received blood from the anterior end of the body of the embryo through the two anterior cardinal veins, and from the posterior end of the embryo through the posterior cardinal veins. The anterior and posterior cardinals of each side unite with each other, just before emptying into the meatus venosus, to form the short ductus Cuvieri (Fig. 66, dc).

The anterior and posterior cardinal veins, during the earlier stages of development, bring back the blood to the heart from practically all parts of the body except from the digestive organs.

The anterior cardinals persist as the jugular veins, being joined, at an early period, by the pectoral veins from the anterior appendages, and the vertebral veins from the head and neck.

So long as the Wolffian bodies remain functional, the posterior cardinals retain their large size; but when the permanent kidneys become functional, these veins diminish in size and ultimately disappear.

The ducti Cuvieri or Cuvierian veins persist as the anterior vence cava of the adult chick (Fig. $78, V . S . L$. and $V . S . R$.). 


\section{Development of the Fourth Day 25I}

It now remains to describe the development of the system of the posterior (inferior) vena cava, which is an evolution, chiefly, of the meatus venosus, whose formation by the union of the two vitelline veins has already been described (Fig. 66).

The meatus venosus, from its first formation, is closely associated with the liver. The diverticula from the digestive tract that form the liver lie close to the meatus venosus, and as they grow they completely surround it. Soon after its formation, blood vessels begin to develop in the liver, and by the fifth day they have opened into the meatus venosus in the following manner: just after entering the posterior edge of the liver, the meatus venosus gives off a collection of afferent hepatic vessels, through which some of the blood, passing towards the heart from the vascular area, may enter the capillaries that are formed in the substance of the liver. Just before leaving the anterior edge of the liver, the meatus venosus is joined by a collection of blood vessels, the efferent hepatic vessels whose capillary terminations are in communication with the capillaries of the afferent hepatic vessels. The blood that passes through the 
liver has now two courses open to it; most of it passes directly through the large meatus venosus to the heart; but a part passes, by way of the afferent hepatic vessels, into the substance of the liver, to be collected and

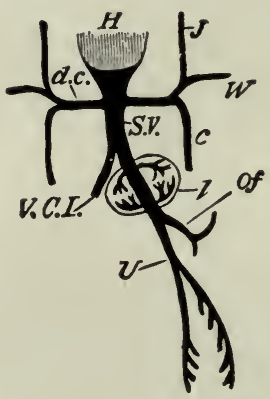

Fig. 77.-Diagram OF THE venous CIRCULATION AT THE COMMENCEMENT OF THE FIFTH DAY. (After Foster and Balfour.)

$H$, heart. d.r., ductus Cuvieri ; into the ductus Cuvieri of each side fall $j$, the jugular vein, $W$, the wing vein, and $c$, the inferior cardinal vein. S.V., sinus venosus. Of, vitelline vein. $U$, allantoic vein, which, at this stage, gives off branches to the body-walls. V.C.I., inferior vena cava. $l$, liver.

brought back to the meatus venosus again by the efferent hepatic vessels (Fig. 77).

The part of the meatus venosus in the liver between the openings of the afferent and efferent hepatic vessels is generally called the ductus venosus.

By the fourth day, the allantois has reached a considerable size, and in it are developed 


\section{Development of the Fourth Day 253}

the two allantoic veins. These veins unite on entering the body, to form a single vein that empties into the left or persistent vitelline vein. During the earlier stages, while the yolk-sac is still large, and the allantois is small, the allantoic vein is much smaller than the vitelline vein, and seems to be a branch of it, (Fig. 76); but, as the allantois increases in size and the yolk-sac diminishes, the relative size of the two veins becomes reversed, and the vitelline vein seems to be a branch of the allantoic (umbilical) vein (Fig 77). At the time of hatching, of course, both veins disappear. During the fourth day, the veins from the walls of the hinder part of the digestive tract unite to form one vein, the mesenteric vein. This vein is at first small and empties into the vitelline vein just before the latter enters the liver (Fig. $78, M$ ), or at the point where it may be said to become the meatus venosus. The blood that enters the liver is, therefore, derived from three sources: (I) through the vitelline vein, from the yolk-sac; this blood is rich in food material, and has been more or less oxidized in the vascular area; (2) through the allantoic vein, from the allantois; this blood is rich in oxygen; (3) 
through the mesenteric vein, from the digestive tract of the embryo; this blood is venous in character.

As the embryo increases in size, the mesen. teric vein also increases, and after the disappearance of the vitelline and allantoic veins, at the time of hatching, it persists as the hepatic portal vein of the adult, which brings the blood from the hinder parts of the digestive canal to the liver.

The posterior (inferior) vena cava, proper, arises about the fourth day, between the hinder ends of the Wolffian bodies, and runs forward in the middle line, ventral to the dorsal aorta. Anteriorly it joins the meatus venosus between the heart and the anterior edge of the liver (Fig. 77, V.C.I.) ; and posteriorly, it becomes connected with the permanent kidneys or metanephra, as soon as the latter are formed, and with the hind limbs and the caudal region. The posterior cava is at first a small and insignificant vessel, but as more and more blood is sent to the heart from the kidneys and from the hinder parts of the body, this vessel becomes larger than the meatus venosus, of which it was at first merely a branch.

Before this change in the relative size of 
Development of the Fourth Day 255

the two vessels has been entirely accomplished, the efferent hepatic vessels shift their position so as to open directly into the posterior cava, instead of into the meatus venosus (Fig. 78); and, before the time of hatching, the part of the meatus venosus between the heart and the liver becomes obliterated, so that all of the blood that flows into the posterior end of the liver, through the portal vein, empties into the posterior cava through the hepatic vein (Fig. 79).

One thing that is sometimes confusing in trying to trace the development of the circulatory system by studying a series of figures like those in the text, is the variation in the relative sizes of the different vessels; if this feature be kept in mind, it may help to make the relationships between the successive stages more evident.

The more important features in the development of the blood vessels, from their earliest beginning to the adult condition, have now been described; and it may help to make the whole subject more clear if a brief description be given of the course of the circulation during the latter part of the period of incubation, together with the changes taking place at the time of hatching. 
The course of the circulation at the end of the third day has already been described (page 20I), and need not be repeated at this place, so that we shall, at once proceed to the

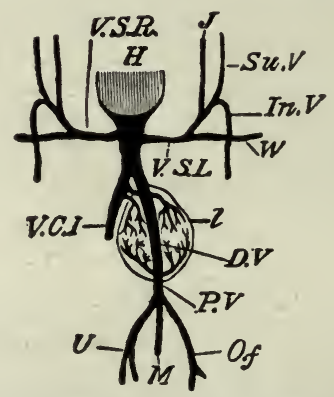

Fig. 78.-Diagram of the venous circulaTION DURING THE LATER DAYS OF INCUBATION. (After Foster and Balfour.)

$H$, heart. V.S.R, right vena cava superior. V.S.L, left vena cava superior. The two venæ cavæ superiores are the original "ducti Cuvieri"; they still open into the sinus venosus and not independently into the heart. $J$, jugular vein. $S u . V$, superior vertebral vein. In.V, inferior vertebral vein. $W$, wing vein. V.C.I, vena cava inferior, which receives most of the blood from the inferior extremities, etc. $D . V$, ductus venosus. $P . V$, portal vein. $M$, vein from intestines to portal vein. $O f$, vitelline vein. $U$, allantoic vein ; the three last-mentioned veins unite to form the portal vein. $l$, liver.

description of the circulation as it is during the latter part of the period of incubation.

"The heart is now fully formed. The sinus venosus has become absorbed into the right auricle, of which it now forms part: the auricular septum is still incomplete, the large foramen ovale allowing blood to pass freely from the right auricle to the left auricle. The ventricular 


\section{Development of the Fourth Day 257}

septum is complete; and the truncus arteriosus is divided into two entirely separate vessels, of which one, the pulmonary trunk, arises from the right ventricle, and the other or systemic trunk from the left ventricle.

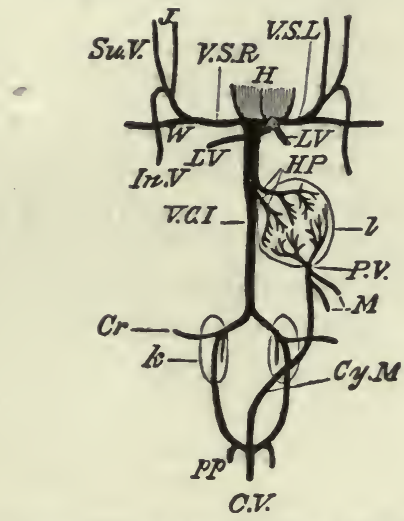

Fig. 79.-Diagram OF THE venous CirculaTION OF THE CHICK AFTER THE COMMENCEMENT OF RESPIRATION BY MEANS OF THE LUNGS. (After Foster and Balfour.)

$W$, wing vein. $J$, jugular vein. $S u . V$, superior vertebral vein. In. I, inferior vertebral vein. These unite on each side to form the corresponding superior vena cava. $L V$, pulmonary veins. V.C.I, vena cava inferior. HP. hepatic veins. $P . V$, portal vein $M$, mesenteric veins. $C y \cdot M$, connecting vessel between the branches of the portal and the system of the vena cava inferior. The ductus venosus has become obliterated. The three venæ cavæ fall independently into the right auricle, and the pulmonary veins into the left auricle. $C r$, crural vein. $k$, kidney. $l$, liver. $p p$, hypogastric veins. C.V, canal vein. $V . S . L$ and $V . S . R$, left and right venæ cavæ superiores.

" Three pairs of aortic arches are present, but these are the third, fourth, and fifth of the complete series, the first and second having disappeared along the greater part of their length. The systemic trunk, arising from the left ventricle, leads to the third and fourth pairs of 
aortic arches, and through these to the head and forelimbs. The pulmonary trunk, arising from the right ventricle, leads to the fifth pair of aortic arches, which are directly continuous with the dorsal aorta of the body of the embryo, and from which also the small pulmonary arteries arise. From the aorta a vitelline artery carries blood to the yolk-sac; and a still larger allantoic artery runs from the aorta to the allantois.

"The blood is brought back to the heart by three veins: - the right and left anterior venæ cavæ, and the posterior vena cava. The right and left anterior venæ cavæ return blood from the head and fore-limbs of the embryo. The posterior vena cava returns blood from the hinder part of the body, the limbs, and the kidneys; just before reaching the heart it is joined by the ductus venosus, which returns blood from the yolk-sac, from the allantois, and from the alimentary canal of the embryo, by the vitelline, allantoic, and mesenteric veins, respectively. The blood in the vitelline vein is arterial as regards nutrient matter; the blood in the allantoic vein is arterial as regards its gaseous components; and the blood in the mesenteric vein is venous. 'The blood in the posterior vena cava is venous as regards nutriment, and as regards gaseous components, but, having just passed through the kidneys, is arterial as regards freedom from nitrogenous excretory matters.

"The blood brought to the heart by the posterior vena cava may therefore be spoken of as arterial, and stands in this respect in marked contrast to the venous blood brought to the heart by the right and left anterior venæ cavæ.

"All three venæ cavæ open into the right auricle of 


\section{Development of the Fourth Day 259}

the heart: but, owing to the position and direction of the opening, and to the Eustachian valu'e, the arterial blood from the posterior vena cava is directed at once through the foramen ovale into the left auricle, while the venous blood from the right and left anterior venæ cavæ remains in the right auricle. The right auricle is thus filled with venous blood, and the left auricle with arterial blood.

"On contraction of the auricles, the blood they contain is driven into the ventricles, so that the right ventricle will be filled with venous, and the left with arterial blood.

"The left ventricle drives its arterial blood along the systemic trunk, and through the third and fourth pairs of aortic arches to the head and fore-limbs; while the right ventricle forces its venous blood through the pulmonary trunk and fifth pair of arches into the dorsal aorta, from which part goes to supply the body and hind limbs of the embryo, and part, in the earlier stages by far the larger part, passes out along the vitelline and allantoic arteries to the yolk-sac and allantois, where it takes up nutriment and oxygen.

"The enormously disproportionate size of the head and anterior part of the embryo and the stunted condition of the hinder part during the earlier stages are to be ascribed, at any rate in part, to this arterial supply of the anterior half as contrasted with the venous supply of the posterior half of the embryo." 1

The changes in actual structure that take place at the time of hatching are comparatively

${ }^{1}$ Marshall. 
slight, but they produce remarkable changes in the course of the circulation, and convert the embryonic circulation just described into that of the adult chick.

The ductus Botalli or ductus arteriosus, it will be remembered, is the part of the fifth aortic arch between the dorsal aorta and the point of origin of the vessel that runs to the lung (Fig. 76, $A^{5}$ ). So long as this vessel remains open, the blood from the right ventricle can pass into the dorsal aorta and thence to the hinder part of the body. At the time of hatching, the ductus Botalli, on each side of the body, closes up entirely, so that the blood from the right ventricle must now pass through the pulmonary arteries to the lungs, and thence, by the pulmonary veins,' back to the left auricle.

The pulmonary circulation is now established; and the allantoic circulation, being no longer necessary nor possible, ceases, and the allantoic veins and arteries disappear. The yolk being entirely absorbed or withdrawn into the now completed digestive tract there is no further use for the vitelline veins and arteries, and they also disappear. By the disappearance of the allantoic and vitelline vessels, the 
Development of the Fourth Day 26I

entire supply of blood to the liver is derived from the mesenteric vein, by which it is brought from the hinder part of the digestive tract; the mesenteric vein may now be called the hepatic portal vein.

The closure of the ductus venosus, by which all of the blood brought to the liver by the portal vein is compelled to pass through the hepatic capillaries before reaching the heart, has already been mentioned.

It is not until some time after hatching that the complete closure of the foramen ovale (the opening between the right and left auricles) takes place. By the closure of this opening, all of the blood brought to the heart by all three venæ cavæ is emptied into the right auricle; and when that auricle contracts, all of this blood is forced into the right ventricle, none of it finding its way directly into the left auricle. As a result of this, also, all of the blood that gets into the left auricle, and, consequently, into the left ventricle, comes from the lungs by the pulmonary veins. Thus are the arterial and venous streams of blood completely separated, and the double circulation is established.

Before passing to the development of the 
fifth day, let us briefly summarize the more important events of the fourth day. They are :

I. Increase in the body and cranial flexure.

2. Growth of the allantois.

3. Growth of the tail-fold.

4. Appearance of the limbs as local thickenings of the Wolffian ridge, just back of the heart and just in front of the tail.

5. Opening of the mouth, by the absorption of the partition between the stomodæum and the pharynx.

6. Development of the olfactory grooves.

7. Vacuolation of the cells of the notochord.

8. Beginning of the vertebral column.

9. Development of the ureter.

IO. Development of the duct of Müller.

I I. Development of the primitive germ cells in the genital ridge.

I2. Appearance of a fourth and a fifth pair of aortic arches, and the partial disappearance of the first and second arches.

13. Growth of the septa dividing the heart into right and left sides. 


\section{CHAPTER VII}

THE DEVFLOPMENT OF THE FIFTH DAY

THERE are no very striking features to be noticed during the fifth day, the changes that take place being mostly the growth and development of the structures that have originated during the previous days.

The allantois is now a large and vascular sac, stretching over the right side of the chick. between the two layers of the amnion (Figs. 38 , and 80 , all ), and serving as the chief organ of respiration.

The yolk is completely enclosed by the blastoderm, and the vascular area covers about two-thirds of the blastoderm. The embryo is so much curved that its head and tail are almost in contact (Fig. 80).

The splanchnic stalk is completely closed, and will remain in about the same condition until nearly the time of hatching : there is still considerable space between it and and the somatic stalk. 
The limbs.-During this day the limbs increase considerably in size, and become marked off into two parts: a more rounded proximal portion, and a somewhat expanded extremity. In the expanded extremity the digits are beginning to be outlined in cartilage, and the rounded proximal portions are slightly bent to form the first indications of the elbow- and knee-joints.

The angles of the elbow and knee are at first directed almost straight out from the body, but at about the eighth day both limbs rotate, so that the elbow-joint now points backwards, while the knee-joint is directed forwards (Fig. 72, B). As the result of this rotation, the digits of the anterior appendage are pointed directly forwards, while those of the leg are directed backwards. About the tenth day, however, the hand and foot rotate on the arm and leg, so that the digits of the former are directed backwards, and the digits of the latter forwards. By the end of the tenth day, the appendages have the outlines of well-developed wings and legs, except for the absence, as yet, of the feathers and nails.

The bony skeleton is early outlined in cartilage, which later becomes ossified. In the 


\section{Development of the Fifth Day 265}

manus are three well-formed digits, with a possible fourth, in a very rudimentary condition. The pes has three well-formed digits, and two others that are in a more or less rudimentary condition.

The ribs and sternum.-The ribs originate as cartilaginous bars in the mesoblast of the body-wall. By the fusion of the ventral ends of certain of these ribs, two longitudinal cartilaginous bars are formed, lying side by side in the ventral body-wall. These bars later segment off from the ribs from which they were formed, and by fusing with each other form a median band of cartilage, the sternum.

The skull.-It probably will not be practicable for the beginner in vertebrate embryology to work out, in the laboratory, the details of the development of the skull; but the main features will be given at this time, since it is at (Fig. 72) about this period that the changes to be discussed begin to take place.

It is convenient to discuss the development of the skull under two heads : (I) the cranium proper; (2) the skeleton of the visceral arches.

The cranium proper. - The notochord, which, as has been said, formed a sort of nucleus around which the centra of the vertebral 
column were formed, forms also a part of the cranium. It extends in the middle line along the under (ventral) side of the brain as far forward as the hinder edge of the pituitary body. On each side of this anterior part of the notochord is developed a horizontal

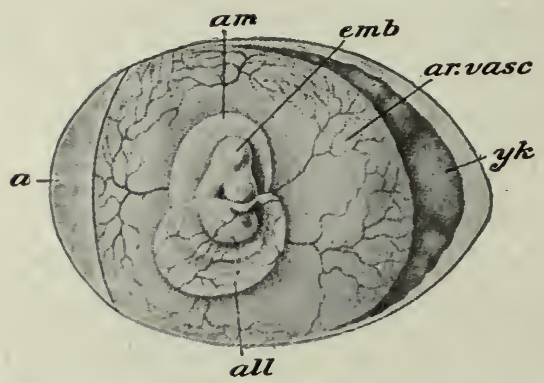

FIG. So.-EgG OF CHICK WITH EMBRyo AND FCETAL APpendages. (After Parker and Haswell, from Duval.)

a, air-space. all, allantois. am, amnion. ar. vasc, area vasculosa. emb, embryo. $y k$, yolk-sac.

sheet of cartilage. These two sheets of cartilage, the parachordal plates, lie in close contact with the notochord, and, with it, form a broad floor for the hind- and mid-brains. The two parachordal plates fuse together, above and below the notochord, thus enclosing the latter, to form the so-called basilar plate which forms the floor of the hinder part of the skull. To the sides of the basilar plate are fused the 


\section{Development of the Fifth Day 267}

auditory capsules, which enclose the auditory organs. The floor and sides of the hinder part of the skull are formed by the growth of the basilar plate and the auditory capsules.

The floor of the anterior end of the skull is formed chiefly by the trabecula cranii. These are two rather short and slender rods that lie in front of the notochord and are continuous with the anterior ends of the parachordal plates. They lie on each side of the pituitary body, and fuse together in front of it, forming the ethmoidal plate. The ethmoidal plate extends forwards to the tip of the beak, and is fused, anteriorly, with the olfactory capsules. The interorbital septum develops as a large vertical plate from the dorsal surface of the ethmoidal plate, along its whole median line.

The above-described structures form the cartilaginous skull, and, as incubation proceeds, this cartilage is gradually changed to bone, and forms the bones of the floor and sides of the adult skull. These bones which are first outlined in cartilage are known as cartilage bones.

The roof of the skull, the parietals, frontals, etc., is chiefly made up of the so-called membrane bones, that is, of bones that are not preformed in cartilage. 
The skeleton of the visceral arches. - The development of this part of the skeleton is also very difficult to follow, and need only be mentioned, at this point, as it has already been discussed in connection with the fate of the visceral clefts and folds. It will be remembered that it was the jaws and the hyoid apparatus that
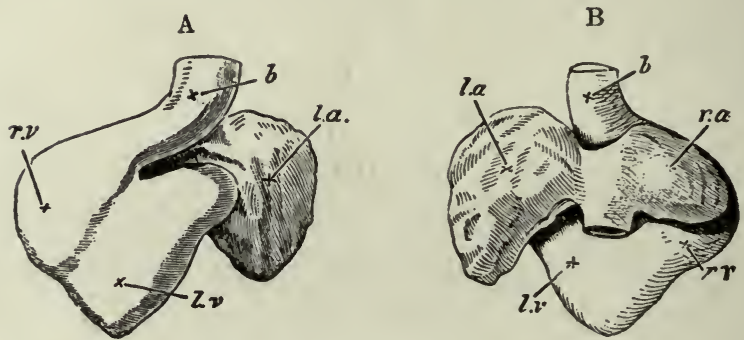

Fig. 8r.-Two views OF THE HEART OF A CHICK ON THE FIFTH DAY OF INCUBATION. (After Foster and Balfour.)

$A$, from the ventral, $B$, from the dorsal side. l. $a$, left auricular appendage. $r . a$, right auricular appendage. $r . v$, right ventricle. $l . v$, left ventricle. $b$, bulbus arteriosus.

were especially concerned in the development of the visceral skeleton. It is the enormous forward-growth of the jaws that is largely responsible for the characteristic outline to the face of the chick.

The heart.-The fifth day is one of the most important in the history of the development of the heart. The most important 


\section{Development of the Fifth Day 269}

changes in the heart from this time until the time of hatching will now be mentioned.

During the fifth day the interventricular septum is completed, and becomes fused anteriorly with the posterior edge of the septum that is developed at this time, in the truncus arteriosus. This latter septum is attached,

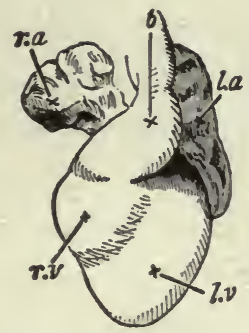

Fig. 82.-HeART OF A CHICK ON THE SIXTh DAY OF INCUBATION, ventral surface. (After Foster and Balfour.)

l.a, left auricular appendage. $r . a$, right auricular appendage. $r . v$, right ventricle. $l . v$, left ventricle. $b$, bulbus arteriosus.

anteriorly, between the fourth and fifth pairs of aortic arches, and follows a sort of spiral course backwards, to where it joins the interventricular septum. The effect of these septa in directing the blood from the right and left ventricles into different channels has already been explained (page 244). Before the completion of the septum of the truncus arteriosus 


\section{Vertebrate Embryology}

the two sets of semilunar valves have been formed between the two divisions of the truncus and the two ventricles into which they open.

During the next two or three days the heart continues to approach more nearly the shape of the adult, though there is no remarkable change in structure.

By the twelfth day, the interauricular septum has increased to such an extent that the opening between the two auricles is reduced to a small opening, the foramen ovale.

Shortly before hatching, the foramen ovale becomes nearly closed by a membranous fold ; and shortly after hatching, the closure is complete, and the heart has practically the adult structure.

During the later stages of incubation, the walls of the ventricles and auricles, especially the former, become much thickened by the inward growth of ridges from the muscular walls, forming the trabeculæ of the adult heart. The truncus becomes thickened simply by the increase in the thickness of the component layers of its walls.

The pericardial and pleural cavities.-It will be seen, by the examination of figures of the 


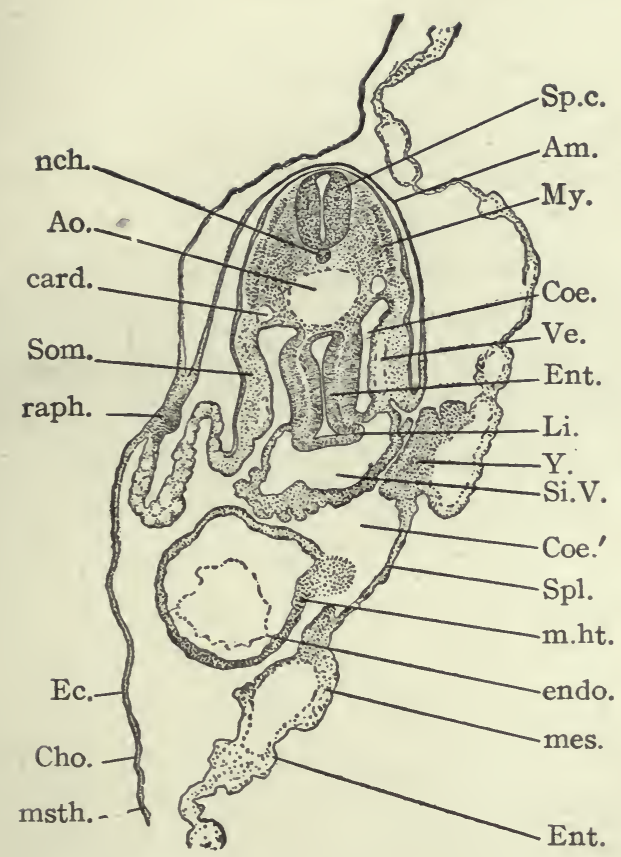

Fig. 83.-Transverse Section through the DORSAL Region OF A CHICK EMBRYO WITH ABOUT TIWENTY-EIGHT SEGMENTS. (After Minot.)

$A m_{.,}$amnion. Ao., aorta. card., cardinal vein. Cho., chorion. Coe., Coe'., cœelom. Ec., ectoderm. endo., endothelial heart. Ent., entoderm. Li., liver. mes., mesoderm. m.ht., muscular heart. msth., mesothelium. $M y$., primitive segment. nch., notochord. raph., raphe of amnion. Si.V., sinus venosus of heart. Som., somatopleure. Sp.c., spinal cord. $S p l$., splanchnopleure. $V e .$, vein. $Y$., accumulation of mesodermic material about the vitelline vein. 
earlier stages in the development of the chick, that the heart at first has no special cavity of its own, but lies freely in the general bodycavity (Figs. 55 and 57). The origin of the pericardial cavity is, briefly, as follows: in the plane of the Cuvierian veins, where they cross the body-cavity from the somatopleure to the sinus venosus, is developed a horizontal membrane or septum. This septum evidently divides the body-cavity into an upper and a lower chamber, in the latter of which lies the heart. These two chambers of the bodycavity are at first in communication with each other both in front and behind the horizontal septum; but the anterior edge of the septum now grows forwards and upwards until it meets and fuses with the ventral wall of the fore-gut, and the posterior edge grows backwards and downwards until it meets the ventral wall of the body-cavity; the space in which the heart lies is thus separated from the rest of the body-cavity, and becomes the pericardial cavity.

As the lungs are formed, as outgrowths from the anterior part of the digestive tract, they lie in the dorsal part of the body-cavity, above the horizontal septum, and on each sidr 


\section{Development of the Fifth Day 273}

of the fore-gut. As they continually increase in size, they gradually force the horizontal septum down on each side of the heart, until the pericardial cavity is reduced to very narrow limits (Fig. 84, $p c$ ).

These spaces in which the lungs lie are the pleural cavities, and in the bird they remain continuous, at their posterior ends, with the general body-cavity.

Histological differentiation. - It is at this time that histological differentiation may be said to commence, though from the earliest hours of embryonic life the cells of the different germlayers were more or less dissimilar.

It may be defined as

" a process by which the structure of the cells is modified, so that cells become dissimilar in structure by acquiring an organization which adapts them to special functions. The cells which arise during the segmentation of the ovum differ but slightly from one another. As development progresses we find the cells change, some in one way, some in another, so that many kinds of cells are produced, but of each kind we find a large number of cells. Each kind of cell may be said, roughly speaking, to form a tissue for itself. Cells of each tissue offer visible peculiarities by which they may be readily distinguished from one another under the microscope. It thus appears that the production of tissues is the main result of differentiation, so that thir 
process of development may be fairly accurately defined as equivalent to histogenesis. As to the factors which cause differentiation, we have no satisfactory knowledge. We can, at present, only note the changes,

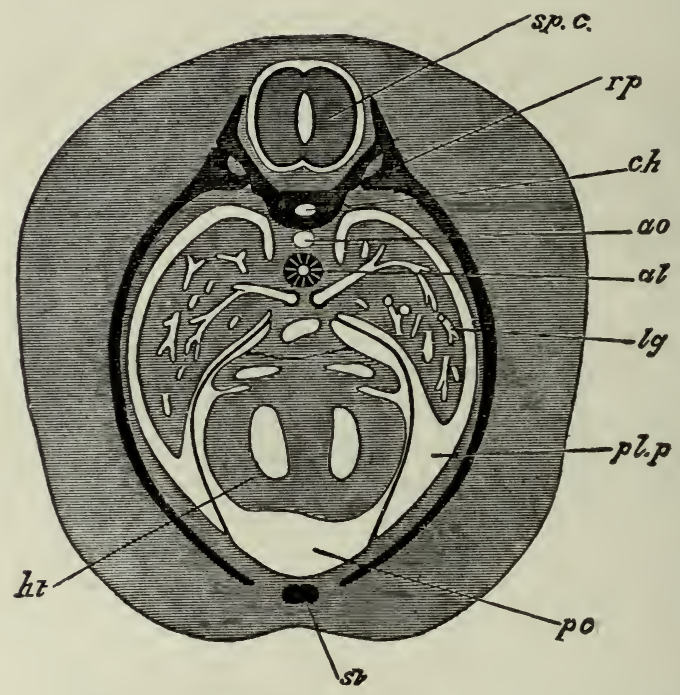

Fig. 84.-SECTION THROUGH AN ADVANCED EMBRYO OF A RABbIT, TO SHOW HOW THE PERICARDIAL CAVITY BECOMES SURROUNDED BY THE Pleural Cavities. (After Foster and Balfour.)

$h t$, heart. $p c$, pericardial cavity. $p l . p$, pleural cavity. $l g$, lung. $a l$, alimentary tract. ao, dorsal aorta. ch, notochord. $r p$, rib. st, sternum. $s p . c$, spinal cord.

when they acquire such magnitude as to become microscopically visible. As to the physiological conditions which cause these changes we have almost no conceptions. It is probable that the nucleus has a leading rôle to play, but our knowledge of this rôle is too litte advanced to permit a profitable discussion of the subject here. 
Development of the Fifth Day 275

"The actual process of differentiation shows itself both in the protoplasm and in the nucleus of the cell. The changes in the former are the more conspicuous, and therefore the better known. The changes in the nucleus have still to be adequately studied." ${ }^{2}$

According to Minot there are two types of differentiation, both starting from the same point - the undifferentiated embryonic cell. In the first type, as the cells are proliferated certain ones are differentiated into new forms, while the rest of them remain undifferentiated and retain the power of proliferation. The epidermis is an illustration of this type. Some of the cells which are formed by the multiplication of its lower layer pass towards the surface and differentiate into horny cells; while other cells remain at the base of the epidermis and continue to multiply. In the second type of differentiation, all the cells become at once differentiated, and lose partly or completely their power of multiplication. This type is illustrated by the central nervous system. The growth of the brain, after the earlier stages, takes place by the growth of the individual cells, rather than by the increase in the number of the cells. After their formation, the 


\section{6}

\section{Vertebrate Embryology}

glia cells divide but slowly, and the neurones not at all.

It should be noted that, according to the so-called law of genetic restriction, " differentiation acts as a progressive restriction upon further development. Each successive stage of differentiation puts a narrower limitation upon the possibility of further advance." ${ }^{1}$ This may be illustrated by the ectoderm. This layer early shows a division into two secondary layers, the epidermal and the nervous. The epidermal layer never forms nervous structures, and the nervous layer never forms epidermal structures. In the nervous layer are soon developed nerve-cells and neuroglia cells; the former never develop into the latter, nor the latter into the former. Similar illustrations might be given from the entodermal and mesodermal layers.

One of the first changes noticed in the ectoblast, besides the separation into two layers, is the formation of certain thickened areas which have been called plakodes. Examples of these local thickenings are seen in the eye, nose, and ear invaginations that have already been described. From the ectoderm are de

${ }^{1}$ Minot. 
rived the following organs-the epidermis and its appendages; the lens of the eye ; the epithelium of the cornea; the olfactory chamber; the auditory organ; the mouth, and the anus; the brain; the spinal chord; the retina; the optic nerve; the nerve-fibres, etc.

The entoderm almost from the first exhibits two or three kinds of cells, found in the area opaca, area pellucida, and embryo proper. This layer also shows variations in thickness, analogous to those seen in the ectoderm. From the entoderm are developed the notochord, and the epithelium of the entire respiratory and digestive tracts with their appendages; the epithelium of the mouth and anus, however, are of ectoblastic origin, as has been stated.

The mesoderm early shows a differentiation into several varieties, which, however, are largely due to the method of grouping or the varying degrees of condensation of the cells. From the mesoderm are derived all the structures not mentioned in connection with the other two germ-layers, such as muscle, bone, blood, urogenital organs, etc.

The most important changes in the develor ment of the fifth day are: 
$278 \quad$ Vertebrate Embryology

I. Growth of the allantois.

2. Growth of the limbs, and the appearance in them of the cartilages and of the elbow-and knee-joints.

3. Appearance of the cartilaginous cranium, and of the bars of cartilage in the visceral arches.

4. Development of parts of the face.

5. Completion of the ventricular septum; and the appearance of the septum of the bulbus arteriosus, and of the semilunar valves.

6. The establishment of the different tissues. 


\section{CHAPTER VIII}

THE DEVELOPMENT FROM THE SIXTH DAY TO THE TIME OF HATCHING

The sixth and seventh days.-It is during this period that the distinctively avian characteristics make their appearance.

Up to this time there is nothing about the embryo that would enable the inexperienced eye to distinguish the chick embryo from that of many other and quite different animals; and, in fact, it would be difficult, if not impossible, for even an experienced eye to distinguish the chick embryo, during the very early stages, from other embryos at a corresponding state of development.

It is at this time that the nasal region begins to lengthen, and the anterior and posterior limbs begin to take on the form of wings and legs (Fig. 72, B).

The amnion does not now lie so close to the embryo as during the earlier stages, and in the enlarged amniotic cavity has collected 
a considerable amount of fluid. Slow, rhythmic pulsations are seen passing over the amnion, caused, probably, by the contraction of the muscle-fibres that are developed in the mesoblastic portion of the amniotic folds. This pulsation of the amnion gives to the embryo a sort of rocking motion in the amniotic fluid. At a later period, such movements, it is said, may be seen in the allantois.

The allantois has increased rapidly in size, and contains a quantity of fluid. Both the vitelline veins and arteries now pass from the body as single vessels; and the yolk, though apparently undiminished in quantity, is much more fluid than during the earlier days. The flexure of the body is less marked than on previous days; and the neck is becoming more apparent. The disproportion between the size of the head and that of the rest of the body is being reduced by the more rapid growth of the body. The width of the somatic stalk is being reduced, with the result that the heart is being enclosed, and no longer seems to hang loosely out of the body: in the wall of the body thus formed, the cartilaginous ribs and sternum are being developed. The growth of the cerebral hemispheres has bees 
From Sixth Day to Hatching 28I

very marked. The structures around the mouth have assumed more avian outlines; while in the floor of the mouth the tongue has begun to develop, as a bud of mesoblast covered with ectoblast.

The eighth, ninth, and tenth days.-About the only change noticed in the amnion is a diminution in the intensity of the pulsations, which were at their height on the eighth day, and now gradually grow less. The allantois covers a large part of the yolk-sac, and is extremely vascular, especially its upper layer which lies close under the shell membranes. The yolk is beginning to diminish rapidly, and the yolk-sac is becoming wrinkled and flabby. The little sacs containing the feathers begin to protrude from the surface, especially along the back, of the rapidly growing embryo. On the tip of the nose is seen a chalky patch, the beginning of the horny beak.

The eleventh day to the time of hatching. - By the eleventh day, the abdominal walls though much less firm than those of the chest, may be said to be fully formed, and the loops of the intestines which have been hanging down loosely are enclosed in the body-cavity. The body is thus completed except for the 
narrow stalks of the umbilicus and the yolksac. The allantois continues to increase in prominence, while the amnion becomes less conspicuous on account of the disappearance of the amniotic fluid.

By the thirteenth day, the feathers are generally distributed over the body, and their form and color may be seen through the thin walls of the sacs in which they are still enclosed. They remain enclosed in the sacs until the nineteenth day, when they are an inch or more in length.

On the thirteenth day, nails and scales appear on the toes; and by the sixteenth day, the nails, scales, and beak are all quite firm and horny.

By the thirteenth day the cartilaginous skeleton is complete, and numerous centres of ossification have made their appearance.

By the sixteenth day, the white of the egg has disappeared, and the cleavage of the mesoblast has extended entirely around the yolk. On the nineteenth day, the remains of the yolk are withdrawn bodily into the body-cavity, which was not nearly filled by the loops of the intestine.

The changes that take place in the circulation 


\section{From Sixth Day to Hatching 283}

during the latter days of incubation have already been described, and need not be mentioned at this place.

As early as the sixth day, movements of the chick may sometimes be noticed, on opening the egg, but whether they are purely voluntary, or caused by the effects of the air on the opened egg, it is difficult to say. Soon after this time undoubted voluntary motions do occur: and on the fourteenth day, the embryo shifts its position, so that, instead of lying transversely to the long axis of the egg, it comes to lie with its head towards the large end of the egg, which brings its beak close to the now much-enlarged air-space that was mentioned in the description of the unincubated egg (Fig. 33,a). About the twentieth day, the beak is thrust into the air-space, and the chick, for the first time, begins to breathe by means of its lungs. As the pulmonary circulation begins, the blood ceases to flow into the umbilical vessels, and the allantois, in consequence, shrivels up, and is left inside the shell as the chick pecks its way out of the egg. 


\section{CHAPTER IX}

THE DEVELOPMENT OF THE MAMMAL

INCE the development of man and other mammals is, in most particulars, strikingly like that of the chick, as described in the preceding chapters; and since there are already available several excellent text-books that discuss the embryology of mammals, the purpose of this chapter will be to point out the main differences between the embryological processes of the chick and those of man or other higher mammalia. These differences are due, largely, to the differences in the amount of food yolk in the ovum, which causes the hen's egg to be many thousand times larger than that of the ordinary mammal.

As has been seen in the preceding chapters, the great mass of yolk in the ovum of birds serves as food for the developing embryo, so that, at the time of hatching, the young chick has acquired, without outside aid, essentially the adult form. In the ovum of man, 


\section{Development of the Mammal 285}

on the other hand, there is practically no food yolk, so that almost from the beginning, the embryo is dependent upon a source outside of itself for food; this source is mainly the blood of the mother, and to make it available there is developed what is known as the placenta, to be described later.

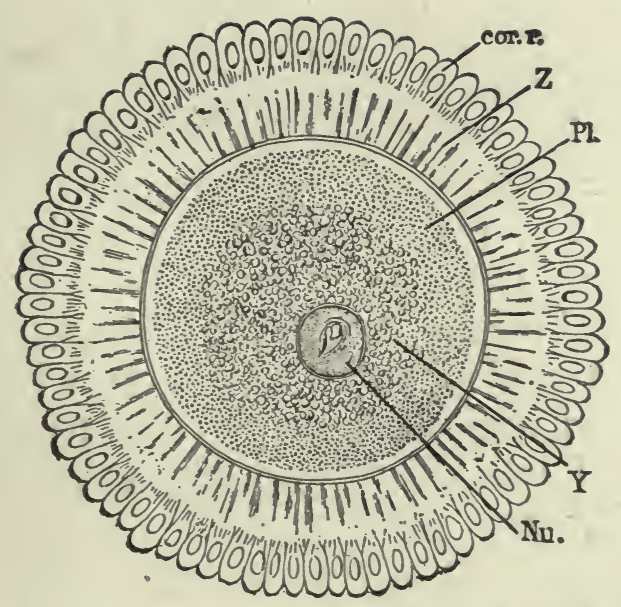

Fig. 85.-FULl-GRowN HUMAN OTUM BEFORE maturation. (From Minot, after Nagel.)

cor. $r_{\text {., }}$ part of corona radiata. $Z$, zona pellucida. $P l$, protoplasm. $Y$, yolk. $N u_{\text {., nucleus. }}$

\section{The Sex Cells}

It will be well to begin the discussion of the embryology of the mammal with a description 
of the sexual cells, ova and sperm, of man, since it is with the development of man that we shall be chiefly concerned.

It has already been said (page 92) that the variation in the size of ova is due mainly to the amount of food yolk. In the human ovum the food yolk is in very small quantity, so that the cell is extremely small, about $\frac{1}{6} \mathrm{~mm}$. in $\mathrm{di}$ ameter; while the ovum of the chick is $25-30$ $\mathrm{mm}$. in diameter.

The human ovum (Fig. 85) consists of a spherical cell, the ovum proper or vitellus, surrounded by the zona pellucida and the corona radiata. In the ovum proper there is a large, spherical nucleus containing a distinct nucleolus. According to Minot, the yolk is chiefly collected near the centre of this part of the ovum, leaving a protoplasmic, yolk-free, peripheral zone.

Between the vitellus and the surrounding zona pellucida is a narrow perivitelline space in which the vitellus is said to rotate freely, in the living condition. The zona pellucida is a clear area around the ovum proper; it shows radial striations which Minot thinks may be due to radially arranged canals. The outermost region of the ovum is the corona 


\section{Development of the Mammal 287}

radiata, which consists of radially arranged oval cells.

The conditions just described are those of the ovum after it is fully grown, but before maturation has taken place. For the process of oögenesis the reader is referred to any good text-book of histology.

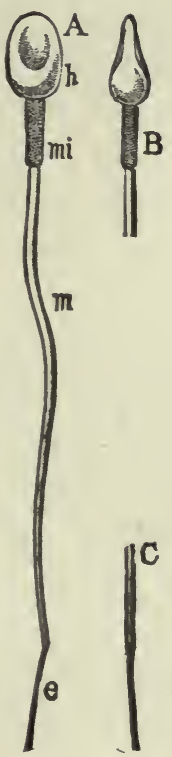

Fig. 86.-Human spermatozoa. (From Minot, after Retzius.)

$A$, complete spermatozoön. $B$, head seen from the side. $C$, extremity of the tail. $e$, end prece. $h$, head. $m$, main piece. $m i$, middle piece. All highly magnified. 
The human spermatozoön (Fig. 86) rcsembles, in a general way, the spermatozoa of the other mammalia. Its most evident parts are the head, middle-piece, and tail. Besides these an end-piece may be made out, under high magnifications, and some observers have described a thread-like tip at the anterior end of the head. The length of the entire spermatozoön is between .05 and $.06 \mathrm{~mm}$. The head is oval in outline, as seen from the flat side, and is pointed when seen in profile (Fig. 86, B); it stains darkly with nuclear stains. The middle-piece is the anterior portion of the tail, where it joins the broad, basal part of the head; it is cylindrical in shape and is thicker than the tail proper, from which it is sharply differentiated. The tail forms the greater part of the length of the spermatozoön, and ends suddenly in the short and extremely fine end-piece. The tail of the living spermatozoön vibrates rapidly, thus acting as a propeller to produce forward motion.

As in the case of oögenesis, so here the reader is referred to larger works on embryology or to text-books of histology for a discussion of the process of spermatogenesis. 


\section{Development of the Mammal 289 Maturation and Fertilization}

Of the processes of maturation and fertilization in man nothing is known by observation. These processes have, however, been studied in mice and, to some extent, in other mammals, and, since they do not differ in their essential features from the corresponding processes as described in connection with the frog, we shall simply refer to the earlier pages (IO-I 7 ) of this book.

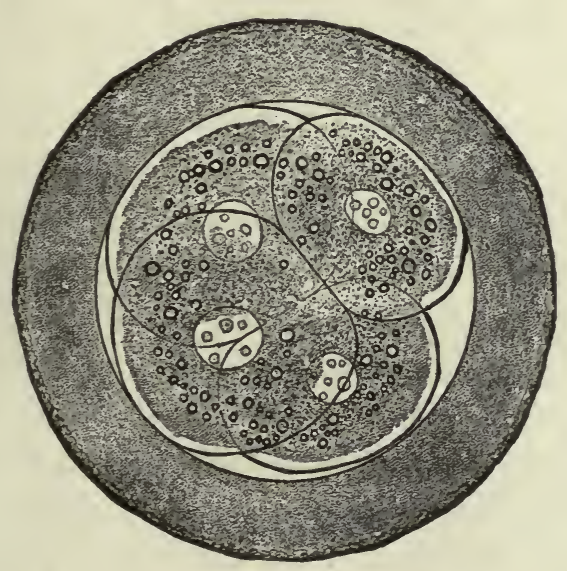

FIG. 87.-OVUM OF BAT WITH FOUR SEGMentation spheres. (From Minot, after Van Beneden and Julin.) 


\section{The Blastodermic Vesicle}

Segmentation has never been observed in man, but the process, we may imagine, is more or less similar to what has been studied in some of the lower mammalia.

The first cleavage, preceded, of course, as are all of the succeeding cleavages, by a mitotic division of the nucleus, divides the egg into two equal blastomeres. Following the twocell stage is the four-cell condition (Fig. 87), although a three-cell stage has been described in some mammals, formed, possibly, by a division of one of the first two blastomeres before the other.

After the four-cell stage segmentation proceeds with some irregularity, but it is soon evident that the blastomeres are arranging themselves into an outer layer, close under the zona radiata, and an inner group. The outer cells are somewhat flattened and are known as the subzonal layer; the inner group of cells, surrounded by the subzonal cells, is the inner cell mass (Fig. 88).

A space now makes its appearance between the inner cell mass and the subzonal layer, but it does not separate these two groups of cells on all sides, the inner cell mass remaining at- 


\section{Development of the Mammal 29x}

tached to the subzonal layer at one place (Fig. 89). This hollow sphere, characteristic of

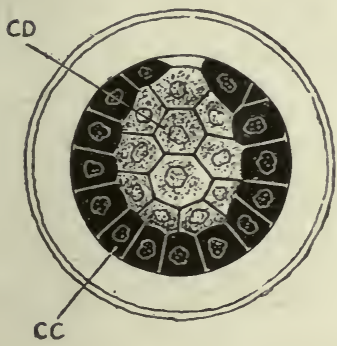

FIG. 88 .

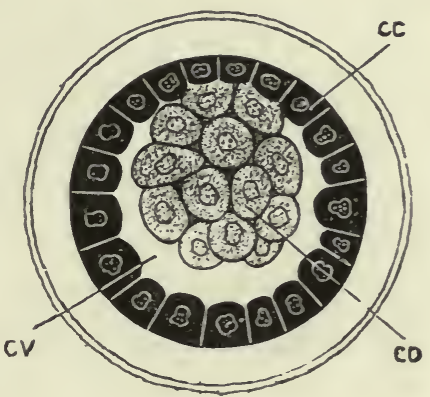

Fig. 89.

Fig. 8S.-A RABBIT's OVUM SEVENTY HOURS AFTER COPULATION, TAKEN FROM THE LOWER END OF THE OVIDUCT JUST BEFORE ENTERING THE UTERUS, AND SHOWING THE CONDITION AT THE CLOSE OF SEgMENTATION. (After Van Beneden.) $\times 200$.

FIG. 89.-A RABBIT'S OVUM SEVENTY-FIVE HOURS AFTER COPULATION, TAKEN FROM 'THE UTERUS, ANU SHOWING THE FIRST STAGE IN THE FORMATION OF THE BLASTODERMIC VEsicle. (After Van Beneden.) $\times 200$.

$C C$, outer layer of cells. $C D$, inner mass of cells. $C V$, cavity of blastodermic vesicle.

mammals, is known as the blastodermic vesicle. It is usually said that the subzonal layer corresponds to the ectoderm, the inner mass to the entoderm.

The changes just described have taken place during the passage of the ovum through the Fallopian tube towards the uterus. How long this period may be in man is not known; Minot 
supposes it to be about a week. On entering the uterus the blastodermic vesicle is, in many mammals, covered with a gelatinous secretion from the uterine glands; this envelope is called $\checkmark$ the pro-chorion and must not be confused with the true chorion to be described later.

The region of attachment of the inner cell mass to the subzonal layer is the position of the future embryo. As development proceeds the inner cell mass spreads out until it forms a layer of cells entirely around the vesicle, inside of the subzonal layer. This growth of the inner mass takes place differently in different animals. The vesicle increases rapidly in size by the flattening and multiplication of the cells, and becomes filled with a fluid of uncertain composition, probably derived from the wall of the uterus.

The shape of the enlarged vesicle and the size to which it grows vary in different animals. There is also much variation in different mammals in regard to the growth of the subzonal or ectodermal layer, which, in some cases, becomes thickened, either in a restricted area, or over the entire vesicle, to form what is called the trophoblast. This trophoblast, according to Minot, has two functions, both of which are 
accomplished by the destruction of the tissues of the uterus. The first function is to aid in the implantation of the ovum; this may consist simply in the formation of a placental attachment, to be described later, or in the practical burial of the ovum in the lining of the uterus, much as a hot bullet would bury itself in a cake of wax. The second function is to supply nourishment to the embryo by the destruction of the uterine tissue.

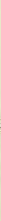

Fig. 90.-Section through the embryonic Shield of A Dog. (From Kollmann, after Bonnet.)

ec, ectoderm of embryonic area. ec,' ectoderm of blastoderm. en, yolk entoderm.

The first indication of the formation of the embryo proper is the embryonic shield. This is formed by a thickening of the outer layer of cells in the region where the inner mass is attached (Fig. 90). Its distinctness varies in different animals, but it soon assumes a circular or oval outline (Fig. 9I), and develops, often near its centre, a small opacity known as the primitive knot. At the primitive knot the two 
layers of the vesicle are closely united. Extending from the primitive knot towards the cir-

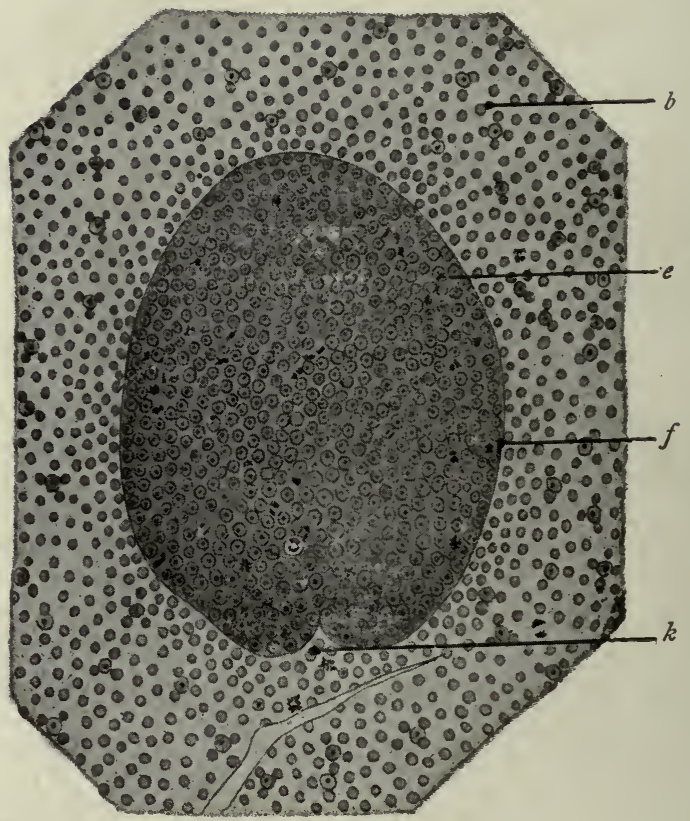

Fig. 9I.-SURFACE VIEW OF THE EMBRyonic SHIELD OF A DOG. MAGNiFIED I 20 DIAMETERs. (From Kollmann, after Bonnet.)

$b$, blastoderm. $e$, embryonic area. $f$, border furrow. $k$, notch.

cumference of the shield is soon seen an opaque line, the primitive streak (Fig. 92), along the axis of which extends a shallow groove, the primitive groove. The embryonic shield at 


\section{Development of the Mammal 295}

this stage has much the same appearance as the blastoderm of the chick at about the sixteenth hour of incubation. So far as is known, it is of about the same size in all mammals.

At the time of the occurrence of the primitive streak, the mesoderm makes its appearance;

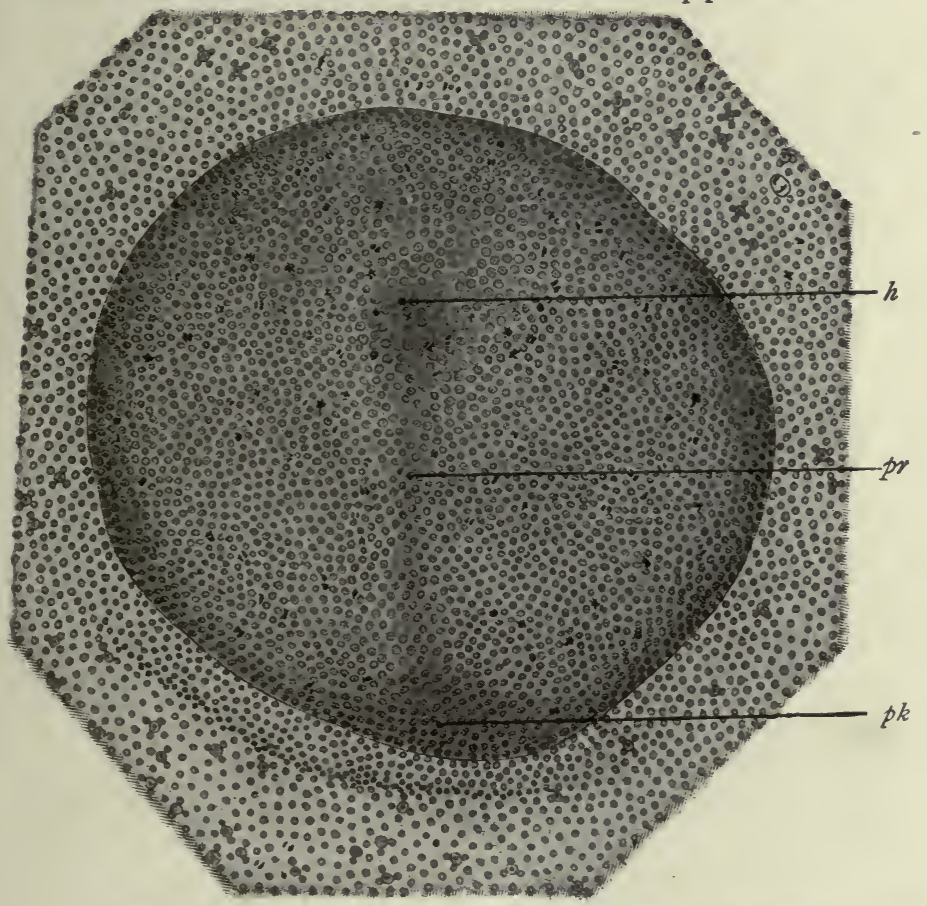

FIG. 92.-EMBRYoNic AREA OF A DOG, SHOWING THE PRIMITIVE STREAK. MAGNifIED 120 DIAMETERS. (From Kollmann, after Bonnet.)

$h$, head process. $p k$, primitive knot. $p r$, primitive streak. 
its exact mode of origin in mammals is, perhaps, uncertain, but it probably originates by delamination from the upper side of the entoderm. In some forms the mesoderm extends entirely around the blastodermic vesicle, in others only a part of the way.

Extending forward from the primitive knot there now appears a linear thickening that, superficially, has somewhat the same appearance as the primitive streak; this is the primitive axis, the long axis of the future embryo. The primitive axis gradually extends backward and encroaches upon the primitive streak, until the latter structure is obliterated.

At this stage of its development the blastodermic vesicle, with its embryonic shield, corresponds to the ovum of a chick of about i 8 to 20 hours, except that in the chick the large yolk sac is filled with yolk, while in the mammal it is filled with a liquid.

The origin of the notochord, neural canal, and other embryonic structures is about the same as has been studied in the chick, so that if these processes be understood in the latter type of development, they will be readily comprehended in the development of the mammal. The folding off of the embryo from the rest 


\section{Development of the Mammal 297}

of the vesicle and the formation of the amnion are also so similar to the corresponding processes in the bird that they will be easily understood by reference to Figures $93-96$.

After the mammalian ovum has reached the stage of the primitive axis, above described,
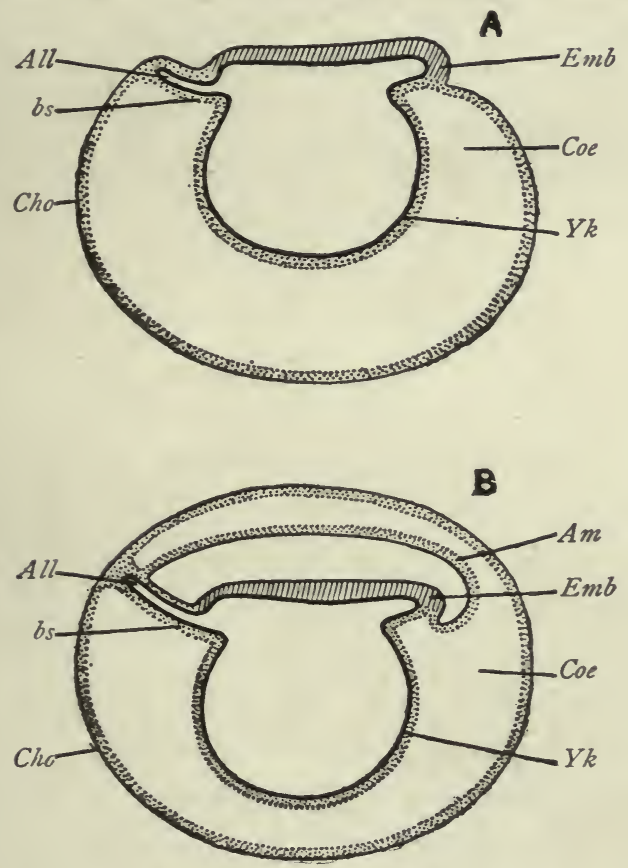

FIG. 93.-Diagrams ILlUStRATING THE RELATIONS OF THE ALl_ANTOIS, ETC., IN UNGUICULATE MAMMALS. (From Minot.)

$A$, before, $B$, after, the formation of the amnion. $A l l$, entodermal allantois. $A m$, amnion. $b s$, body stalk. Cho, chorion. Coe, extra-embryonic coelom. $E m b$, anterior end of the embryo. $Y k$, yolk-sac. 
the only features of development that will need description here are those connected with the placenta, umbilical cord, etc., with, perhaps, a short description of the decidua and of the development of the external genitalia.

It will be remembered, in connection with the chick, that, when the head, tail, and lateral folds of the amnion meet over the back of the embryo, the inner layers of the folds fuse together to form the inner or true amnion, while the outer

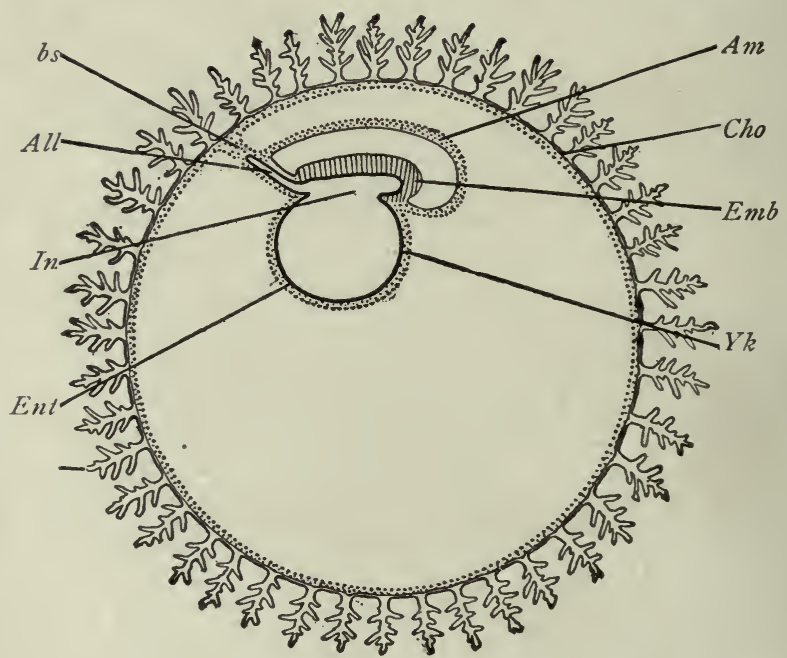

Fig. 94.-Diagram of an Early stage of a primate embryo. (From Minot.)

$A l l$, allantois. Am, amnion. $b s$, body stalk. Cho. chorion. Emb, embryo, Ent, entoderm. In, entodermal cavity of embryo. $V i$, villi of chorion. $Y k$, yolk sac. 


\section{Development of the Mammal 299}

layers form what is called the false omnion, or serous membrane, or chorion (Fig. 38).

In the chick the chorion is merely a thin membrane that lies close against the inner-shell

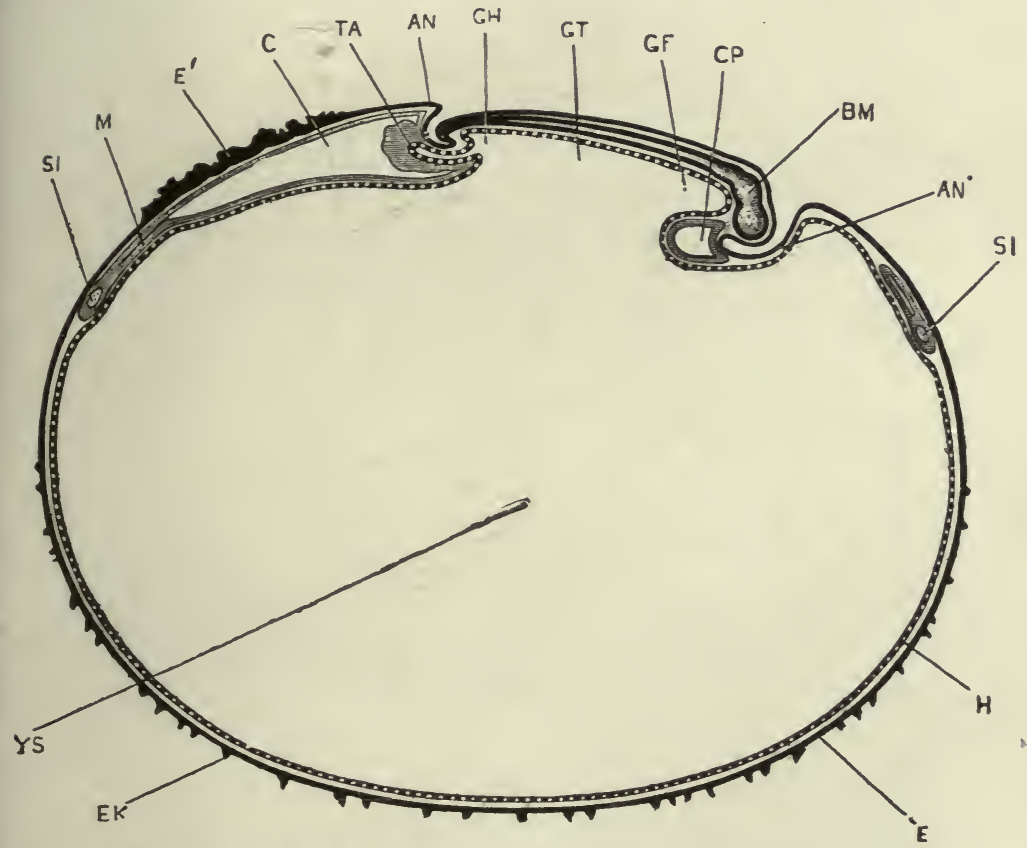

Fig, 95.-A MEdian IONGitudinal, OR SAgitTal, SECTion THROUGH A RABBIT EMBRYO AND BLASTODERMIC VESICLE AT THE END OF THE NINTH DAY. (From Marshall, in part after Van Beneden and Julin.) $\times 10$.

$A N$, tail fold of amnion. $A N^{\prime}$, proamnion. $B M$, mid-brain. $C$, extraembryonic part of the coelom or body-cavity. $C P$, pericardial cavity. $E$, epiblast. $E^{\prime}$, thickened epiblast by which the blastodermic vesicle is attached to the uterus (from Marshall). $E K$, epiblastic villi. $G F$, fore-gut. $G H$, hind-gut. $G T$, mid-gut. $H$, hypoblast. $M$, mesoblast. $S /$, sinus terminalis. $T A$, allantois. YS, cavity of yolk-sac, of blastodermic vesicle. 
membrane, but in the placental animals it is a much more important structure, and takes an

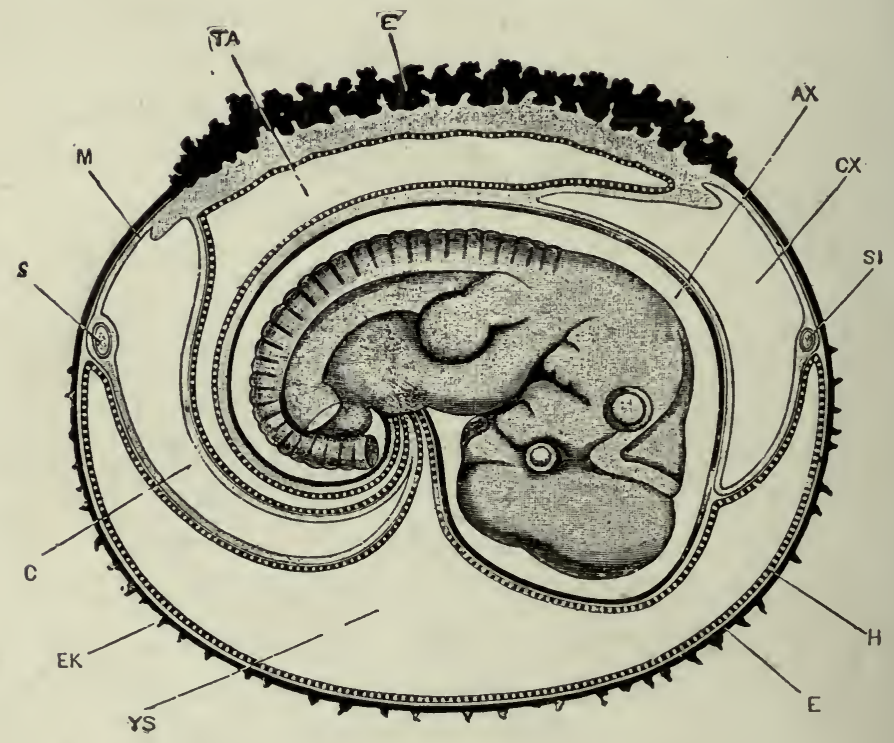

FIG. 96.-A RABBIT EMBRYO AND FCETAL APPENDAGES AT THE END OF THE TWELFTH DAY. THE EMBRYO IS REPRESENTED IN SURFACE VIEW FROM THE RIGHT SIDE ; THE YOLK-SAC AND FETTAL MEMBRANES ARE SHOWN IN MEDIAN LONGITUDINAL, OR SAGITTAL SECTION. THE HIND-LIMB AND PART OF THE TAI, HAVE BEEN REMOVED TO ALLOW THE YOLK-STALK AND ALLANTOIC STALK TO BE FULLY SEEN. (From Marshall, in part after Van Beneden and Julin.) $\times 8$.

$A X$, amniotic cavity, between the inner or true amnion and the embryo. $C, C X$, extra-embryonic part of the cœlom or body-cavity. $E$, epiblast. $E^{\prime}$, ectoplacenta, or thickened part of the epiblast from which the placenta is formed. $E K$, epiblastic villi. $H$, hypoblast. $M$, mesoblast. $S I$, sinus terminalis. $T A$, cavity of allantois. $Y S$, cavity of yolk-sac or blastodermic vesicle. 


\section{Development of the Mammal 3or}

important part in the formation of the foetal placenta, that part of the organ of attachment that is derived from the embryo, in distinction to the maternal placenta which is a specially modified region of the uterus. A careful study of Figures 93-96 will make plain the similarity in the formation of the false amnion or chorion in the mammal and in the chick.

In the chick, as has been noted above, the chorion remains as a thin, smooth membrane, but in the mammal its outer surface soon becomes roughened by small thickenings, which thickenings become large and branched to form the chorionic villi. That part of the chorion which lies next to the uterine wall, and is most intimately associated with the formation of the placenta, retains the villi as large, vascular, branching turfs and is known as the chorion frondosum. That part of the chorionic vesicle that is away from the region of attachment to the wall of the uterus is the chorion lave (Fig. 97).

It will be well, at this point, to say something of the position of the embryo in the uterus, and of the uterine walls during pregnancy. The "implantation" of the ovum by the action of the trophoblast has already been mentioned. In some animals the ovum, even after complete 
implantation has taken place, is partially uncovered; but with other mammals, including

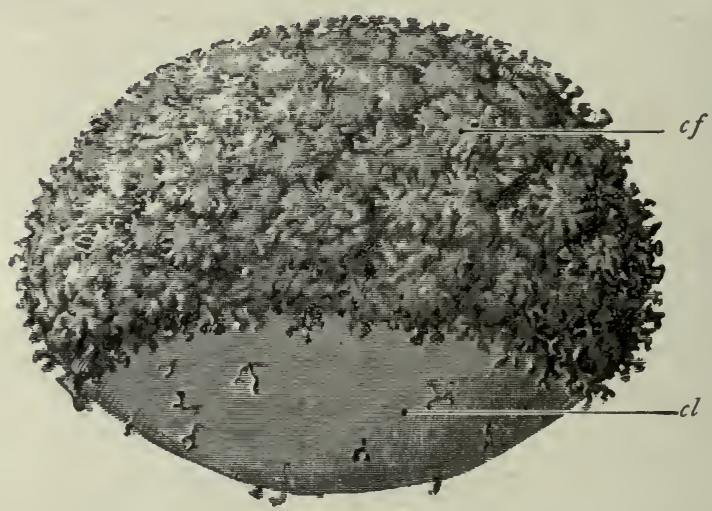

Fig. 97.-Human embryo. Age seven weeks. (From Kollmann.)

$c f$, chorion frondosum. $c l$, chorion læve.

man, the uterine mucosa grows over the ovum until it is entirely covered. The human ovum is normally implanted in the dorsal wall of the uterus.

When pregnancy occurs, a marked change takes place in the mucous lining of the uterus, consisting chiefly in the degeneration of the glandular epithelium and a conversion of a great number of the connective-tissue cells into the large, so-called decidual cells. This transformed mucosa is now called the decidua or 


\section{Development of the Mammal 303}

caduca. That part of the decidua to which the ovum becomes attached (Fig. 98) is called the decidua serotina; the part that is reflected

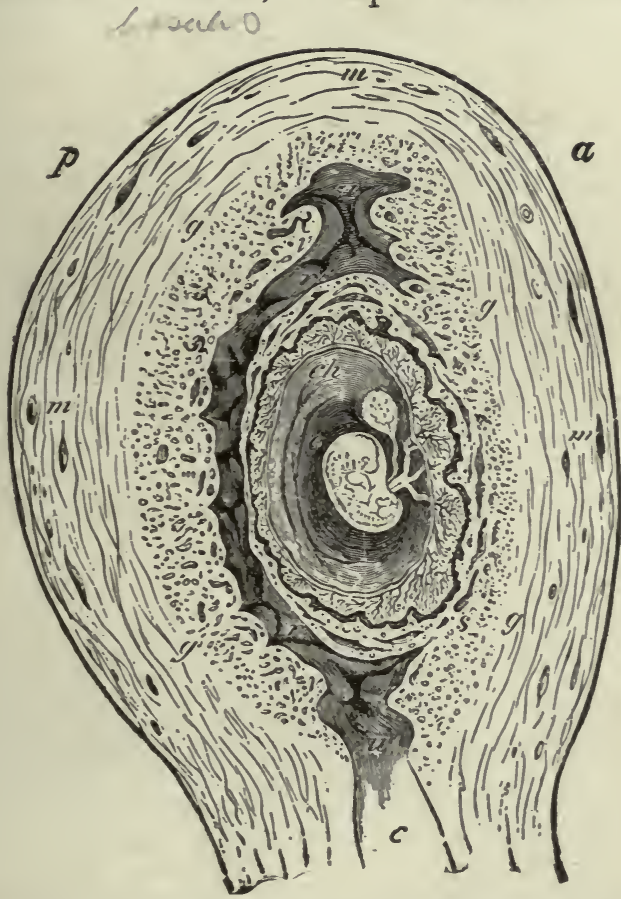

Fig. 98.-Semi-diagrammatic OUtLINe of an ANTERO-POSTERIOK SECTION OF A HUMAN UTERUS CONTAINING AN EMBRYO OF ABOUT FIVE WEEKS. (From Minot, after Allan Thompson.)

$a$, anterior surface. $c h$, chorion, within which is the embryo enclosed by the amnion, and attached to the chorion by the umbilical cord; from the cord hangs the pedunculate yolk-sac. $g$, outer limit of the decidua. $b$, posterior surface. $r r$, decidua reflexa. $s s$, limits of the decidua serotina. 
over the ovum is the decidua reflexa; and all the remaining portions of the decidua are called the decidua vera. As the embryo increases in size and the chorionic vesicle becomes large, the decidua reflexa is stretched out as a thin layer, and the boundaries of the three regions of the decidua become more distinct (Fig. 99). The surfaces of the vera and reflexa remain fairly smooth, while that of the serotina becomes more and more irregular as pregnancy proceeds, until the projections may reach a height of Io to I $5 \mathrm{~mm}$., as seen in the maternal placenta, to be described later. Further details as to the structure of the human uterus may be obtained from any text-book of histology.

Let us now return to the growth of the embryo and of the blastodermic vesicle. As has been said, the folding off of the embryo from the rest of the vesicle and the formation of the amnion take place in much the same way in the mammal as in the chick. As the embryo develops and the amnion is completed, the entire structure (embryo and amnion) comes to lie inside of the chorion; how this condition comes about will be easily understood by examining Figures 93-96. 


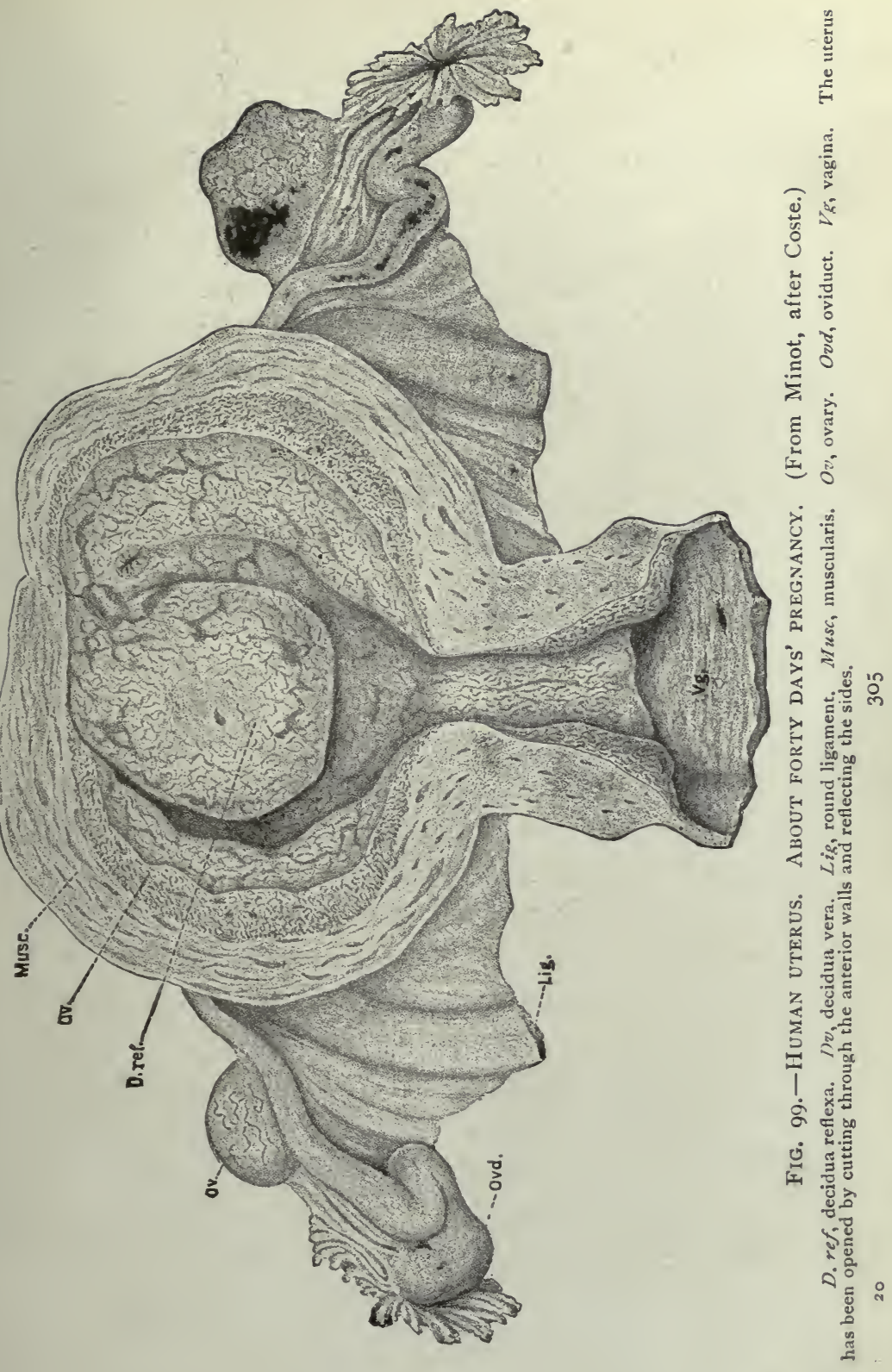


The Body-Stalk and Placenta

In the ungulate mammals (horse, pig, sheep, etc.) the fotal placenta is formed, practically, from the allantois, though the chorion is intimately concerned. In the unguiculate mammals (cat, dog, monkey, man, etc.) the conditions are rather different and will here be briefly described.

As seen in Figures 93-94, the embryo of the unguiculate mammal, when it becomes enclosed in the chorionic vesicle, retains a stalk-like connection between its posterior end and the inner surface of the chorion ; this stalk is mainly of mesoblast and is called the body-stalk. Into this stalk extends, as a narrow diverticulum from the hind-gut, the allantois. In the ungulates, where the body-stalk is not persistent, the allantois becomes a large vascular structure as in the chick, and is known as a free allantois. In the unguiculates, on the other hand, it is relatively small, though varying in size ; in man it is merely a long narrow tube extending into the body=stalk where it ends blindly.

In the ungulates the chorion is not vascular, though it comes into very close union with the vascular allantois.

In the body-stalk of the unguiculates there 
Development of the Mammal 307

are developed, from the embryonic angioblast, four blood-vessels, two veins and two arteries, the umbilical vessels. The two veins push their way into the embryo to open into the heart; the arteries also grow in the same direction until they connect with the dorsal aorta. At their distal ends these vessels extend through the body-stalk into the chorion, where they branch extensively to form the vascular network extending into the chorionic villi that have already been described. This very vascular chorion is the main part of the fotal placenta ; it varies in extent in different mammals. A brief description of the human placenta is given below.

During the growth of the embryo the chorionic villi have become closely dovetailed in between the corresponding projections of the decidua serotina, which projections, like the chorionic villi, become extremely vascular; the serotina may now be called the maternal placenta.

By the close juxtaposition of the capillaries of the fœtal and maternal placentæ there is possible an interchange of food and waste products between the blood of the mother and that of the fœtus, though there is no actual 


\section{8 Vertebrate Embryology}

passage of blood from the mother to the fotus, as is sometimes said to be the case.

As growth proceeds, the body-stalk becomes more and more elongated to form the umbilical cord (Fig. 105). At birth the human unbilical cord is usually about $50 \mathrm{~cm}$. long and Io to I 2 $\mathrm{mm}$. in diameter. It has a smooth, glistening, white surface, and appears to be spirally twisted. The spirals vary from about three to thirty in number, and are usually, though not always, from left to right; the cause of this spiral twist is not certainly known. Proximally the cord
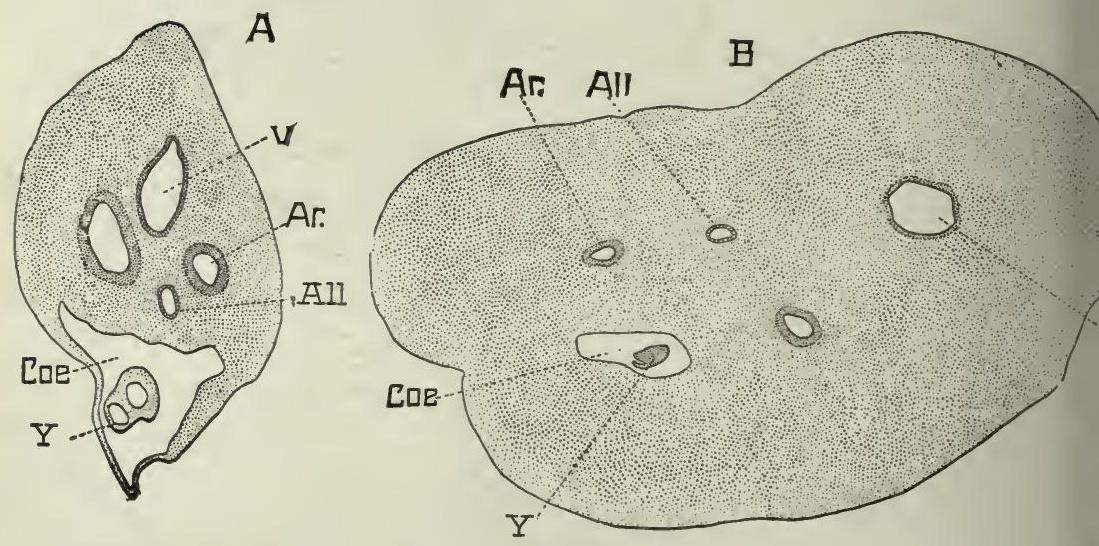

Fig, 100.-Sections of two human Umbilical cords. (From Minot.)

\footnotetext{
$A$, from an embryo of $2 \mathrm{r}$ min. $B$, from an embryo of sixty-four to sixty-nine days. All, allantois. $A r$, umbilical artery. Cre, colom. $V$, umbilical vein. $\mathrm{Y}$, yolk-stalk.
} 


\section{Development of the Mammal 309}

is attached to the fœtus at the umbilicus, while distally it is continuous with the fotal placenta. Its structure, as seen in cross section, varies with the period of pregnancy and somewhat with the plane of the section.

Figure 100" shows two sections of the cord, at different periods. In the younger section, which is, of course, the smaller, there is a considerable portion of the body-cavity; the yolkstalk and allantois are well marked, while the two arteries and one vein (formed by the fusion of the two original veins) are comparatively small. In the older section the body-cavity is smaller or absent, the yolk-stalk and allantois are less distinct, or even invisible, and the blood vessels are larger. The greater part of the substance of the cord is made up of angular or stellate mesoblast cells which form a sort of reticulum, the meshes of which are filled with fibres and a soft, jelly-like substance; it is often called jelly of Wharton. Surrounding the jelly of Wharton is a boundary of ectoderm. consisting of three or four layers of cells.

The human placenta, as has been said, consists of two parts, the maternal and the fœtal ; the former is simply the much-thickened decidua serotina, in whose villi very numerous blood 


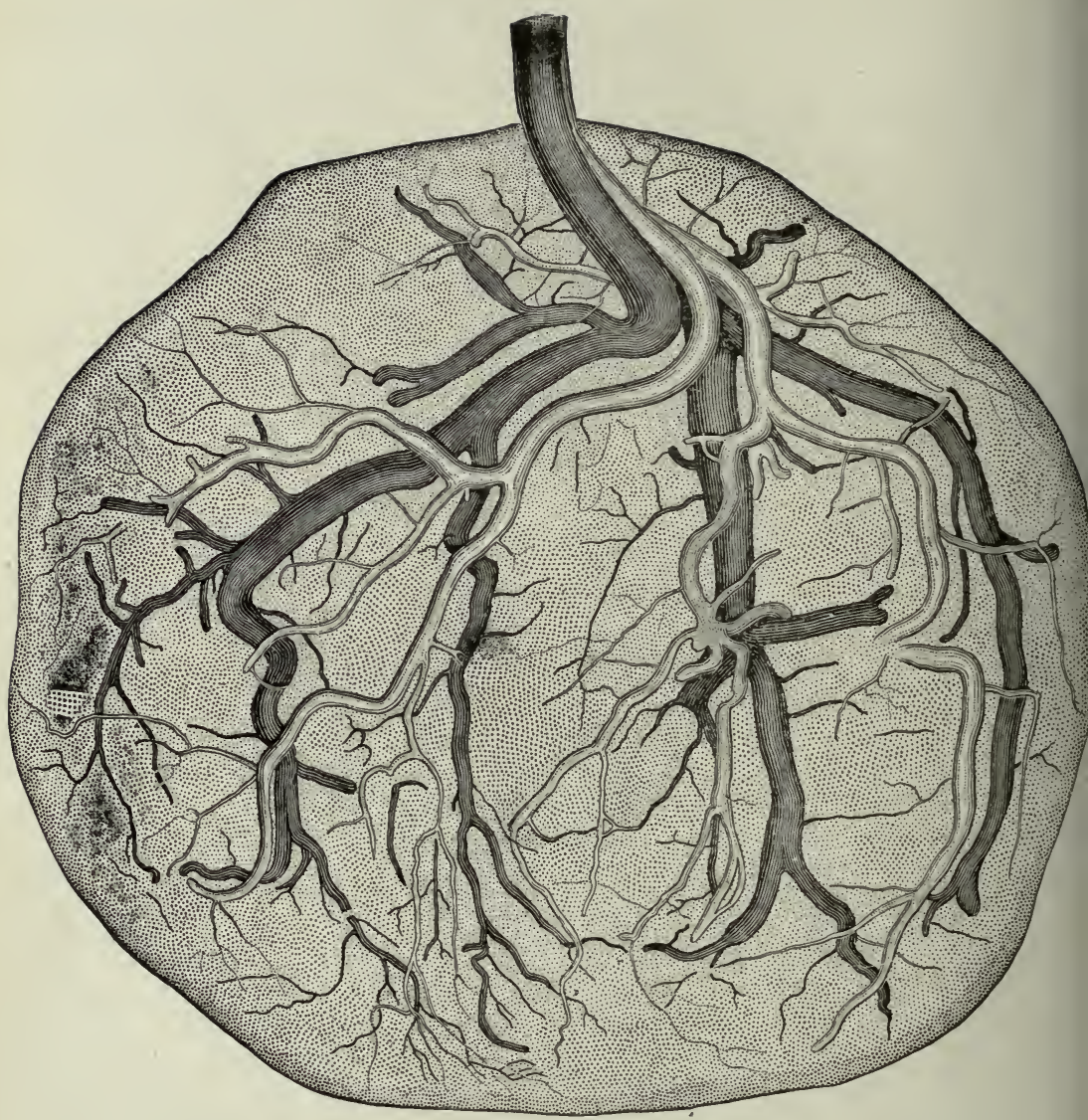

Fig. ior.-Human placenta at Full term, Doubly injected TO SHOW THE SUPERFICIAL DISTRIBUTION OF THE BLOOD-VESSELS. (From Minot.) The veins are drawn dark and lie deeper than the arteries. One-half natural
size. 


\section{Development of the Mammal 3i I}

vessels and sinuses have developed; while the latter is the thickened, discoidal portion of the chorion at the end of the umbilical cord. The size of the fotal placenta varies considerably, but is usually about $17 \mathrm{~cm}$. in diameter and $25 \mathrm{~mm}$. thick. It is oval or circular in outline, and the cord is generally attached eccentrically. The side away from the wall of the uterus and towards the embryo is more or less smooth, except where the ramifying vessels from the cord spread over it as small ridges (Fig. IOI); this side is covered by the

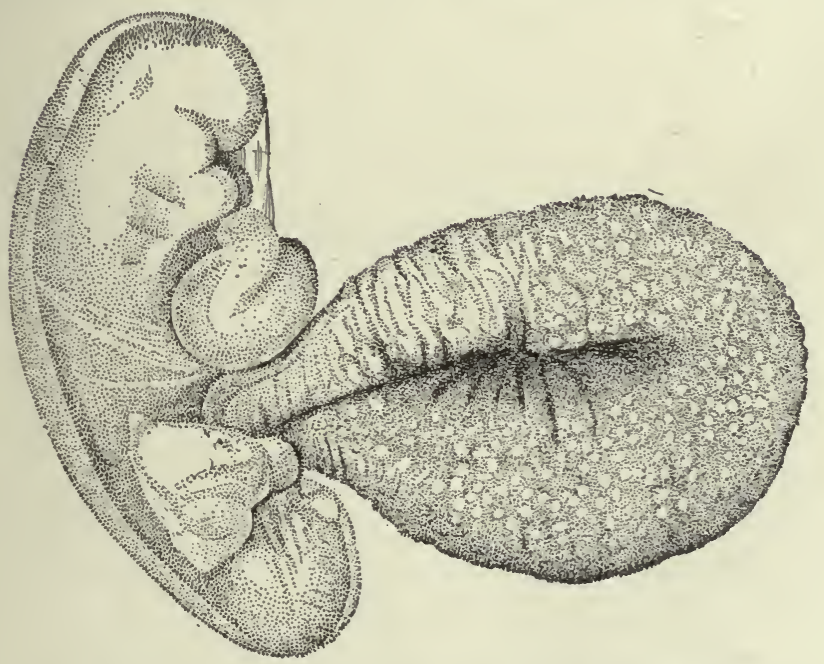

Fig. IO2.-Human embryo of 2.6 ma. (From Minot, after His.) 
amnion. The side next to the decidua serotina is soft and irregular, and is of a darker, though varying color, because of the blood vessels in it. The villi are separated by furrows into rounded or angular areas of about $25 \mathrm{~mm}$. diameter, the cotyledons. Covering this rough, villous surface and dipping down into the furrows just mentioned is a thin membrane, a part of the decidua that clings to the placenta when the latter tears away from the uterus.

When the child is born the amnion and chorion are ruptured, allowing the amniotic fluid to escape, but the infant remains attached, for a time, to the uterus, by means of the umbilical cord and the placenta; then the foetal placenta separates from the maternal and is passed out. This fœtal placenta, together with the remains of the amnion and chorion, and portions of the decidua, is known as the afterbirth.

That part of the allantois, in man, which lies in the umbilical cord remains in a rudimentary condition, but the intra-embryonic portions undergo further development; the proximàl portion becomes enlarged and hollow to form the urinary bladder, while the part between the apex of the bladder and the um- 


\section{Development of the Mammal 3r3}

bilicus is reduced to a solid cord of fibrous tissue, the urachus.

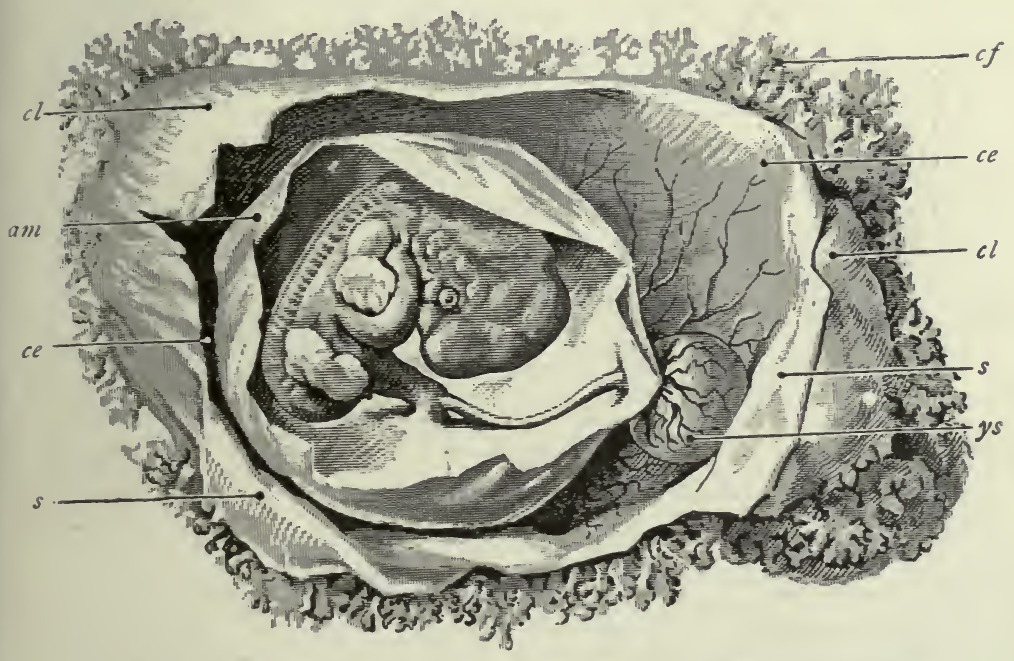

Fig. 103. - Human EMBRyo AT THE END OF THE SEVENTH WEEK. (From Kollmann.)

$a m$, amnion. ce, external cœlom. $c f$, chorion frondosum. $c l$, chorion læve. $s$, serosa. $y s$, yolk-sac.

The Yolk-Sac

The yolk-sac as seen in the frog and the chick has already been described. In the mammal it varies in size but is a very inconspicuous structure, and contains a liquid instead of the food yolk, as has already been said.

The early structure of the yolk-sac in the mammals is shown in Figures 93 and 94. 
At an early period, in most mammals, the entoderm and mesoderm extend entirely around the inside of the blastodermic vesicle, beneath the subzonal layer or ectoderm. The cleavage of this masoderm forms the cœlom, which extends entirely around the vesicle, except at the body-stalk, as the extra-embryonic cœlom (Fig. 93, Coe). This extra-embryonic cœlom separates the ectoblast and somatic mesoblast, now called the chorion, from the entoblast and splanchnic mesoblast which surrounds the original cavity of the blastodermic vesicle. This cavity, connected, as is seen in Figures 93 and 94 , by a wide stalk with the digestive cavity of the embryo, is called the yolk-sac, though it contains no yolk. The human yolk-sac is very small, at its greatest development being only 8-10 mm. in diameter. At its earliest known stage it is covered with blood vessels. As development proceeds it becomes constricted off from the intestine until it is connected with it by merely a slender, hollow neck, the whole structure being pear-shaped (Fig. IO2). The sac continues to increase in size until about the end of the fourth week. In later stages of development it is seen as a small, pear-shaped mass connected with the embryo by a long slen- 


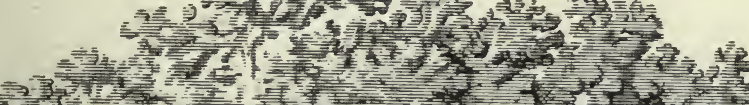

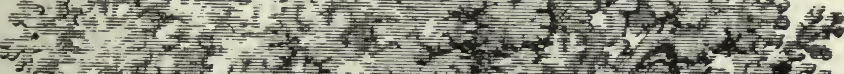
In

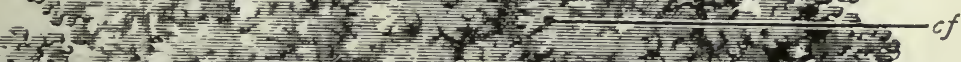

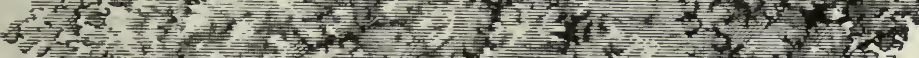

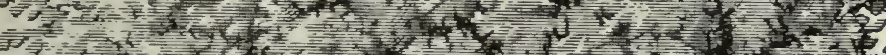

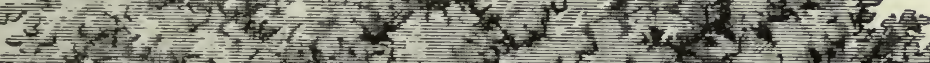

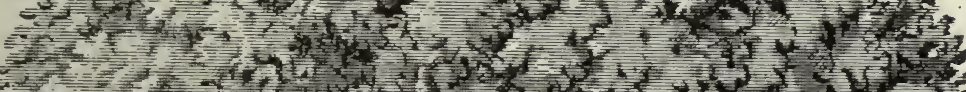
j. 2.

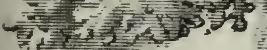

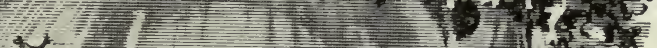

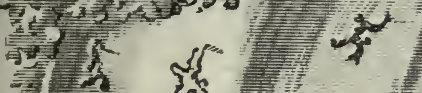
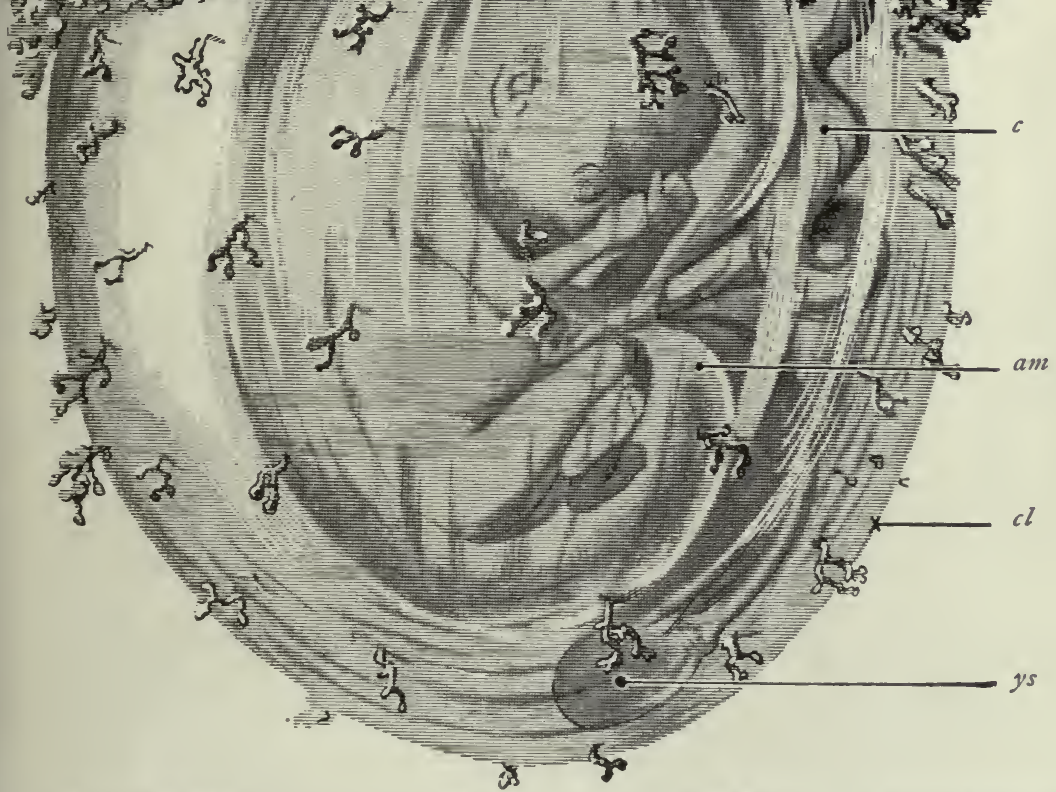

Fig. 104. - Human Fetus at The END OF THE FoukTh MoNTh. (From Kollmann.) am, amnion. $c$, umbilical cord. $c f$, chorion frondosum. $c l$, chorion lave. $y s$, yolk-sac. 
der thread, the yolk-stalk (Figs. 103 and IO4). This stalk is formed from the neck of the sac, which becomes greatly elongated and loses its central lumen; it enters the umbilical cord near its placental end and passes through it to its attachment to the intestine. The yolk-sac and stalk are so small in proportion to the other structures, during the latter periods of pregnancy, that they are easily lost sight of.

Development of the External Genitalia IN MaN

In the frog and chick there are no structures, save the cloaca, that could be called "external genitalia," so that it may be well, here, to give a brief summary of the development of these structures in the human embryo.

Until about the fifth week of development there is in man, as in the adult frog and chick, a common external opening, the cloaca, for both the rectum and the urogenital organs. Towards the end of the fifth week, before the completion of the septum (the future perineum) dividing the cloaca into an anterior portion, the uro-genital sinus, and a posterior portion, the anus, the anterior wall of the uro-genital sinus thickens to form a blunt projection, the 


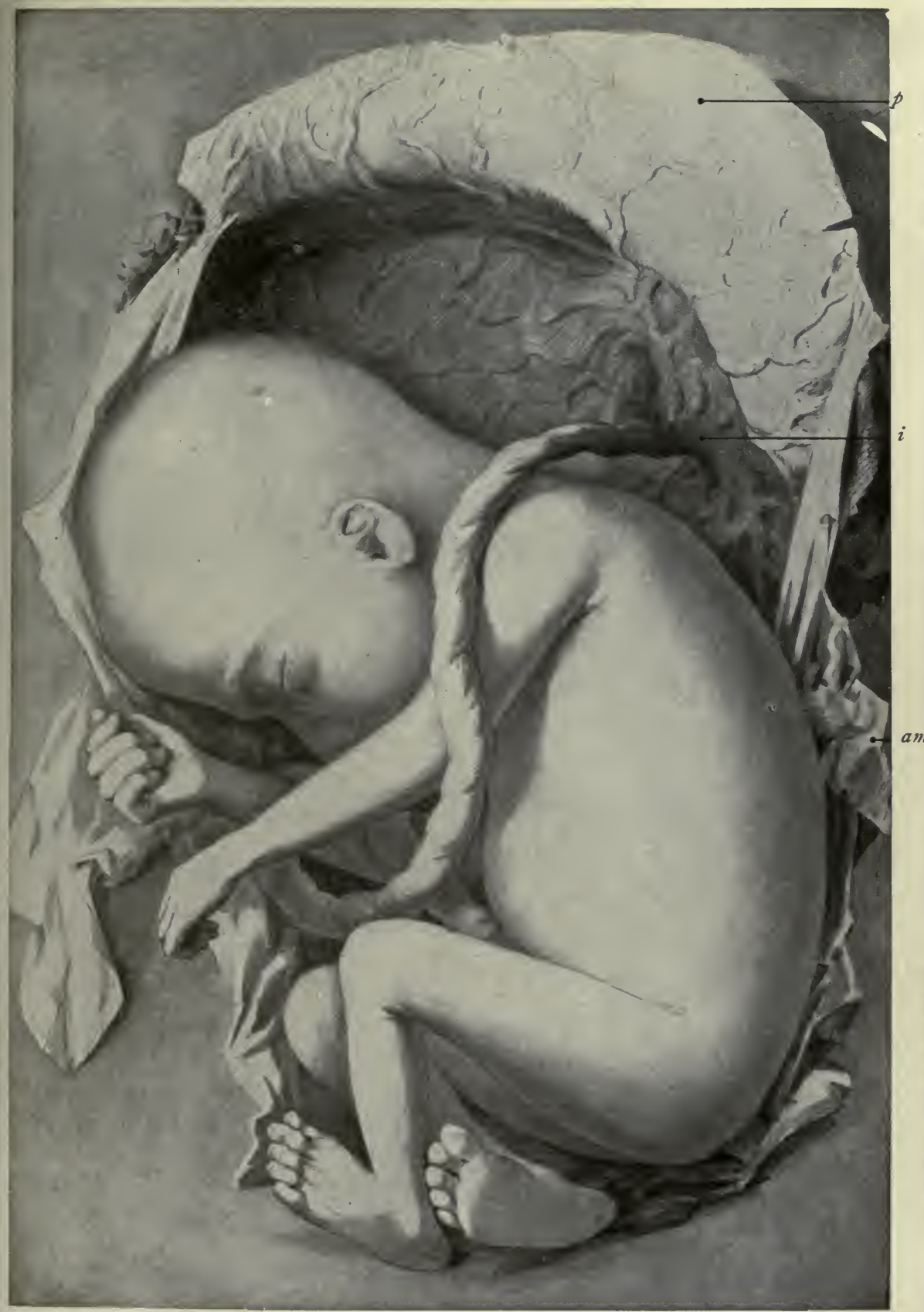

Fig. 105.-Human Feetus of SiX Months. (From Kollmann.) am, amnion and chorion læve. $i$, insertion of umbilical cord. $p$, placenta, covered by serosa and amnion. 317 
genital tubercle or clitero-penis (Figs. 106-I I 7). The end of this tubercle soon shows a slight enlargement, the glans. Along the posterior part of the ventral side of the tubercle is a groove, the genital groove or uro-genital sinus, whose edges are thickened to form the genital folds. Lateral to these folds are two others of greater extent, the genital swellings. This condition is reached at about the tenth week of fœtal life and is the same in both sexes; or, in other words, the external genitalia do not begin to show sexual differentiation until about the tenth week.

In the female the genital tubercle remains small and becomes the clitoris. The genital groove remains open as the vestibule, the genital folds becoming the labia minora, and the genital swellings the labia majora.

In the male the genital tubercle continues to increase in size and becomes the penis. The genital groove normally closes to become the penial urethra. The genital folds become the prepuce. The genital swellings fold over to become the scrotum, into which the testes later descend (about the eighth or ninth month) from their early position in the body-cavity. 
FIgURES IO6 TO I I7.-A SERIES OF FIGURES OF THE CAUDAL REGION TO SHOW THE DEVELOPMENT OE THE EXTERNAL GENITALIA IN THE HUMAN EMBRYO. (From Kollmann.)

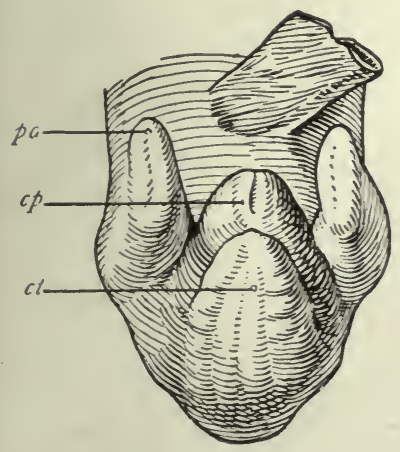

Fig. 106. - $17 m m$. in length. Sex not yet determinable.

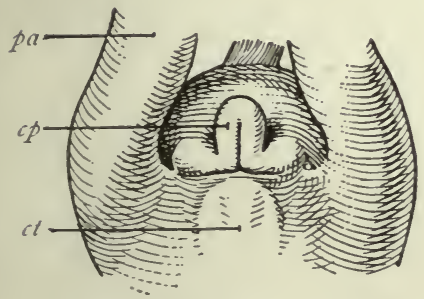

Fig. ro8. $-2+m m$, in length. Sex not yet determinable.

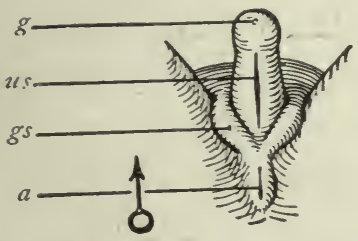

Fig. II0. $-37 \mathrm{~mm}$. in length. Male

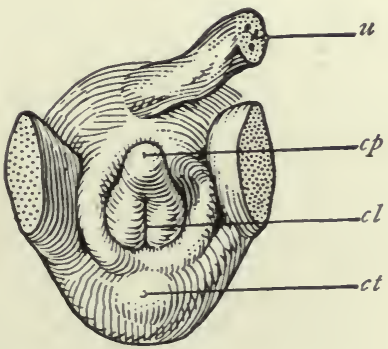

Fig. 107. $-23 \mathrm{~mm}$. in length. Sex not yet determinable.

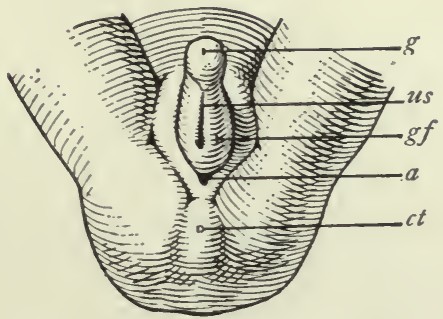

Fig. rog. $-29 \mathrm{~mm}$. in length. Sex not yet determinable.

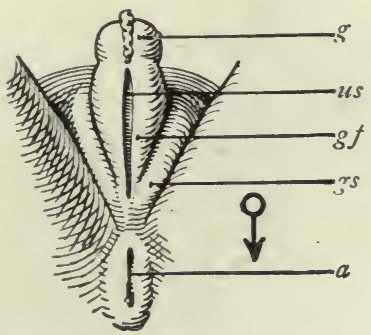

Fig. III. $-50 \mathrm{~mm}$. in length. Female. 


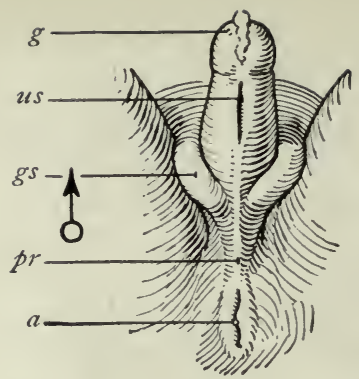

Fig. I $12 .-50 \mathrm{~mm}$. in length. Male.

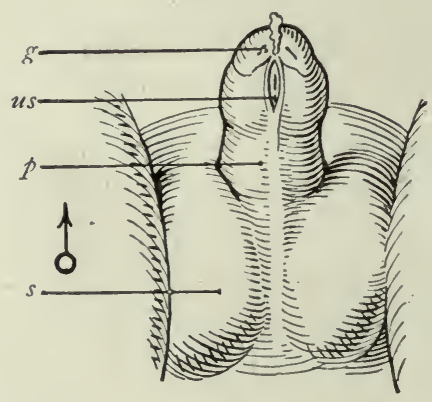

Fig. Ir $4 .-41 \mathrm{~mm}$. in length. Male.

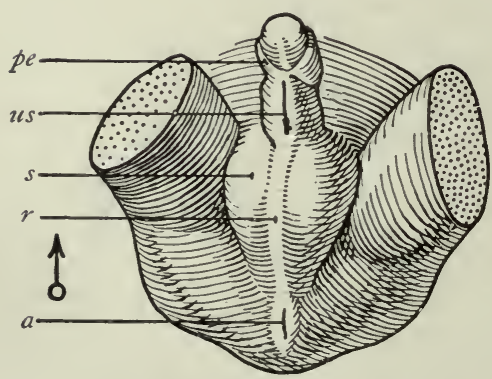

Fig. I $16 .-145 \mathrm{~mm}$. in length. (16 weeks.) Male.

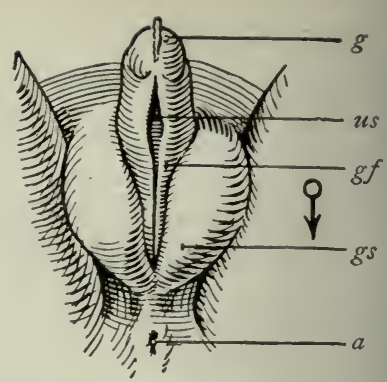

Fig. $x_{3} .-65 \mathrm{~mm}$. in length. Female.

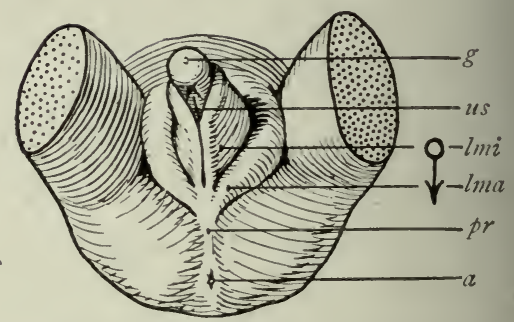

Fig. I $15 .-70 \mathrm{~mm}$. in length. (II weeks.) Female.

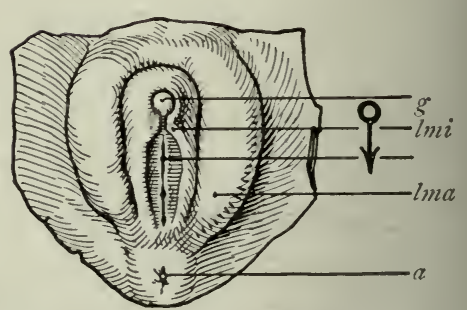

Fig. II7.-I $50 \mathrm{~mm}$. in length. (I6 weeks.) Female.

$a$, anus. $c l$, cloaca. $c p$, clitero-penis or genital tubercle. $c t$, caudal tubercle (tail). $g$, glans, $g f$, genital fold. $g s$, genital swelling. Ima, labia majora. $l m i$, labia minora. $\not$, penis. $p a$, posterior appendage. pe, prepuce. pr, perineum. $r$, raphe. $s$, scrotum. $u$, umbilical cord. us, urogenital sinus or genital groove. 
Development of the Mammal 32r

As was said above this differentiation begins at about the tenth week and is usually completed by the end of the third month. Abnormalities in the development of these structures will be noted below.

\section{Development of the Mammary Glands}

The mammary glands, being so typical of the mammalia, should, perhaps, be mentioned here, though their development, like that of the hair, another mammalian character, may be found in almost any text-book of histology.

Among most of the lower mammalia the mammary glands are first seen, in early embryos, as two lines of thickened epidermis, the milk ridges, one on either side of the abdominal wall. These ridges become more prominent at certain places where the glands develop, while they disappear in the intermediate regions. Similar milk ridges are said to occur in some early human embryos, but it is likely that the human mammary gland normally begins as a single circular thickening of the epidermis, which grows downwards, as a spherical mass, into the dermis. This mass loses its spherical form by the outgrowth of lobes into the surrounding tissue; these lobes con- 
tinue to elongate as solid rods of cells, which later become hollowed out to form the acini and ducts of the gland. Further growth of the gland consists chiefly in the increase in the number and length of the ducts and acini. This growth continues in both sexes until puberty, when it normally ceases in the male; in the female, at this time, a rapid development of the adjacent dermal tissues, especially the adipose, takes place, forming the breast. The nipple appears at different periods of embryonic life in different individuals; it sometimes does not appear until after birth.

In both sexes there is normally a slight secretion of milky fluid, witch milk, just after birth. In adult males, cases have been known where the mammary glands were functionally active.

\section{Calculation of the Age of Human Embryos}

The term "embryo" is usually applied to those. stages of development up to about the end of the second month; after that time it is customary to use the term "fœtus."

The life of the embryo is considered to begin with the fertilization of the ovum, which is supposed to occur in man in the upper third of the Fallopian tube. Ovulation most frequently 
Development of the Mammal 323

takes place at about the time of menstruation; and, this process of menstruation being the preparation of the uterus for the implantation of the fertilized ovum, it is likely that pregnancy can occur only when fertilization takes place at the beginning of the menstrual period. The occurrence of pregnancy stops the menstrual flow, hence it is customary to calculate the age of an embryo from the date of the first menstrual period which has lapsed. Sometimes conception may occur without interrupting the menstrual flow of that particular month, the interruption not occurring until the following period; in this case the difference of twentyeight days between the supposed and real time of conception would be so great that it would be apparent and would not cause error in the calculation of the age of the embryo.

It frequently happens, in the study of human embryos, that information as to the time of conception cannot be had. In such cases it is necessary to calculate the age of the embryo chiefly from its size, though there is considerable variation in this.

There are several methods of measuring the size of a human embryo. Perhaps the best single measurement is that known as the 


\section{$324 \quad$ Vertebrate Embryology}

"crown-rump" or "vertex-breech" measurement; it is the distance, in a straight line, between the point immediately over the midbrain and the lowest point of the rump (Fig. I $8, a-b)$. When this measurement has been carefully made, the age of an embryo, up to Ioo $\mathrm{mm}$., may be calculated, with more or less accuracy, by using the following formula: $a=\sqrt{l} \times 10$, in which $a$ is the age in days, and $l$ is the crown-rump measurement in millimeters.

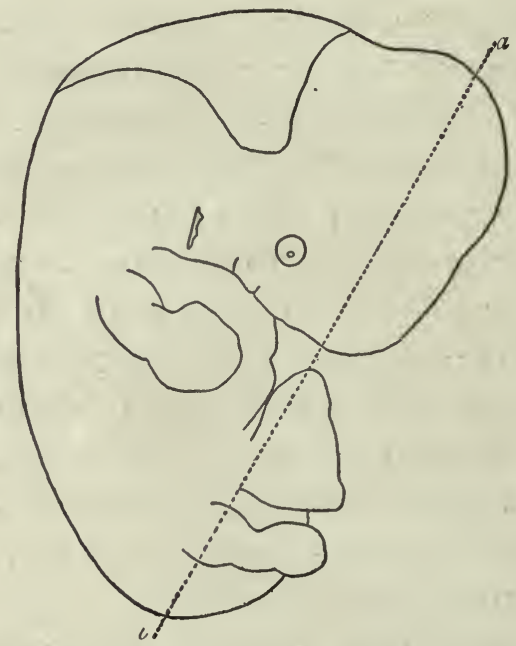

Fig, il 8.-Figure to illustrate the “VERTEX-BREECH" METHOD OF MEASURING HUMAN EMBRYOS. (Altered from Kollmann.)

$a-b$, vertex-breech length of the embryo. 
For example, an embryo with a crown-rump length of $16 \mathrm{~mm}$. would be about forty days old. This formula may be employed until a length of $100 \mathrm{~mm}$. is reached; from $100 \mathrm{~mm}$. to $220 \mathrm{~mm}$. the length in millimeters equals the age in days.

\section{Abnormalities in Human Development}

Attention will here be called to some of the more common abnormalities in the development of man, but for more detailed information upon this subject the reader is referred to treatises upon teretology and obstetrics.

Abnormalities occur in connection with both the fœtal membranes and the fœtus proper. Of the former group two or three will be mentioned. Amniotic abnormalities may consist in a deficiency or an excess of fluid. The normal amount is one to two pints at term. A deficiency may cause fœtal abnormalities through adhesions; while an excess, which sometimes reaches five or six gallons, may also cause abnormalities or premature birth. Amniotic bands, caused by the pulling out into bands of adhesions between the amnion and fœtus, may produce deformities or death.

The umbilical cord, which is usually about 
$50 \mathrm{~cm}$. long at birth, may be reduced to Io $\mathrm{cm}$., making parturition difficult or impossible; or it may reach a length of 2 to 3 meters, in which case its coils may cause trouble by producing knots to impede circulation. Various abnormalities of the chorion and placenta also occur.

Abnormalities of the fotus proper will be described in two groups: first, monstra per defectum; and second, monstra per excessum.

Monstra per defectum.-Abnormalities of this class may be grouped in two divisions: $A$, simple anomalies; $B$, abnormalities of arrested development. As examples of class $A$ may be mentioned : amorphous embryos, shapeless, skin-covered masses ; acephalous, or headless embryos ; microcephalic embryos, or those with very small heads; cyclops, or one-eyed embryos; embryos with one or more extremities or parts of extremities missing; embryos with ribs, vertebræ, or, in fact, almost any other part of the body missing.

The abnormalities of class $B$, arrested development, are among the most interesting of human anomalies. Among these may be mentioned : double uterus, caused by the incomplete fusion of the Müllerian ducts, the normal con- 


\section{Development of the Mammal}

dition among many mammals; hare-lip, which was described in connection with the chick, page 196 ; cleavage of the chest or abdomen, caused by the incomplete fusion of the somatopleure; branchial fistula, the incomplete closure of a gill cleft; various forms of hernia; umbilical fistula, the incomplete closure of the outer end of the intra-embryonic allantois, allowing urine to escape from the bladder through the urachus; cloacal formation, the incomplete separation of vagina and rectum; hypospadias, the incomplete fusion of the lips of the genital folds, thereby leaving the urethra as an open groove; true hermaphroditism (of perhaps doubtful occurrence), where both ovaries and testes are found in the same individual, though probably never functionally active, even if found; false or spurious hermaphroditism, where a male (an individual with testes) may have some of the accessory reproductive organs of the opposite sex, or a female (an individual with ovaries) may have some of the accessory reproductive organs of the male; almost any combination of male and female accessory organs may be found, but it is to be noticed that most false hermaphrodites are males and have, when grown, the beard, voice, and in- 
stincts of the male. Other examples of arrested development might be given, but the above will give an idea of what is meant by that class of abnormalities.

Monstra per excessum. - Abnormalities of this class also may be arranged in two groups : $A$, over-large development, as in giants, where the whole body is abnormally large; megacephalic individuals, with very large heads; individuals with any other part of the body abnormally enlarged. $B$, supernumerary formation, as in twin monsters, joined in all conceivable ways; supernumerary mammæ, fingers, or almost any other part of the body.

Before leaving the subject of abnormalities it may be well to say a few words as to the supposed cause of multiple births, of both normal and abnormal infants. The occurrence of twins is, of course, quite common, and triplets and quadruplets are not unknown. Cases of six or even eight embryos in one uterus have been reported, but they are of very doubtful authenticity.

In the case of double births we may have either fraternal or duplicate twins, or double monsters. Fraternal twins are usually no more alike than any two children of the same parents; 


\section{Development of the Mammal 329}

they have probably been formed by the simultaneous fertilization of two ova, each of which developed into a normal individual, either male or female. Duplicate twins, on the other hand, are usually so much alike as to be with difficulty distinguishable from each other. They may be explained by supposing the ovum to have separated into two parts, at the two-cell or other early stage of development, and each part to have developed into a normal fetus. Such duplicate twins may be produced by cutting apart the blastomeres of the egg of some of the lower animals, in the two-cell stage, when each blastomere will develop into a small, but otherwise normal embryo.

Should the separation of the parts of the human embryo not be complete, or should two embryos develop in too close proximity in the uterus, a double monster may be formed, the extent of fusion varying from a comparatively slender cord, as in the famous Siamese Twins, to an almost complete fusion, so that one fœtus may look like a mere parasite upon the other. 



\section{INDEX}

Abnormalities in human development, 325-329

Acephalous embryos, 326

Afterbirth, 3 I 2

Air sacs: Chick, 209

Air space: Chick, 9o

Albumen of egg: Chick, 90

Alimentary canal: Frog, 455 I Chick, 203-2 I 2

Allantois: Chick, 16r, 263 complete history of: Chick, I 69-1 72

(mammal), 306

Amnion: Chick, I I 7, I32, I 6o-I 6I

entire history of: Chick, I $67-169$

formation of (mammal), 297

(human), abnormalities of, 325

Amniotic, bands, 325

cavity: Chick, 168

Amorphous embryos, 326

Angioblast, 147

Anterior chamber: Chick, 183

Anus (man), 3 I 6

Aortic arches: Frog, 62; Chick, I45, 243; (see Branchial blood-vessels) fate of: Chick, 246

Archenteron: Frog, 25

Archinephric duct: Frog, 78

Area, opaca: Chick, I04 pellucida: Chick, Iо4
Arrested development, 326-327

Artery, allantoic: Chick, 248 carotid: Frog, 6r; Chick, 244

lingual: Chick, 244

mandibular: Chick, 244

pulmonary: Chick, 245

subclavian: Chick, 245

umbilical: Chick (see Allantoic artery)

vitelline: Chick, I45, 248

Auditory, capsules: Frog, 77 ; Chick, 267

pits: Chick, I4I

vesicle: Frog, 43; Chick, 185

Auricle: Chick, I 56

Auricular chamber: Frog, 6I

Basilar plate: Frog, 75 ; Chick, 226

Beak: Chick, 2SI

Bladder: Frog, 50 urinary (mammal), 3 I 2

Blastoderm: Chick, 91, ro3, ${ }_{1} 6_{3}$

section of: Chick, I 2 I

Blastodermic vesicle, 290

Blastomere: Frog, 18

Blastopore: Frog, 22, 46

Blastula: 100

Blood: Chick, I46-I 5 I corpuscles (see Blood) islands: Chick, I47 
Blood-Continued

vessels: Frog, 56-69; Chick, I 46-I 5 I

Body-cavity: Frog, 30, 6972 ; Chick, 132

Body-stalk, 304-308

Brain: Frog, 36-40; Chick, I 54, I 72-I 73

Branchial arch: (see Visceral clefts and folds)

Branchialblood-vessels: Frog, 62

Branchial cleft: (see Visceral clefts and folds)

Branchial fistula, 326

Branchial folds: (see Visceral clefts and folds)

Breast, 322

Bulbus arteriosus: Chick, I45, I 56

Caduca, 302

Carotid arch: Frog, 67

Carotid gland: Frog, 68

Cartilage bones: Chick, 267

Centra: Frog, 73

Cerebellum: Frog, 37; Chick, 224

Cerebral hemispheres: Frog, 38; Chick, I 54, 224

Chalazæ: Chick, 9 I

Chorion, 298, 306-308

Chorion læve, 3 ㅇ

Chorionic villi, 3 이

Choroid coat: Chick, I 8I

Choroid fissure or slit: Frog, 42 ; Chick, I 79

Chromosome: I 2

Cicatricula: (see Blastoderm)

Circulation, changes in, at metamorphosis: Frog, 63-69

Circulation, changes in, at time of hatching: Chick, 259-261

at end of second day:
Chick, I 57-I 59

of third day: Chick, $201-$ 203

at end of third day: Chick, 256-26I

Cleavage of chest, 326

Cleavage of the egg: (see Segmentation of the egg)

Cleavage plane: Frog, I 7

Clitoris, 3 I 8

Clitero-penis, 3 I 6,3 I 8

Cloaca: Frog, 45-48; Chick, 206; Man, 3 I 6

Cloacal formation, 327

Coelom: (see Body-cavity)

Concrescence, $24-25$

Conjunctival epithelium: Chick, 183

Cornea: Chick, r 83

Corneal corpuscles: Chick, I 83

Corona radiata, 286

Cotyledons, placental, 3 I I

Cranial flexure: Frog, 36; Chick, I 55, I67, 223

Cranial nerves: Chick, I55, 226

Cranium: Frog, 75; Chick, $265-267$

Crown-rump measurement of embryo, 323

Crura cerebri: Frog, 37

Cyclops, 326

Decidua, 302

Decidua reflexa, 302

Decidua serotina, 302

Decidua vera, 302

Decidual cells, 302

Descent of testis, 318

Development, rate of: Frog, r; Chick, I 20

Discoidal cleavage: 97

Dorsal aorta: Frog, 6r ; Chick, I 45 


\section{Index}

Double monsters, formation of, 329

Double or bifid uterus, 326

Ductus arteriosus: (see Ductus Botalli)

Ductus Botalli: Chick, 246, 260

Ductus Cuvieri: (see Cuvierian vein)

Ductus venosus: Chick, 199 closure of: Chick, 26I

Duodenum: Chick, 206

Ear: Frog, 43 ; Chick, I $84-187$ Ectoderm or ectoblast: Frog, 24 ; Chick, 104 ; (in mammals), 29 I

organs from: Frog, 3I; Chick, 276-277

Egg: (see Ovum) Frog, 6-10, 88; Chick, 90-93; Starfish, 5-6

passage through oviduct: Chick, 94-95

Eighth day, development of: Chick, 28 I

Eleventh day to hatching, development of: Chick, $28 \mathrm{I}-283$

Embryo, change in position of: Chick, 165-167, 283

calculation of age of, 322 ; definition of, 322

cloth model of: Chick, I I 4Ir 9

curvature of body of: Chick, I 67

estimation of age of: Chick, $134-135$

folding off of (mammal), 296

(human), formula for calculation of age of, 324 method of measuring, 323 movements of: Chick, 28,3 rocking motion of: Chick, I69

Embryo-sac: Chick, I 16, I65

Embryonic shield: Chick, I 22; (mammal), 293-294

Entoderm or entoblast: Frog, 26; Chick, I2I; Mammals, 20 I

organs from: Frog, 3I ; Chick, 277

Epididymis: Chick, 236

Equal segmentation, 97

Ethmoidal plate: Chick, 267

Eustachian tube: Frog, 53; Chick, 193

Eustachian valve: Chick, 259

Exoccipital: Frog, 77

External auditory meatus: Chick, I 93

External genitalia of man, development of, 3 I 6-320

External nares: Frog, 45; Chick, I 87

Eye: Frog, 4I-43; Chick, I 75I 84

Eyelids: Chick, 183

Fallopian tube: (see Oviduct) False amnion: Chick, 168

Fat bodies: Frog, 88

Feathers: Chick, $28 \mathrm{I}-28_{2}$

Female pronucleus: Frog, I I

Fertilization of the egg: Frog, I6-I 7; Chick, 95; Mammal, 289

Fifth day, development of: Chick, $263-278$

First day, development of: Chick, I 20-139

Fœtal, membranes, abnor$\therefore$ malities of, 325

placenta, 299, 307, 309, 3 I 2 Fœtus, abnormalities of, $3^{2} 6$ 329

definition of, 322 
Foramen ovale of heart: Chick, 256-26r

Fore-brain: Frog, 37; Chick, I 4 I

Fore-gut: Chick, r3 I, 203

Formula for calculation of age of human embryos, 324

Fourth day, development of: Chick, 22 2-262

Fourth ventricle: Frog, 37

Frontal bone: Frog, 77

Fronto-nasal process: Chick, I95

Gastrula, Ioo

Gastrulæ, kinds of, $100-102$

Gastrulation, relation to amount of yolk, 98-103

Genetic restriction, law of, 276

Genital organs: Frog, 87-89; Chick, 237-24I; Man, 3I6-320

folds, $3 \times 8$

groove, 316,318

ridge: Frog, 87 ; Chick, 237 , 239

swellings, 3 r 8

tubercle, 3 I 6,3 I 8

Germ layers, fate of: Frog, 30-31; Chick, 276-277

formation of: Frog, $2 \mathrm{I}-3 \mathrm{O}$;

Chick, IO3-IO4, I 2 I-I 27

Germinal disc: Chick, 94

Germinal vesicle: Frog, 7; Chick, 94; Starfish, 6

Giants, 327

Gill clefts and folds, development and fate of: Frog, 5I-56; Chick, I 92-198

Gill pouch: (see Gill clefts and folds)

Gills, external and internal: Frog, $53-56$

Gizzard: Chick, 207

Glomerulus: Frog, 82
Glottis: Chick, $2 \circ 9$

Gonoblast: Frog, 88; Chick, 239-240

Graafian follicle: Chick, 240

Harelip: 196

Hatching: Chick, 283

Head: Chick, 224-226

Head-fold: Chick, I30-I3I, I 60

Head-kidney: Frog, 78-82;

Chick, 233-234

fate of: Frog, 8 I-82; Chick. 236

Heart: Frog, 56-69; Chick, I 43, I 55, I 98, 24 I-242, $268-270$

beginning of pulsations of: Chick, I 45

and blood-vessels, develop. ment of: Frog, 56-69

endothelial lining of: Frog, $5^{8}$

looping of: Chick, I 44

musculature of; Frog, 60

Hermaphroditism, false, 327 ; true, 327

Hernia, 326

Hind-brain: Frog, 37; Chick, I 4 I

Hind-gut: Chick, 203

Histological differentiation, 273-277

types of, 275

Holoblastic segmentation: (see Segmentation, complete)

Hyoid apparatus: Chick, I 94 Hyoid arch: Frog, 5I: Chick, I 9 I

Hyomandibular cleft: Frog, 5 I; Chick, I 9 I

Hypospadias, 327

Implantation of ovum, 293. 301 


\section{Index}

Infundibulum: Frog, 37

Inner cell-mass, 290

Interauricular septum: Chick, 270

Intermediate cell-mas : Chick, 2 I 6

Interorbital septum: Chick, 267

Interventricular septum : Chick, 269

Invagination:Frog, 22 ; Chick, I 30-1 31

Iris: Chick, 182

Jelly of Wharton, $3 \circ 9$

Karyokineses, 18

Kidney, permanent: Chick, 2 I 6-2I $7,235^{-2} 36$

Labia majora, 3 r 8

Labia minora, 318

Labyrinths of ear: Chick, 185

Lachrymal gland and duct:

Chick, $188_{3}-184$

Larynx: Frog, $5 \circ$

Lateral plate: Chick, I 34

Lens capsule: Chick, I 78

Lens vesicle: Frog, 43; Chick, I 76

Ligamenta suspensoria: Chick, 230

Limbs: Frog, 4; Chick, 224 , 264

rotation of: Chick, 264

Liver: Frog, 48; Chick, 2092 I I

blood supply of: Chick, 253254

Lower layer cells: Chick, 105

Lungs: Frog, 49; Chick, $207-$ 209

Male pronucleus, I 6

Malpighian bodies: Frog, 83; Chick, 2 I 7
Mammary glands, development of, $321-322$

Mandible: Chick, I95

Mandibular arch: Frog, 5r ; Chick, r9I

Manus: Chick, 264

Maternal placenta, 300, 307, 309-3 I 2

Maturation of egg: Frog, roI6; Chick, 94-95; Mammal, 289

Maturation, theories of, III 6

Maxillary process: Chick, 195

Meatus venosus: Chick, I99, $25 \mathrm{I}-25^{2}$

Medulla: Frog, 37 ; Chick, 224

Medullary, canal: Frog, 34; Chick, r 30

folds: Frog, 32 ; Chick, 129 groove: Frog, 32 ; Chick, I 29

plate: Frog, 32; Chick, I 29 Megacephalic embryos, 328

Membrane bones: Chick, 267 Membranous vertebral column; Chick, 227

Menstruation (human), 322

Meroblastic cleavage: (see Partial cleavage)

Mesenteron: Frog, 25, 45

Mesentery: Chick, 204

Mesoblast or mesoderm: Frog, 28-29; Chick, I22; Mammal, 295

changes in: Chick, 2 I 2-2 I 6 cleavage of: Frog, 30; Chick, ${ }^{2} 32$

organs from: Frog, 3r; Chick, 277

origin of: Frog, 28-29; Chick, 125

Mesoblastic somites: Frog, 7०; Chick, I 34

number of, in relation to age: Chick, r $34-135^{-1}$ 
Mesonephros: (see Wolffian body)

Metanephros: (see Kidney, permanent)

Microcephalic embryos, 326

Mid-brain: Frog, 37; Chick, I4 I

Mid-gut: Chick, $2 \circ 3$

Milk ridges, $32 \mathrm{I}$

Monsters, double, formation of, 329

Monstra per defectum, 326327

Monstra per excessum, $3^{2} 7^{-}$ 329

Müllerian duct: Frog, 83-85; Chick, 233-234

fate of: Frog, 85 ; Chick, 237

Multiple births, 328

Muscle plate: Chick, 2 I 4

Muscular system, development of: Frog, 69-72

Myocœl: Chick, 2 I4

Myotomes: (see Mesoblastic somites)

Nails: Chick, 282

Nares: Frog, 45; Chick, I 87

Nasal pits: Frog, 44; Chick, 187

Nephrostomes: Frog, 78; Chick, 2 I 8

Nervous system, development of: Frog, 3I-40

Neural arch, canal, fold, groove, and plate: (see Medullary)

Neural canal: Mammal, 296

Neurenteric canal: Frog, 34; Chick, $135^{-1} 36,206$

Nictitating membrane: Chick, 183

Ninth day, development of: Chick, 28 I

Nipple, 322
Nose, development of: Frog, 44-45; Chick, I87-I88

Notochord: Frog, 27-28; Chick, I26, I55; Mammal, 296

disappearance of: Chick, 230

vacuolation of: Chick, 23 I233

Nucleus: (see Germinal vesicle)

Nucleus of Pander: Chick, IO4

Odontoid process: Chick, 230 Esophagus: Frog, 50; Chick, 207

closure of: Chick, 205-206

Olfactory capsule: Frog, 77 ; Chick, 267

lobe: Frog, 40; Chick, I 73 pit: Frog, 44; Chick, 187

Opercular fold: Frog, 55

Optic capsule: Frog, 77

cup: Frog, 42; Chick, I 78

lobe: Frog, 37

nerve: Chick, I 8 I

stalk: Chick, I 76

thalami: Frog, 37

vesicle: Frog, 42; Chick, I 4 I, I 55, I 76

Orientation of embryo: Frog, r 8; Chick, 123

Ossification of vertebral column: Chick, 230

Otic vesicle: (see Auditory vesicle)

Ovary: Frog, 87-88; Chick, 240

Over-large development, 327

Oviduct: Frog, 85 ; Chick, 237

Ovulation (human), 322

Ovum: (see Egg) human, 286

Pancreas: Frog, 48; Chick, 2 I I 


\section{Index}

Parachordal rods: Frog, 75; Chick, 266

Parasphenoid: Frog, 75

Parietals: Frog, 77

Parovarium: Chick, 236

Parthenogenesis, I 5

Partial cleavage or segmentation, 97

Pecten: Chick, I82

Penial urethra, 318

Penis, 318

Pericardial cavity: Frog, 6o, 72 ; Chick, $270-273$

Perineum, 316-320

Peripheral nerves: Frog, 40; Chick, 173

Perivitelline space, 286

Permanent segmentation: (see Secondary segmentation)

Pes: Chick, 265

Pharynx: Frog, 46; Chick, 204

Pineal body: Frog, 39

Pituitary body: Frog, $37-38$

Placenta, 93, I 72 fotal, $307-3$ I 2 maternal, 300

Plakodes: 276

Pleural cavity: Chick, 270273

Polar bodies, I I

Polyspermy, I 7

Pregnancy (human), occurrence of, 322

Prepuce, 3 I 8

Primary segmentation: Chick, 229

Primitive axis, 296

groove: Frog, 30; Chick, 124

knot, 293

ova: Chick, 240

streak: Frog, 30; Chick, I23; Mammal, 294

streak, cross-section of: Chick, 124 streak and groove, meaning of: Chick, I 25

Primitive germ cell (see Gonoblast)

Pro-amnion: Chick, I6o

Pro-chorion, 292

Pronephros: (see Head-kidney)

fate of: (see Head-kidney)

Pro-otic: Frog, 77

Protodæum: Frog, 45-47; Chick, 206-207

Proto-vertebra: (see Mesoblastic somite)

Pulmo-cutaneous arch: Frog, 67

Pulmonary trunk: Chick, $24+$

Pupil: Chick, 182

Pygostyle: Chick, 230

Rana temporaria: Frog, I

Reduction division, I 2

Reproductive organs: Frog, 87-89; Chick, 237-24I

Retina: Chick, I 79

Ribs: Chick, 265

Scales: Chick, 282

Sclerotic coat: Chick, I 8 I

Scrotum, 318

Second day, development of: Chick, 139

Secondary segmentation: Chick, 229

Segmental duct: (see Archinephric duct)

Segmental plate: Frog, 70; Chick (see Vertebral plate)

Segmentation, cavity: Frog, 20-2 r; Chick, I05; Mammal, 290

complete: 96-97

of the egg; Frog, I7-2I;

Chick, 96-103

nucleus: Frog, 16 
Segmentation-Continued relation of, to amount of yolk, 98-ı०3

Sense capsules: Frog, 77

Sense organs: Frog, 40-45; Chick, I 75-1 88

Serous membrane: Chick, I I I

Seventh day, development of: Chick, 279-28I

Sex cells: Man, 285

Sexual eminence: Chick, 239 differentiation: Man, 3 I 8

Shell: Chick, 90

Shell membrane: Chick, 90

Simple anomalies, 326

Sinus rhomboidalis:Chick, I 4 I

Sinus terminalis: Chick, 147

Sinus venosus: Frog, 60; Chick, I99

Sixth day, development of: Chick, 279-28I

Skeleton, development of: Frog, 72-77; Chick, 226230, 264-265

Skull: Frog, 74; Chick, 265268

Somatic stalk: Chick, II6, I 65

Somatopleure: Frog, 29; Chick, I 32

Spawning: Frog, 2

Spermatogenesis: (see Spermatozoa)

Spermatozoa: Frog, 87-88; Chick, 24I; Human, 287288

Sperm duct: (see Vas deferens)

Sphenethmoid: Frog, 77

Spinal nerve roots: Frog; 40

Splanchnic stalk: Chick, I65

Splanchnopleure: Frog, 29; Chick, I 32

Spleen: Frog, 69

Sternum: Chick, 265

Stomach: Chick, 206

Stomodæum: Frog, 45-46 perforation of: Chick, 226 Subgerminal cavity: Chick, 105

Subzonal layer, 290

Summary of development: Frog, 2-4; Chick, II 4I 9

of first day: Chick, I 36-I 37

of first half of second day: Chick, I 5 I-I 54

of second half of second day: Chick, 162

of third day: Chick, 220$22 \mathrm{I}$

of fourth day: Chick, 262 of fifth day: Chick, 278

Superficial cleavage, 97

Supernumerary formation, 328

Sylvian aqueduct or iter: Frog, 37

Sympathetic nerves: Chick, I 73-I 74

Systemic arch: Frog, 67; Chick, 245

Systemic trunk: Chick, 245

Tenth day, development of: Chick, $28 \mathrm{I}$

Testis: Frog, 87-88; Chick, 240

Thalamencephalon: Frog, 37; Chick, 224

Third day, development of: Chick, I63-22I

Third ventricle: Frog, 37

Thyroid body: Frog, 50: Chick, 2 II

Tongue: Chick, 28 I

Trabeculæ cranii: Frog, 75; Chick, 267

Trachea: Frog, 207

Transverse process: Frog, 74

Trophoblast, 292

True amnion: Chick, 168

Truncus arteriosus: Frog, 6I 


\section{Index}

Twins, duplicate, formation of, $328-329$

Twins, fraternal, formation of, 328

Tympanic cavity: Frog, 53; Chick, 193

Tympanic membrane: Chick, I93

Umbilical cord, 307 abnormalities of, 325

Umbilical fistula, 326 vessels, 306

Umbilicus, 308

Unequal segmentation, 97

Unguiculate mammals, 304

Ungulate mammals, 304

Urachus, 3 I 2

Ureter: Frog, 85; Chick, 235

Uro-genital organs, development of: Frog, 78-89; sinus (man), 3 I 6

Urostyle: Frog, 73

Uterus, mammalian, 305

Vasa efferentia: Frog, 87

Vascular area: Chick, 147, I $63-165$

Vascular system: Chick, 145 , I 56-I 59, I 98-203, 242$26 \mathrm{I}$

Vas deferens: Chick, 236

Veins, a ff e re n t hepatic: Chick, $25 \mathrm{r}$

cardinal: Chick, 200

cardinal, fate of: Chick, 250

Cuvierian: Chick, $20 \mathrm{I}$

efferent hepatic: Chick, $25 \mathrm{I}$

hepatic: Chick, 255

hepatic-portal: Chick, 254

jugular: Chick, 250

mesenteric: Chick, 253

pectoral: Chick, 250

portal: (see Hepatic-portal) pulmonary: Frog, 6r ;

Chick, 260, 26 I

vertebral: Chick, $25^{\circ}$

vitelline: Chick, 144, 199

Vena cava, anterior (superior), posterior (inferior):

Chick, 250-254

Venous system, development of: Chick, 249-26r

Ventricle: Frog, 6r ; Chick, 156

Ventricular septum: Chick, 244

Vertebræ: Frog, 73: Chick, 229

Vertebral column: Frog, 7274; Chick, 226-233

Vertebral plate: Chick, I 34

Vertex-breech measurement of embryos, 323

Vesicula seminalis: Frog, 85

Vestibule, 3 r 8

Visceral arches, skeleton of: Chick, 268

clefts and folds: Frog, $5^{\mathrm{I}-}$ 53; Chick, 188-198

clefts and folds, fate of: Chick, 1 92-198

clefts and folds, meaning of: Chicks, I 92

skeleton: Frog, 77

Vitelline membrane: Frog, 5; Chick, 91

Vitellus, 286

Vitreous humor: Chick, I 8 I

Wings: Chick, 244

Witch milk, 322

Wolffian body: Frog, 78, 8283 ; Chick, I 59, 2 1 6-220, 233

body, fate of: Chick, 236 duct: Frog, 83-85; Chick, I 5 I, I 59

duct, fate of: Frog, 84 ;

Chick, 236 


\section{Index}

Wolffian body-Continued ridge: Chick, 223, 237

Yolk: Chick, 90-92 in relation to cleavage: $98-$ 103

plug: Frog, 23 sac: Chick, I I 6, I 65 stalk: (see Somatic stalk) Yolk-sac: Mammal, 3123 I 6

Yolk-stalk, 3 I 4-3 I 6

Zona pellucida, 286 


\title{
A Selection from the Catalogue of
}

\section{G. P. PUTNAM'S SONS}

\author{
w \\ omplete Catalogues sent \\ on application
}


1. 


\section{WORKS BY PROF. A. M. MARSHALL}

\section{VERTEBRATE EMBRYOLOGY}

By A. Milnes Marshall, M.D., Professor of Zoölogy in Owens College, England. Fully illustrated. 8vo, pp. xxiv. +640 . . $\$ 600$

" It is certainly the best text-book for student's use and dealing with vertebrate embryology known to me in any language; it is adapted in the most satisfactory manner to guide practical laboratory work. I admire both the clearness and accuracy of the author's descriptions."-Charles S. Minot, Professor of Histology and Human Embryology, Harvard University.

"It is an admirable book. It will prove a convenient reference book for investigators and teachers, and an extremely valuable guide to students. It worthily fills a place heretofore unoccupied. I have already brought the book to the attention of several specialists in embryology, and it will be a pleasure to continue to do so."Frederick S. LeE, M.D., Demonstrator of Physiology, Columbia College.

"The book should be studied by all who wish to obtain as clear an insight as possible into the present state of our knowledge of embryology."-N. Y. Medical fournal.

\section{A JUNIOR COURSE IN PRACTICAL ZOÖLOGY}

By A. Milnes Marshall, M.D., Professor of Zoölogy in Owens College, England, and C. H. HURST, Demonstrator of Zoölogy in Owens College, England. With 48 woodcuts. 8vo,

"Has special value for students of anatomy."-Prof. HENRY F. Osborn, Princeton College.

NEW YORK

\section{G. P. PUTNAM'S SONS}

97 WEST TWENTY-THIRD STREET
LONDON

24 BEDFORD STREET, STRAND 
"Remarkable for its simple language and clear style. . - Bears the stamp of a production of an erudite scientist and a deep thinker,"-Science.

\title{
The Prolongation of Life
}

\author{
Optimistic Essays \\ By Élie Metchnikoff \\ Author of "The Nature of Man," etc. \\ 8vo. Price, \$2.50 net
}

M. Êlie Metchnikoff is one of those rare scientists who have found a way to lay hold of and present to the world in untechnical phraseology, intelligible to the lay mind, such results of his researches as are of universal interest and go straight home to the bosoms and business of intelligent men. The Nature of Man, by the same author, was one of the most fascinating books, at once popular, and scientific, which have appeared for decades. The book here in question will stand beside it as a worthy companion volume. It is satisfactory to report that, absorbed as Metchnikoff is in "material" problems, and deep as he is in the mysteries of the physical universe, these essays show him to be an optimist who speaks with no uncertain voice.

A great deal of attention is given in The Prolongation of Human Life to the subject of old age and its causes, with scientific observations of special cases among human beings and the lower animals. The author suggests means of prolonging life and health, while contemplating natural death with serenity, and finding that agreeable sensations accompany its approach. Beyond a certain point it seems to him a disadvantage to prolong life. Passing on from these mortuary lucubrations, the essays concern themselves with psychological matters, with optimism and pessimism and in general with questions of science and morals. The temperaments of certain great men are analyzed in studies that have for their subjects respectively Byron, Leopardi, Schopenhauer, and Goethe. In the preface the author says that he has avoided, as far as possible, repeating points which have been sufficiently treated in The Nature of Man.

\section{G. P. PU T N A M' S S O N S NEW YORK LONDON}


The most valuable production since Darwin's " Origin of Species."

\section{The Nature of Man}

\section{Studies in Optimistic Philosophy \\ By Élie Metchnikoff}

Professor at the Pasteur Institute

Translated with an Introduction by

\section{P. Chambers Mitchell}

Secretary of the Zoölogical Society

Octavo. Illustrated - . - Net, $\$ 2.00$

It is not often that a scientific book may be read with ease, profit, and pleasure by the general reader, so that M. Metchnikof's book comes in the nature of an agreeable surprise. It is marked by a refreshing naĩveté and a large simplicity which are characteristically Russian. The scientific importance of this work is so great that it is spokpn of in England as the most valuable production since Darwin's Origin of Species.

\section{Opinions of the Press}

"An extremely interesting and typical sook. . . . Wich a distinguished frankness, M. Metchnikoff defines his attitude to our universal prepossessions. It is his theory that the infirmities of age are to be overcome. If there be ground for this conception, humanity is to be profoundly changed and what we call life now, will be the childhood and youth of that longer and larger life."-H. G. WELLS, in London Speaker.

"Undoubiedly a great book (in some quarters it has been hailed as the greatest since Darwin's famous message to the world) and should be read by all intelligent men and women." - The Nation.

"A book to be set side by side with Huxley's Essays, whose spirit it carries a step further on the long road towards its goal."-Mail and Express.

New York-G. P. Putnam's Sons-London 
"One of the classics of the nineteenth century."

\section{The Evolution of Man}

\section{A Populat Scientific Study}

\section{By Ernst Haeckel}

Professor at Jena University

Translated from the Fifth (enlarged) Edition by

\section{Joseph McCabe}

Two volumes, 8vo, with 30 Colored Plates and 512 other Jllustrations, together with 60 genealogical tables . . Net $\$ 10.00$

The work is a comprehensive statement of the scientific grounds for evolution as applied to man. It does not deal with religious controversies, and is scientific throughout. The work is unique in design, which is carried out in the last edition with the highest degree of Haeckel's literary and artistic skill. Haeckel has always been distinguished for pressing the combination of the evidence from embryology with the evidence of zoölogy and paleontology. In the present work he devotes one volume broadly to embryology, or the evolution of the individual, and the second to the evolution of the human species, as shown in the comparative anatomy, zoölogy, and paleontology. The last few chapters deal in detail with the evolution of particular organs right through the animal kingdom: the eye, ear, heart, brain, etc. Every point is richly illustrated from Haeckel's extensive knowledge of every branch of biology and his well-known insistence on comparative study.

The work is written for the general reader, all technical terms being explained, and no previous knowledge being assumed; but the scientific reader, too, will find it a unique presentation of all the evidence for man's evolution, and especially as a study of embryonic development in the light of race-development.

In this edition, to which Haeckel gave six months' hard work, the plan is carried out with great skill, and the illustrations are very fine. All the most recent discoveries in every branch of science involved are included. It is a thoroughly up-to-date, non-controversial, most comprehensive, and scientific treatise on the evolution of man by the greatest living authority on the subject.

\section{New York-G. P. Putnam's Sons-London}


Y 
$\lambda$

$+$

- 


DATE DUE SLIP

UNIVERSITY OF CALIFORNIA MEDICAL SCHOOL LIBRARY I

THIS BOOK IS DUE ON THE LAST DATE STAMPED BELOW

MAY 271930

AR 1 色, 1931

MAR SEEP 171932

57t? I: 1939

hov \& 193.

APR 30 กิ3

NOY 3 - 1027

Nov 20 lg3?

JUN $1-1939$ APR 231940

IUL 31.1944 


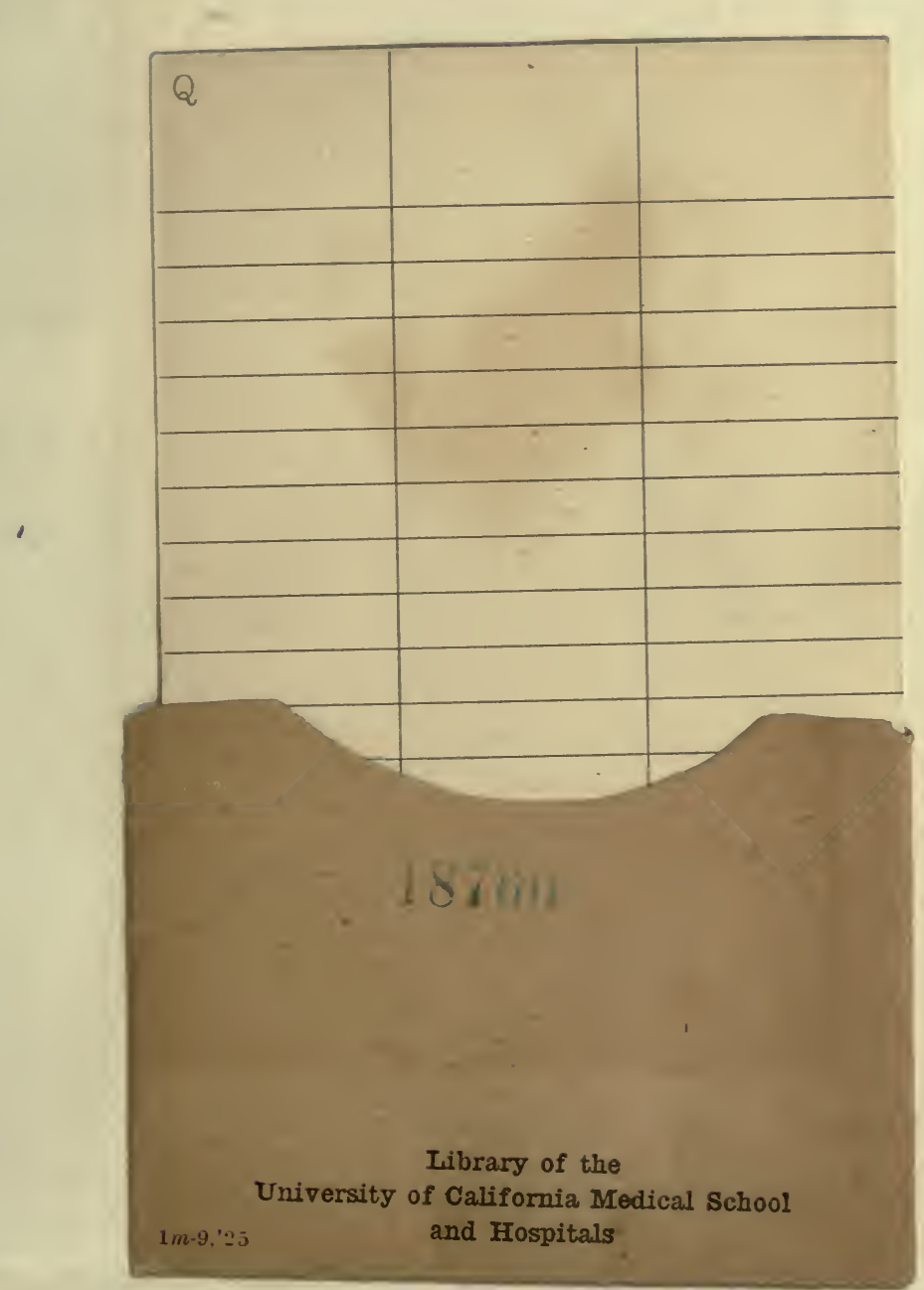


